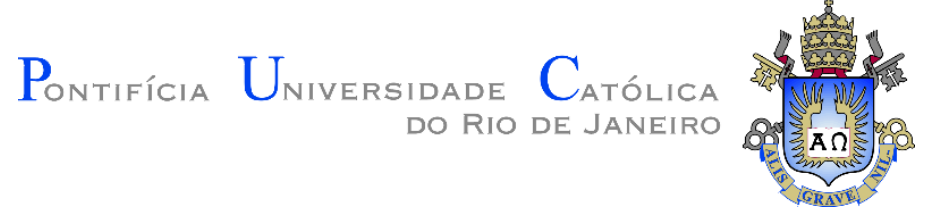

Ícaro Rodrigues Marques

\title{
Influência de Modos Normais Não Lineares e de Simetrias no Comportamento Dinâmico de Torres Estaiadas
}

Dissertação de Mestrado

Dissertação apresentada como requisito parcial para obtenção do grau de Mestre pelo Programa de PósGraduação em Engenharia Civil do Departamento de Engenharia Civil e Ambiental da PUC-Rio.

Orientador: Prof. Paulo Batista Gonçalves

Coorientadora: Profa. Deane de Mesquita Roehl

Rio de Janeiro Dezembro de 2019 


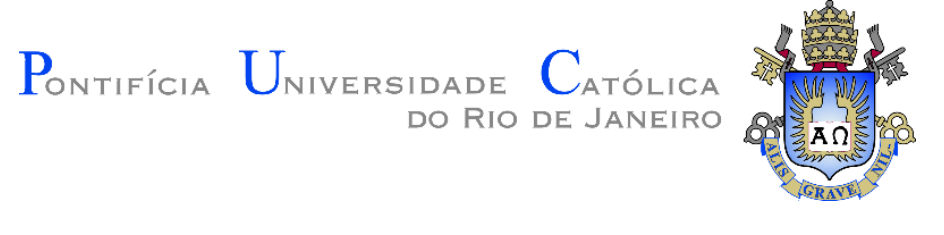

Ícaro Rodrigues Marques

\title{
Influência de Modos Normais Não Lineares e de Simetrias no Comportamento Dinâmico de Torres Estaiadas
}

\begin{abstract}
Dissertação apresentada como requisito parcial para obtenção do grau de Mestre pelo Programa de PósGraduação em Engenharia Civil da PUC-Rio. Aprovada pela Comissão Examinadora abaixo.
\end{abstract}

Prof. Paulo Batista Gonçalves Orientador Departamento de Engenharia Civil e Ambiental - PUC-Rio

Profa. Deane de Mesquita Roehl Coorientador Departamento de Engenharia Civil e Ambiental - PUC-Rio

Prof. Raul Rosas e Silva Departamento de Engenharia Civil e Ambiental - PUC-Rio

Prof. Carlos Magluta UFRJ 
Todos os direitos reservados. É proibida a reprodução total ou parcial do trabalho sem autorização da universidade, do autor e do orientador.

\section{Ícaro Rodrigues Marques}

Graduado em Engenharia Civil pela Universidade de Fortaleza - UNIFOR (Fortaleza, Ceará) e graduado em Tecnologia de Estradas pelo Instituto Federal de Educação, Ciência e Tecnologia do Ceará - IFCE (Fortaleza, Ceará). Sua área de interesse compreende instabilidade de estruturas, análise dinâmica de estruturas e modelagem numérica.

Ficha Catalográfica

Marques, Ícaro Rodrigues

Influência de modos normais não lineares e de simetrias no comportamento dinâmico de torres estaiadas / Ícaro Rodrigues Marques; orientador: Paulo Batista Gonçalves; co-orientadora: Deane de Mesquita Roehl. - 2019.

187 f.: il. color.; $30 \mathrm{~cm}$

Dissertação (mestrado)-Pontifícia Universidade Católica do Rio de Janeiro, Departamento de Engenharia Civil e Ambiental, 2019

Inclui bibliografia

1. Engenharia Civil e Ambiental - Teses. 2. Torre estaiada. 3. Frequências naturais. 4. Vibrações não lineares. 5. Modos normais não lineares. 6. Análise por elementos finitos. I. Gonçalves, Paulo Batista. II. Roehl, Deane de Mesquita. III. Pontifícia Universidade Católica do Rio de Janeiro. Departamento de Engenharia Civil e Ambiental. 


\section{Agradecimentos}

Primeiramente gostaria de agradecer a todos que contribuíram direta ou indiretamente para o desenvolvimento dessa pesquisa.

Ao professor Paulo Batista, pela orientação nesse trabalho. Também gostaria de agradecer pelas conversas, pelo constante auxílio e paciência. Pude aprender muito com seus ensinamentos.

À professora Deane Roehl, pela Co-orientação e por todos os ensinamentos durante esse período. Pela sua paciência, atenção, vontade de ajudar e disponibilidade. Também pelo carinho.

Aos professores que participaram da comissão examinadora.

Aos meus pais, Maria Tereza e Ademar Marques, que me apoiaram e me incentivaram durante toda essa jornada e durante toda a vida. Que dedicaram atenção e carinho de forma incondicional, além de serem sempre minha fonte inspiração e exemplo.

À Beatriz Rodrigues que desde a faculdade vem me apoiando a cada passo dessa jornada acadêmica. E não só por isso, mas por toda parceria, companheirismo e amor diário. E aos seus pais, Maninha e Hélio, que desde o início me apoiaram e incentivaram, mostrando um afeto ímpar, me acolhendo como parte da família.

Aos meus amigos e companheiros de mestrado, que levarei para o resto da vida, em especial Eric, Felipe, Lucian, Chris, Marcello, João Victor, Daniel, Manuel e Osmar. Obrigado pelo apoio, incentivo, momentos de descontração e estudo durante esse período de mestrado.

À Fernanda Pereira que me ajudou bastante ao longo dos primeiros meses de pesquisa.

Ao professor e grande amigo Ítalo Salomão pelo constante incentivo, ajuda e amizade.

Aos demais professores do departamento de Engenharia Civil da PUC Rio.

À secretaria do departamento de Engenharia Civil da PUC Rio, em especial Luana e Rita, por toda ajuda.

Ao instituto Tecgraf pelo suporte para o desenvolvimento dessa pesquisa. 
O presente trabalho foi realizado com apoio da Coordenação de Aperfeiçoamento de Pessoal de Nível Superior -Brasil (CAPES) - Código de Financiamento 001. 


\section{Resumo}

Marques, Ícaro Rodrigues; Gonçalves, Paulo Batista; Roeh, Deane de Mesquita. Influência de Modos Normais Não Lineares e de Simetrias no Comportamento Dinâmico de Torres Estaiadas. Rio de Janeiro. 187 p. Dissertação de Mestrado - Departamento de Engenharia Civil e Ambiental, Pontifícia Universidade Católica do Rio de Janeiro.

As torres estaiadas estão entre as estruturas mais altas construídas pelo homem. Estas estruturas usualmente são muito esbeltas e a interação cabos/mastro leva a comportamentos altamente não lineares. Devido a sua complexidade, modelos simplificados são desenvolvidos para as simulações dessas estruturas. Um modelo discreto de dois graus de liberdade investigado por diversos autores apresenta fenômenos característicos de estruturas não lineares, como a superabundância de modos normais não lineares similares e modos normais não similares (NNMs), bifurcações de NNMs, ressonância interna e interação modal. O presente trabalho visa investigar o comportamento de um modelo estrutural contínuo de uma torre estaiada com um a três níveis de estais. O método dos elementos finitos (MEF) com uma formulação não linear é usado para realizar análises paramétricas da influência na resposta estática e dinâmica, linear e não linear, das características geométricas e físicas dos cabos, do peso próprio dos cabos e do mastro e de imperfeições iniciais nas frequências naturais e carga crítica da torre. As simetrias geradas pela distribuição uniforme dos cabos têm grande influência na resposta, dando origem a cargas críticas e frequências naturais coincidentes. Isso gera interação modal na flambagem e ressonância interna 1:1, aumentando o efeito da não linearidade geométrica na resposta. Uma análise qualitativa é desenvolvida, comparando as respostas da análise de vibração não linear do modelo contínuo com as do modelo de dois graus de liberdade. Essa análise comparativa indica a existência de múltiplos NNMs e multimodos. A influência desses modos e simetrias inerentes à torre é investigada através de uma análise paramétrica da torre sob excitação harmônica lateral. Os resultados mostram que a torre exibe uma resposta altamente não linear, mesmo sob baixos níveis de carga, o que deve ser considerado com cuidado na fase de projeto e indica a 
necessidade de investigações adicionais da resposta dinâmica não-linear dessas estruturas, considerando as diferentes distribuições dos cabos utilizadas na prática.

\section{Palavras-chave}

Torre Estaiada; Frequências Naturais; Vibrações Não Lineares; Modos Normais Não Lineares; Análise por Elementos Finitos. 


\section{Abstract}

Marques, Ícaro Rodrigues; Gonçalves, Paulo Batista (Advisor); Roeh, Deane de Mesquita (Co-Advisor). Influence of Non-linear Normal Modes and Symmetries on the Dynamic of a Slender Guyed Tower. Rio de Janeiro. 187 p. Dissertação de Mestrado - Departamento de Engenharia Civil e Ambiental, Pontifícia Universidade Católica do Rio de Janeiro.

The guyed towers are among the tallest man-made structures. These structures are usually very slender and their guy/mast interaction leads to highly nonlinear behaviors. Due this, simplified models are developed for simulating these structures. The discrete model of tow-degree of freedom investigated by several authors exhibits characteristic phenomena of nonlinear structures such as a superabundance of similar nonlinear normal modes and non-similar normal modes (NMNs), bifurcations of NMNs, internal resonance, and modal interaction. The present work aims to investigate the behavior of a continuous structural model of a tower with one to three guyed levels. The nonlinear finite element method (FEM) is used to parametric analyzes of the influence on static and dynamic responses, linear and nonlinear, of the geometric and materials characteristics of the guys, of the mast and guys self-weight and initial imperfections of the tower's natural frequencies and critical loads. The symmetries generated by the uniform distribution of guys have a great influence on the response, given rise to coincident critical loads and natural frequencies. This generates modal interaction in the buckling and 1:1 internal resonance, increasing the effect of the geometric nonlinearity on the response. A qualitative analysis is developed, comparing as the response of the nonlinear vibration of the continuous model as those of the two degrees of freedom model. This comparative analysis indicates the existence of the multiple NNMs and multimodes. The influence of theses modes and tower inherent symmetries are investigated through a parametric analysis of the tower under lateral harmonic excitation. tower modes. The results show that the tower exhibits a highly nonlinear response, even at low load levels, which must be considered with care in the design stage and indicates the necessary of further investigations of the nonlinear dynamic response of these structures considering the different guys distribution used in practice. 


\section{Keywords}

Guyed Towers; Natural Frequencies; Nonlinear Vibrations; Nonlinear Normal Modes; Finite Element Analysis. 


\section{Sumário}

1 Introdução 27

1.1. Generalidades 27

1.2. Motivação 29

1.3. Objetivos 32

1.3.1. Objetivos específicos 32

1.4. Organização do trabalho 33

2 Fundamentação Teórica 35

2.1. Torres Estaiadas 35

2.1.1. Características gerais 36

2.2. Revisão Bibliográfica 38

2.3. Modos Normais Não Lineares 42

2.4. Modelo conceitual com 2GL 43

3 Modelo Numérico $\quad 47$

3.1. Geral 47

3.2. Procedimentos de Modelagem. 47

3.3. Modelos Estruturais de Torre Estaiadas 48

3.3.1. Modelos Sintéticos 49

3.4. Tipos de Análises 56

3.4.1. Análise global 56

3.4.2. Análise estática 56

3.4.3. Análise Dinâmica 58

4 Análise da Estabilidade e Sensibilidade a Imperfeições 61

4.1. Aspectos gerais 61 4.1.1. Equilíbrio estático do Modelo Sintético com 1 nível de
estais

4.2.1. Validação da metodologia de modelagem 63

4.2.2. Influência do peso próprio e pré-tensão dos cabos na
carga crítica da estrutura 
4.2.3. Influência da distribuição dos cabos

4.2.4. Influência da quantidade de níveis de estais

4.3. Análise Estática Não Linear

4.3.1. Validação da metodologia de modelagem

4.4. Influência dos cabos no comportamento pós-crítico de torres estaiadas

4.4.1. Modelo bidimensional de torre com um nível de estais

4.4.2. Análise paramétrica

4.4.3. Modelos tridimensionais de torres com um ou mais níveis de estais

5 Análise dinâmica linear

5.1. Introdução

5.2. Análise paramétrica

5.2.1. Validação da metodologia de modelagem

5.2.2. Influência das características dos cabos 86

5.2.3. Influência de imperfeições iniciais

5.2.4. Influência da quantidade de níveis de estais

5.3. Comentários finais

6 Análise dinâmica não-linear

6.1. Parâmetros da análise numérica

6.2. Modos normais não lineares

6.3. Vibração livre amortecida 98

6.3.1. Vibração livre amortecida - Ângulo $\beta$ 98

6.3.2. Vibração livre amortecida - ângulo $\beta$ com imperfeição inicial

6.4. Vibração não-linear forçada amortecida

7 Estudo de caso

7.1.2. Desenvolvimento do modelo equivalente 
7.3. Análises Não Lineares

7.3.1. Análise Estática Não-Linear

7.3.2. Análise Dinâmica Não Linear

8 Conclusões e Sugestões

8.1. Conclusões

Apêndice A Desenvolvimento de Análises dinâmicas lineares e não-lineares no ABAQUS

A. 1 Definição do modelo de Torre Estaiada

A. 1.1 Definindo amortecimento proporcional

A. 1.2 Definindo pré-tensão nos cabos

A. 2 Análise geral estática

A. 2.1 Peso Próprio

A. 2.2 Imperfeições e Carregamentos Estáticos

A. 2.3 Não Linearidade Geométrica

A. 3 Análise Modal

A. 3.1 Estática linear

A. 3.2 Dinâmica linear

A. 4 Análise Não Linear

A. 4.1 Análise Estática Não Linear

A. 4.2 Dinâmica Não Linear

Apêndice B Respostas dinâmicas para $\beta=0^{\circ}$

Apêndice $C$ Respostas dinâmicas para $\beta=60^{\circ}$ 


\section{Lista de figuras}

Figura 1.1 - Exemplos de torre autoportante (a), [1], e torre estaiada (b), [2].

Figura 1.2 - Exemplos de torres estaiadas com alturas elevadas [4]-[6].

Figura 1.3 - Colapsos de torres por consequência de ações da natureza e sabotagem no E.U.A e no Brasil.

Figura 2.1 - Representação dos tipos mais usuais de distribuição dos cabos em torres estaiadas.

Figura 2.2 - Distribuição dos cabos ao redor da torre.

Figura 2.3 - Representação do modelo conceitual 2GL de uma torre estaiada.

Figura 2.4 - Projeções dos caminhos e pós-críticos para $\Theta=$ $120^{\circ}$ - caso anticlinal. Modelo de torre [19].

Figura 2.5 - Modos normais não-lineares para um modelo de Pêndulo estaiado, (a) e (b) [19], [21].

Figura 3.1 - Representação esquemática dos modelos de mastro isolado.

Figura 3.2 - Representação esquemática de uma torre estaiada 2D.

Figura 3.3 - Representação esquemática de uma torre estaiada com apenas um nível de estais.

Figura 3.4 - Representação esquemática dos modelos com mais de um nível de estais.

Figura 3.5 - Fluxograma de metodologia de desenvolvimento de modelo no ABAQUS.

Figura 4.1 - Modelo de torre 3D e suas dimensões. 
Figura 4.2 - Distribuição desigual dos cabos de uma torre estaiada

Figura 4.3 - Configurações do modo de flambagem para torres com múltiplos níveis de estais.

Figura 4.4 - Coluna engastada e livre: configurações deformadas

(a) e trajetória de equilíbrio da extremidade livre (topo) da coluna 70 (b).

Figura 4.5 - Sensibilidade às imperfeições laterais.

Figura 4.6 - Trajetórias de equilíbrio para a torre estaiada bidimensional: (a) $\alpha \times X$; (b) $\alpha \times Y$.

Figura 4.7 - Evolução da deformação de uma Torre 2D com um nível de estais, por incremento de carga.

Figura 4.8 - Trajetórias de equilíbrio para torres com e sem cabos.

Figura 4.9 - Modelo sintético de torre estaiada com um nível de estais.

Figura 4.10 - Trajetórias de equilíbrio com geometria inicial deformada por imperfeições modais.

Figura 4.11 - Visões esquemáticas da torre com a presença de carga estática no topo.

Figura 4.12 - Diferentes vistas das trajetórias de equilíbrio da torre com imperfeições em diferentes direções.

Figura 4.13 - Trajetórias de equilíbrio para torre com imperfeições gerada por prettensão assimétrica dos cabos.

Figura 4.14 - Diferentes vistas das trajetórias de equilíbrio da torre com imperfeições por distribuição desigual de cabos.

Figura 4.15- Trajetória de equilíbrio para modelos com diferentes níveis de estais. 
Figura 5.1 - Modelo sintético com um nível de estais no espaço, (a), e vista de topo, (b).

Figura 5.2 - Relação diâmetro do cabo x $1^{\text {ạ }}$ frequência natural da torre, com e sem peso-próprio dos cabos.

Figura 5.3 - Distribuição desigual dos cabos de uma torre estaiada.

Figura 5.4 - Relação frequência fundamental com o ângulo $\theta$, $55^{\circ} \leq \theta \leq 85^{\circ}$.

Figura 5.5 - Primeiro modo normal de vibração para uma torre com $55^{\circ} \leq \theta \leq 85^{\circ}$.

Figura 5.6 - Relação frequência natural $x$ porcentagem da força de ruptura do cabo, para o modelo sintético padrão.

Figura 5.7 - Relação entre carregamento lateral estático e frequências dos dois primeiros modos de uma torre estaiada.

Figura 6.1 - Seção de Poincaré do sistema Hamiltoniano,(a), [19], e modos normais não-lineares para um modelo de Pêndulo 98 estaiado,(b) e (c),[21].

Figura 6.2 - Vistas do modelo sintético padrão com uma perturbação inicial atuando em um ângulo $\beta$ em relação ao eixo $X$. (a) Perspectiva da torre com carregamento distribuído; (b) Vista de topo da torre com perturbação com orientação $\beta$.

Figura 6.3 - Movimento horizontal do topo da torre no espaço em função das perturbações nas direções $\beta$.

Figura 6.4 - Resposta no tempo, (a), e projeções dos planos de fase para o ângulo $\beta=30^{\circ}$, para $200 \mathrm{~s}$ e $60 \mathrm{~s}$. (b) Plano de fase velocidade $\mathrm{x}$ deslocamento no eixo $\mathrm{X}$; (c) Plano de fase velocidade $x$ deslocamento no eixo $Z$.

Figura 6.5 - Movimento do topo da torre em função da perturbação na direção $\beta$ com imperfeição inicial a $45^{\circ}$. 
Figura 6.6 - Vistas da torre com as componentes da carga harmônica nas direções $\mathrm{X}$ e Z .

Figura 6.7 - Influência da direção do carregamento $\beta$ na resposta permanente da torre, $\mathrm{F}=2 \mathrm{kN} / \mathrm{m}$.

Figura 6.8 - Influência da magnitude da força na resposta do regime permanente para $\beta=60^{\circ}$, plano de fase $X Z$.

Figura 6.9 - Influência da magnitude da força na resposta do regime permanente para $\beta=60^{\circ}$, análise de frequências e análise espectral.

Figura 6.10 - Resposta no tempo nos eixos X e Z.

Figura 6.11 - Seções de mapeamento de Poincaré, plano XZ, dos atratores caóticos, para $\beta=60^{\circ}$.

Figura 6.12 - Planos de fase relacionado velocidade $x$ deslocamento eixo $X$.

Figura $6.13-$ Resposta do regime estacionário para $\beta=0^{\circ}$ e $\mathrm{F}=$ $2 \mathrm{kN} / \mathrm{m}$ considerando uma perturbação de $2^{\circ}$ e $5^{\circ}$.

Figura 6.14 - Influência da magnitude da força na resposta do regime permanente $\operatorname{com} \beta=0^{\circ}$, plano de fase $X Z$

Figura 6.15 - Influência da magnitude da força na resposta permanente $\operatorname{com} \beta=0^{\circ}$, análise de frequências e análise espectral.

Figura 6.16 - Planos de fase velocidade $x$ deslocamento no eixo $X$, para regime permanente com $\beta=0^{\circ}$.

Figura 6.17 - Influência da magnitude da força na resposta do regime permanente $\operatorname{com} \beta=30^{\circ}$, plano de fase $X Z$ e análise de frequências.

Figura 7.1 - Vistas da torre treliçada com indicações dos diâmetros dos elementos. 
Figura 7.2 - Esquema de distribuição dos cabos ao longo da torre, (a) Distribuição vertical; (b) vista em planta.

Figura 7.3 - Ilustrações das forças e momento aplicados a estrutura para obtenção das propriedades equivalentes da seção.

Figura 7.4 - Caminho de equilíbrio pós-crítico para o modelo de equivalente.

Figura 7.5 - Resposta no tempo, linear e não linear, amplitude (m) $x$ tempo (s) do modelo real para diferentes níveis de carregamento.

Figura 7.6 - Espectro de frequências para análise de vibração forcada amortecida, linear e não linear para diferentes níveis de carregamentos, modelo real.

Figura A. 1 - Inserindo restrição à compressão no material.

Figura A. 2 - Inserção do amortecimento da estrutura a partir dos parâmetros $\alpha$ e $\beta$ no programa ABAQUS $\AA$.

Figura A .3 - Inserindo pré-tensão nos cabos.

Figura A. 4 - Fluxograma esquemático das análises desenvolvidas no trabalho.

Figura A. 5 - Inserção da gravidade no modelo.

Figura A. 6 - Ativação da Não Linearidade Geométrica no modelo.

Figura A. 7 - Criação das etapas de "BUCKLE" e FREQUENCY". 156

Figura A. 8 - Tipos de algoritmos de solução para etapa de "BUCKLE".

Figura A. 9 - Algoritmos de solução para etapa de "FREQUENCY".

Figura A. 10 - Criação das etapas de análise não linear estática e dinâmica. 
Figura A. 11 - Janela para geração de arquivo de saída com coordenadas dos nós para os modos de flambagem.

Figura A. 12 - Inserção das imperfeições modais.

Figura A. 13 - Tipos de controle de integração "RIKS".

Figura A. 14 - Arquivos de saída para análise de "RIKS".

Figura A. 15 - Inserção de Força de Pulso.

Figura A. 16 - Inserção de força harmônica.

Figura A. 17 - Tipos de controle para análise dinâmica.

Figura A. 18 - Manipulação do método HTT-alpha para método Newmark- $\beta$.

Figura A. 19 - Geração dos arquivos de resposta para análise dinâmica.

Figura B. 1 - Influência da magnitude da força na resposta em regime permanente $\operatorname{com} \beta=0^{\circ}$, resposta no tempo.

Figura B. 2 - Influência da magnitude da força na resposta em regime permanente $\operatorname{com} \beta=0^{\circ}$, análise de frequências FFT.

Figura B. 3 - Influência da magnitude da força na resposta em regime permanente $\operatorname{com} \beta=0^{\circ}$, análise de frequências espectrograma 2D.

Figura B. 4 - Influência da magnitude da força na resposta em regime permanente $\operatorname{com} \beta=0^{\circ}$, análise de frequências espectrograma 3D

Figura B. 5 - Influência da magnitude da força na resposta em regime permanente $\operatorname{com} \beta=0^{\circ}$, Planos de fase Velocidade $x$ Deslocamento no eixo $X$.

Figura B. 6 - Influência da magnitude da força na resposta em regime permanente $\operatorname{com} \beta=0^{\circ}$, Mapeamento de Poincaré no plano XZ. 
Figura B. 7 - Influência da magnitude da força na resposta em regime permanente $\operatorname{com} \beta=0^{\circ}$, Mapeamento de Poincaré relacionando Velocidade $x$ Deslocamento no eixo $X$.

Figura C. 1 - Influência da magnitude da força na resposta em regime permanente $\operatorname{com} \beta=60^{\circ}$, resposta no tempo.

Figura C. 2 - Influência da magnitude da força na resposta em regime permanente com $\beta=60^{\circ}$, análise de frequências FFT.

Figura C. 3 - Influência da magnitude da força na resposta em regime permanente com $\beta=60^{\circ}$, análise de frequências espectrograma 2D.

Figura C. 4 - Influência da magnitude da força na resposta em regime permanente com $\beta=60^{\circ}$, análise de frequências espectrograma 3D.

Figura C. 5 - Influência da magnitude da força na resposta em regime permanente com $\beta=60^{\circ}$, Planos de fase Velocidade $x$ Deslocamento no eixo $X$.

Figura C. 6 - Influência da magnitude da força na resposta em regime permanente com $\beta=60^{\circ}$, Mapeamento de Poincaré no 186 plano XZ.

Figura C. 7 - Influência da magnitude da força na resposta em regime permanente com $\beta=60^{\circ}$, Mapeamento de Poincaré relacionando Velocidade $x$ Deslocamento no eixo $X$. 


\section{Lista de tabelas}

Tabela 1.1 - Lista colapsos catastróficos de mastros e torres, [12] 30

Tabela 3.1 - Organização dos modelos de viga-coluna.

Tabela 3.2 - Propriedades físicas e geométricas dos elementos do modelo bidimensional de torre estaiada.

Tabela 3.3 - Propriedades dos cabos, [91].

Tabela 3.4 - Propriedades físicas e geométricas da torre estaiada

Tabela 4.1 - Propriedades físicas e geométricas da coluna

circular.

Tabela 4.2 - Valores de carga crítica para modelos de viga-

coluna, ABAQUS e solução analítica.

Tabela 4.3 - Carga crítica da torre em kN para cinco diferentes valores de diâmetro de cabo $\phi$, com e sem a consideração do peso-próprio dos cabos.

Tabela 4.4 - Cargas críticas para torre com distribuição desigual dos cabos.

Tabela 4.5 - Carga crítica (kN) da torre estaiada com cinco

diferentes tipos de configurações de cabos.

Tabela 4.6 - Propriedades físicas e geométricas dos elementos do modelo bidimensional de torre estaiada.

Tabela 4.7 - Cargas críticas referentes as imperfeições modais.

Tabela 4.8 - Taxas de pré-tensão aplicadas nos cabos.

Tabela 4.9 - Propriedades aplicadas para análise não linear estática de torres com múltiplos níveis de estais.

Tabela 5.1 - Comparativo entre valores analíticos e modelos numéricos para coluna engastada e livre com e sem o peso próprio como carga distribuída ao longo da coluna. 
Tabela 5.2 - Influência do peso próprio do cabo nas frequências naturais da torre $(\mathrm{Hz})$, para cinco valores diferentes de diâmetro de cabo, $\phi$, para - pcabo $\left(\mathrm{kg} / \mathrm{m}^{3}\right)=0$.

Tabela 5.3 - Influência do peso próprio do cabo nas frequências naturais da torre $(\mathrm{Hz})$, para cinco valores diferentes de diâmetro de cabo, $\phi$, para - pcabo $\left(\mathrm{kg} / \mathrm{m}^{3}\right)=7580$.

Tabela 5.4 - Frequências naturais para um modelo de torre com distribuição assimétrica dos cabos.

Tabela 5.5 - Frequências naturais da torre com um nível de estais em função da inclinação $\theta$ do cabo $-\varphi=48 \mathrm{~mm}-\mathrm{T}=125 \mathrm{kN}$

Tabela 5.6 - Frequências naturais da torre em função de carregamentos laterais estáticos uniformemente distribuídos $-\phi$ $=48 \mathrm{~mm}-\mathrm{T}=125 \mathrm{kN}$.

Tabela 5.7 - Frequências naturais para diferentes configurações de cabos ao longo da torre.

Tabela 7.1 - Propriedades geométricas para seção equivalente

Tabela 7.2 - Deslocamentos obtidos pelas análises para os dois modelos

Tabela 7.3 - Cargas Críticas para modelos reais e equivalentes com e sem cabos.

Tabela 7.4 - Frequências naturais para modelos reais e equivalentes com e sem cabos.

Tabela 7.5 - Parâmetros de controle para análise dinâmica linear e não linear. 


\section{Lista de Abreviaturas}

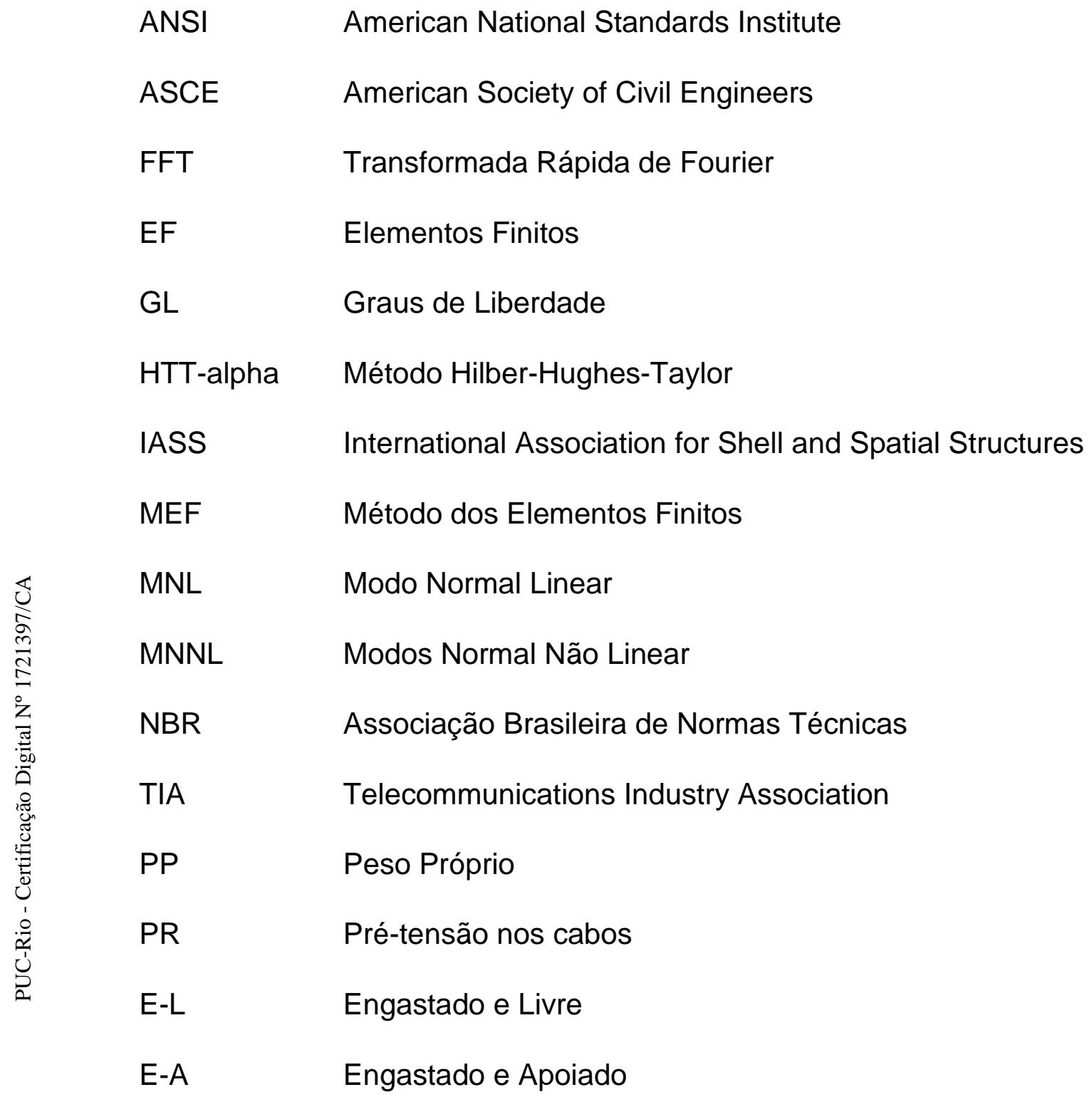




\section{Lista de Símbolos}

\section{Romanos:}

A, Área transversal;

$A_{\text {eq, }} \quad$ Área transversal para modelo equivalente;

$1^{\circ}$ parâmetro de controle do método de integração numérica no

Alpha, ABAQUS para análise dinâmica;

Beta,

$2^{\circ}$ parâmetro de controle do método de integração numérica no ABAQUS para análise dinâmica;

C, $\quad$ Matriz de amortecimento;

d, $\quad$ Diâmetro interno;

D, $\quad$ Diâmetro externo;

E, $\quad$ Módulo de Elasticidade;

EA, $\quad$ Rigidez elástica do cabo;

$f(t), \quad$ Carga horizontal periódica uniformemente distribuída;

$F(t), \quad$ Carga periódica;

$F_{0}, \quad$ Magnitude da carga aplicada;

$F_{2 G L}, \quad$ Relação $F_{b} / L$

$F_{b}, \quad$ Magnitude da força aplicada no modelo conceitual;

Componente horizontal da força de tração no cabo proposta por

Hartman e Davenport;

$f_{i}, \quad$ Frequência natural para modelos de coluna esbelta;

$F_{x}, \quad$ Componente no eixo $\mathrm{X}$ da força aplicada;

$F_{z}, \quad$ Componente no eixo $\mathrm{Z}$ da força aplicada;

g, $\quad$ Aceleração da gravidade $\mathrm{em} \mathrm{m} / \mathrm{s}$;

G, $\quad$ Módulo de cisalhamento; 
$3^{\circ}$ parâmetro de controle do método de integração numérica no

ABAQUS para análise dinâmica;

H( ), $\quad$ Função Hamiltoniana adimensional;

I, Momento de inércia;

$I_{e q}, \quad$ Momento de inércia para modelo equivalente;

$J_{e q}, \quad$ Inércia polar para modelo equivalente;

$\boldsymbol{K}, \quad$ Matriz de rigidez;

$K_{e}$

Parcela referente a rigidez elástica do cabo proposta por Hartman e

Davenport;

$K_{g}$, Davenport;

$K_{i}, \quad$ Coeficiente de rigidez de mola;

$L$,

Comprimento do elemento;

$m$,

Massa concentrada na extremidade da barra rígida, modelo conceitual;

M, Parâmetro de massa do cabo proposta por Hartman e Davenport;

M, $\quad$ Matriz de massa;

$\bar{m}, \quad$ Massa por unidade de comprimento para viga-coluna;

$N_{\text {incremento, }} \quad$ Número de incrementos.

$P, \quad$ Carga aplicada no topo da estrutura;

$P_{c r}, \quad$ Carga crítica;

$P_{\text {unitário, }} \quad$ Carga unitária no topo da estrutura;

q, $\quad$ Carga distribuída por unidade de comprimento para viga-coluna;

$t, \quad$ Tempo;

T, $\quad$ Força de pré-tensão nos cabos;

T1, Força de pré-tensão no cabo 'EB'; 
T2, $\quad$ Força de pré-tensão no cabo 'EC';

T3, $\quad$ Força de pré-tensão no cabo 'ED';

U1, Deslocamentos no eixo $\mathrm{X}$;

U2, Deslocamentos no eixo Y;

U3, $\quad$ Deslocamentos no eixo Z;

$u_{i}, \quad$ Graus de liberdade do modelo conceitual;

V, Parcela referente a energia potencial do sistema;

$V_{\text {real, }} \quad$ Volume do modelo real.

\section{Gregos:}

$\alpha, \quad$ Parâmetro adimensional, $\alpha=\mathrm{PL}^{2} / \mathrm{EI}$;

A Parâmetro multiplicador da matriz de massa para amortecimento proporcional;

Ângulo de atuação do carregamento em relação ao eixo X nos

$\beta$, modelos;

$B$, Parâmetro multiplicador da matriz de rigidez para amortecimento proporcional;

$\Gamma$ Parâmetro adimensional de carga, Gavassoni;

$\delta_{\text {Horizontal, }} \quad$ Deslocamento horizontal do modelo real;

$\delta_{\text {Vertical }}, \quad$ Deslocamento vertical do modelo real;

$\Delta t, \quad$ Incremento de tempo;

$\theta_{i}, \quad$ Inclinação dos cabos em relação ao nível do solo;

$\theta, \quad$ Ângulo entre planos verticais dos cabos ao redor do mastro;

$\lambda$, Parâmetro de carga, relação $\lambda=P / P_{c r}$;

$\Lambda$ i, $\quad$ Blevins;

$\xi_{i} \quad \quad$ Fator de amortecimento para os modos ou total do sistema; 


\begin{tabular}{|c|c|}
\hline$\xi_{\text {IASS }}$ & $\begin{array}{l}\text { Indicação para fator de amortecimento pela International } \\
\text { Association for Shell and Spatial Structures; }\end{array}$ \\
\hline$\xi_{N B R} 6123$, & $\begin{array}{l}\text { Indicação para fator de amortecimento pela Norma Brasileira para } \\
\text { torres e chaminés de seção uniforme de aço, NBR } 6123 \text {; }\end{array}$ \\
\hline$\rho$ & Densidade; \\
\hline$\rho_{\text {cabo }}$ & Densidade do cabo; \\
\hline$\tau$, & Relação frequência de excitação com o tempo, $\tau=\omega_{e} t$; \\
\hline$T$, & Parcela referente a energia cinética do sistema; \\
\hline$\varphi$ & $\begin{array}{l}\text { Ângulo de atuação da força em ralação ao eixo X, modelo } \\
\text { conceitual; }\end{array}$ \\
\hline$\Phi$ & Ângulo rotação do modelo real; \\
\hline$\phi$ & Diâmetro de uma seção; \\
\hline$\Omega$, & Frequência de excitação da carga harmônica aplicada no sistema; \\
\hline $\mathbf{\Omega}_{2 G L}$, & Relação entre frequências $\Omega_{2 G}=\omega_{e} / \omega_{P}$, modelo conceitual; \\
\hline$\omega_{e}$ & Frequência de excitação no modelo conceitual; \\
\hline$\omega_{i}$ & Frequência natural do sistema referente ao modo $i$; \\
\hline$\omega_{P}^{2}$ & Relação entre gravidade e comprimento, $\omega_{P}^{2=} g / L$. \\
\hline
\end{tabular}


1

\section{Introdução}

\section{1.}

\section{Generalidades}

Ao longo das últimas décadas, os grandes avanços tecnológicos, principalmente na área de telecomunicações, demandaram um crescente investimento no setor de infraestrutura para suprir essa demanda. Um exemplo é o exponencial uso de celulares que aumentou a necessidade de construções de um número cada vez maior de torres de transmissão e captação dos sinais. Dentre os modelos estruturais empregados destacam-se as torres estaiadas e as torres autoportantes, Figura 1.1.

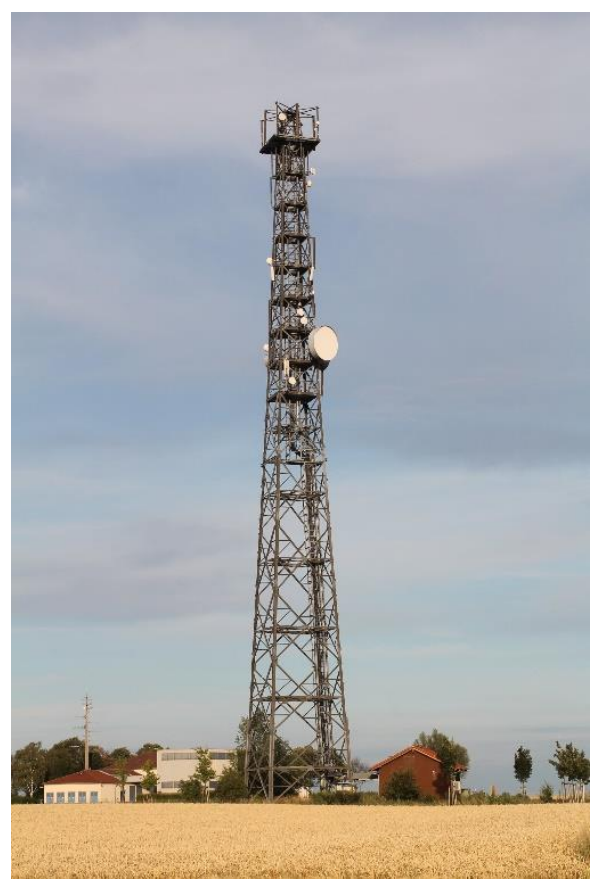

(a)

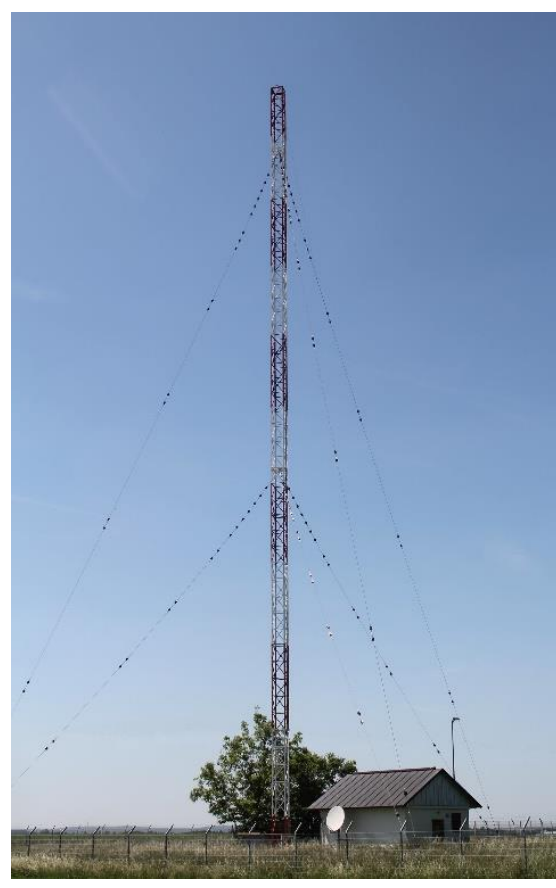

(b)

Figura 1.1 - Exemplos de torre autoportante (a), [1], e torre estaiada (b), [2].

As torres estaiadas são estruturas esbeltas e, embora sejam semelhantes as torres autoportantes, a sua estrutura muito leve se apresenta como uma vantagem para construção de torres com alturas elevadas, apesar de seu projeto e fabricação 
apresentarem um maior nível de complexidade. Malli et al. [3] comentam que do ponto de vista da economia de materiais, essa vantagem é preponderante, se comparado às torres autoportantes, para faixas de $100 \mathrm{~m}$ a $150 \mathrm{~m}$ de altura. Os autores afirmam ainda que acima dessas alturas, a economia de material supera as complexidades adicionais de projeto e fabricação, tornando as torres estaiadas mais atrativas. Atualmente, estas estruturas chegam a alturas elevadas, podendo superar 600 m, e são constituídas por materiais leves e de alta resistência, sendo altamente flexíveis e levemente amortecidas, como ilustra a Figura 1.2.

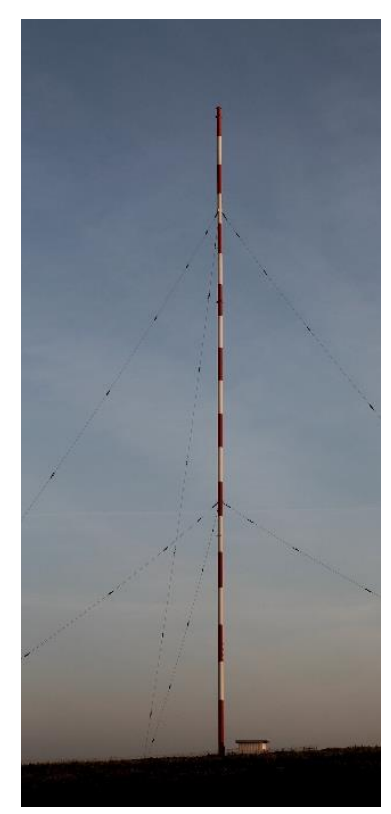

(a). Ausblendmast Mühlacker - 130 $\mathrm{m}$

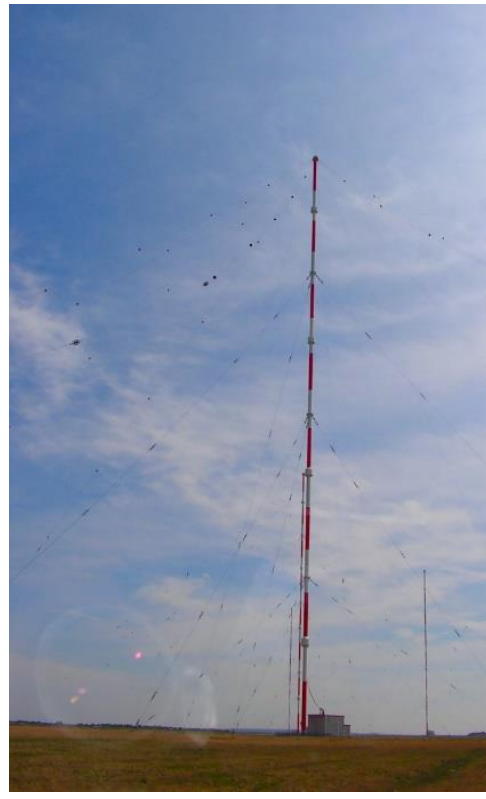

(b). Sendemasten Marinefunkstelle SaterlandRamsloh $-352,8$ m

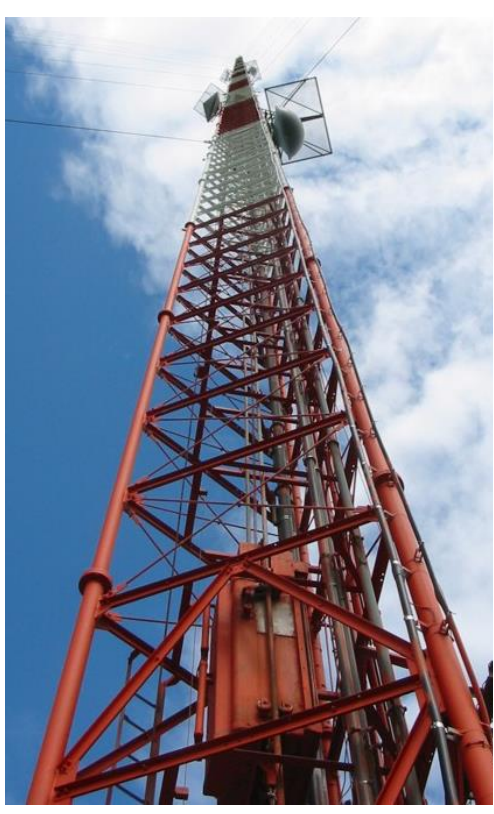

(c). WOI Television Tower $609,6 \mathrm{~m}$

Figura 1.2 - Exemplos de torres estaiadas com alturas elevadas [4]-[6].

Tendo em vista a sensibilidade da estrutura a imperfeições, esta deve seguir severas exigências em termos de limitações quanto aos deslocamentos e rotações máximos. Além disso, essas estruturas apresentam comportamento altamente não linear, tanto em condições estáticas como dinâmicas. Isto leva a preocupações durante a elaboração do projeto quanto às instabilidades estáticas e dinâmicas e às vibrações não lineares.

Os carregamentos atuantes na torre são predominantemente as cargas de peso próprio e cargas ambientais, como vento, terremotos e gelo. O próprio mastro garante resistência à compressão, enquanto os cabos tensionados fornecem restrições aos deslocamentos laterais. 
Assim, pode-se afirmar que uma das complexidades dos projetos dessas torres está diretamente associada ao seu comportamento altamente não linear. As cargas transversais que atuam no mastro causam uma deflexão na torre, introduzindo momentos de flexão no mastro. Além disso, a curvatura e rigidez do cabo são funções não lineares de suas propriedades, o que, aliado às condições de carregamento, podem levar a tensões excessivas de compressão e à flambagem do mastro. Com isso, as consequências variam desde dificuldades operacionais a falhas estruturais.

Com base no contexto ilustrado, desenvolvem-se neste trabalho análises estáticas e dinâmicas lineares e não lineares utilizando o método dos elementos finitos com o intuído de colaborar para um melhor entendimento do comportamento de torres estaiadas.

\section{2. Motivação}

Nielson [7], comenta sobre os desafios do ponto de vista da engenharia associados a torres estaiadas e o alto número de colapsos destas estruturas. $\mathrm{O}$ autor sustenta que um dos motivos de colapso é o comportamento não-linear dos cabos e comenta sobre as normas a serem seguidas para evitar a falha da estrutura. Lahiho [8], apresenta um levantamento de colapsos de torres e mastros, onde $70 \%$ dos casos apresentados são relacionados a cargas de gelo e $8 \%$ a ruptura de cabos, sendo estes os mais comuns.

Podem-se citar centenas de catástrofes de mastros e torres estaiadas que ocorreram principalmente por terremotos, vento, fogo e gelo, aliados a falhas construtivas. Uma extensa lista e discussões desses colapsos catastróficos de torres são apresentados na literatura, [9]-[12]. Na Tabela 1.1 é apresentado um levantamento de colapsos catastróficos de mastros e torres nos últimos dez anos. Nessa lista é apresentado a localização da torre, data do colapso, tipo de torre, altura e o motivo do colapso, [12]. Nos colapsos dos anos de 2014 e 2018, houveram vítimas fatais, no ano de 2018 um operário e no de 2014 quatro operários que trabalhavam na manutenção. Pode-se encontrar mais detalhes dos colapsos listados, e também mais casos semelhantes nos últimos 100 anos em [12]. 
Tabela 1.1 - Lista colapsos catastróficos de mastros e torres, [12]

\begin{tabular}{|c|c|c|c|c|}
\hline Localização & Ano & $\begin{array}{l}\text { Tipo de } \\
\text { Torre }\end{array}$ & $\begin{array}{l}\text { Altura } \\
(\mathbf{m})\end{array}$ & Razão do Colapso \\
\hline Fortland, Missouri & 2018 & Estaiada & 597 & Durante manutenção \\
\hline Borås, Suécia & 2016 & Estaiada & 332 & Sabotagem \\
\hline Rekowo, Polônia & 2015 & Estaiada & 60 & Tempestade \\
\hline $\begin{array}{l}\text { Logbessou, Douala, } \\
\text { Camarões }\end{array}$ & 2014 & Estaiada & 200 & Corrosão \\
\hline Houston, E.U.A & 2013 & Estaiada & 152 & Desconhecido \\
\hline $\begin{array}{l}\text { Oberndorf-Boll, } \\
\text { Alemanha }\end{array}$ & 2012 & Autoportante & 30 & $\begin{array}{c}\text { Caminhão colidiu com } \\
\text { estrutura }\end{array}$ \\
\hline $\begin{array}{c}\text { Felsberg-Berus, } \\
\text { Alemanha }\end{array}$ & 2012 & Estaiada & 280 & Falha do cabo \\
\hline Hoogersmilde, Holanda & 2011 & Estaiada & 303 & Fogo \\
\hline Wisconsin, E.U.A & 2011 & Estaiada & 609 & Geada com ventos fortes \\
\hline Geórgia, E.U.A & 2010 & Estaiada & 86 & Sabotagem \\
\hline Washington, E.U.A & 2009 & Estaiada & $?$ & Terrorismo \\
\hline $\begin{array}{c}\text { Nova Gales do Sul, } \\
\text { Austrália }\end{array}$ & 2009 & Estaiada & 102 & Tempesteado \\
\hline Kansas, E.U.A & 2009 & Estaiada & 326 & Gelo \\
\hline
\end{tabular}

Parnás [13], apresenta 33 casos de colapsos de torres reticuladas de telecomunicações entre 1996 e 2006 em Cuba, onde as estruturas colapsadas são classificadas a partir de suas características geométricas e características climatológicas e topográficas da região.

As torres estaiadas são submetidas a uma grande variedade de carregamentos dinâmicos provenientes do vento, de terremotos, de geadas, ruptura repentina de cabos, galope dos cabos, etc. Estas cargas, juntamente com fatores construtivos e características não lineares da estrutura podem levar ao colapso da estrutura. Malli et al. [3], informam que desde a década de 50 nos Estados Unidos foram registrados o colapso de mais de 100 de torres autoportantes e estaiadas, indicando que o comportamento desse conjunto de estruturas não é totalmente compreendido e necessita de estudos mais aprofundados. Além dos apresentados por Malli, há diversos outros casos de colapsos de torres nos Estados Unidos. E também no Brasil há casos de colapsos de torres, alguns com vítimas, nos últimos dez anos, Figura 1.3. A imagem apresenta casos de colapso de torres por ações da natureza e por sabotagem. 


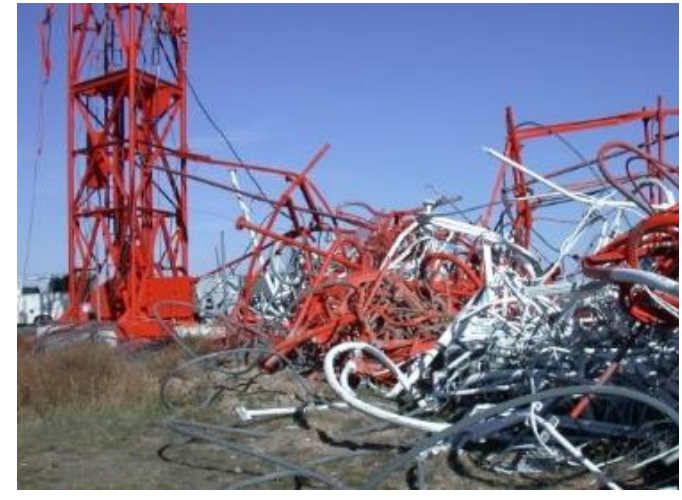

(a). Nebraska, E.U.A-2002 [14]

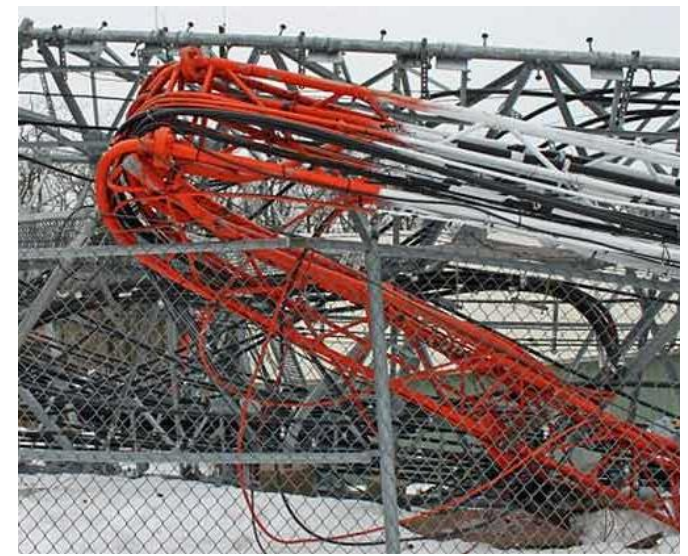

(c). Massachusetts, E.U.A-2014 [16]

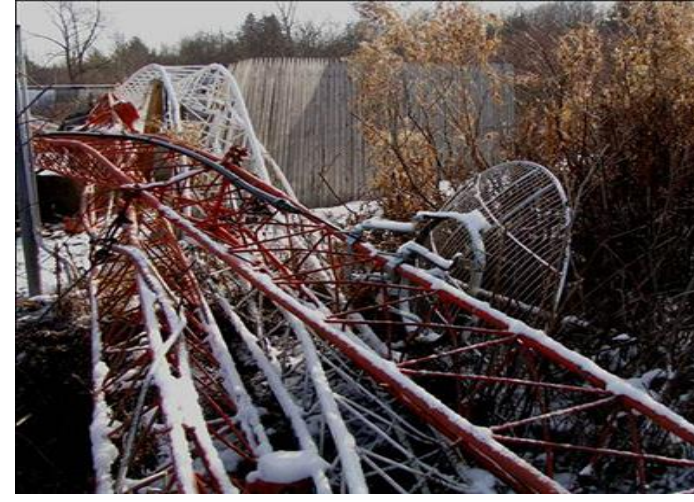

(b). Estados Unidos-2009 [15]

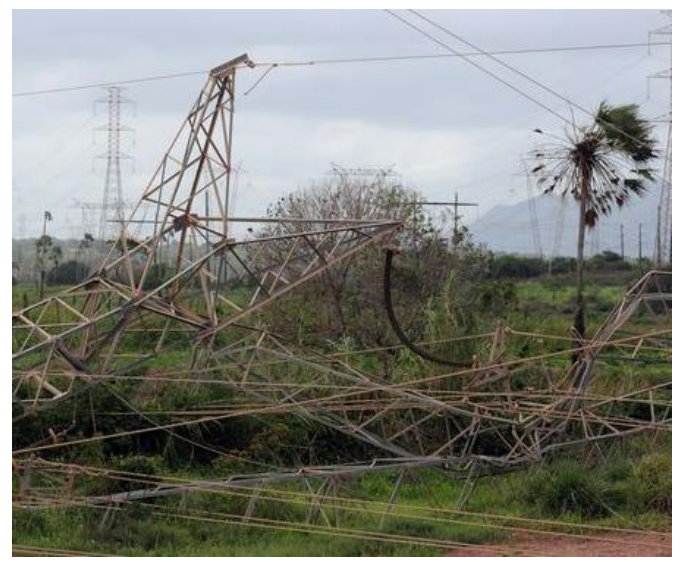

(d). Ceará, Brasil-2019 [17]

Figura 1.3 - Colapsos de torres por consequência de ações da natureza e sabotagem no E.U.A e no Brasil.

O comportamento dinâmico das torres isoladas é caracterizado pelas suas frequências naturais mais baixas, o que permite uma abordagem mais simplificada da avaliação do carregamento dinâmico. Entretanto as torres estaiadas, exibem uma alta interação modal, e a determinação direta dos modos mais importante pode ser extremamente complicada, [3].

Essa dissertação está inserida na linha de pesquisa de Instabilidade e Dinâmica das Estruturas do Departamento de Engenharia Civil da PUC-Rio. A linha de pesquisa com foco no comportamento de torres estaiadas iniciou-se com o trabalho de Pasquetti [18], onde foi desenvolvida uma avaliação do comportamento estático e dinâmico das torres estaiadas. Para isso foi analisado um modelo simplificado plano, onde o mastro é representado por uma barra rígida e os cabos por molas lineares ou não lineares. Como resultado dessas análises foram obtidas os caminhos pós-críticos e as frequências naturais do sistema, observando que essas 
estruturas são altamente não lineares e apresentam saltos, bifurcações de período e caos. Seguindo nessa linha de pesquisa, Orlando [19], investiga a influência dos modos acoplados de flambagem e de vibração no comportamento estático e dinâmico não linear, com base no modelo proposto por Thompson e Gaspar [20]. Ao longo do trabalho são determinados as os modos normais de vibração lineares e não lineares e estudadas a influência do acoplamento e interação modal e das simetrias do modelo no comportamento pós-crítico, sensibilidade a imperfeições e vibrações não lineares sob excitação de base. Gavassoni [21], investiga em um de seus modelos as vibrações não lineares de um pêndulo invertido, por meio dos modos normais não lineares. Avaliando o comportamento dinâmico não linear desse tipo de estrutura, identifica a multiplicidade de modos normais não lineares e interação multimodal, a partir das seções de Poincaré e diagramas de bifurcação.

\section{3 . \\ Objetivos}

O objetivo geral do presente trabalho é aprofundar o conhecimento do comportamento de torres estaiadas, avaliando o comportamento não linear estático e dinâmico a partir de um modelo simplificado de torre estaiada. Adicionalmente, aplicam-se as metodologias de análise desenvolvidas para o modelo sintético a um modelo de estrutura de dimensões e características reais.

\subsection{1.} Objetivos específicos

De modo a atingir o objetivo geral da dissertação, são propostos os seguintes objetivos específicos:

- Desenvolver um estudo paramétrico sobre a influência das características materiais e geométricas dos cabos; influência de imperfeições iniciais e a influência do peso próprio dos cabos e da estrutura nas frequências naturais e cargas críticas.

- Avaliar o efeito de imperfeições nas frequências naturais e cargas críticas.

- Discutir a influência das simetrias dessas estruturas nas respostas não lineares. 
- Estudar o comportamento pós-crítico e sensibilidade a imperfeições.

- Avaliar o efeito de perturbações iniciais no comportamento dinâmico não linear e o efeito de uma carga lateral harmônica próxima a faixa de ressonância nas vibrações não lineares, acoplamento modal e bifurcações.

\section{4 . \\ Organização do trabalho}

O presente trabalho está organizado em oito capítulos e três apêndices, incluindo esse de introdução, onde é apresentado um resumo sobre torres estaiadas, a complexidade de seu comportamento, o número elevado de colapsos e, com base nestes dados, a motivação e os objetivos da pesquisa.

O Capítulo 2 descreve no que consiste uma torre estaiada, junto com um breve relato de prescrições de projeto e orientações para a concepção de uma torre estaiada. Logo em seguida é apresentada uma breve revisão bibliográfica e uma descrição conceitual do modelo de mastro estaiado com dois graus de liberdade

No capítulo 3 é apresentada a metodologia de modelagem utilizando o software de elementos finitos ABAQUS, e as principais funcionalidades para análises estáticas e dinâmicas lineares e não lineares utilizadas nesse trabalho. Por fim, são descritos todos os modelos utilizados como base da pesquisa, assim como suas propriedades e características.

No capítulo 4 é desenvolvida uma análise paramétrica da influência na resposta estática, linear e não linear, das características geométricas e materiais dos cabos, do peso próprio dos cabos e do mastro, além a influência de imperfeições iniciais.

O capitulo 5 apresenta uma análise paramétrica da influência das características geométricas e matérias dos cabos, do peso próprio dos cabos e do mastro, além a influência de imperfeições iniciais, nas frequências naturais e modos de vibração.

O capítulo 6 discute a influência das simetrias do modelo na superabundância dos modos normais não lineares e multimodos, seguido pela análise da quebra de simetria por imperfeições geométricas iniciais. O resultado é comparado qualitativamente com os apresentados para o modelo conceitual de dois graus de 
liberdade. Esses resultados são obtidos a partir da análise não linear da vibração livre amortecida. É realçada a importância do conhecimento dos modos normais não lineares para o entendimento do comportamento dinâmico não linear das torres estaiadas sob vibração forçada nas regiões de ressonância. Para isto, é investigada a resposta forçada da torre sob excitação harmônica.

No capítulo 7 é investigado o comportamento de uma torre estaiada com múltiplos níveis de estais desenvolvida a partir de uma torre treliçada de seção triangular. Os resultados são comparados aos obtidos ao longo do trabalho para o modelo sintético, observando as respostas estáticas e dinâmicas lineares e não lineares.

Finalmente, no capítulo 8 são apresentadas as conclusões obtidas no estudo e também algumas sugestões para trabalhos futuros.

Os apêndices são apresentados ao final do trabalho. O apêndice A consiste em um roteiro das análises desenvolvidas ao longo deste estudo, como indicação dos comandos e metodologias para desenvolvimento dessas análises no programa ABAQUS. Os apêndices B e C, apresentam as respostas no tempo, planos de fase, mapeamentos de Poincaré, análise no espectro de frequência por FFT e espectrogramas, $2 \mathrm{D}$ e $3 \mathrm{D}$. 


\section{2 \\ Fundamentação Teórica}

Neste capítulo, são abordados alguns conceitos básicos e apresentados alguns estudos e resultados de trabalhos recentes relacionados ao comportamento estático e dinâmico de torres estaiadas.

\section{1.}

\section{Torres Estaiadas}

Torres estaiadas, Figura 2.1, consistem de uma coluna central, com seção tubular circular cheia ou vazada ou poligonal, sendo a seção constante ou variável ao longo da altura. Outra solução estrutural bastante utilizada são as torres treliçadas de seção triangular ou quadrada. A torre é usualmente engastada ou rotulada na base e ancorada lateralmente por estais, em geral cabos de aço. Em algumas aplicações tem-se também usado cabos de material polimérico como KEVLAR, em função de sua alta resistência e baixa massa específica [22]. Estas estruturas são frequente mente utilizadas para suporte de antenas de telecomunicação. Também podem ser empregadas para suporte de painéis de energia solar e em estruturas off-shore, [23]. Pasquetti, [18] comenta que nas últimas décadas este tipo de estrutura vem também sendo utilizado como suporte de coberturas de grandes espaços, como estádios, galpões e até tabuleiros de pontes. Quanto a distribuição dos cabos nessas estruturas, há diversas configurações usuais na prática; dentre estas pode-se destacar como mais comuns os cabos dispostos em leque, com o ponto de concorrência na torre ou no ponto de ancoragem no solo, respectivamente os itens (a), (b) e (c) da Figura 2.1(a) e (b). Outra configuração usual é a distribuição de cabos em paralelo, Figura 2.1(c). 


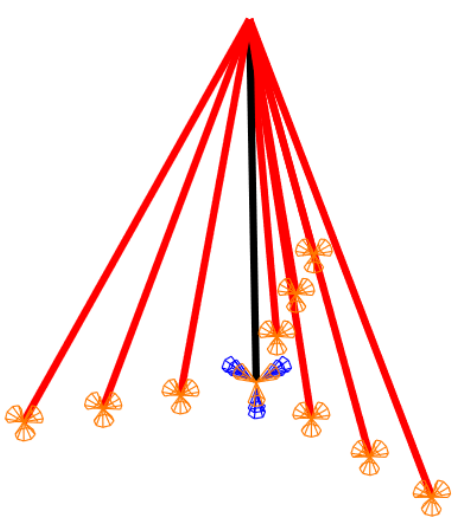

(a) Cabos com mesma origem na torre.

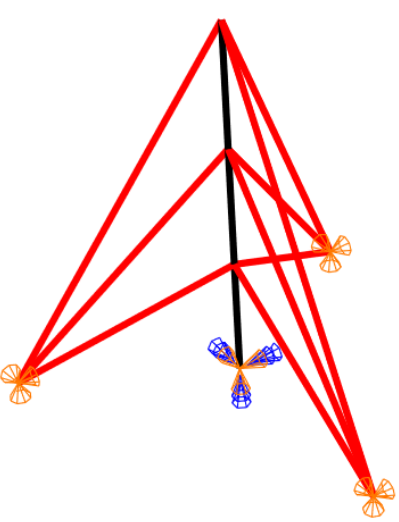

(b) Cabos com mesmo ponto de fixação no solo.

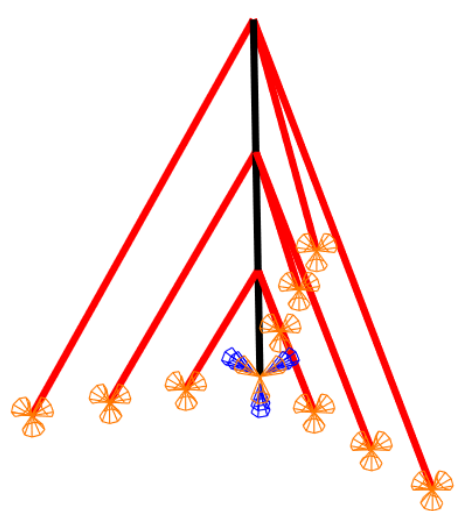

(c) Cabos com distribuição em paralelo.

Figura 2.1 - Representação dos tipos mais usuais de distribuição dos cabos em torres estaiadas.

Torres estaiadas, em particular aquelas usadas na área de telecomunicações, são estruturas extremamente esbeltas apresentando uma grande não-linearidade geométrica [18]. Também os cabos em virtude da pré-tensão e peso próprio, de sua configuração em catenária incompleta e ao fato de não suportar cargas de compressão exercem forças não lineares dependentes dos deslocamentos sobre a torre. Esta não linearidade se mostra particularmente importante no comportamento da torre quando submetida a cargas dinâmicas como vento e terremoto.

\subsection{1.}

\section{Características gerais}

A escolha de torres estaiadas comumente é relacionada diretamente com fatores como localização e altura da estrutura. Geralmente, esse tipo de estrutura prevalece sobre torres autoportantes quando há a necessidade de torres muito altas. Estas estruturas são muito esbeltas com uma relação altura/largura na faixa de 80 a 200, o que as torna extremamente flexíveis.

Usualmente o mastro central, como supracitado, pode ser composto por treliças metálicas, ou estruturas tubulares de seção circular cheia ou vazada ou na forma de um polígono regular. A vantagem de se utilizar seções circulares é um baixo coeficientes de arrasto quando comparado a outros tipos de geometrias, reduzindo as de forças de vento. 
Quanto a base dessas estruturas pode ser fixa ou rotulada na base. O dimensionamento do apoio engastado é mais simples quando comparado à conexão rotulada, sendo o mais utilizado.

Os cabos possuem uma função de contraventamento e estabilização da estrutura, quando a torre é solicitada por forças externas laterais, o que reduz o momento na base da estrutura. Estes cabos são fixados ao longo da torre e ancorados no solo. A rigidez dos cabos depende da pré-tensão inicial imposta durante a construção da torre.

Geralmente os cabos são distribuídos uniformemente em três planos verticais, igualmente espaçados de $120^{\circ}$, como mostra a Figura 2.2(a). Estes planos de simetria, como será mostrado neste trabalho, têm grande influência no comportamento não linear da torre estaiada. O raio da área ocupada pela estrutura, delimitado pelo cabo mais externo, é um fator importante para segurança e custo dessas estruturas, Figura 2.2(b). À medida que esse raio é reduzido, cresce o ângulo $\theta$ e a força de compressão no mastro proveniente dos cabos torna-se maior. Com isso, o mastro necessitará ser mais robusto e mais caro, assim como o sistema de cabos será mais caro para suportar uma estrutura mais pesada. A maioria dos fabricantes sugerem que o raio seja na faixa de $75 \%$ a $90 \%$ da altura da torre. Para valores abaixo de $70 \%$ a força de compressão na torre é maior. Entretanto, se projetada adequadamente, pode-se reduzir o raio para $40 \%$ a $50 \%$ da altura total sem compromete a capacidade de carga e segurança da torre, ANSI/TIA-222. [24] [30].

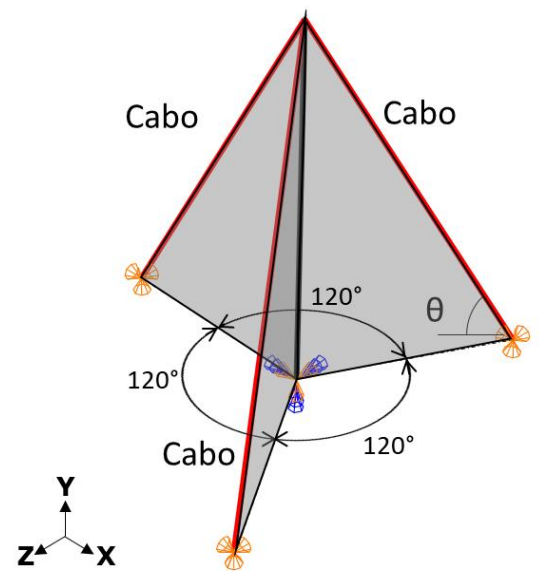

(a) Planos verticais formados pelos cabos.

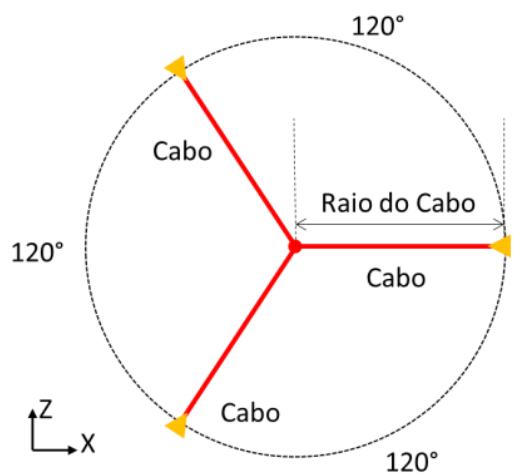

(b) Distribuição dos cabos ao redor da torre.

Figura 2.2 - Distribuição dos cabos ao redor da torre. 
As torres estaiadas podem possuir um ou mais níveis de estais, dependendo da sua altura e geometria das antenas acopladas a ela, sendo os cabos distribuídos simetricamente a cada nível. O número de cabos varia de acordo com as especificações técnicas de cada país e influenciam diretamente o projeto de dimensionamento dessas estruturas e de suas fundações. Em áreas com incidência de neve e geadas é indicado diminuir o número de cabos e suas inclinações em relação ao mastro deve ser mais acentuada.

Outro fator de bastante influência no comportamento da torre, como já mencionado, é o tensionamento dos cabos, dado que a rigidez horizontal da torre depende da rigidez destes elementos. No cálculo da rigidez deve-se incluir o efeito do peso próprio dos cabos, para uma análise mais precisa. Quando estes elementos apresentam uma folga, a rigidez é consideravelmente menor que quando estes estão totalmente tracionados.

A norma Canadense recomenda que a pré-tensão desses cabos esteja dentro da faixa de $8 \%$ a $15 \%$ da tensão de ruptura dos cabos, [31]. Quando esse valor da tensão é maior que 15\%, deve-se considerar os efeitos de vibrações eólicas e quando é menor que 8\%, deve-se levar em consideração os efeitos de galope e afrouxamento nos cabos, [32]. O valor exato da pré-tensão dos cabos varia de acordo com o tipo de cabo e as características da torre, como altura e utilização. Quando a pré-tensão é pequena ou nula, o cabo assume uma configuração em catenária, sendo seu comportamento uma função não linear das propriedades geométricas e físicas do cabo, assim como da tensão atuante., [33].

Mendonça e Barros [34] comentam que pequenas imperfeições em uma torre estaiada, para fins de telecomunicações, resultam em uma má qualidade na transmissão e captação de sinais, levando a uma ineficiência no fornecimento adequado do serviço para o cliente. Em função disso, é estabelecido um limite máximo para o deslocamento horizontal da torre em 3\% da sua altura. Para estruturas treliçadas o valor limite desse deslocamento é reduzido para 1,5\% da altura da torre, seção 3.8.2 da Norma Americana TIA 222 [24], [32].

\section{2. \\ Revisão Bibliográfica}

A complexa relação não linear entre o mastro e cabos torna difícil a determinação analítica do comportamento da torre. Outro fator que influência esse 
comportamento são os diferentes tipos de carregamentos dinâmicos que incidem nessas estruturas, podendo leva-las a vibrações indesejáveis. Com isso diversos estudos são voltados à investigação da interação não linear entre mastros e cabos. Alguns desses estudos podem ser encontrados no trabalho de Amiri [35], que desenvolveu um levantamento dos trabalhos mais relevantes desenvolvidos na área de pesquisa do comportamento de torres estaiadas.

Muitos autores focam seus estudos no comportamento dos cabos quando submetidos à diversos tipos de carregamentos; dentre estes pode-se citar Irvine [36], Leonard [37], Triantafyllou [38], Veletsos e Darbre [39] e Starossek [40], [41]. Irvine [36]

também investiga o comportamento dinâmico de torres, com o objetivo de obter expressões analíticas para as frequências de vibrações dos cabos. Diversos autores têm desenvolvido estratégias de modelagem para simular essas torres, dentre eles pode-se citar: Albermani e Kitipornchai [42], [43], Albermani et al. [44], Carril Júnior [45]; El-Ghazaly e Al-Khaiat [23]; Kahla [46], [47]; Menin [48]; Rao e Kalyanarama [49]; Ribeiro [50], Saxena et al. [51]; Wahba et al [52] e Wahba et al. [53].

Sparling [54], investiga o comportamento dinâmico dos cabos e da torre quando submetidos a cargas provenientes de ventos turbulentos, comparando resultados para os cabos e para torre quando se aplicavam modelos simplificados do tipo massa mola e modelos totalmente não lineares dos cabos. Também estuda a resposta dinâmica por técnicas de análise do domínio de frequência. Seguindo a mesma linha de pesquisa Kaul [55], utilizando a metodologia de programação orientada ao objeto, analisa a resposta dinâmica de torres estaiadas sob ação de cargas de vento considerando a não linearidade do cabo no modelo completo.

Kahla [46], modelou numericamente os efeitos dinâmicos presentes em uma torre estaiada, incluindo o efeito de galope do cabo. Posteriormente, [47], analisou os efeitos da ruptura dos cabos nessas torres, comentando ser essa uma das situações mais críticas a qual a torre pode estar submetida, sem considerar as ações do vento.

Wahba et al. [52], apresentam um estudo onde a torre é submetida a ações dinâmicas como as cargas de vento, terremotos e galope dos cabos. Nesse trabalho o modelo é desenvolvido utilizando o método dos elementos finitos, onde são empregados modelos de vigas e treliças 3D para simular os elementos da elementos 
da estrutura. Os resultados encontrados são comparados a resultados experimentais. Nesse trabalho também são desenvolvidos estudos paramétricos experimentais para identificar quais parâmetros possuem maior influência nos modos de vibração da torre e suas frequências naturais.

Wahba et al. [53], comparam dois modelos não lineares em elementos finitos, onde em um modela-se o mastro com elementos de treliça e no outro, com elementos de vigas. Em ambos se adotam elementos cabo não lineares. Usando estes modelos analisam o comportamento de seis torres considerando o efeito de cargas de vento e gelo. Em um trabalho subsequente Magdula e Wahba, [56], usam o mesmo modelo para encontrar as frequências naturais do grupo de torres. Nos dois estudos, os resultados obtidos com as duas metodologias de modelagem são bem próximas. Wahba [57] apresenta um novo estudo onde compara a modelagem uma torre utilizando elementos de treliças para os cabos e um elemento de viga para um mastro com um modelo onde os cabos são modelados da mesma forma, porém o mastro é discretizado com vários elementos de viga. A seguir desenvolve uma análise paramétrica de 33 torres utilizando elementos finitos para investigar qual o parâmetro possui maior influência nas vibrações livres dessas estruturas. Seguindo a linha de pesquisa de modelagem de torres estaiadas, Oliveira et al. [58] propõe uma metodologia de modelagem com elementos de vigas para o mastro e treliça para os cabos, avaliando a resposta linear estática e dinâmica de três torres com alturas diferentes.

Algumas vezes, no projeto de torre estaiadas, não se faz uma análise dinâmica sob cargas de vento. O efeito de vento é avaliado de forma simplificada utilizando coeficientes de rajada e fatores de amplificação, como sugerem algumas normas [24], [31], [32], [59]-[62]. Entretanto, e virtude do grande número de acidentes envolvendo torres estaiadas [12], diversos pesquisadores têm estudado o comportamento dessas estruturas quando submetidas a cargas de vento. Menirn [48] avalia as respostas estáticas e dinâmicas dessas estruturas, comparando na análise estática resultados de modelos matemáticos lineares e não lineares. $\mathrm{Na}$ análise dinâmica emprega o método de simulação de Monte Carlo incluindo as parcelas flutuantes da carga de vento. Seguindo essa linha de pesquisa Ribeiro [50] avalia torres de seção quadrada sob as mesmas características avaliadas por Menin e dá ênfase a ruptura de cabos, mas não considera as cargas de vento. Também avalia os 
esforções axiais máximos nos elementos da estrutura durante as análises. Carlos [63] investiga o efeito da ruptura de cabos nas respostas estáticas e dinâmicas usando carregamentos estáticos equivalentes.

Em torres estaiadas não é apenas o modo fundamental de vibração que governa o seu comportamento pois, em virtude das simetrias, esse tipo de estrutura pode apresentar modos acoplados, além de muito modos com frequências baixas que poderem contribuir para a sua resposta quanto submetido a carregamentos de ventos turbulentos. Malli et al. [3] comenta sobre o efeito da interação modal nas respostas dessas estruturas.

Um ponto a se ressaltar é que não apenas os modos do mastro influenciam a resposta do sistema. Em muitos casos os modos de vibração dos cabos são importantes. No caso de cargas de vento, a resposta depende não apenas das frequências das estruturas, mas também das cargas no mastro e da direção relativa do vento. Logo, um entendimento completo do comportamento não linear dinâmico dessas estruturas necessita de uma análise criteriosa e detalhada. Sparling et al. [64] e Meshmesha et al. [65] apresentam metodologias simplificadas de análises de torres estaiadas utilizando elementos finitos, possibilitam uma compreensão de alguns dos acoplamentos dinâmicos presentes nessas estruturas.

Shi e Salim [66] investigam a resposta não linear de torres estaiadas sujeitas a carregamentos estáticos e dinâmicos utilizando modelos em elementos finitos. No trabalho de Albermani et al. [67] é apresentado uma formulação analítica não linear com o objetivo de prever a falha de torres de transmissão. $\mathrm{O}$ método é calibrado com base em resultados obtidos por testes em uma torre em escala real.

Um dos parâmetros mais significativos para a resposta dinâmica dessas estruturas é a pré-tensão nos cabos. Uma recomendação usual do valor desse prétensionamento é $10 \%$ da carga de ruptura do cabo. Entretanto, frequentemente estes elementos podem estar submetidos a tensões maiores ou menores, ou até com valores acima ou abaixo das recomendações, o que pode afetar a resposta dinâmica da estrutura. Como esses parâmetros pode influenciar de diversas formas a estrutura, estudos de sensibilidade da resposta dinâmica linear (frequências e modos de vibração) de uma torre estaiada em função das pretensões iniciais dos cabos são apresentados por Ballaben [68], por meio de análise de um modelo tridimensional de torre estaiada submetida a cargas laterais uniformes. Nesse trabalho a torre é 
representada como uma viga-coluna com três cabos inclinados e dispostos simetricamente ao redor dela e conectados ao seu topo. É apresentado uma variedade de comportamentos dependendo da pré-tensão inicial. Estudos semelhantes são desenvolvidos por Luzardo et al. [69] e em um estudo anterior de Ballaben [70], onde se estuda o efeito da pré-tensão dos cabos na resposta dinâmica das torres submetidas a condições de vento e terremoto. Ainda nessa vertente Ballaben [71]-[73] desenvolve análises de sensibilidade da estrutura quanto a metodologia de aplicação da carga de vento e seu comportamento dinâmico. Ismail e Hassnien [74], também analisa a resposta dessas estruturas submetidas a cargas de vento.

\section{3.}

\section{Modos Normais Não Lineares}

Modo normais não lineares (MNNLs) podem ser considerados como uma generalização dos modos normais lineares (MNLs). O conceito inicial foi introduzido por Rosenberg [75], que definiu um MNNL de um sistema discreto, conservativo e não linear como uma oscilação periódica síncrona (vibração em uníssono). Em 1991, Shaw e Pierre [76] introduziram um conceito mais geral de MNNLs, onde os definiram como movimentos em variedades invariantes tangentes e com as mesmas dimensões que os auto espaços lineares no espaço de fase. Posteriormente, Bovin et. all [77] introduziu o conceito de variedades invariantes multimodais, que podem ser entendidos com uma extensão dos MNNLs quanto dois ou mais modos não lineares interagem. Multimodos não lineares podem ser observados em sistemas com ressonância interna, [78].

Uma característica dos MNNLs que não condiz com a teoria linear, é que eles podem se apresentar em número maior que o número de graus de liberdade, gerando o efeito chamado de superabundância de modos. Assim, alguns MNNLs não podem ser considerados como uma continuação não linear dos MNLs. Os modos gerados pela ressonância interna é um exemplo. Outro exemplo corresponde a geração de MNNLs por simetrias existentes no sistema [19], [21], [79]-[84]. Além disso, os MNNLs não possuem propriedades de superposição ou ortogonalidade. 


\section{4. \\ Modelo conceitual com 2GL}

Thompson e Gaspar [20] propuseram um modelo conceitual com dois graus de liberdade (2GL) composto de uma coluna rígida suportada lateralmente por três molas lineares, como um exemplo de flambagem interativa no contexto da teoria de catástrofes. Seus resultados mostram que as simetrias do sistema têm uma influência marcante na função potencial subjacente e, consequentemente, nas soluções pós-critica acopladas e na resposta não linearidade dinâmica do sistema.

A Figura 2.3 ilustra o modelo de 2GL, que consiste em um pendulo espacial invertido, composto por uma barra rígida rotulada, de comprimento $L$ na extremidade inferior e livre na extremidade superior, sendo nesta extremidade aplicada uma carga axial vertical, representada pelo peso de uma massa concentrada, $m$. Os deslocamentos laterais são restringidos por três molas lineares, inclinadas a $45^{\circ}$. Estas molas estão localizadas simetricamente em relação ao eixo Y, sendo suas posições definidas pelo ângulo $\alpha$. Isto é, estão distribuídas simetricamente ao redor da torre, espaçadas do ângulo $\alpha$. As molas possuem rigidez $K_{1}, K_{2}$ e $K_{3}$. Os dois graus de liberdade são $u_{1}=\operatorname{sen} \theta_{1}$ e $u_{2}=\operatorname{sen} \theta_{2}$, onde $\theta_{1}$ e $\theta_{2}$ são as rotações nos planos verticais $x \times y$ e $\mathrm{y} \times z$, respectivamente, [19]. Thompson e colaboradores [20], [85] observaram que o valor do ângulo $\alpha$ possui uma influência significativa na estabilidade do modelo. Para a torre adota-se ângulo $\theta=120^{\circ}$.

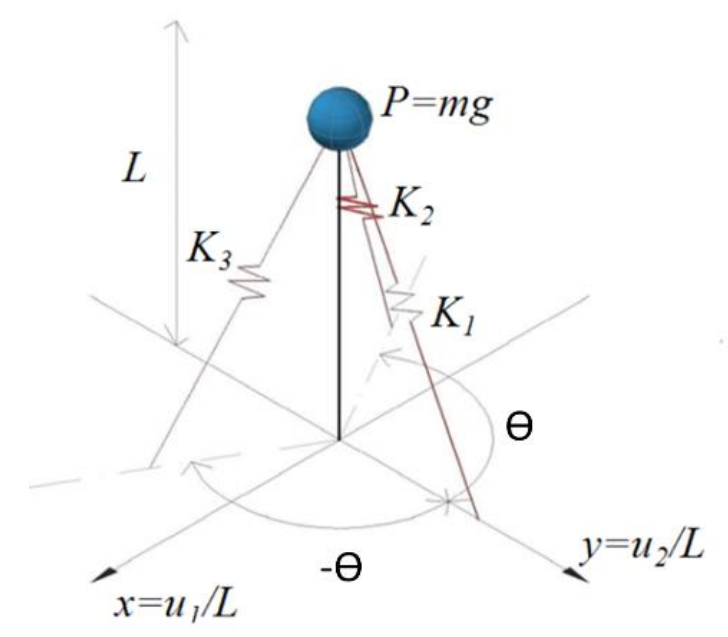

Figura 2.3 - Representação do modelo conceitual 2GL de uma torre estaiada. 
Orlando et al. [83] mostra que a energia potencial e a energia cinética desse modelo são dadas por

$$
\begin{gathered}
V=\frac{1}{2} K_{1}\left(\sqrt{2}-L \sqrt{2-2 u_{2}}\right)^{2}+\frac{1}{2} K_{2}\left(\left(L \sqrt{2}-L \sqrt{2-\sqrt{3 u_{1}+} u_{2}}\right)^{2}+\right. \\
\left.\left(L \sqrt{2}-L \sqrt{2+\sqrt{3 u_{1}+} u_{2}}\right)^{2}\right)-P L\left(1-\sqrt{1-u_{1}^{2}-u_{2}^{2}}\right) \\
T=\frac{1}{2} m\left(L^{2} \dot{u}_{1}^{2}+L^{2} \dot{u}_{2}^{2}-\frac{\left(L \dot{u}_{1} u_{1}+L \dot{u}_{2} u_{2}\right)^{2}}{u_{1}^{2}+u_{2}^{2}-1}\right)
\end{gathered}
$$

Orlando et al. [83] deduzem então as equações de movimento do sistema forçado e amortecido na forma adimensional, considerando as não linearidades geométricas e inerciais, sendo estas dadas por:

$$
\begin{aligned}
& \ddot{u}_{1}\left(1-u_{1}^{2}-2 u_{2}^{2}+u_{1}^{2} u_{2}^{2}+u_{2}^{4}\right)+\ddot{u}_{2}\left(u_{1} u_{2}-u_{1}^{3} u_{2}-u_{1} u_{2}^{3}\right)+\dot{u}_{1}^{2}\left(u_{1}-u_{1} u_{2}^{2}\right)+ \\
& \dot{u}_{2}^{2}\left(u_{1}-u_{1}^{3}\right)+2 u_{1}^{2} u_{2} \dot{u}_{1} \dot{u}_{2}+\left[\frac { 2 } { \sqrt { 3 } \lambda \Omega _ { 2 G L } ^ { 2 } } \left\{\left(\frac{\left(\sqrt{2}-\sqrt{2-\sqrt{3} u_{1}+u_{2}}\right)}{\sqrt{2-\sqrt{3} u_{1}+u_{2}}}\right)-\right.\right. \\
& \left.\left.\frac{\left(\sqrt{2}-\sqrt{2+\sqrt{3} u_{1}+u_{2}}\right)}{\sqrt{2+\sqrt{3} u_{1}+u_{2}}}\right\}+\frac{4}{3 \lambda \Omega_{2 G L}^{2}} \frac{\left(\sqrt{2}-\sqrt{2-2 u_{2}}\right)}{\sqrt{2-2 u_{2}}} \frac{1}{\Omega_{2 G L}^{2}} \frac{u_{2}}{\sqrt{1-u_{1}^{2}-u_{2}^{2}}}+\frac{2 \xi_{2}}{\Omega_{2 G L}} \dot{u}_{2}\right] \times \\
& \left(-1-u_{1}^{2}-u_{2}^{2}\right)^{2}=F_{2 G L} \cos \varphi \operatorname{sen} \tau\left(\left(-1-u_{1}^{2}-u_{2}^{2}\right)^{2}\right. \\
& \ddot{u}_{2}\left(1-u_{2}^{2}-2 u_{1}^{2}+u_{1}^{2} u_{2}^{2}+u_{1}^{4}\right)+\ddot{u}_{1}\left(u_{1} u_{2}-u_{1}^{3} u_{2}-u_{1} u_{2}^{3}\right)+\dot{u}_{2}^{2}\left(u_{2}-u_{2} u_{1}^{2}\right)+ \\
& \dot{u}_{1}^{2}\left(u_{2}-u_{2}^{3}\right)+2 u_{2}^{2} u_{1} \dot{u}_{1} \dot{u}_{2}+\left[\frac { 2 } { \sqrt { 3 } \lambda \Omega _ { 2 G L } ^ { 2 } } \left\{\left(\frac{\left(\sqrt{2}-\sqrt{2-\sqrt{3} u_{1}+u_{2}}\right)}{\sqrt{2-\sqrt{3} u_{1}+u_{2}}}\right)-\right.\right. \\
& \left.\left.\frac{\left(\sqrt{2}-\sqrt{2+\sqrt{3} u_{1}+u_{2}}\right)}{\sqrt{2+\sqrt{3} u_{1}+u_{2}}}\right\}+\frac{4}{3 \lambda \Omega_{2 G L}^{2}} \frac{\left(\sqrt{2}-\sqrt{2-2 u_{2}}\right)}{\sqrt{2-2 u_{2}}} \frac{1}{\Omega_{2 G L}^{2}} \frac{u_{2}}{\sqrt{1-u_{1}^{2}-u_{2}^{2}}}+\frac{2 \xi_{2}}{\Omega_{2 G L}} \dot{u}_{2}\right] \times \\
& \left(-1-u_{1}^{2}-u_{2}^{2}\right)^{2}=F_{2 G L} \operatorname{sen} \varphi \operatorname{sen} \tau\left(\left(-1-u_{1}^{2}-u_{2}^{2}\right)^{2}\right.
\end{aligned}
$$


onde $\varphi$ é o ângulo de atuação da força com relação ao eixo x, o ponto representa a derivada no tempo e $\Omega_{2 G L}=\omega_{e} / \omega_{p}$, sendo $\omega_{p}^{2}=g / L, \tau=\omega_{e} t, F_{2 G L}=F_{b} / L, \frac{K}{m L^{2}}=$ $\omega_{p}^{2} / \lambda, \lambda=P / P_{c r} . F_{b}$ representa a magnitude do deslocamento da base, $\omega_{e}$ é a frequência de excitação e $\xi_{i}$ são os fatores de amortecimento.

Quando este modelo é apresentado com suas três molas, $\theta=120^{\circ}$ e $K_{1}=$ $K_{2}=K_{3}=1 / 3 K$, pode-se toma-lo como uma representação simplificada de um modelo de uma torre estaiada. Nessa configuração há presença de duas cargas críticas coincidentes, $P_{c r 1}=P_{c r 2}=P_{c r}=K L / 4$, decorrente da simetria do modelo. $\mathrm{O}$ mesmo fenômeno é encontrado para as frequências naturais, levando a uma ressonância interna 1:1 [83].

Para diferentes valores de $\theta$, esse modelo simplificado gera uma sequência completa de catástrofes umbilicais, [20], [86]. Para $\alpha=120^{\circ}$, o sistema resulta no caso anticlinal, [19], [20], [85]. Recentemente, Orlando et al. [19], [82], [83] e Gavassoni [21], exploração o comportamento não linear estático e dinâmico desse modelo. Na Figura 2.4 é apresentado a trajetória de equilíbrio fundamental e os caminhos pós-críticos. Quando $\lambda=1$, obtém-se três trajetórias pós-críticas: duas soluções instáveis acopladas, e uma solução instável desacoplada, com deslocamento na direção $\mathrm{X}$ igual a zero. As soluções instáveis com grande declividade inicial resultam em uma significativa sensibilidade a imperfeições. Quanto ao comportamento dinâmico desse sistema, os autores observaram que esse modelo apresenta três modos normais não lineares similares nas direções dos cabos e soluções multimodais em fase e fora de fase, como ilustrado na Figura 2.5 que mostra o movimento do topo da torre em cada modo de vibração não linear. 


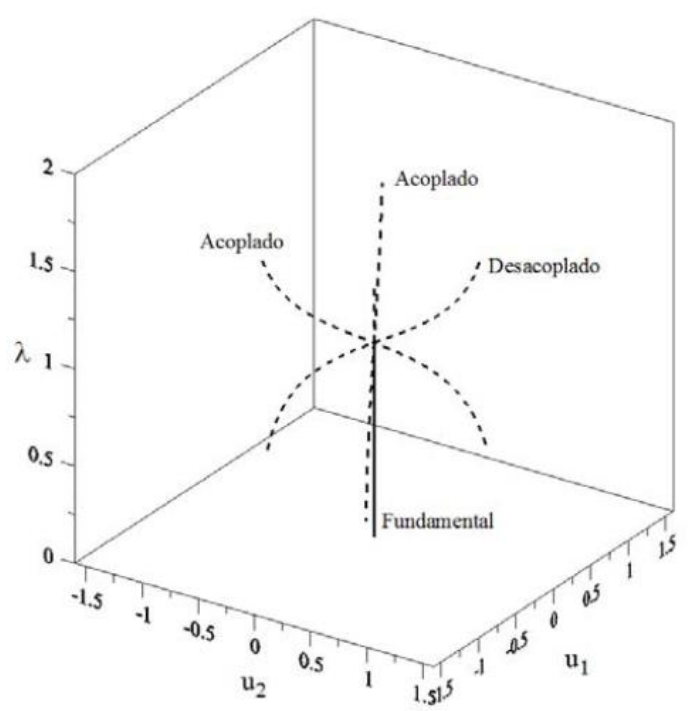

(a) Caminhos pós-crítico para $\Theta=120^{\circ}$.

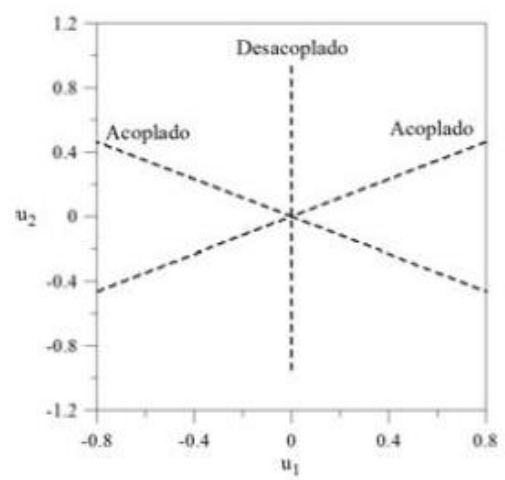

(b) Projeção $u_{1} \times \lambda$.

(c) Projeção $u_{1} \times u_{2}$.

Figura 2.4 - Projeções dos caminhos e pós-críticos para $\Theta=120^{\circ}$ - caso anticlinal. Modelo de torre [19].

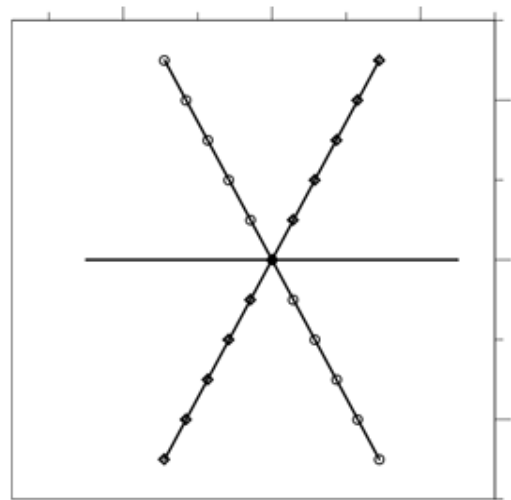

(a) Três modos não-lineares similares

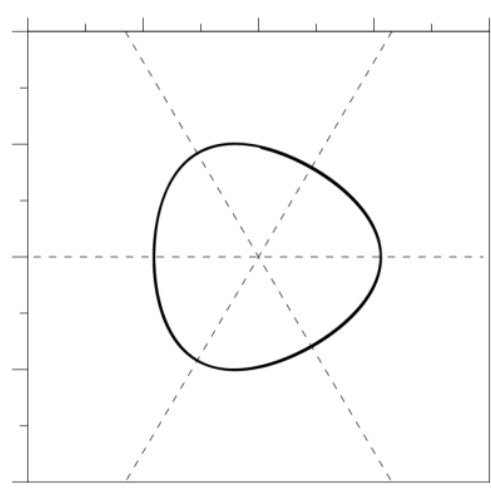

(b) Soluções multimodais

Figura 2.5 - Modos normais não-lineares para um modelo de Pêndulo estaiado, (a) e (b) [19], [21]. 


\section{3 Modelo Numérico}

\section{1.}

\section{Geral}

Para avaliar o comportamento de torres estaiadas submetidas a diversas condições de carregamento este estudo utiliza o método dos elementos finitos (MEF), usando o programa ABAQUS ${ }^{\circledR}$. Diversos modelos de torres, idealizados como sistemas reticulares, são apresentados e usados para investigar a seu comportamento não linear sob cargas estáticas e dinâmicas. Neste capítulo são abordadas as técnicas de modelagem utilizadas para as simulações por meio do MEF, além de apresentar as características de cada um dos modelos propostos.

\section{2. \\ Procedimentos de Modelagem.}

Para o desenvolvimento dos modelos utiliza-se a interface gráfica do ABAQUS, o ABAQUS/CAE, que permite o pré- e pós-processamento dos modelos. No pré-processamento são gerados os arquivos de entrada que contêm as características físicas e geométricas dos elementos e também as indicações dos nós, além das condições de contorno, carregamentos aplicados, tipos de análises e as características da malha de elementos finitos. Isto é, esse arquivo possui todas as informações do modelo necessárias para cada etapa do processamento.

Uma característica bastante útil destes arquivos de entrada é a possibilidade da sua alteração manual, modificando-os de acordo com as necessidades do usuário, sem recorrer novamente ao módulo gráfico. Permitem-se, assim, alterações nas configurações default do programa para o processamento apenas do texto do arquivo.

Ao fim do processamento é gerado um arquivo de saída que contém todo o histórico de dados de resposta do modelo, com base na sequência de eventos e características de cada etapa. Este pós-processamento, apresenta uma visualização 
dos resultados de forma gráfica e permite exportar os resultados dos nós de cada elemento para arquivos de texto e planilhas.

Quanto ao processamento dos modelos, o ABAQUS é composto por dois módulos principais de análise, o ABAQUS/Standard e o ABAQUS/Explicit. Neste trabalho foi utilizado o módulo ABAQUS/Standard, que é capaz de resolver problemas estáticos e dinâmicos lineares e não-lineares. Este módulo permite diversos tipos de análises que são divididas em dois grupos, um grupo para análise geral e outro para análises a partir de perturbações lineares.

O grupo de análise geral define uma sequência de eventos e passos do modelo, onde o estado final do modelo ao fim de cada passo é a configuração inicial do próximo. O grupo de análises a partir de perturbações não lineares fornece respostas de análises lineares a partir de uma perturbação linear no estado base do passo anterior, que pode ser gerado pelas análises gerais. Um modelo pode conter diversos módulos de análises dos dois grupos apresentados. Neste trabalho foram utilizados os módulos de análise geral estática, análise estática não linear usando o método RIKS, análises de problemas de autovalor para obtenção de cargas e modos de flambagem e frequências naturais e modos de vibração, e análise dinâmica não linear através da integração das equações não lineares de movimento. No apêndice A é apresentado um tutorial descrevendo todos os comandos necessários à geração dos arquivos de entrada no ABAQUS/CAE.

\section{3. Modelos Estruturais de Torre Estaiadas}

A partir das orientações para projetos, indicações de confiabilidade de torres, dos modelos conceituais de dois graus de liberdade e dos modelos apresentados no Capítulo 2, são propostos para as análises neste trabalho diversos modelos sintéticos de torre. Estes modelos têm como intuito fundamentar e possibilitar uma avaliação paramétrica do comportamento de uma torre estaiada. As condições de estudo incluem desde o mastro como um elemento isolado até uma torre com múltiplos níveis de estais.

Para a construção dos modelos são utilizados elementos 2D e 3D. Elementos de treliça representam os cabos e elementos de viga, o mastro central. Cada um desses modelos é submetido a diferentes tipos de análises lineares e não-lineares 
estáticas e dinâmicas. As metodologias de modelagem no programa ABAQUS são semelhantes às utilizadas por Wahba, [57], para investigação de torres estaiadas, e Andersson \& Malm, [87], para análises dinâmicas.

\subsection{1. Modelos Sintéticos}

Os modelos sintéticos propostos são modelos simplificados de torres e representados como estruturas reticulares de comportamento elástico linear. A simplificação consiste em representar o mastro por apenas um elemento central e ligado a ele cabos, em um ou mais níveis. O mastro possui uma seção transversal tubular circular vazada. Os cabos são representados por elementos de seção transversal circular maciça, conectados diretamente ao mastro.

\subsubsection{1. Modelo de mastro isolado}

Os primeiros modelos abordados são os modelos de mastro isolado, sem consideração dos cabos. Estes modelos, são constituídos por um modelo de vigacoluna com diferentes combinações de restrições em seu topo. O objetivo dessa variação das restrições no topo é simular os dois comportamentos extremos de uma torre. Isto é, quando esta possui uma restrição lateral por influência dos cabos e quando o topo desta está completamente livre, [33]. Quando há a presença de cabos, estes transmitem uma força vertical ao topo da torre, comprimindo-a. Uma carga axial aplicada ao topo da viga-coluna possibilita uma simulação simplificada deste efeito.

Os mastros são modelados como elementos de viga-coluna tridimensionais com três nós, com formulação quadrática, denominados B32 na biblioteca do ABAQUS, [88]. O elemento possui seis graus de liberdade por nó, onde três são referentes a deslocamentos e os outros três referentes a rotações. Esse modelo permite reproduzir as deformações do mastro com maior precisão, pois o mesmo pode apresentar deslocamentos axiais, transversais e rotações, em todos os eixos.

Os seguintes casos são analisados:

- Os cabos não exercem influência no sistema e o topo movimenta-se livremente; 
- Os cabos atuam de forma preponderante e evitam qualquer movimento transversal no topo da estrutura;

- Em ambos os casos se considera ou não o efeito do peso-próprio do mastro;

- Os cabos além de travarem o topo da estrutura transmitem uma força de compressão ao topo da torre.

Essas considerações simplificadas da influência dos cabos e da consideração do peso-próprio da estrutura são representadas em forma de combinações de efeitos na Tabela 3.1, originando os modelos de mastro isolado, utilizados neste estudo. $\mathrm{Na}$ tabela são apresentadas as considerações adicionais de condições de contorno e também de carregamentos aplicados diretamente na estrutura. Tais condições de contorno são impostas para simular as condições limites de deslocamentos do topo da torre. A Figura 3.1 apresenta desenhos esquemáticos de cada modelo considerado para as análises de mastro isolado.

Tabela 3.1- Organização dos modelos de viga-coluna.

\begin{tabular}{c|c}
\hline Modelos & Descrição do Modelo \\
\hline E-L & Modelo engastado e livre. \\
\hline E-A & Modelo engastado e apoiado. \\
\hline E-L PP & $\begin{array}{c}\text { Modelo engastado e livre com } \\
\text { presença de peso-próprio. }\end{array}$ \\
\hline E-A PP & $\begin{array}{c}\text { Modelo engastado e apoiado com } \\
\text { presença de peso-próprio. }\end{array}$ \\
\hline E-L PP + PR & $\begin{array}{c}\text { Modelo engastado e livre com } \\
\text { presença de peso-próprio e com carga } \\
\text { axial no topo. }\end{array}$ \\
\hline E-A PP + PR & $\begin{array}{c}\text { Modelo engastado e apoiado com } \\
\text { presença de peso-próprio e com carga } \\
\text { axial no topo. }\end{array}$ \\
\hline
\end{tabular}




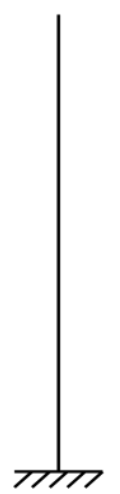

E-L

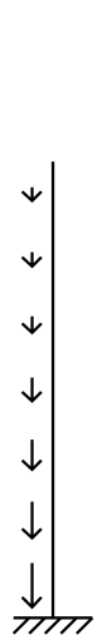

E-L PP

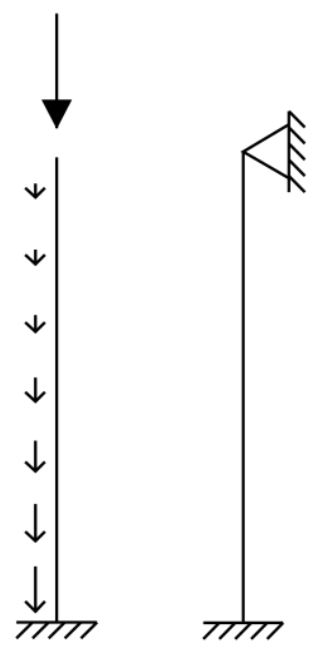

E-L PP + P
E-A

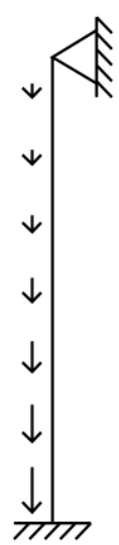

E-A PP

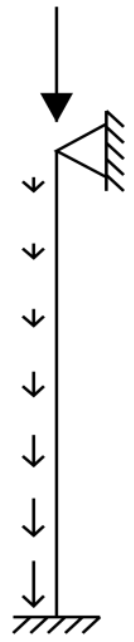

$\mathrm{E}-\mathrm{A} \mathrm{PP}+\mathrm{PR}$

Figura 3.1 - Representação esquemática dos modelos de mastro isolado.

O peso próprio do mastro é considerado a partir da densidade do material e de suas propriedades geométricas. Para se inserir a gravidade no modelo, basta aplicar o valor da aceleração da gravidade no eixo referente à mesma, na opção de carregamento "GRAVITY”.

\subsubsection{2. \\ Modelos Bidimensional de Torre}

A seguir, utiliza-se um modelo de torre estaiada bidimensional, "Torre 2D", com apenas um nível de estais. Tal modelo foi estudado anteriormente por Del Prado et. al. [89], [90] e está apresentado na Figura 3.2.

Neste modelo são utilizados na discretização do mastro elementos de viga bidimensionais com três nós, cada nó com três graus de liberdade. Para os cabos empregam-se elementos de treliça bidimensional com dois nós, cada qual com dois graus de liberdade. Esses elementos são denominados respectivamente B22 e T2D2 na biblioteca do ABAQUS. Os elementos de mastro e cabos possuem seção transversal constate ao longo dos respectivos comprimentos.

Os elementos de cabo suportam apenas forças de tração. No ABAQUS, essa característica é inserida selecionando-se a opção de "NO COMPRESSION".

Os elementos de cabo estão submetidos a uma força de pré-tensão. A tensão correspondente é inserida na etapa inicial da sequência de análises e mantida nas 
etapas subsequentes como um carregamento pré-existente no modelo. Esta situação de pré-tensão é a responsável por gerar uma força vertical no topo da estrutura.

Quanto às condições de contorno dos elementos, são adotadas basicamente duas: uma para a base do mastro e outra para o ponto de ancoragem dos cabos no solo. A base do mastro é considerada engastada, se restringido todos os deslocamentos e rotações, e para os pontos de ancoragem dos cabos no solo, há apenas restrições a deslocamentos.

O objetivo desta modelagem, especificamente, é o estudo do comportamento pós-crítico deste tipo de estrutura. São adotadas as mesmas propriedades físicas e geométricas apresentadas por. [89], [90] e reproduzidas na Tabela 3.2.

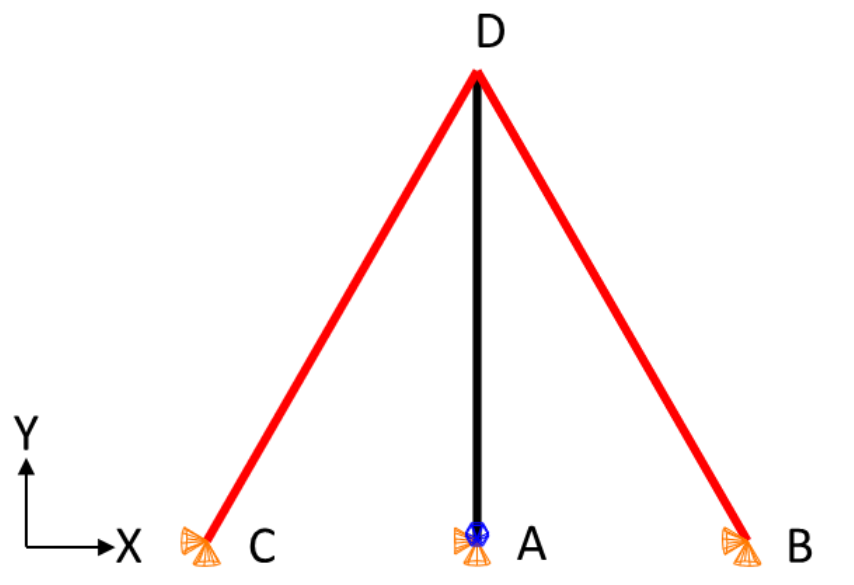

Figura 3.2 - Representação esquemática de uma torre estaiada 2D.

Tabela 3.2 - Propriedades físicas e geométricas dos elementos do modelo bidimensional de torre estaiada.

\begin{tabular}{l|l|l}
\hline \multicolumn{1}{c|}{ Propriedades } & \multicolumn{1}{|c}{ Coluna Circular Oca } & \multicolumn{1}{c}{ Cabo } \\
\hline Diâmetro Interno $(D)$ & $0,475 \mathrm{~m}$ & - \\
Diâmetro Externo $(d)$ & $0,500 \mathrm{~m}$ & $1.8 \mathrm{E}-02 \mathrm{~m}$ \\
Comprimento $(L)$ & $100 \mathrm{~m}$ & $115.47 \mathrm{~m}$ \\
Área Transversal $(A)$ & $1,914 \mathrm{E}-02 \mathrm{~m}^{2}$ & $2.54 \mathrm{E}-04 \mathrm{~m}^{2}$ \\
Momento de Inércia $(I)$ & $5,691 \mathrm{E}-02 \mathrm{~m}^{4}$ & - \\
Módulo de Elasticidade $(E)$ & $1,18 \mathrm{E}+11 \mathrm{~N} / \mathrm{m}^{2}$ & $1.0 \mathrm{E}+11 \mathrm{~N} / \mathrm{m}^{2}$ \\
Densidade $(\rho)$ & $7850 \mathrm{~kg} / \mathrm{m}^{3}$ & $7850 \mathrm{~kg} / \mathrm{m}^{3}$ \\
Força de pré-tensão & - & $10 \mathrm{kN}$ \\
\hline
\end{tabular}




\subsubsection{3.}

\section{Modelo de torre com um nível de estais}

O modelo sintético de torre tridimensional com apenas um nível de estais, "modelo sintético padrão", é utilizado como base para a maioria dos estudos aqui desenvolvidos. Neste modelo os cabos são ligados diretamente ao topo da estrutura, tendo uma inclinação inicial $\theta$. Estes cabos são dispostos de forma equidistante, formando entre eles um ângulo de $120^{\circ}$, como ocorre na maioria das aplicações práticas, gerando três planos de simetria, os quais têm grande influência no comportamento não linear. A Figura 3.3 mostra uma representação esquemática desse modelo. As referências quanto às coordenadas utilizadas no ABAQUS neste trabalho, são sempre 1, 2 e 3 para respectivamente os eixos $\mathrm{X}, \mathrm{Y}$ e Z.

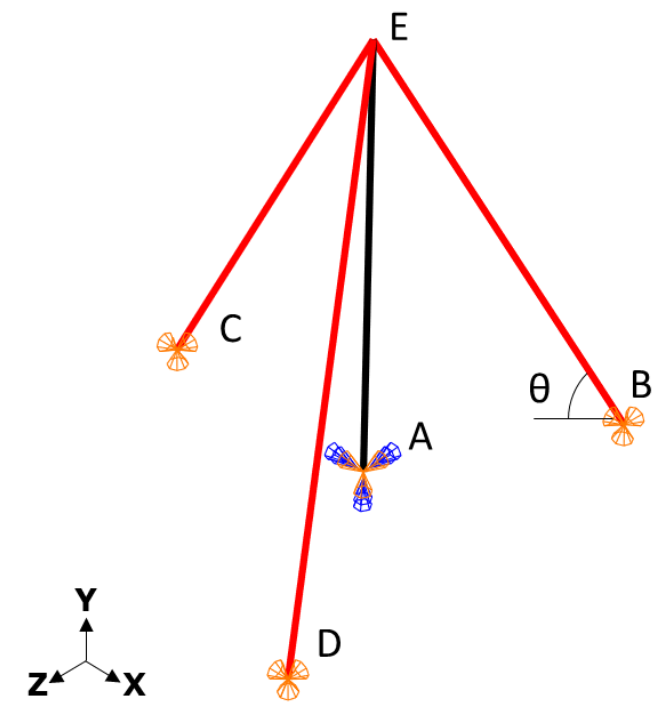

Figura 3.3 - Representação esquemática de uma torre estaiada com apenas um nível de estais.

O mastro é modelado como elementos de viga-coluna tridimensionais com três nós, com formulação quadrática, com seis graus de liberdade por nó, denominados B32 na biblioteca do ABAQUS.

Quanto aos cabos, estes são modelados como elementos de treliça tridimensionais com dois nós e três graus de liberdade cada, com formulação linear, denominado na biblioteca do ABAQUS como T3D2. Os graus de liberdade desse elemento são referentes aos deslocamentos. Foram considerados os efeitos de inércia e amortecimento no cabo. Não foi incluída no modelo a geometria do cabo 
em catenária. Estas considerações para o cabo são semelhantes às utilizadas por [91].

Recomenda-se adotar para os cabos uma pré-tensão inicial de $8 \%$ a $15 \%$ da sua carga de ruptura, [31]. Neste trabalho, na maioria dos estudos, adota-se uma pré-tensão de $10 \%$ do valor da carga de ruptura do cabo. As propriedades dos cabos utilizados nas análises são apresentadas na Tabela 3.3. Cada estudo desenvolvido faz referência ao diâmetro do cabo durante a apresentação de seus resultados.

Tabela 3.3 - Propriedades dos cabos, [92].

\begin{tabular}{ccccc}
\hline \multicolumn{2}{c}{ Diâmetro } & \multicolumn{2}{c}{ Carga de Ruptura } & Pré-tensão \\
\hline$\phi($ in $)$ & $\phi(\mathrm{mm})$ & lbf & $\mathrm{kN}$ & $\mathrm{T}(\mathrm{kN})$ \\
\hline $3 / 4$ & 19 & 47600 & 212 & 21.2 \\
$7 / 8$ & 22 & 64400 & 286 & 28.6 \\
$11 / 8$ & 29 & 105200 & 468 & 46.8 \\
$11 / 2$ & 38 & 184000 & 818 & 81.8 \\
$17 / 8$ & 48 & 282000 & 1250 & 125 \\
\hline
\end{tabular}

Assim como no modelo bidimensional, o peso próprio de cada elemento é calculado pelo programa a partir da densidade do material e de suas propriedades geométricas. As condições de contorno são basicamente as duas apresentadas anteriormente; engaste para a base do mastro e restrição a deslocamentos para a ancoragem dos cabos no solo.

As propriedades geométricas e físicas adotadas para o modelo sintético padrão nas análises lineares e não lineares estáticas e dinâmicas são apresentadas na Tabela 3.4.

Tabela 3.4 - Propriedades físicas e geométricas da torre estaiada

\begin{tabular}{l|l|l}
\hline \multicolumn{1}{c|}{ Propriedades } & Coluna Circular Vazada & \multicolumn{1}{c}{ Cabo } \\
\hline Diâmetro Interno $(D)$ & $0,95 \mathrm{~m}$ & - \\
Diâmetro Externo $(d)$ & $1 \mathrm{~m}$ & - \\
Comprimento $(L)$ & $100 \mathrm{~m}$ & $115.47 \mathrm{~m}$ \\
Área da Seção Transversal $(A)$ & $7,658 \mathrm{E}-02 \mathrm{~m}^{2}$ & $2.84 \mathrm{E}-04 \mathrm{~m}^{2}$ \\
Momento de Inércia $(I)$ & $9,105 \mathrm{E}-02 \mathrm{~m}^{4}$ & - \\
Módulo de Elasticidade $(E)$ & $2,1 \mathrm{E}+11 \mathrm{~N} / \mathrm{m}^{2}$ & $1.3 \mathrm{e}+11 \mathrm{~N} / \mathrm{m}^{2}$ \\
Densidade $(\rho)$ & $7850 \mathrm{~kg} / \mathrm{m}^{3}$ & $7850 \mathrm{~kg} / \mathrm{m}^{3}$ \\
Força de Ruptura & - & - \\
Força de pré-tensão & - & $10 \%$ da Força de Ruptura kN \\
\hline
\end{tabular}




\subsubsection{4.}

\section{Modelo de torre com múltiplos níveis de estais}

Neste trabalho são apresentados quatro modelos sintéticos com mais de um nível de estais. Dois desses modelos têm dois níveis de estais, dividindo a torre em dois vãos de mesmo comprimento. Os outros dois modelos possuem três níveis de estais que dividem a torre em vãos de comprimento, L/3. A diferença entre os modelos com o mesmo número de estais está na ancoragem do cabo no solo, o que modifica sua forma de distribuição na estrutura, paralelo ou em leque. Ou seja, um modelo possui cabos paralelos e o outro possui cabos ancorados em um mesmo ponto. A Figura 3.4 apresenta os quatro modelos estudados. Os modelos seguem o mesmo padrão de modelagem do modelo sintético padrão apresentado anteriormente.

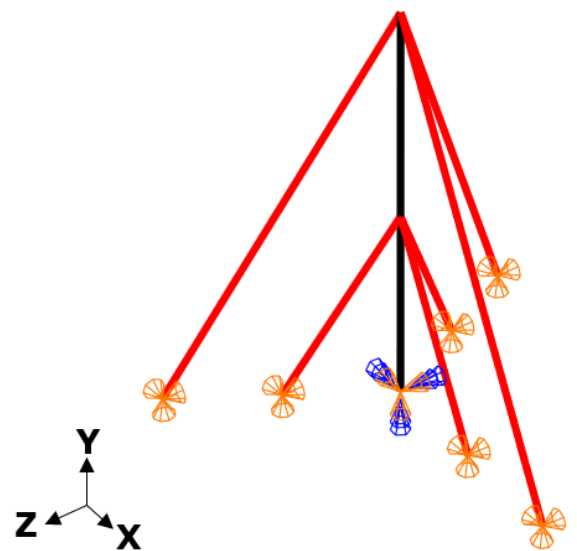

(a) Modelos com 2 níveis de estais paralelos.

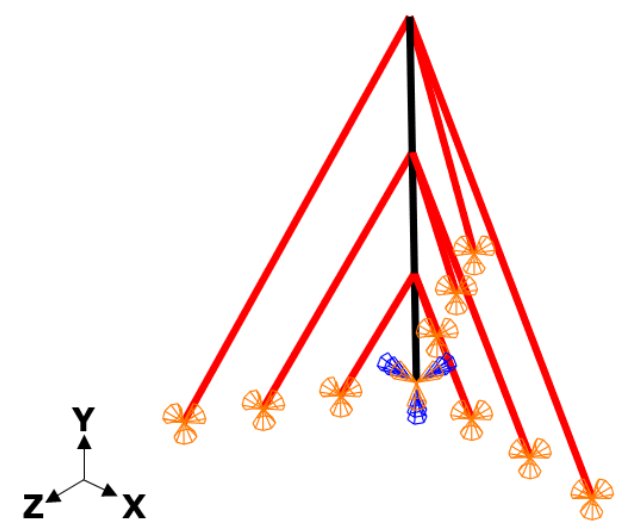

(c) Modelos com 3 níveis de estais paralelos.

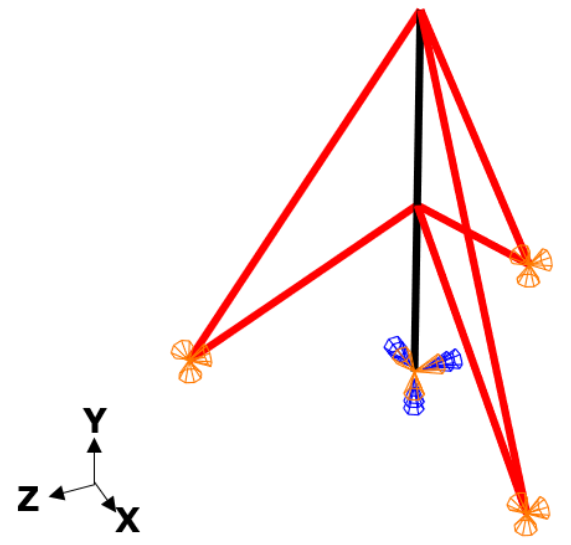

(b) Modelos com 2 níveis de estais partindo do mesmo ponto de ancoragem.

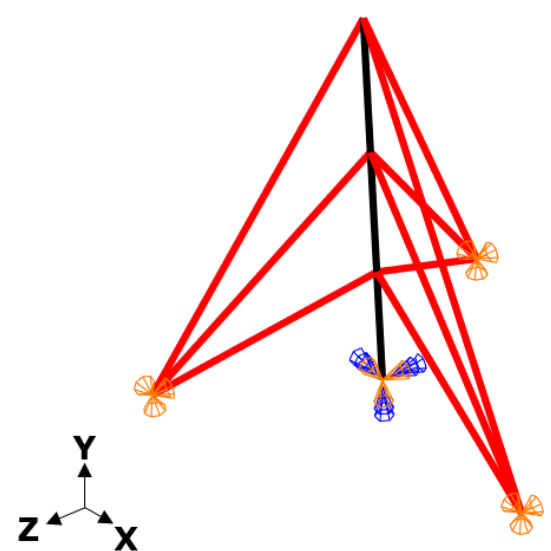

(d) Modelos com 3 níveis de estais partindo do mesmo ponto de ancoragem.

Figura 3.4 - Representação esquemática dos modelos com mais de um nível de estais. 


\section{4 . Tipos de Análises}

A análises desenvolvidas para os modelos levam em consideração a nãolinearidade geométrica da estrutura, ou seja, as associadas ao mastro e as causadas pela interação dos cabos com o mastro. A primeira parte do estudo refere-se a um estudo paramétrico da influência das características físicas e geométricas dos cabos e do peso-próprio da estrutura nas frequências naturais e carga crítica. A segunda parte consiste em avaliar os efeitos da não linearidade geométrica na resposta estática e dinâmica.

\subsection{1.}

\section{Análise global}

Inicialmente são adotadas algumas técnicas de modelagem que simulam os efeitos de carregamentos preexistentes na torre para se obter o seu estado inicial de equilíbrio.

Nesta etapa inicial considera-se o peso próprio da torre e dos cabos e tensionamento pré-tensão inicial dos cabos aplicada durante a fase de construção da torre. Esses carregamentos geram uma deformação inicial na estrutura. $\mathrm{O}$ equilíbrio do sistema é então estabelecido para as condições iniciais e utilizado como estado inicial para as análises subsequentes.

O estabelecimento do equilíbrio estático considerando as não linearidades geométricas é executado através de um módulo de análise geral estática, com a ativação do comando "NLGEOM". Este o módulo é utilizado em todas as análises como etapa inicial do processamento.

\subsection{2.}

\section{Análise estática}

As análises estáticas do modelo sintético têm como foco a análise de estabilidade da estrutura. Na maioria dos casos, onde o objetivo é o dimensionamento da estrutura, uma análise de autovalores pode ser considerada suficiente. Porém, se existem preocupações quanto à falha da estrutura por efeitos não lineares geométricos ou de material, bem como das imperfeições geométricas 
e de carregamento, faz-se necessária a obtenção do caminho pós-crítico da estrutura e o estudo da sensibilidade a imperfeições [93].

As primeiras análises estáticas avaliam a influência das características dos cabos e do peso-próprio da estrutura na carga crítica a partir da solução de um problema de autovalor. Para isto o ABAQUS utiliza um módulo denominado "BUCKLE", que determina a partir de métodos iterativos de solução os autovalores e autovetores da estrutura, que representam as cargas e os modos de bifurcação da estrutura.

Neste trabalho utiliza-se o método de Lanczos [88]. Na modelagem adota-se no topo da estrutura uma carga pontual unitária na entrada de dados de forma que os autovalores obtidos assumem o próprio valor das cargas críticas nas unidades adotadas.

A segunda parte da análise estática de estabilidade busca a avaliação do comportamento pós-crítico do sistema. Para a obtenção do caminho pós-crítico de equilíbrio, o ABAQUS usa o método de RIKS modificado, [88], [94]-[96]. Este método de continuação permite a obtenção de caminhos pós-críticos estáveis e instáveis além de permitir ultrapassar pontos limites de carga e deslocamento [93].

Para a obtenção dos resultados neste tipo de análise não linear impõe-se, no presente trabalho, uma imperfeição inicial, prática usual em programas de elementos finitos, a fim de evitar a identificação do ponto de bifurcação e passagem do caminho fundamental (solução trivial) para o caminho secundário de equilíbrio ao sistema. Essa imperfeição pode ser inserida como um pequeno carregamento inicial transversal ao mastro ou uma imperfeição geométrica, geralmente tomada na forma do modo de flambagem da estrutura ou combinação de modos.

O ABAQUS possibilita a inserção do primeiro tipo de imperfeição durante e antes da etapa de RIKS, como uma carga atuante ou uma configuração de equilíbrio preestabelecida, o critério de aplicação desse carregamento varia de acordo com o tipo de simulação desejada. Para a introdução de imperfeições na forma do modo de flambagem, deve-se inserir a imperfeição modal na etapa de RIKS. Esta é inserida com um fator de escala do modo, podendo ser aplicada apenas em um modo isolado ou em vários modos, resultando em uma combinação desses. No presente estudo as imperfeições iniciais são inseridas como imperfeições geométricas na forma do modo de flambagem isolado, ou como combinação de modos. Também é 
aplicada uma carga inicial no topo da estrutura com valor igual à da carga crítica do modelo, encontrado na análise linear.

\subsection{3.}

\section{Análise Dinâmica}

Torres estaiadas apresentam comportamento não-linear, evidenciado quando se desenvolvem análises dinâmicas. Para as investigações do comportamento dinâmico dos modelos sintéticos, dividiu-se o estudo em duas partes. Na primeira parte determinam-se as frequências naturais e os modos de vibração através da solução de um problema de autovalor. Para isto utiliza-se o módulo "FREQUENCY" do ABAQUS. O módulo oferece dois algoritmos para determinação de autovalores, Lanczos ou subespaços. Neste trabalho é utilizado o método de Lanczos. Esta primeira parte é importante, pois indica as frequências de ressonância da estrutura. Com essa informação pode-se desenvolver a análise dos efeitos das condições inicias e carregamentos harmônicos na resposta não linear da estrutura.

A influência das não linearidades é avaliada de modo mais crítico na segunda parte da análise dinâmica da estrutura através de análises de vibração livre e vibração forçada amortecida do sistema. Para tal são utilizados métodos de análise de resposta no tempo.

As análises dinâmicas são executadas através do módulo "DYNAMIC IMPLICIT” do ABAQUS. Esse módulo permite calcular a resposta transiente e permanente em sistemas com ou sem amortecimento e utiliza para a integração no tempo o método de Hilber-Hughes-Taylor, HTT-alpha, [88]. Em todas as análises dinâmicas não lineares, define-se o tempo total de integração e o incremento de tempo, determinado em função das frequências naturais da estrutura. Um amortecimento numérico é introduzido nas análises, para evitar uma propagação acentuada de erros. Esse amortecimento no ABAQUS, é controlado pelo parâmetro alpha, beta e gamma. Para alpha $=0$, o método passa a ser chamado de Newmark- $\beta$, onde para os valores beta $=0.25$ e gamma $=0.5$ o algoritmo não apresenta amortecimento numérico[88], [97]-[99]. Neste trabalho considera-se um pequeno amortecimento numérico e, para isso, utilizam-se os parâmetros alpha $=$ 0 , beta $=0.3025$ e gamma $=0.6$, [97], [100]. 
Também são inseridos os parâmetros de amortecimento da estrutura, que não são características do método e sim do material. Neste trabalho o amortecimento estrutural é inserido como propriedade do material tanto no mastro, quanto nos cabos, com amortecimento modal igual a $\xi=1 \%$. Esse valor é um pouco acima do indicado para todos os modos de vibração, $\xi_{N B R 6123}=0,8 \%$, pela NBR 6123 (1988), [101], para o caso de torres e chaminés de aço com seção uniforme, [48], mas um pouco abaixo do valor indicado pela IASS (19811), [102], $\xi_{\text {IASS }}=1,5 \%$, para situações com fundações com estacas, [33]. Para cada análise os parâmetros da formulação de Rayleigh mudam, pois são definidos em função das frequências naturais da estrutura

A aplicação de carregamentos difere das demais análises, pois os carregamentos são aplicados durante um período de tempo de acordo com o tipo de análise dinâmica. Para análises de vibração livre amortecida, são aplicados pulsos iniciais e, para vibrações forçadas, são aplicados carregamentos durante todo o tempo de integração da análise. Para inserir um carregamento variável no tempo, utiliza-se a opção "AMPLITUDE" do ABAQUS, no qual se fornece por meio de uma tabela, a variação da magnitude do carregamento em função tempo.

Assim como nas análises estáticas, nas análises dinâmicas o efeito da não linearidade geométrica é incluído na etapa inicial do processamento, onde se contabilizam as influências dos carregamentos pré-definidos, como a tensão nos cabos e o peso-próprio da estrutura. O processamento se dá em duas etapas; a primeira etapa inclui todos os carregamentos estáticos e a segunda ativa o módulo de análise dinâmica para extração dos autovalores e autovetores (caso linear), ou para a resposta no tempo a partir de carregamentos aplicados em um intervalo específico de tempo (caso não linear). A Figura 3.5 - Fluxograma de metodologia de desenvolvimento de modelo no ABAQUS. apresenta um fluxograma no qual são apresentadas as etapas para desenvolvimento de um modelo no ABAQUS. No Apêndice A são apresentados fluxogramas e metodologias para o desenvolvimento e análises presentes neste trabalho. 


\section{Análise e Desenvolvimento dos Modelos Numéricos no ABAQUS}

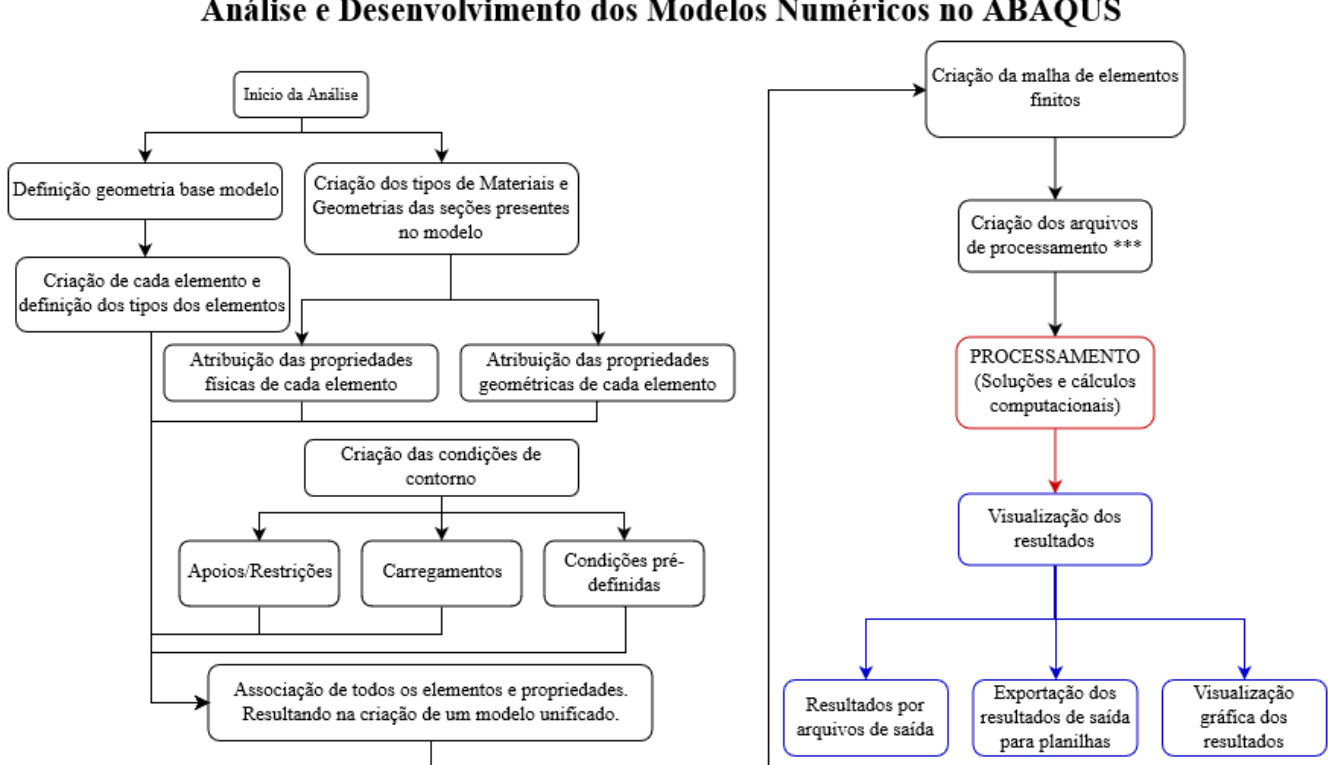

Comentários:

* = Na metodologia utilizando o controle de arco, consideram-se imperfeições iniciais. Quando ocorre "BUCKLE" em etapa anterior a este passo, considera-se imperfeição modal

** = Na metodologia utilizando o método HTT-alpha, há a necessidade de definição do tempo total e do tamanho de passo incremental. No caso de tamanho de passo automático, devem ser indicados seus valores máximo e mínimo.

*** $=$ Quando $\circ$ arquivo texto é criado, todas as propriedades podem ser alteradas diretamente no mesmo

Definição das etapas para processamento, atribuindo cada passo de análise ao modelo arquivo, através das linhas de comando correspondentes.

Definição das variáveis de saída para cada

$$
\uparrow
$$

Pré-Processamento passo do processamento

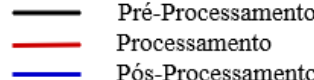

Figura 3.5 - Fluxograma de metodologia de desenvolvimento de modelo no ABAQUS. 


\section{4}

\section{Análise da Estabilidade e Sensibilidade a Imperfeições}

\section{1.}

\section{Aspectos gerais}

No capítulo anterior, foram apresentados os modelos e metodologias para o estudo do comportamento dinâmico linear e não linear e da estabilidade de torres estaiadas utilizando o método dos elementos finitos.

\subsection{1.}

\section{Equilíbrio estático do Modelo Sintético com 1 nível de estais}

A abordagem inicial do estudo, consiste na análise do equilíbrio estático do modelo sintético sob peso próprio e pré-tensão nos cabos. As propriedades utilizadas para esta análise são apresentadas na Tabela 4.1. Essa análise é um prérequisito, pois todas as análises posteriores têm como referência a posição inicial de equilíbrio.

O único carregamento presente nesta primeira análise é a pré-tensão nos cabos de $19 \mathrm{~mm}$, no valor de $10 \%$ do valor da força de ruptura do cabo, mesmo valor adotado por Amiri, [103], Wahaba, [104], e Grey,[105].

Tabela 4.1 - Propriedades físicas e geométricas da coluna circular.

\begin{tabular}{l|l|l}
\hline \multicolumn{1}{c|}{ Propriedades } & Coluna tubular circular & \multicolumn{1}{c}{ Cabo } \\
\hline Diâmetro Interno $(D)$ & $0,95 \mathrm{~m}$ & - \\
Diâmetro Externo $(d)$ & $1 \mathrm{~m}$ & $1.9 \mathrm{E}-02 \mathrm{~m}$ \\
Comprimento $(L)$ & $100 \mathrm{~m}$ & $115.47 \mathrm{~m}$ \\
Área Transversal $(A)$ & $7,658 \mathrm{E}-02 \mathrm{~m}^{2}$ & $2.84 \mathrm{E}-04 \mathrm{~m}^{2}$ \\
Momento de Inércia $(I)$ & $9,105 \mathrm{E}-02 \mathrm{~m}^{4}$ & - \\
Módulo de Elasticidade $(E)$ & $2,1 \mathrm{E}+11 \mathrm{~N} / \mathrm{m}^{2}$ & $1.3 \mathrm{e}+11 \mathrm{~N} / \mathrm{m}^{2}$ \\
Densidade $(\rho)$ & $7850 \mathrm{~kg} / \mathrm{m}^{3}$ & $7850 \mathrm{~kg} / \mathrm{m}^{3}$ \\
Força de Ruptura $(\mathrm{BrS})$ & - & $212 \mathrm{kN}$ \\
Força de pré-tensão & - & $21,1 \mathrm{kN}$ \\
\hline
\end{tabular}


Para o modelo em questão é adotada uma distribuição de cabos ilustrada na Figura 4.1, mesma distribuição utilizada por [106]. Pelo equilíbrio de forças obtémse uma reação vertical em A (base da torre) de $54828.9 \mathrm{~N}$ e de $-18276.3 \mathrm{~N}$ nos pontos B, C e D (pontos de ancoragem dos cabos). Vale ressaltar que para esta análise não foi considerado o peso próprio dos elementos estruturais.

Cada elemento de cabo é submetido a tensões axiais de 7,477E+07 N/m², que simulam a pré-tensão destes. Este valor é obtido a partir da relação entre a força de pré-tensão e a área dos cabos. Logo, ao se resolver o equilíbrio do sistema sem considerar o peso próprio dos elementos obtém-se o valor da força resultante vertical no topo do mastro (ponto E) de $54828.9 \mathrm{~N}$, compatível com a reação na base da torre.
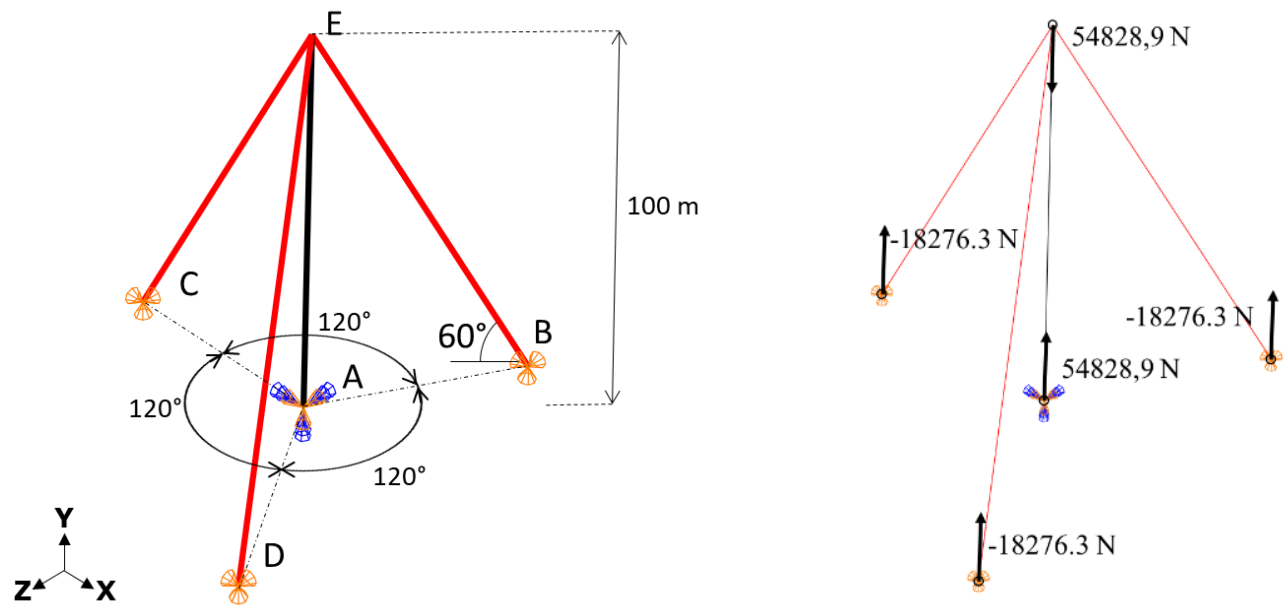

Figura 4.1 - Modelo de torre 3D e suas dimensões. 


\section{2.}

\section{Analise Estática Linear}

\subsection{1.}

\section{Validação da metodologia de modelagem}

Inicialmente o comportamento do mastro isolado nas diversas situações apresentadas no Capítulo 3.3.1 é estudado para validar a modelagem. Para isso, são obtidos os valores de carga crítica e modo crítico da estrutura considerando diferentes carregamentos e condições de apoio, sendo estes comparados aos resultados analíticos encontrados na literatura. As propriedades destes modelos são as mesmas do modelo sintético padrão com um nível de estais, mas sem a presença dos cabos.

A carga crítica de uma coluna engastada (E) e livre (L) sem a consideração do peso próprio é igual a $P_{c r}=\pi^{2} E I / 4 L^{2}$, e igual a $P_{c r}=\pi^{2} E I / 0.49 L^{2}$, para uma coluna engastada e apoiada (A). Já para uma coluna sob peso-próprio (PP), a carga crítica é igual a $P_{c r}=0.7837 E I / L^{2}$.para a coluna engastada e livre, [107] e $P_{c r}=$ $52.5007 E I / L^{2}$ para a coluna engastada e apoiada, [108]. Analiticamente, as combinações de carregamentos compressivos do peso-próprio e das cargas concentradas no topo, podem ser determinadas de modo aproximado, assumindo que o valor do peso próprio, $q l$, seja aplicado no topo da estrutura como uma carga equivalente de $1 / 3$ do seu valor total. Logo, pode-se determinar a carga crítica de uma coluna engastada e livre considerando o efeito do peso próprio pela expressão $P_{c r} \approx \pi^{2} E I / 4 L^{2}-0,3 q L,[109]$.

Para a avaliação numérica da influência do peso-próprio na carga crítica do modelo, adota-se uma coluna de seção circular vazada, com diferentes condições de contorno.

Utiliza-se para a determinação da carga crítica a função 'BUCKLE' do ABAQUS. O peso-próprio da estrutura é incluído a partir inserção da aceleração da gravidade com valor de $9,81 \mathrm{~m} / \mathrm{s}^{2}$ e uma carga vertical unitária é aplicada no topo da estrutura de modo que o resultado da análise de autovalor fornece diretamente $o$ valor da carga crítica.

Os valores encontrados para as cargas críticas obtidas por elementos finitos e por expressões analíticas para os diferentes modelos apresentados em 3.3.1.1, são 
apresentados na Tabela 4.2. As siglas PP e PR referem-se respectivamente ao peso próprio e a carga no topo da coluna gerada pela pré-tensão nos cabos igual a $P=$ $54,83 \mathrm{kN}$ (PR), determinada pelo equilíbrio estático.

Tabela 4.2 - Valores de carga crítica para modelos de viga-coluna, ABAQUS e solução analítica.

\begin{tabular}{c|c|c}
\hline Modelo & $\boldsymbol{P}_{\boldsymbol{c r}}-$ ABAQUS $(\mathbf{k N})$ & $\boldsymbol{P}_{\boldsymbol{c r}}-$ Analítico $(\mathbf{k N})$ \\
\hline E-L & 471,4 & 471,8 \\
E-A & 3851,4 & 3851,4 \\
E-L PP & 1498,5 & 1498,5 \\
E-A PP & 10039,0 & 10038,8 \\
E-L PP + Punitário & 292.3 & 295.1 \\
E-A PP+ Punitário & 3648.2 & - \\
E-A PP+PR & 3593,4 & - \\
\hline
\end{tabular}

A partir dos valores apresentados na Tabela 4.2, pode-se perceber que a carga crítica considerando apenas a presença do peso-próprio da estrutura é bem maior que a carga crítica relativa a uma carga de compressão no topo. Isto se dá por ser o preso próprio uma carga distribuída ao longo da estrutura. Outro ponto importante é que as condições de apoios influenciam de modo preponderante a carga crítica da estrutura. Logo, os casos apresentados como casos extremos de capacidade de carga são relevantes. Verifica-se, por exemplo, que a capacidade de carga do modelo EA PP+PR é aproximadamente 12 vezes maior que a do modelo E-L PP $+\mathrm{P}_{\text {unitário. }}$. Isso mostra que o modelo simplificado, onde os cabos atuam de forma a impedir o deslocamento horizontal do topo é muito mais rígido que o modelo onde o topo permanece livre. Outra constatação é que o efeito gerado pela pré-tensão nos cabos, que para estas análises atua como uma força concentrada no topo provoca uma redução na capacidade de carga da estrutura. Tal constatação é observada ao comparar os valores de $P_{c r}$ para os modelos E-A PP $+\mathrm{P}_{\text {unitário }}$ e E-A PP+PR, onde se verifica uma redução na carga crítica do modelo de $1,5 \%$. 


\subsection{2. Influência do peso próprio e pré-tensão dos cabos na carga crítica da estrutura}

A Tabela 4.3 mostra as cargas de bifurcação obtidas pelo MEF em kN para cinco diferentes valores de diâmetro de cabo, $\phi$, Tabela 3.3, 3.3.1.3, com e sem a consideração do peso próprio dos mesmos. Com a variação das propriedades desses cabos, além da mudança do peso próprio dos mesmos há também uma mudança na força aplicada ao topo da torre devida à pré-tensão inicial destes que é mantida igual a $10 \%$ da carga de ruptura do cabo. Verifica-se que as cargas de bifurcações se apresentam em pares em virtude das simetrias do modelo estrutural, apresentando, portanto, uma bifurcação múltipla. Isto pode gerar o fenômeno de interação modal como observado para o modelo discreto com $2 \mathrm{GL}$, na seção 2.4 deste trabalho, e nos trabalhos de Orlando et al., [19], [82], [83].

Como apresentado anteriormente, para uma estrutura composta apenas pelo mastro, desprezando o peso-próprio do elemento, a carga crítica tem valor de 471,4 kN, para a condição engastada-livre e o valor de 3851,4 kN, para a condição engastada-apoiada. A carga de peso-próprio do mastro é de $589,10 \mathrm{kN}$ e dos cabos varia de 2,52 kN a $10.07 \mathrm{kN}$, em função do diâmetro $\phi$. Logo, ao se comparar a carga crítica de uma torre estaiada com um nível de estais e uma torre composta apenas pelo mastro engastado e livre, nota-se um acréscimo significativo na carga crítica do sistema. Este efeito é favorável mostrando que os cabos aumentam significativamente a capacidade de carga e a rigidez do sistema. A estrutura com apenas um nível de estais apresenta uma pequena redução da carga crítica quando se acrescenta o peso-próprio dos cabos na análise, estes resultados podem ser observados no valores apresentados na Tabela 4.3. 
Tabela 4.3 - Carga crítica da torre em kN para cinco diferentes valores de diâmetro de cabo $\phi$, com e sem a consideração do peso-próprio dos cabos.

\begin{tabular}{c|c|c|c|c|c|c|c}
\hline \multicolumn{8}{c}{ Carga de bifurcação em kN } \\
\hline \multirow{2}{*}{$\begin{array}{c}\boldsymbol{\phi} \\
(\mathbf{m m})\end{array}$} & $\begin{array}{c}\boldsymbol{\rho}_{\text {cabo }} \\
\left(\mathbf{k g} / \mathbf{m}^{\mathbf{3}}\right)\end{array}$ & $\mathbf{1}$ & $\mathbf{2}$ & $\mathbf{3}$ & $\mathbf{4}$ & $\mathbf{5}$ & $\mathbf{6}$ \\
\cline { 3 - 8 } & 7850 & $\mathbf{3 4 8 2 . 1 9}$ & 3482.19 & 9616.61 & 9616.61 & 13582.40 & 13582.40 \\
\cline { 2 - 8 } $\mathbf{1 9}$ & 0 & $\mathbf{3 6 5 8 . 1 3}$ & 3658.13 & 9881.47 & 9881.47 & 13887.20 & 13887.20 \\
\hline \multirow{2}{*}{$\mathbf{2 2}$} & 7850 & $\mathbf{3 5 1 0 . 9 6}$ & 3510.96 & 10441.90 & 10441.90 & 16128.60 & 16128.60 \\
\hline \multirow{2}{*}{$\mathbf{2 9}$} & 0 & $\mathbf{3 6 9 7 . 7 8}$ & 3697.78 & 10710.20 & 10710.20 & 16414.60 & 16414.60 \\
\cline { 2 - 8 } & 7850 & $\mathbf{3 5 2 2 . 3 2}$ & 3522.32 & 10925.70 & 10925.70 & 21499.90 & 21499.90 \\
\hline \multirow{2}{*}{$\mathbf{3 8}$} & 0 & $\mathbf{3 7 2 3 . 0 8}$ & 3723.08 & 11206.70 & 11206.70 & 21765.40 & 21765.40 \\
\cline { 2 - 8 } & 7850 & $\mathbf{3 4 7 6 . 4 0}$ & 3476.40 & 11050.30 & 11050.30 & 22537.10 & 22537.10 \\
\hline \multirow{2}{*}{$\mathbf{4 8}$} & 0 & $\mathbf{3 6 8 8 . 0 9}$ & 3688.09 & 11340.90 & 11340.90 & 22825.10 & 22825.10 \\
\cline { 2 - 8 } & 0 & $\mathbf{3 4 0 7 . 7 1}$ & 3407.71 & 11102.70 & 11102.70 & 22843.90 & 22843.90 \\
\hline
\end{tabular}

Em suma, para estas estruturas, que apresentam um elevado índice de esbeltez, o peso-próprio é relevante nas análises, bem como a pré-tensão inicial dos cabos e outras cargas provenientes de outros elementos que compões a estrutura. Essas considerações reforçam as observações de norma e da literatura da área, [62], [110], [111]. Para o presente trabalho, são consideradas as cargas provenientes do peso próprio dos cabos e do mastro.

\subsection{3. \\ Influência da distribuição dos cabos}

Um dos parâmetros característicos desse tipo de estrutura é a simetria gerada pela distribuição uniforme dos cabos ao redor do mastro. Neste trabalho os ângulos entre cabos é de $120^{\circ}$. Porém, um dos pontos a ser investigado é quando esses ângulos sofrem uma pequena variação. Isto é, quando a distribuição não gera mais a simetria perfeita. Esse tipo de distribuição com uma pequena diferença entre os ângulos pode ocorrer, por exemplo, na etapa construtiva com uma alocação errada dos blocos de ancoragem.

Para investigar o efeito dessa imperfeição, um dos cabos foi deslocado em $5^{\circ}$. Agora a estrutura possui uma distribuição de cabos com ângulos de $120^{\circ}, 115^{\circ}$ e $135^{\circ}$, como pode ser observado na Figura 4.2. Os cabos têm de diâmetro de 48 mm e pré-tensão de $69077,7 \mathrm{kN} / \mathrm{m}^{2}$, referente a $10 \%$ da tensão de ruptura do desse 
tipo de cabo. Os valores de carga crítica obtidos para esse modelo são apresentados na Tabela 4.4. Pode observar que a pequena quebra de simetria causa uma influência sistema, onde as cargas antes coincidentes passam a ser distintas, porém muito próximas, apresentando a diferença entre os dois menores autovalores muito pequena menor que $0,1 \%$.

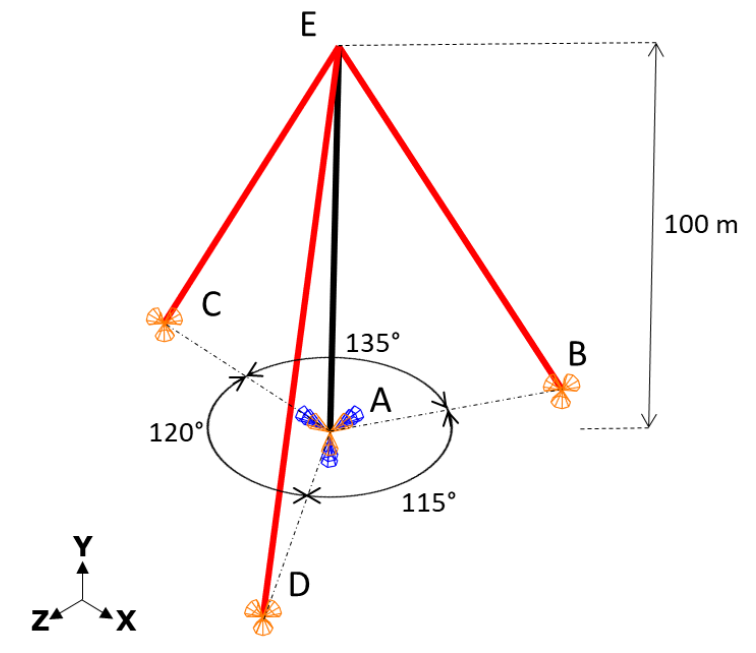

(a) Vista 3D.

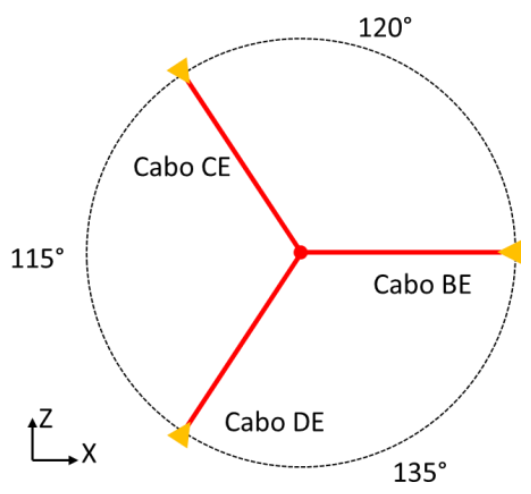

(b) Vista superior.

Figura 4.2 - Distribuição desigual dos cabos de uma torre estaiada

Tabela 4.4 - Cargas críticas para torre com distribuição desigual dos cabos.

\begin{tabular}{c|cccccc}
\hline Modo & 1 & 2 & 3 & 4 & 5 & 6 \\
\hline Carga Crítica $(\mathrm{kN})$ & 3394.77 & 3396.78 & 10990.1 & 10999.1 & 22407.8 & 22433.8 \\
\hline
\end{tabular}

\subsection{4.}

\section{Influência da quantidade de níveis de estais}

Analisa-se agora a influência da quantidade de níveis de estais e de sua geometria na carga crítica $(\mathrm{kN})$ da torre estaiada. A Tabela 4.5 mostra as seis primeiras cargas de bifurcação para cinco diferentes tipos de configurações de cabos. Consideram-se de um a três níveis de estais. Para dois e três níveis de estais, estes podem ser paralelos, com diferentes pontos de ancoragem, ou em leque com um único ponto de ancoragem no solo. Todos os modelos desenvolvidos possuem as mesmas propriedades do modelo com apenas um nível de estais e o cabo utilizado para estas análises tem o de diâmetro de $48 \mathrm{~mm}$. 
Quanto à influência da quantidade de níveis de estais, observa-se que há um aumento significativo na carga crítica em virtude do aumento na rigidez do sistema. Outra condição que interfere na carga crítica do sistema é a distribuição destes cabos em relação à sua ancoragem no solo. Para um mesmo número de níveis de estais, verifica-se que a disposição de cabos em leque leva a um aumento da carga crítica quando comparado com cabos em paralelo. Na Figura 4.3, são apresentados os modos de flambagem de cada um dos casos analisados, onde se observa a influência das restrições laterais devidas aos cabos na deformada da torre.

Tabela 4.5 - Carga crítica $(\mathrm{kN})$ da torre estaiada com cinco diferentes tipos de configurações de cabos.

\section{Cargas críticas (kN) - Variação de níveis de estais}

\begin{tabular}{c|c|c|c|c|c}
\hline \multirow{3}{*}{ Modo } & 1 Nível & 2 Níveis & 2 Níveis & 3 Níveis & 3Níveis \\
\cline { 2 - 6 } & $\begin{array}{c}\text { Cabos } \\
\text { unitários }\end{array}$ & $\begin{array}{c}\text { Cabos } \\
\text { Paralelos }\end{array}$ & $\begin{array}{c}\text { Cabos em } \\
\text { Leque }\end{array}$ & $\begin{array}{c}\text { Cabos } \\
\text { Paralelos }\end{array}$ & $\begin{array}{c}\text { Cabos em } \\
\text { Leque }\end{array}$ \\
\hline 1 & 3407.71 & 9038.95 & 9197.18 & 14809.90 & 16366.30 \\
2 & 3407.71 & 9038.95 & 9197.18 & 14809.90 & 16366.30 \\
3 & 11102.70 & 20934.50 & 21540.90 & 19323.60 & 20028.10 \\
4 & 11102.70 & 20934.50 & 21540.90 & 19323.60 & 20028.10 \\
5 & 22843.90 & 25386.50 & 28843.30 & 38339.30 & 38115.90 \\
6 & 22843.90 & 25386.50 & 28843.30 & 38339.30 & 38115.90 \\
\hline
\end{tabular}




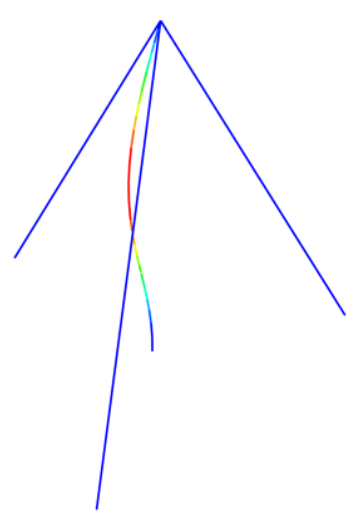

(a) Torre com um nível de estais.

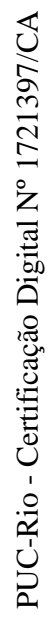

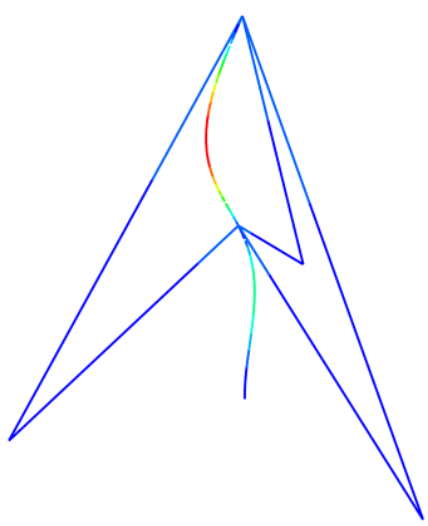

(c) Torre com dois níveis de estais em leque.

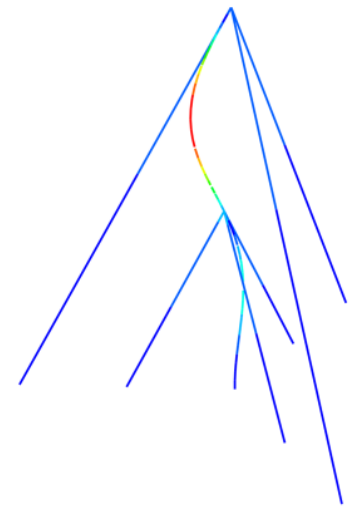

(b) Torre com dois níveis de estais paralelos.

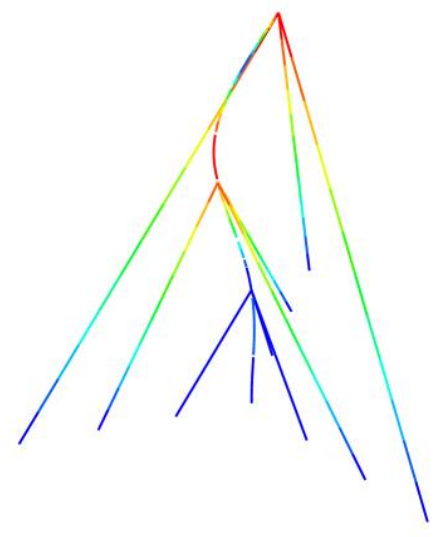

(d) Torre com três níveis de estais paralelos.

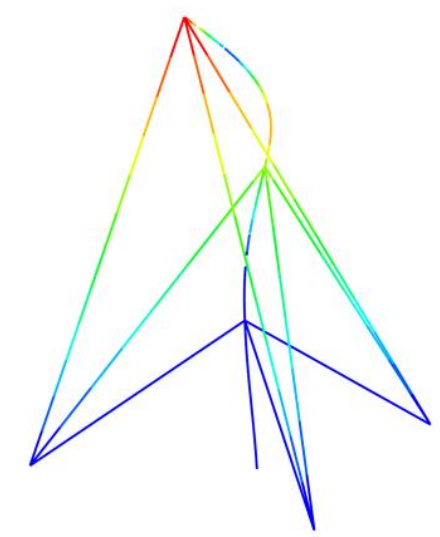

(e) Torre com três níveis de estais em leque.

Figura 4.3 - Configurações do modo de flambagem para torres com múltiplos níveis de estais. 


\section{3.}

\section{Análise Estática Não Linear}

O comportamento pós-crítico de torres estaiadas pelo método dos elementos finitos tem sido abordado por alguns autores, Pezo et al. [106], [112], Carvalho et. al. [89], [113]. Nestes itens, para efeito de comparação, é analisada uma torre com um nível de estais quanto a sua estabilidade e comportamento pós crítico.

\subsection{1.}

\section{Validação da metodologia de modelagem}

O primeiro modelo analisado é o modelo de mastro engastado e livre. $\mathrm{Na}$ modelagem por EF aplica-se uma força de compressão $P$ de valor igual à carga crítica do modelo e se insere uma perturbação no sistema através da aplicação de uma carga lateral, ocasionando um pequeno deslocamento lateral inicial [112].

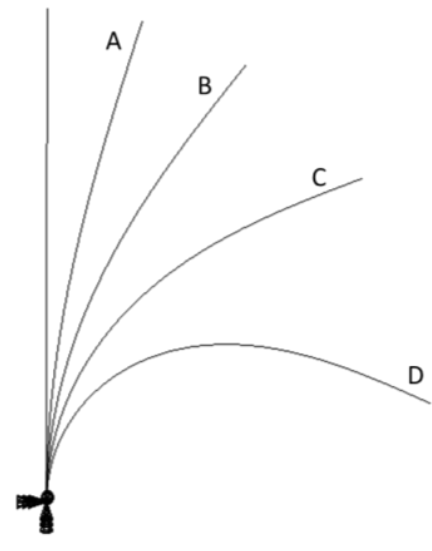

(a)

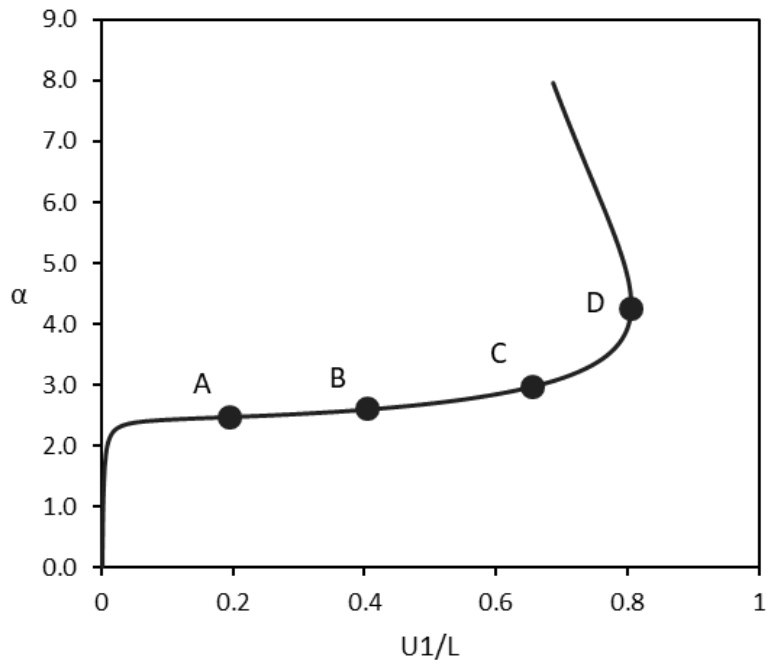

(b)

Figura 4.4 - Coluna engastada e livre: configurações deformadas (a) e trajetória de equilíbrio da extremidade livre (topo) da coluna (b).

A Figura 4.4. mostra a trajetória de equilíbrio relacionando parâmetro de carga vertical, $\alpha=P L^{2} / E I$, e o deslocamento transversal, na direção do eixo $\mathrm{X}, U_{l}$, normalizado em função do comprimento, $L$. Mostra-se também a deformada em pontos selecionados do caminho pós-crítico. Para a análise foi utilizado método de RIKS modificado. Este método permite a obtenção dos pontos críticos e da trajetória pós-crítica. Verifica-se que a coluna apresenta uma bifurcação simétrica 
estável com pequena curvatura inicial. Ao se observar a trajetória de equilíbrio do modelo, nota-se que, inicialmente, o caminho de equilíbrio apresenta uma pequena rigidez pós-crítica, sendo a trajetória quase horizontal até valores bastante elevados de flecha (ver configuração B). Para grandes deslocamentos observa-se um ganho contínuo de rigidez.

Para avaliar o efeito das imperfeições iniciais são adotadas cargas concentradas horizontais no topo da estrutura de $1 \mathrm{~N}, 10 \mathrm{~N}, 100 \mathrm{~N}$ e $1 \mathrm{kN}$, respectivamente. Com isso pode-se obter a trajetória de equilíbrio para os modelos com essas imperfeições de carga, verificando a sensibilidade do modelo a esses tipos de imperfeição.

A Figura 4.5 mostra as trajetórias de equilíbrio relacionando o parâmetro de carga vertical, $\alpha=P L^{2} / E I$, e o deslocamento transversal, na direção $\mathrm{X}$, normalizado em função da altura da torre, $U_{1} / L$. À medida que a força lateral cresce, cresce o efeito da carga vertical na flexão da torre induzindo deslocamentos cada vez maiores à medida que a carga se aproxima do valor crítico, decrescendo a capacidade de carga da estrutura.

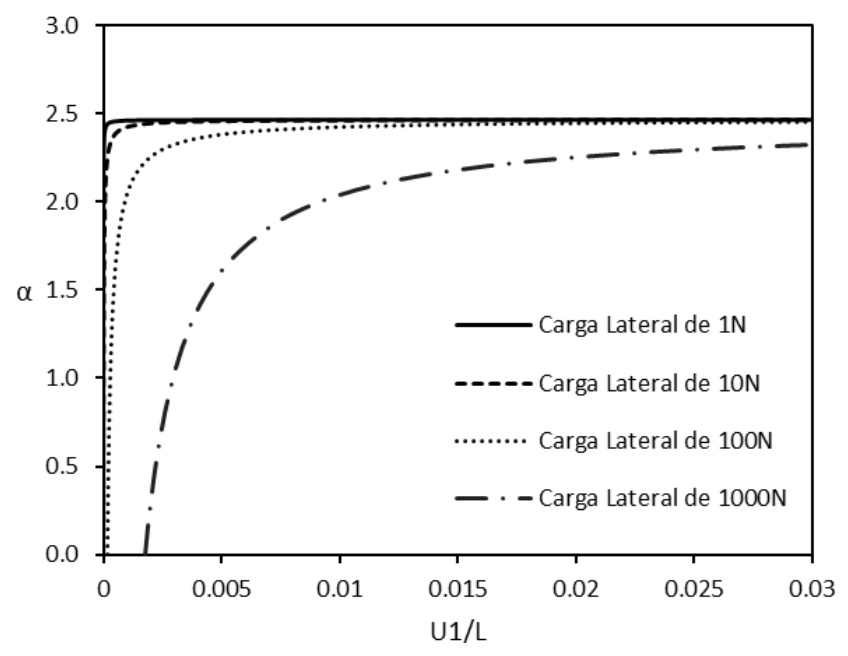

Figura 4.5 - Sensibilidade às imperfeições laterais. 


\section{4. Influência dos cabos no comportamento pós-crítico de torres estaiadas}

\subsection{1. Modelo bidimensional de torre com um nível de estais}

Agora se a mesma viga-coluna utilizada nas simulações anteriores, porém com a presença de dois cabos no topo, o que configura uma torre estaiada em um plano, situação abordada por Carvalho et al.[89], [113].

Quanto aos parâmetros utilizados para modelagem, adotou-se para a torre uma discretização com 10 elementos, a mesma utilizada por Carvalho et al. [89], [112], [113]. Cada cabo foi discretizado em apenas um elemento. As propriedades para este modelo são apresentadas na Tabela 4.6. Uma carga vertical de $12 \mathrm{~N}$ foi aplicada ao topo da estrutura. É gerada uma imperfeição decorrente de uma carga lateral no topo da estrutura de $0.05 \mathrm{~N}$. A partir desses parâmetros iniciais pode-se obter o caminho pós-crítico da estrutura através do método de Riks modificado. e traçar sua trajetória de equilíbrio em função dos parâmetros $\alpha$ e do deslocamento transversal, $U 1 / L$ e axial, $U 2 / L$. Na Figura 4.6, são apresentadas as duas trajetórias de equilíbrio.

Tabela 4.6 - Propriedades físicas e geométricas dos elementos do modelo bidimensional de torre estaiada.

\begin{tabular}{l|l|l}
\hline \multicolumn{1}{c|}{ Propriedades } & \multicolumn{1}{|c}{ Coluna Circular Oca } & \multicolumn{1}{c}{ Cabo } \\
\hline Diâmetro Interno $(D)$ & $0,475 \mathrm{~m}$ & - \\
Diâmetro Externo $(d)$ & $0,500 \mathrm{~m}$ & $1.8 \mathrm{E}-02 \mathrm{~m}$ \\
Comprimento $(L)$ & $100 \mathrm{~m}$ & $115.47 \mathrm{~m}$ \\
Área Transversal $(A)$ & $1,914 \mathrm{E}-02 \mathrm{~m}^{2}$ & $2.54 \mathrm{E}-04 \mathrm{~m}^{2}$ \\
Momento de Inércia $(I)$ & $5,691 \mathrm{E}-02 \mathrm{~m}^{4}$ & - \\
Módulo de Elasticidade $(E)$ & $1,18 \mathrm{E}+11 \mathrm{~N} / \mathrm{m}^{2}$ & $1.0 \mathrm{E}+11 \mathrm{~N} / \mathrm{m}^{2}$ \\
Densidade $(\rho)$ & $7850 \mathrm{~kg} / \mathrm{m}^{3}$ & $7850 \mathrm{~kg} / \mathrm{m}^{3}$ \\
Força de pré-tensão & - & $10 \mathrm{kN}$ \\
\hline
\end{tabular}




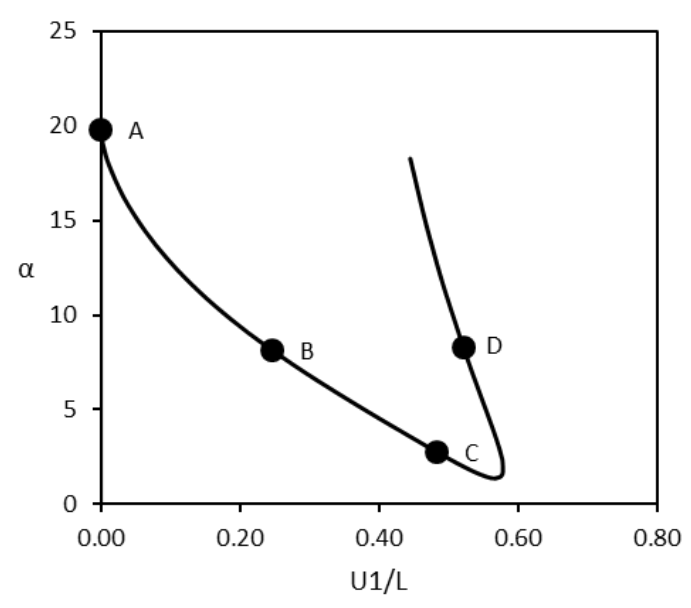

(a) Trajetória de equilíbrio na direção $\mathrm{x}$.

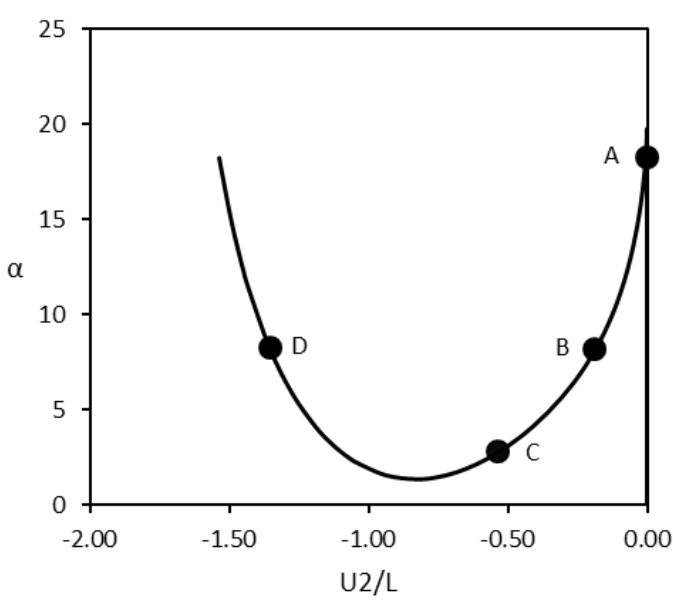

(b) Trajetória de equilíbrio na direção y.

Figura 4.6 - Trajetórias de equilíbrio para a torre estaiada bidimensional: (a) $\alpha \times \mathrm{X}$; (b) $\alpha \mathrm{x} \mathrm{Y}$.

Ao se observar a trajetória do caminho pós-crítico da coluna com cabos, notase que a mesma apresenta uma bifurcação instável com grande declividade inicial o que gera uma perda acentuada da rigidez após a flambagem até atingir um mínimo pós-crítico associado a grandes deflexões (ponto limite de carga) a partir do qual se observa um caminho estável com ganho de rigidez. Este comportamento se dá pela presença dos cabos na estrutura. Na Figura 4.7 é apresentada a evolução da deformação do sistema ao longo do caminho não linear de equilíbrio.

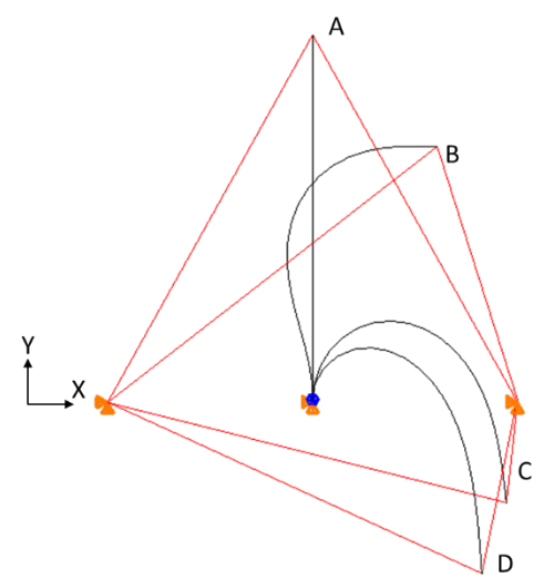

Figura 4.7 - Evolução da deformação de uma Torre 2D com um nível de estais, por incremento de carga.

Quando comparadas as trajetórias de uma coluna sem cabos e uma coluna com dois cabos simétricos, pode-se observar um ganho acentuado na capacidade de carga da estrutura com a presença dos cabos. Entretanto, nota-se a existência de uma bifurcação assimétrica com grande inclinação inicial, indicando alta 
sensibilidade à imperfeição. Outro ponto a ser ressaltado é o valor da carga póscrítica mínima, que é inferior à carga crítica da torre sem cabos, Figura 4.8, que possui um comportamento pós-flambagem estável com rigidez pós-crítica quase nula [85].

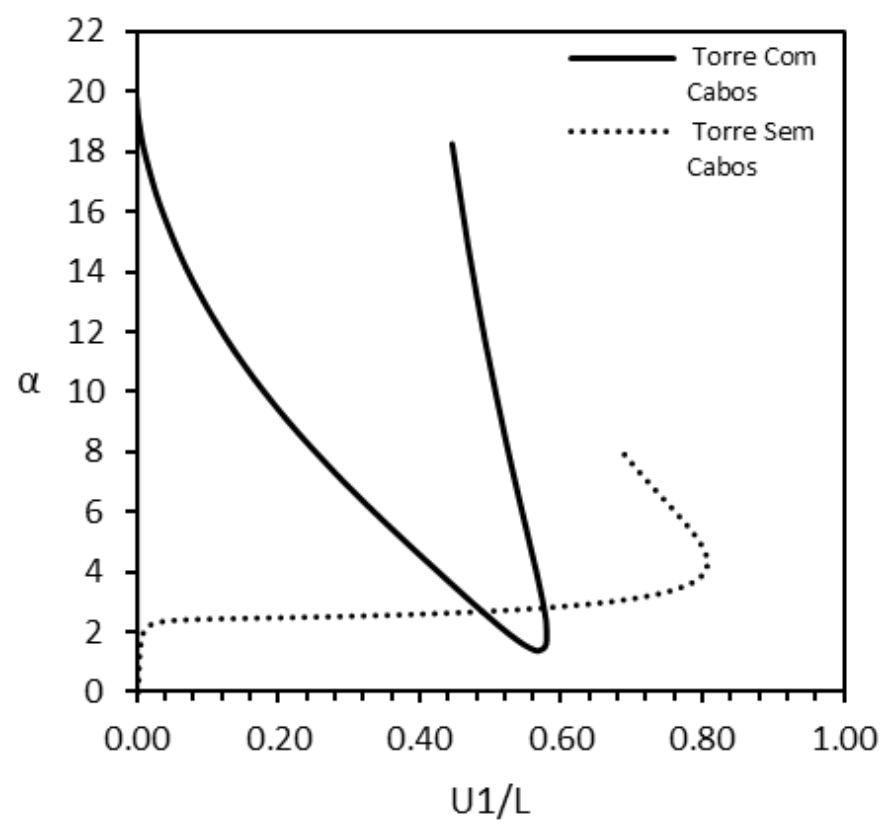

Figura 4.8 - Trajetórias de equilíbrio para torres com e sem cabos.

\subsection{2.}

\section{Análise paramétrica}

Como supracitado, esse tipo de estrutura é bastante sensível a imperfeições e estas influenciam sua capacidade de carga e seu comportamento pós-crítico. Para avaliar como esse comportamento é afetado, são desenvolvidas análises com quatro tipos de imperfeições: (1) uma imperfeição geométrica função dos modos de flambagem; (2) cargas externas que geram uma deformação inicial, (3) uma deformação gerada por nível de pré-tensão desigual em um dos cabos, destruindo a simetria do modelo e (4) uma distribuição desigual dos cabos.

Para os estudos, é utilizado o modelo sintético padrão, com cabo de diâmetro de $48 \mathrm{~mm}$ e força de ruptura de $1250 \mathrm{kN}$. A Figura 4.9 apresenta o modelo esquemático da torre utilizada nas análises. A tração nos três cabos (T1, T2 e T3) têm o mesmo valor $125 \mathrm{kN}$. Estas forças geram uma tensão inicial nos cabos de $69077,7 \mathrm{kN} / \mathrm{m}^{2}$. 


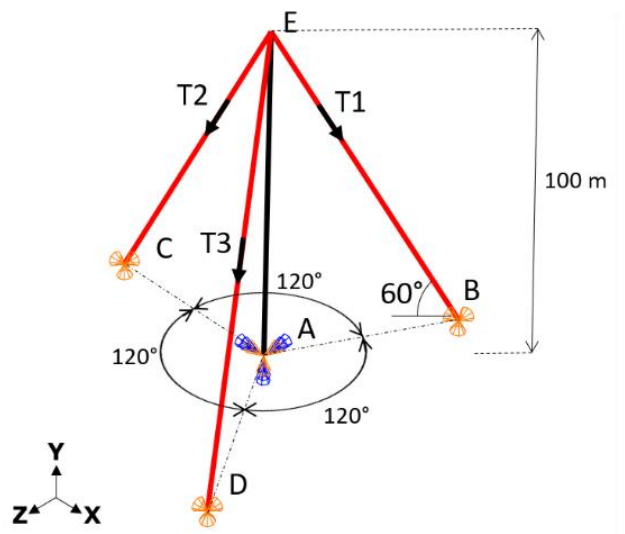

Figura 4.9 - Modelo sintético de torre estaiada com um nível de estais.

\subsubsection{1. Imperfeição modal}

Para avaliar a sensibilidade a imperfeições, considera-se inicialmente uma imperfeição geométrica na forma do modo crítico e um fator de escala com magnitude de L/1E5, L/1000, L/400, L/200, L/133, L/100 no primeiro modo de flambagem. Esses valores são variações a partir do parâmetro L/1000 que é tomado como referência [114], [115]. Essas relações correspondem a porcentagens de 1\%, 10\%, 25\%, 50\% e 100\%. Na Figura 4.10 são apresentadas as trajetórias de equilíbrio para as diferentes porcentagens de deformações iniciais relacionando o parâmetro de carga, $\alpha$, e o deslocamento transversal no topo da estrutura, $U 1 / L$. Na Tabela 4.7 é apresentado o valor da carga crítica para cada uma das trajetórias de equilíbrio.

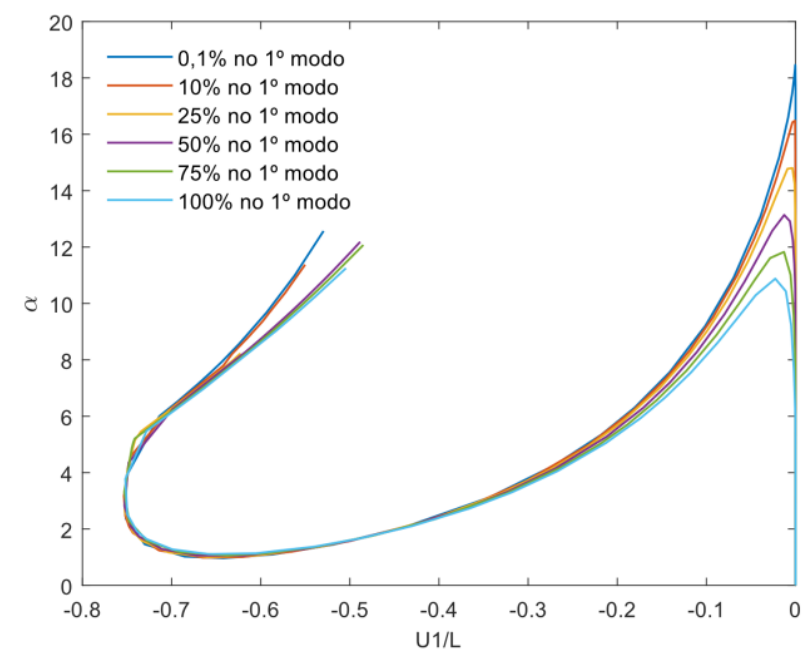

Figura 4.10 - Trajetórias de equilíbrio com geometria inicial deformada por imperfeições modais. 
Tabela 4.7 - Cargas críticas referentes as imperfeições modais.

\begin{tabular}{ccccccc}
\hline $\begin{array}{c}\text { Carga crítica } \\
(\mathbf{k N})\end{array}$ & 3407.7 & 3151.2 & 2830.0 & 2512.5 & 2262.1 & 2084.2 \\
\hline Imperfeições & $0,1 \%$ & $10 \%$ & $25 \%$ & $50 \%$ & $75 \%$ & $100 \%$ \\
\hline
\end{tabular}

O caso onde a imperfeição é de $0,1 \%$ possibilita que o valor de pico (carga limite) obtido seja praticamente igual ao valor da carga crítica da estrutura perfeita. Ao comparar esse caso com os demais, nota-se que as trajetórias passam a ter uma carga limite cada vez menor. Para uma imperfeição de 10\% (L/1000) tem-se uma redução de carga de aproximadamente $8 \%$, para os valores de $25 \%, 50 \%, 75 \%$ e $100 \%$, a carga crítica reduz respectivamente de aproximadamente de $17 \%, 26 \%$, $34 \%$ e $39 \%$.

\subsubsection{2.}

\section{Imperfeições por variação do ângulo da força horizontal no topo}

Seguindo com as avaliações quanto à sensibilidade a imperfeições, submetese a estrutura a deformações iniciais geradas por uma carga horizontal estática no topo da torre, aplicada com uma inclinação de $\beta$ relativa ao eixo X, como mostra a Figura 4.11. Para poder inserir o carregamento com a direção desejada, decompôsse a força em suas componentes horizontais nas direções X e Z.

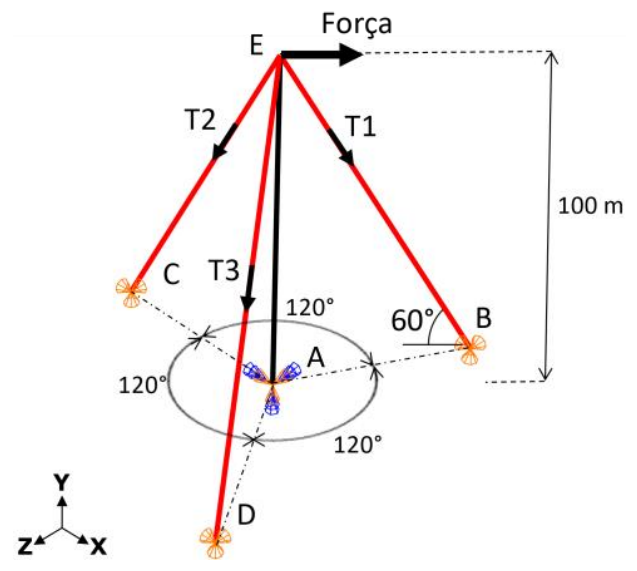

(a) Modelo sintético.

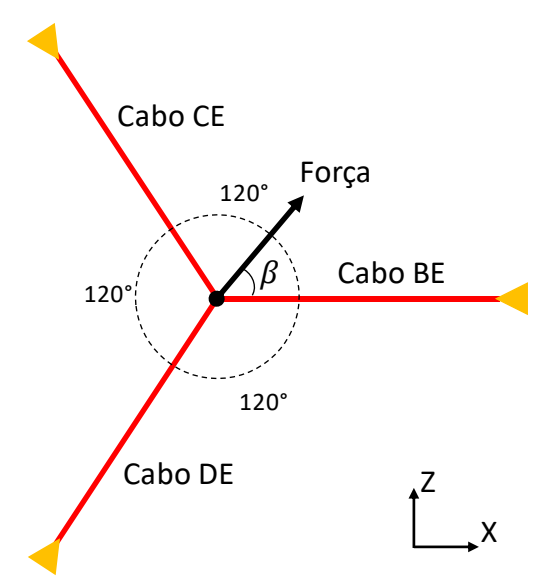

(b) Vista de topo da estrutura.

Figura 4.11 - Visões esquemáticas da torre com a presença de carga estática no topo. 
Para $\beta=0^{\circ}, 30^{\circ}$ e 60 e uma carga de $1 \mathrm{kN}$, foi obtido o caminho não linear de equilíbrio. A Figura 4.12 apresenta as trajetórias de equilíbrio em diferentes projeções, com identificação das direções dos cabos na estrutura. Observa-se que não a mudança no valor da carga limite, mas constata-se que o comportamento póscrítico depende da direção da carga. Na Figura 4.12(a), observa-se que para um ângulo $\beta$ de $60^{\circ}$ a carga pós-crítica mínima é inferior às demais, chegando próximo a zero. Há também um ganho brusco de rigidez pós-critica do sistema após este mínimo para essa orientação. Para ângulo $\beta$ de $30^{\circ}$ nota-se uma tangente à trajetória pós-crítica mais acentuada que as demais, ainda que as outras também apresentem alta declividade. Outro ponto a se observar, Figura 4.12(b), é que a imperfeição para $\beta=0^{\circ}$ e $30^{\circ}$ a trajetória de equilíbrio são na direção de cabos, e para $60^{\circ}$ tem-se um movimento exatamente no sentido oposto ao de um dos cabos. Isto salienta a influência da distribuição dos cabos no comportamento da estrutura, evidenciando o movimento acoplado entre mastro e os estais. No item (c) da Figura 4.12, são apresentadas as três trajetórias no espaço. Todas as relações apresentadas na imagem relacionam o parâmetro adimensional de carga $\alpha$ com os deslocamentos no plano no eixo x e z, normalizados em função do comprimento. 


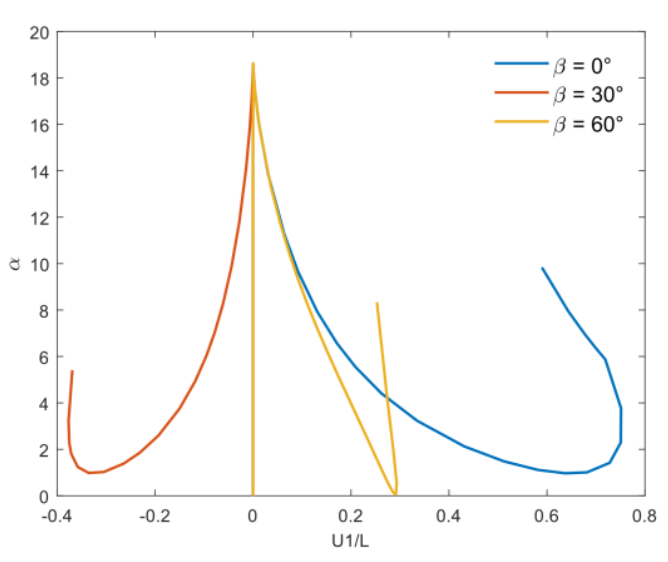

(a) Trajetória de equilíbrio no plano $\alpha \times U 1 / L$, força orientada a $\beta=0^{\circ}$, $30^{\circ}$ e $60^{\circ}$.

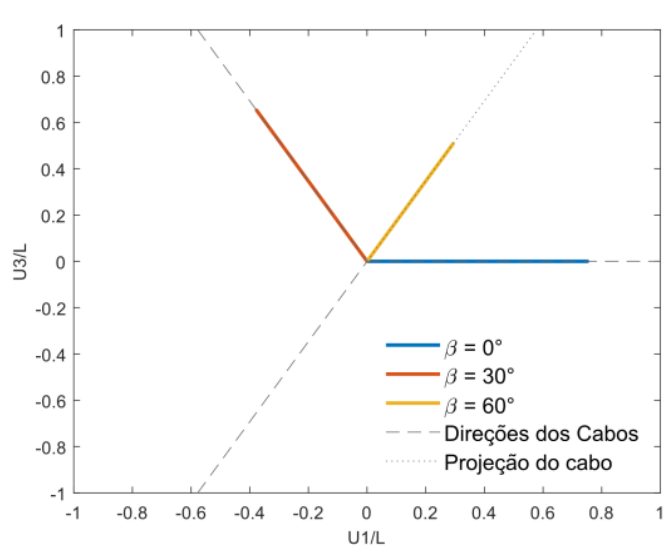

(b) Trajetória de equilíbrio no plano $U 1 / L \times U 3 / L$, força orientada a $\beta=$ $0^{\circ}, 30^{\circ}$ e $60^{\circ}$.

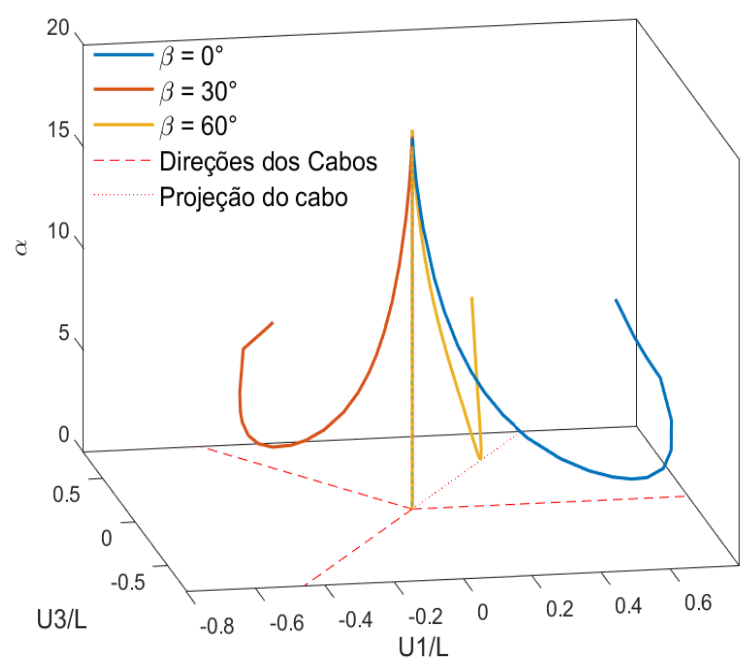

(c) Trajetória de equilíbrio para força com ângulo $\beta$ de $0^{\circ}, 30^{\circ}$ e $60^{\circ}$.

Figura 4.12 - Diferentes vistas das trajetórias de equilíbrio da torre com imperfeições em diferentes direções.

\subsubsection{3.}

\section{Imperfeições por variação da força de pré-tensão em um cabo}

Como se pode observar das demais análises do comportamento pós-crítico desse tipo de estrutura, os cabos influem significativamente na resposta estática não-linear do sistema. Durante a construção da torre ou durante sua vida útil pode ocorrer uma variação na pré-tensão dos cabos. Por isso, desenvolveram-se mais análises onde um dos cabos apresenta uma pré-tensão diferente dos outros dois, gerando uma flexão inicial da torre. Utilizam-se níveis diferentes de tensionamento 
com base nas recomendações técnicas onde a faixa de pré-tensão encontra-se entre $8 \%$ e $15 \%$ da força de ruptura, intervalo aceito pela norma Canadense, [31]. Ao longo do trabalho, para as demais investigações é utilizado um nível de pré-tensão de $10 \%$.

Para este estudo, foram desenvolvidas análises variando apenas a pré-tensão do cabo 'DE' (veja Figura 4.9). Os outros dois cabos permaneceram com a mesma pré-tensão de $10 \%$ da carga de ruptura. Utilizaram-se para o cabo T3 as taxas de $8 \%, 10 \%$ (pré-tensão igual em todos os cabos) e 11\%, como mostra a Tabela 4.8. Também foram avaliados valores de $12 \%$ a $15 \%$, mas os caminhos pós-críticos coincidiram com o de $11 \%$.

Tabela 4.8 - Taxas de pré-tensão aplicadas nos cabos.

\begin{tabular}{cccc}
\hline Taxa de pré-tensão no cabo 'DE.' & $\mathbf{8 \%}$ & $\mathbf{1 0 \%}$ & $\mathbf{1 1 \%}$ \\
\hline Força aplicada $(\mathbf{k N})$ & 100,0 & 125,0 & 137,5 \\
Tensão aplicada $\left(\mathbf{k N} / \mathbf{m}^{2}\right)$ & 55260,8 & 69077,7 & 75983,6 \\
\hline
\end{tabular}

Na Figura 4.13, são apresentadas e as trajetórias de equilíbrio e as direções dos cabos. Pode-se observar que para níveis diferentes de tensões nos cabos há uma mudança na trajetória de equilíbrio devido a deformação por flexão da torre que surge em virtude da assimetria das forças geradas pelos cabos, com uma resultante não nula na direção horizontal. 


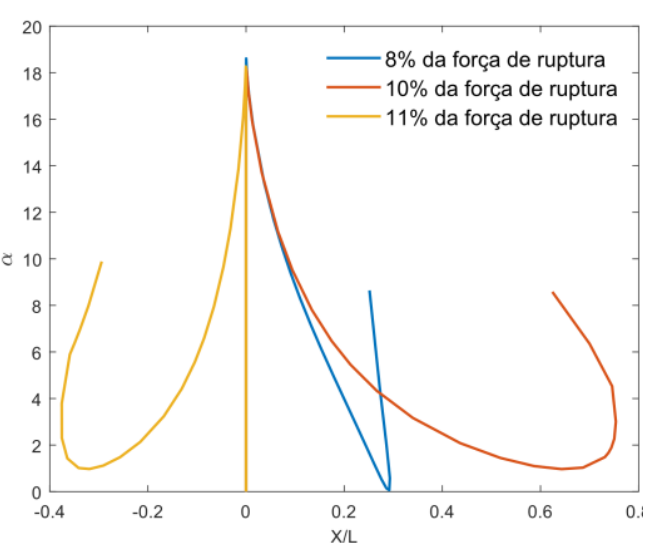

(a) Trajetória de equilíbrio no plano $\alpha \times U 1 / L$.

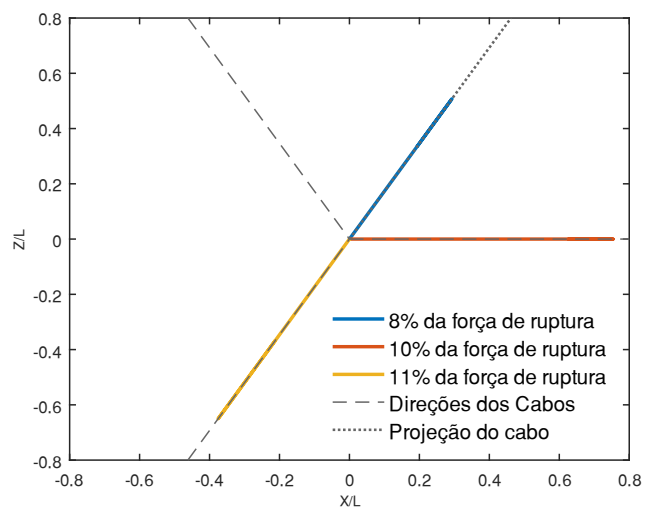

(b) Trajetória de equilíbrio no plano $U 1 /$ $L \times U 3 / L$.

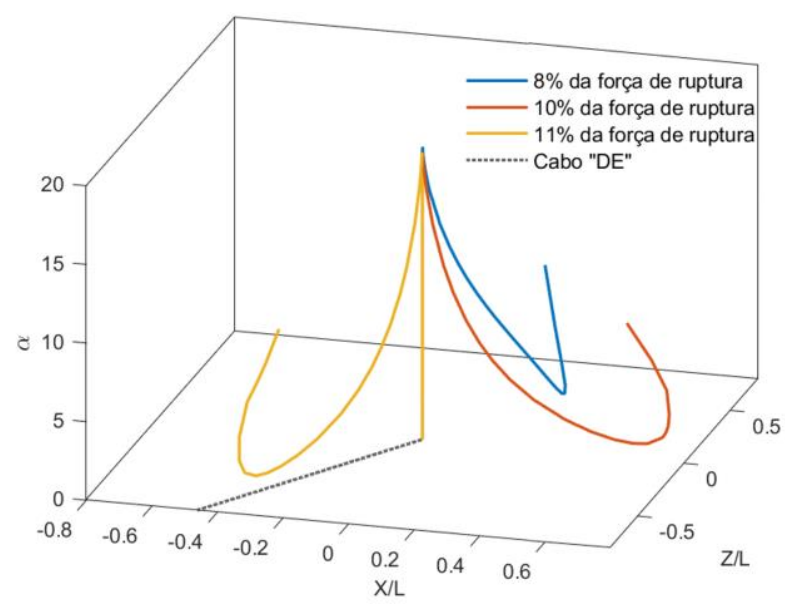

(c) Trajetória de equilíbrio 3D.

Figura 4.13 - Trajetórias de equilíbrio para torre com imperfeições gerada por prettensão assimétrica dos cabos.

\subsubsection{4.}

\section{Imperfeições por distribuição desigual dos cabos}

A distribuição desigual dos cabos gera uma imperfeição inicial da torre. Pois esta, antes com uma simetria perfeita, passa a ter um pequeno deslocamento do topo na posição de equilíbrio inicial. Utilizando uma distribuição de $120^{\circ}, 115^{\circ}$ e $135^{\circ}$ entre os cabos, foi determinada a trajetória do caminho pós-crítico da torre, Figura 4.14. Pode-se observar que a trajetória de equilíbrio pós-crítico é semelhante a trajetória de equilíbrio para a estrutura perfeita. Porém, nota-se que a direção do cominho pós-critico é alterada, não seguindo mais as direções dos cabos. 


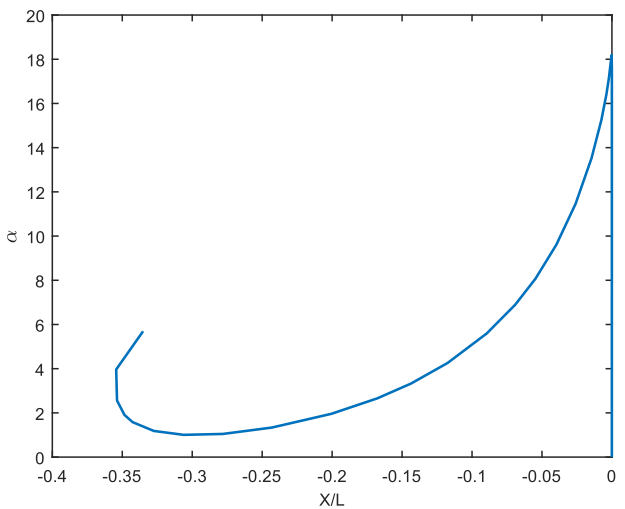

(d) Trajetória de equilíbrio no plano $\alpha x \frac{U 1}{L}$.

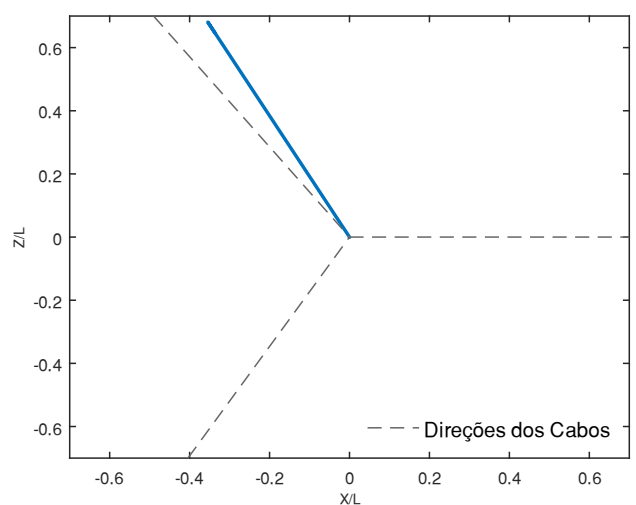

(e) Trajetória de equilíbrio no plano $U 1 /$ $L x U 3 / L$.

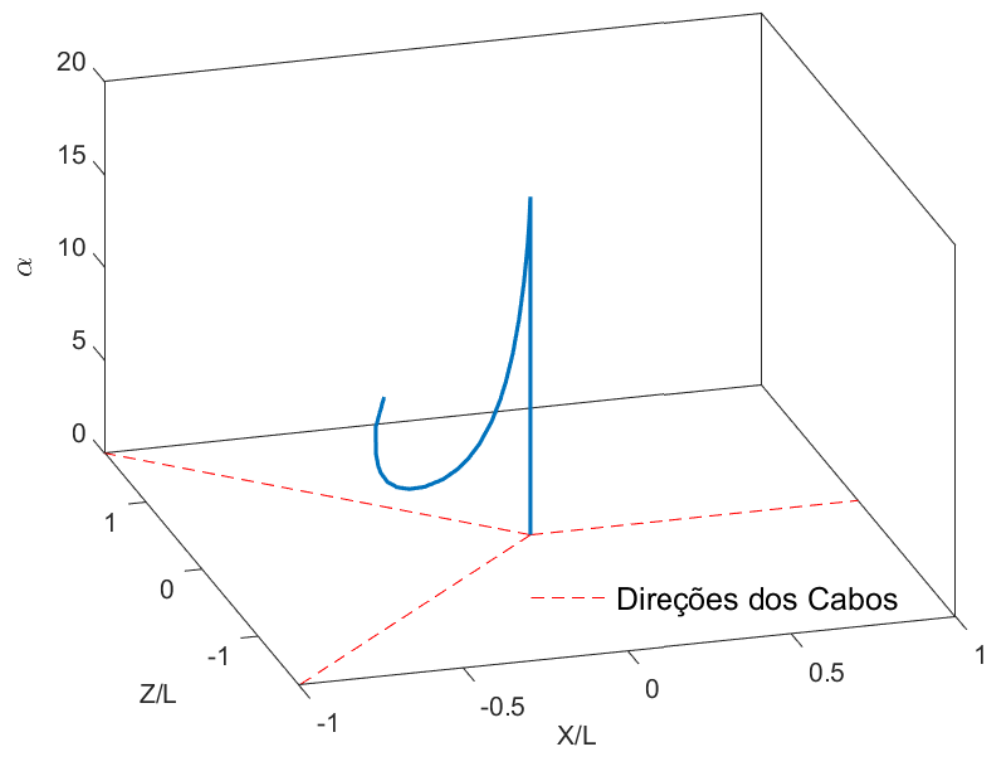

(f) Trajetória de equilíbrio. ${ }^{\circ}$.

Figura 4.14 - Diferentes vistas das trajetórias de equilíbrio da torre com imperfeições por distribuição desigual de cabos.

\subsection{3.}

\section{Modelos tridimensionais de torres com um ou mais níveis de estais}

Avalia-se agora a influência do número de níveis de estais e de sua disposição na resposta da estrutura. As propriedades da torre são as mesmas dos estudos anteriores. Todos os cabos possuem o mesmo nível de pré-tensão e mesmo diâmetro. 
São considerados os modelos com um, dois e três níveis de estais, o que respectivamente divide o mastro em uma, duas e três partes iguais. Eles podem ser paralelos ou apresentar uma configuração em leque.

A análise desses modelos com múltiplos níveis de estais difere das demais pois em alguns modelos para determinação do caminho pós-critico, é utilizada interação modal. Mais de uma escala de deformação é empregada como imperfeição modal. Para isso são inseridas escalas de deformação em mais de um modo. Para cada modelo foi aplicada como carregamento de topo sua carga crítica e também inserido um tipo de imperfeição modal. Esses dados são apresentados na Tabela 4.9. A necessidade de se desenvolver uma relação entre modos é para evitar que em alguns casos a análise se inicie de deformações diferentes daquela do primeiro modo. Caso ocorra tal condição a estrutura assume uma configuração deformada de outros modos, e com isso picos de cargas ficam acima da carga crítica da estrutura analisada.

Tabela 4.9 - Propriedades aplicadas para análise não linear estática de torres com múltiplos níveis de estais.

\begin{tabular}{cccccc}
\hline $\begin{array}{c}\text { Níveis de } \\
\text { Estais }\end{array}$ & $\mathbf{1}$ nível & $\begin{array}{c}\mathbf{2} \text { níveis } \\
\text { paralelo }\end{array}$ & $\begin{array}{c}\mathbf{2} \text { níveis } \\
\text { leque }\end{array}$ & $\begin{array}{c}\mathbf{3} \text { níveis } \\
\text { paralelo }\end{array}$ & $\begin{array}{c}\mathbf{3} \text { níveis } \\
\text { leque }\end{array}$ \\
\hline $\begin{array}{c}\text { Escala no } \\
\text { modo 1 }\end{array}$ & 0.0010 & 0.0010 & 0.0100 & 0.0045 & 0.0090 \\
$\begin{array}{c}\text { Escala no } \\
\text { modo 2 }\end{array}$ & 0 & 0 & 0 & 0.0030 & 0.0070 \\
$\begin{array}{c}\text { Escala no } \\
\text { modo 3 }\end{array}$ & 0 & 0 & 0 & 0.0030 & 0.0050 \\
\hline $\begin{array}{c}\text { Carga Crítica } \\
\text { (kN) }\end{array}$ & 3407.7 & 9039.0 & 9197.2 & 14809.9 & 16366.3 \\
\hline
\end{tabular}

$\mathrm{Na}$ Figura 4.15, são apresentados os caminhos pós-críticos das estruturas analisadas. Nota-se que, à medida que há o aumento da quantidade de estais, há um aumento da capacidade de carga. Entretanto, observa-se que a inclinação inicial da resposta pós crítica aumenta, ocasionando uma maior sensibilidade a imperfeições. Para estruturas com a mesma quantidade de estais, nota-se que a configuração dos cabos em paralelo resulta em uma carga crítica um pouco menor que a da 
configuração em leque. Os modelos com dois níveis de estais apresentam uma carga mínima pós-critica menor que os demais e as configurações em paralelo e em leque possuem um comportamento muito semelhante.

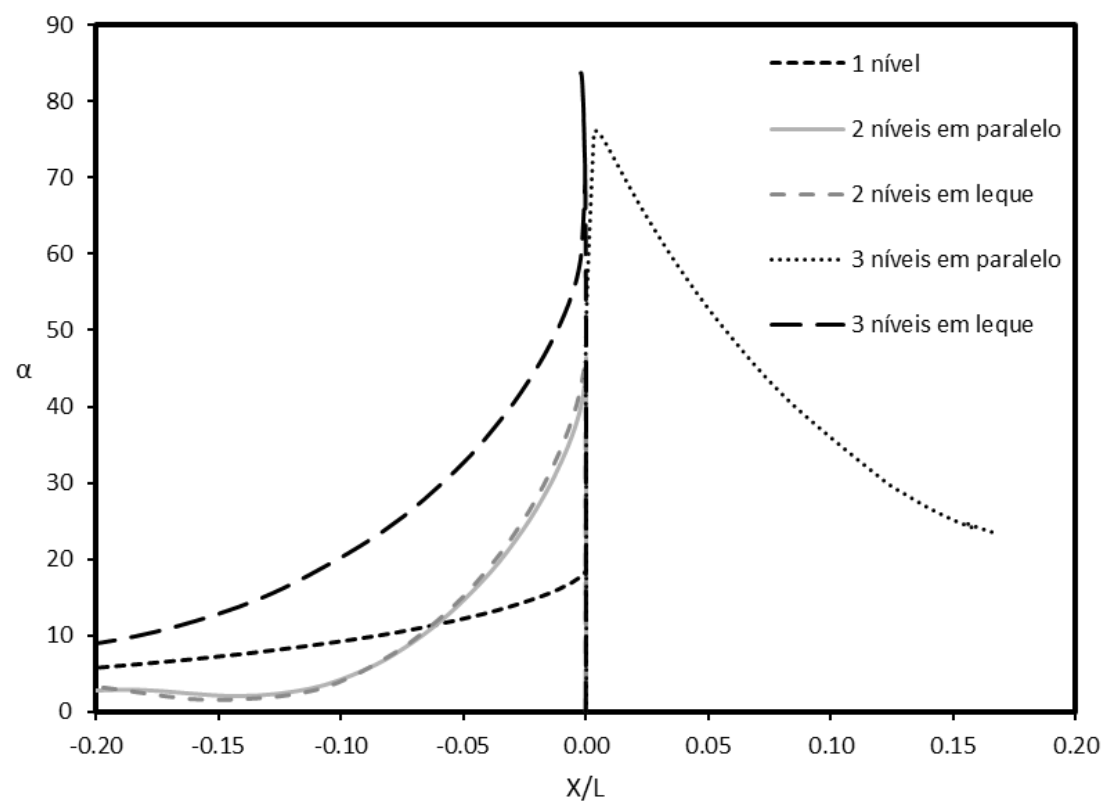

Figura 4.15- Trajetória de equilíbrio para modelos com diferentes níveis de estais. 


\section{5}

\section{Análise dinâmica linear}

Neste capítulo estuda-se a influência de características geométricas e físicas dos cabos, bem como do peso próprio da estrutura nas suas frequências naturais e modos de vibração.

\section{1.}

\section{Introdução}

Os modos de vibração e as frequências naturais do sistema têm influência fundamental na resposta da estrutura sob vibração livre e forçada, e isto não é diferente para os casos de torres de telecomunicações. Estas respostas são também dependentes das características do carregamento, das condições iniciais e das características de amortecimento da estrutura. [33]. Neste capítulo estuda-se a influência dos estais nas frequências naturais e modos de vibração. A Figura 5.1 apresenta o modelo base utilizado para as investigações da torre com apenas um nível de estais.

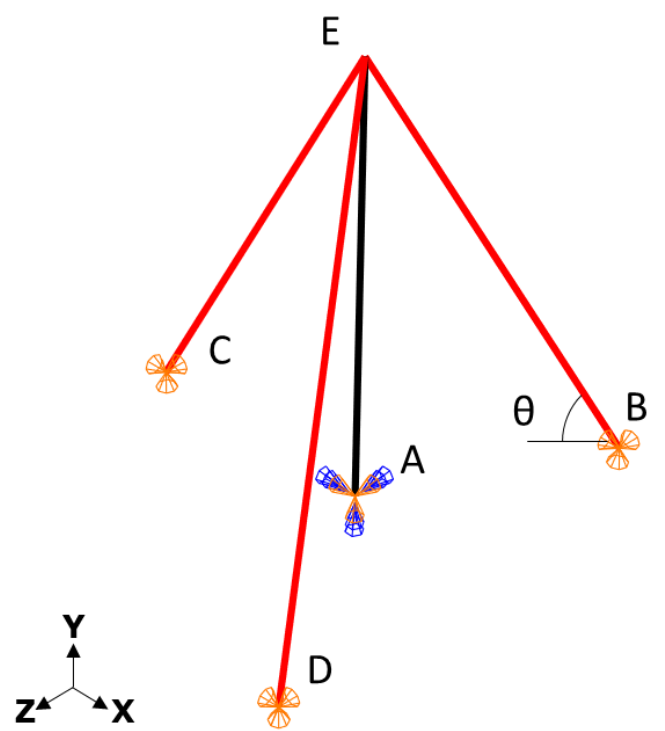

(a)

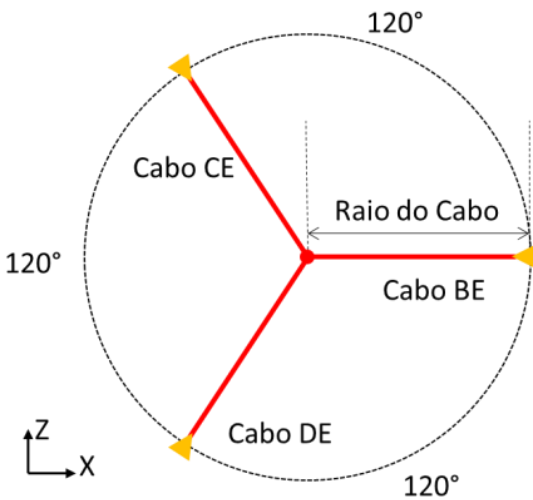

(b)

Figura 5.1 - Modelo sintético com um nível de estais no espaço, (a), e vista de topo, (b). 


\section{2.}

\section{Análise paramétrica}

Um dos pontos importantes nas análises abordadas nesse estudo é a influência dos cabos na resposta dinâmica da estrutura. Hartman e Davenport [116] propõe uma abordagem para o modelo de cabos, onde estes são considerados como um sistema massa-mola com duas molas. Uma mola representa a rigidez elástica do cabo, dada por $K_{e}=\left(A E \cos ^{2} \theta \sin (\theta) / H\right)$, a outra representa a rigidez devida ao peso próprio do cabo, dada por $K_{g}=\left(12 F_{h}^{3} /(\rho g A)^{2}(H \operatorname{cotg} \theta)^{3}\right)$, onde $F_{h}$ é a componente horizontal da tração média, $T$, do cabo. O parâmetro de massa é dado pela expressão $M=12 T /\left(\pi^{2} g\right)$. Essa formulação apresenta de forma aproximada a influência dos diversos parâmetros relacionados à geometria e material dos cabos na resposta da torre. A seguir é desenvolvida uma análise paramétrica da influência dos cabos e imperfeições iniciais da geometria da torre, utilizando modelos em elementos finitos.

\subsection{1.}

\section{Validação da metodologia de modelagem}

Inicialmente, foram realizadas análises dinâmicas lineares para determinar os modos normais e as frequências naturais de uma coluna esbelta. Este modelo representa o mastro. A frequência natural para uma viga-coluna pode ser obtida pela expressão, $f_{i}=\Lambda_{i}^{2} \sqrt{E I / 4 \pi^{2} \rho A L^{4}}(\mathrm{~Hz})$, onde o índice i define a i-ésima frequência natural e $\Lambda_{i}$ é função das condições de contorno do sistema. Os valores de $\Lambda_{i}$ são apresentados por Blevins [117] para diferentes condições de contorno.

Considerando uma coluna esbelta com condições de contorno engastada e livre, de seção circular tubular com diâmetros interno e externo de $0,95 \mathrm{~m}$ e $1 \mathrm{~m}$, respectivamente, módulo de elasticidade de $2,1 \mathrm{GPa}$ e densidade de $7850 \mathrm{~kg} / \mathrm{m}^{3}$, a menor frequência natural encontrada é $f_{1}=0,0998 \mathrm{~Hz}\left(\Lambda_{1}=1,8751\right)$.

Ao se considerar o peso próprio da coluna como uma carga distribuída ao longo da mesma, pode-se utilizar a formulação apresentada por Jurjo [118] para determinar a menor frequência natural dessa estrutura, sendo esta dada por 


$$
\begin{aligned}
& \omega_{1}=\frac{0,0009755256162}{\bar{m} L^{2}}\left(\operatorname { s q r t } \left(\overline { m } \left(0,522398204 \times 10^{9} q L^{3}+0,3088478529 \times 10^{11} E I\right.\right.\right. \\
& \left.\left.\left.-1 \sqrt{0,1276350973 \times 10^{18} q^{2} L^{6}+0,2106761186 \times 10^{20} E I q L^{3}+0,8750008982 \times 10^{21} E I^{2}}\right)\right)\right)
\end{aligned}
$$

As variáveis $q, \bar{m}$, se referem ao peso e à massa por unidade de comprimento. $\mathrm{O}$ valor de $q$ na Eq (5) deve ser negativo quando orientado para abaixo.

Utilizando um modelo em elementos finitos da coluna esbelta pode-se obter os primeiros modos normais e suas frequências. As características do modelo são as mesmas empregadas para o modelo sintético padrão, na seção 3.3.1.3 deste trabalho, e as propriedades são as adotadas para a determinação da menor frequência natural por métodos analíticos. Para se determinar a influência do peso próprio no modelo, há a necessidade da ativação da não linearidade geométrica na análise no início do processamento. A partir desses resultados, podem-se comparar os valores das frequências naturais para uma coluna engastada e livre com e sem a consideração do peso-próprio. Os resultados são apresentados na Tabela 5.1. onde nota-se que os valores são idênticos, validando a metodologia utilizada.

Tabela 5.1 - Comparativo entre valores analíticos e modelos numéricos para coluna engastada e livre com e sem o peso próprio como carga distribuída ao longo da coluna.

\begin{tabular}{c|c|c}
\hline \multicolumn{3}{c}{ Menor Frequência Natural $(\mathrm{Hz})$} \\
\hline Modelo & ABAQUS & Analítico \\
\hline Com Peso-Próprio & 0,0777 & 0,0742 \\
Sem Peso-Próprio & 0,0998 & 0,0998 \\
\hline
\end{tabular}

\subsection{2.}

\section{Influência das características dos cabos}

\subsubsection{1.}

\section{Peso Próprio dos Cabos}

Com o intuito de avaliar a influência de características dos cabos nas frequências naturais da torre, utiliza-se o modelo sintético padrão com um nível de estais. A partir desse modelo, utilizando o MEF, podem-se determinar as dez primeiras frequências naturais da estrutura e observar como o peso próprio dos 
cabos altera estes valores. Para isso, consideram-se cinco tipos de cabos, apresentados no Capítulo 3, onde cada um possui tensão de ruptura e diâmetros diferentes. Os resultados da analise modal para os modelos são apresentados na Tabela 5.2 e Tabela 5.3. A Figura 5.2 apresenta a influência do tipo de cabo na frequência fundamental do modelo.

Tabela 5.2 - Influência do peso próprio do cabo nas frequências naturais da torre $(\mathrm{Hz})$, para cinco valores diferentes de diâmetro de cabo, $\phi$, para $-\rho_{\text {cabo }}\left(\mathrm{kg} / \mathrm{m}^{3}\right)=0$.

\begin{tabular}{c|c|c|c|c|c}
\hline \multicolumn{6}{c}{ Frequências $(\mathbf{H z})-\boldsymbol{\rho}_{\text {cabo }}\left(\mathbf{k g} / \mathbf{m}^{\mathbf{3}}\right) \mathbf{0}$} \\
\hline Modos & $\boldsymbol{\phi}=\mathbf{1 9} \mathbf{~} \mathbf{m}$ & $\boldsymbol{\phi}=\mathbf{2 2} \mathbf{~} \mathbf{m}$ & $\boldsymbol{\phi}=\mathbf{2 9} \mathbf{~ m m}$ & $\boldsymbol{\phi}=\mathbf{3 8} \mathbf{~ m m}$ & $\boldsymbol{\phi}=\mathbf{4 8} \mathbf{~ m m}$ \\
\hline $\mathbf{1}$ & $\mathbf{0 , 3 4 3 4}$ & $\mathbf{0 , 3 6 2 7}$ & $\mathbf{0 , 3 8 9 0}$ & $\mathbf{0 , 4 0 2 0}$ & $\mathbf{0 , 4 0 5 4}$ \\
\hline $\mathbf{2}$ & 0,3434 & 0,3627 & 0,3890 & 0,4020 & 0,4054 \\
\hline $\mathbf{3}$ & 0,7816 & 0,8309 & 0,9466 & 1,0720 & 1,1699 \\
\hline $\mathbf{4}$ & 0,7816 & 0,8309 & 0,9466 & 1,0720 & 1,1699 \\
\hline $\mathbf{5}$ & 1,7626 & 1,7736 & 1,8070 & 1,8630 & 1,9394 \\
\hline $\mathbf{6}$ & 1,7626 & 1,7736 & 1,8070 & 1,8630 & 1,9394 \\
\hline $\mathbf{7}$ & 3,3549 & 3,3496 & 3,3354 & 3,3125 & 3,2848 \\
\hline $\mathbf{8}$ & 3,3549 & 3,3496 & 3,3354 & 3,3125 & 3,2848 \\
\hline $\mathbf{9}$ & 5,4829 & 5,4682 & 5,4299 & 5,3747 & 5,3133 \\
\hline $\mathbf{1 0}$ & 5,4829 & 5,4682 & 5,4299 & 5,3747 & 5,3133 \\
\hline
\end{tabular}

Tabela 5.3 - Influência do peso próprio do cabo nas frequências naturais da torre (Hz), para cinco valores diferentes de diâmetro de cabo, $\phi$, para $-\rho_{\text {cabo }}\left(\mathrm{kg} / \mathrm{m}^{3}\right)=7580$.

\begin{tabular}{c|c|c|c|c|c}
\hline \multicolumn{6}{c}{ Frequências $(\mathbf{H z})-\boldsymbol{\rho}_{\text {cabo }}\left(\mathbf{k g} / \mathbf{m}^{\mathbf{3}}\right)=\mathbf{7 5 8 0}$} \\
\hline Modos & $\boldsymbol{\phi}=\mathbf{1 9} \mathbf{~ m m}$ & $\boldsymbol{\phi}=\mathbf{2 2} \mathbf{~} \mathbf{m}$ & $\boldsymbol{\phi}=\mathbf{2 9} \mathbf{~ m m}$ & $\boldsymbol{\phi}=\mathbf{3 8} \mathbf{~ m m}$ & $\boldsymbol{\phi}=\mathbf{4 8} \mathbf{~ m m}$ \\
\hline $\mathbf{1}$ & $\mathbf{0 , 3 3 5 0}$ & $\mathbf{0 , 3 5 3 6}$ & $\mathbf{0 , 3 7 8 6}$ & $\mathbf{0 , 3 9 0 3}$ & $\mathbf{0 , 3 9 2 6}$ \\
\hline $\mathbf{2}$ & 0,3350 & 0,3536 & 0,3786 & 0,3903 & 0,3926 \\
\hline $\mathbf{3}$ & 0,7683 & 0,8185 & 0,9355 & 1,0610 & 1,1577 \\
\hline $\mathbf{4}$ & 0,7683 & 0,8185 & 0,9355 & 1,0610 & 1,1577 \\
\hline $\mathbf{5}$ & 1,7458 & 1,7570 & 1,7911 & 1,8485 & 1,9265 \\
\hline $\mathbf{6}$ & 1,7458 & 1,7570 & 1,7911 & 1,8485 & 1,9265 \\
\hline $\mathbf{7}$ & 3,3370 & 3,3317 & 3,3176 & 3,2948 & 3,2672 \\
\hline $\mathbf{8}$ & 3,3370 & 3,3317 & 3,3176 & 3,2948 & 3,2672 \\
\hline $\mathbf{9}$ & 5,4646 & 5,4499 & 5,4116 & 5,3562 & 5,2946 \\
\hline $\mathbf{1 0}$ & 5,4646 & 5,4499 & 5,4116 & 5,3562 & 5,2946 \\
\hline
\end{tabular}




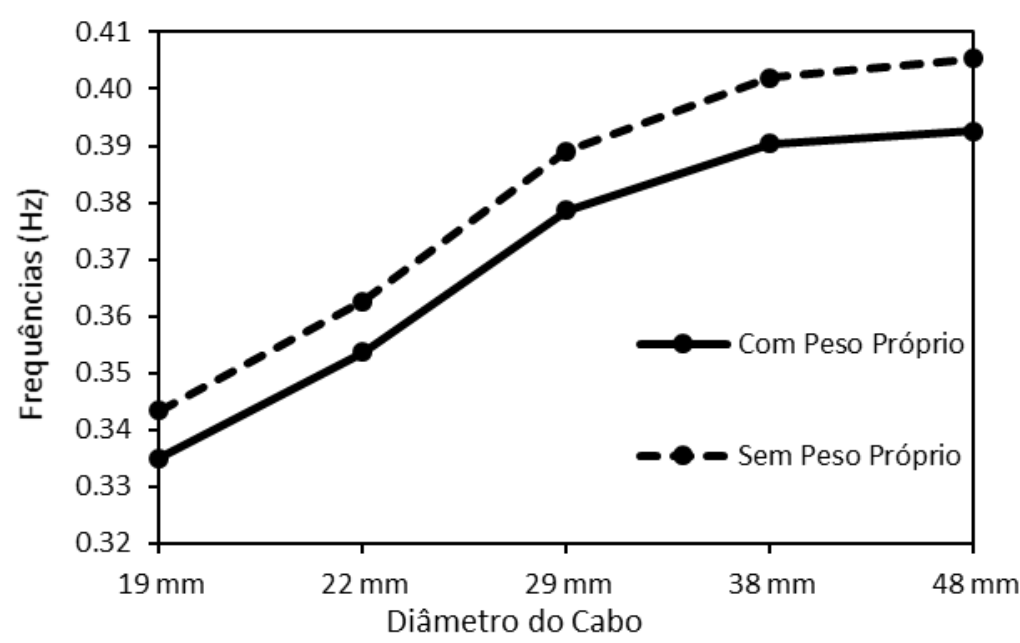

Figura 5.2 - Relação diâmetro do cabo x $1^{\mathrm{a}}$ frequência natural da torre, com e sem peso-próprio dos cabos.

A rigidez elástica do cabo, $E A$, e a pré-tensão dos cabos aumentam a frequência natural do sistema, visto que os cabos exercem a função de suportes elásticos no topo da torre. Entretanto, a consideração do peso próprio reduz entre $2 \%$ e $3 \%$ as frequências naturais do sistema.

Em virtude dos três planos de simetria a torre estaiada apresenta sempre dois modos de vibração rotacionalmente simétricos associados à mesma frequência natural, como observado na Tabela 5.2 e Tabela 5.3. Isto ocasiona uma situação de ressonância interna 1:1 e uma transferência de energia entre modos, fenômenos observados no modelo discreto de uma torre nos trabalhos de Orlando, [19], [82], [83] e de Gavassoni Neto [21], [84].

\subsubsection{2.}

\section{Distribuição desigual dos cabos}

Os modos rotacionalmente simétricos associados a mesma frequência natural são devido a característica de distribuição dos cabos da torre. Essa distribuição é responsável por gerar a simetria quando uniforme. Porém, quando esta distribuição pode passa a ser assimétrica por diversos fatores, dentre eles, construtivos ou por problemas gerados por agentes externos à uma torre estaiada. Seguindo nesse contexto, são investigados os modos de vibração e frequências naturais do modelo padrão com cabo de $48 \mathrm{~mm}$, quando a distribuição dos cabos é desigual, 
apresentando angulações de $120^{\circ}, 115^{\circ}$ e $135^{\circ}$ entre eles, Figura 5.3. Os valores referentes aos dez primeiros modos de vibração dessa estrutura são apresentados na Tabela 5.4.

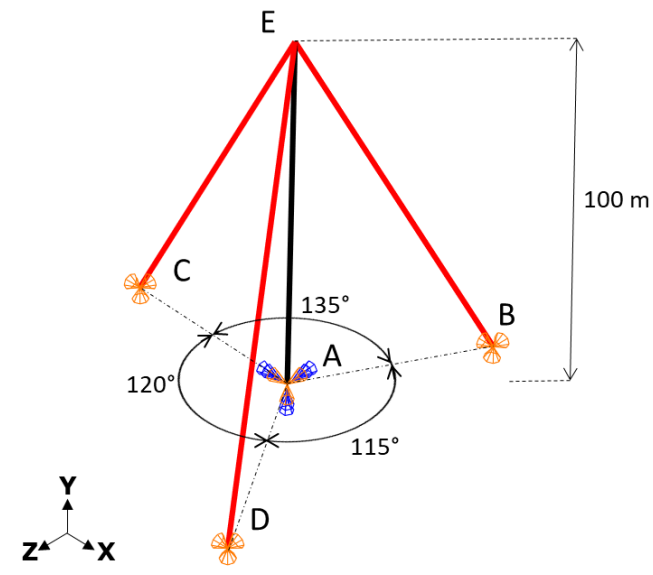

(a) Vista 3D.

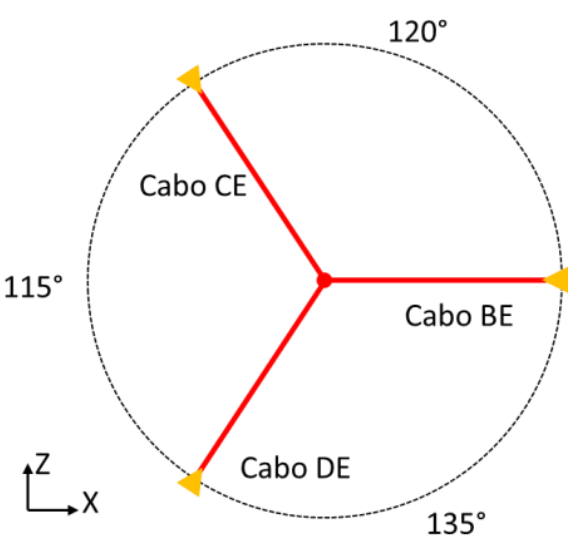

(b) Vista superior.

Figura 5.3 - Distribuição desigual dos cabos de uma torre estaiada

Tabela 5.4 - Frequências naturais para um modelo de torre com distribuição assimétrica dos cabos.

\begin{tabular}{c|c|c|c|c|c|c|c|c|c|c}
\hline Modos & $\mathbf{1}$ & $\mathbf{2}$ & $\mathbf{3}$ & $\mathbf{4}$ & $\mathbf{5}$ & $\mathbf{6}$ & $\mathbf{7}$ & $\mathbf{8}$ & $\mathbf{9}$ & $\mathbf{1 0}$ \\
\hline $\begin{array}{c}\text { Frequência } \\
\text { (Hz) }\end{array}$ & 0,3919 & 0,3934 & 1,1439 & 1,1708 & 1,916 & 1,9627 & 3,2929 & 3,3088 & 5,3595 & 5,3657 \\
\hline
\end{tabular}

Observa-se que a pequena quebra de simetria possui uma leve influência, mas não o suficiente para desfazer a condição na rotacional de associação dos modos. Os valores para as frequências naturais do sistema mesmo que diferindo na quarta casa decimal para as frequências mais baixas. Porém para frequências mais altas essa diferença entre valores chega a aproximadamente 2,4\%. Entretanto, ainda são muito próximos. Logo com autovetores ortogonais entre si, a situação de ressonância interna de 1:1 passa a deixar de ocorrer no sistema.

\subsubsection{3.}

\section{Inclinação do cabo em relação a torre}

Além de características físicas e geométricas do cabo, a sua inclinação em relação ao ponto de ancoragem na torre possui efeitos significativos nas frequências naturais da estrutura, como mostra a formulação analítica de Hartman e Davenport 
[116] Na Tabela 5.5 são apresentadas as dez primeiras frequências naturais para uma torre com um nível de estais, quando se varia o ângulo $\theta$ no intervalo $55^{\circ} \leq$ $\theta \leq 85^{\circ}$, considerando um cabo com $\phi=48 \mathrm{~mm}$ e $T=125 \mathrm{kN}$.

Com o aumento de $\theta$ há uma redução do raio de ancoragem do cabo, Figura 5.1 item (b), e o aumento da força de compressão no topo da estrutura. Como consequência da verticalização dos cabos, há também uma redução na estabilização lateral do sistema, levando a frequências naturais mais baixas. Entretanto, com o valor de $\theta$ mais agudo, há uma redução na área necessária para instalação da torre e também no comprimento e peso dos cabos. Estas observações são exemplificadas pelas configurações do primeiro modo de vibração para diferentes valores de $\theta$, Figura 5.5.

Tabela 5.5 - Frequências naturais da torre com um nível de estais em função da inclinação $\theta$ do

$$
\text { cabo }-\phi=48 \mathrm{~mm}-T=125 \mathrm{kN} \text {. }
$$

\begin{tabular}{c|c|c|c|c|c|c|c}
\hline \multirow{2}{*}{ Modo } & \multicolumn{7}{|c}{ Arequência $(\mathbf{H z})$} \\
\cline { 2 - 8 } & \multicolumn{7}{|c}{$\mathbf{\text { Angulo do cabo } - \boldsymbol { \theta } ( { } ^ { \circ } )}$} \\
\cline { 2 - 8 } & $\mathbf{5 5}$ & $\mathbf{6 0}$ & $\mathbf{6 5}$ & $\mathbf{7 0}$ & $\mathbf{7 5}$ & $\mathbf{8 0}$ & $\mathbf{8 5}$ \\
\hline $\mathbf{1}$ & 0,39585 & 0,39262 & 0,38769 & 0,37905 & 0,36096 & 0,31475 & 0,19982 \\
\hline $\mathbf{2}$ & 0,39585 & 0,39262 & 0,38769 & 0,37905 & 0,36096 & 0,31475 & 0,19982 \\
\hline $\mathbf{3}$ & 1,2032 & 1,1577 & 1,0856 & 0,97711 & 0,83166 & 0,67452 & 0,56641 \\
\hline $\mathbf{4}$ & 1,2032 & 1,1577 & 1,0856 & 0,97711 & 0,83166 & 0,67452 & 0,56641 \\
\hline $\mathbf{5}$ & 2,0133 & 1,9265 & 1,8316 & 1,7434 & 1,6748 & 1,6295 & 1,6047 \\
\hline $\mathbf{6}$ & 2,0133 & 1,9265 & 1,8316 & 1,7434 & 1,6748 & 1,6295 & 1,6047 \\
\hline $\mathbf{7}$ & 3,2907 & 3,2672 & 3,2421 & 3,2189 & 3,1997 & 3,1856 & 3,1771 \\
\hline $\mathbf{8}$ & 3,2907 & 3,2672 & 3,2421 & 3,2189 & 3,1997 & 3,1856 & 3,1771 \\
\hline $\mathbf{9}$ & 5,2975 & 5,2946 & 5,2893 & 5,283 & 5,2771 & 5,2722 & 5,2691 \\
\hline $\mathbf{1 0}$ & 5,2975 & 5,2946 & 5,2893 & 5,283 & 5,2771 & 5,2722 & 5,2691 \\
\hline
\end{tabular}

Nota-se que para o intervalo investigado há uma diferença de quase o dobro entre o ângulo de $55^{\circ}$ e o de $85^{\circ}$. Ao se observar a relação frequência/ângulo $\theta$ constata-se que um valor ótimo deve ser definido para esse parâmetro, Figura 5.4. Esse valor ótimo pode ser determinado utilizando a formulação proposta por Hartmann e Davenport [116] para rigidez elástica do cabo, $K_{e}=\left(A E \cos ^{2} \theta \sin (\theta) /\right.$ $H$ ), obtendo-se um valor ótimo de $35^{\circ}$. Entretanto, esse ângulo é bastante baixo para aplicações práticas e causa um aumento excessivo no peso próprio dos cabos. 


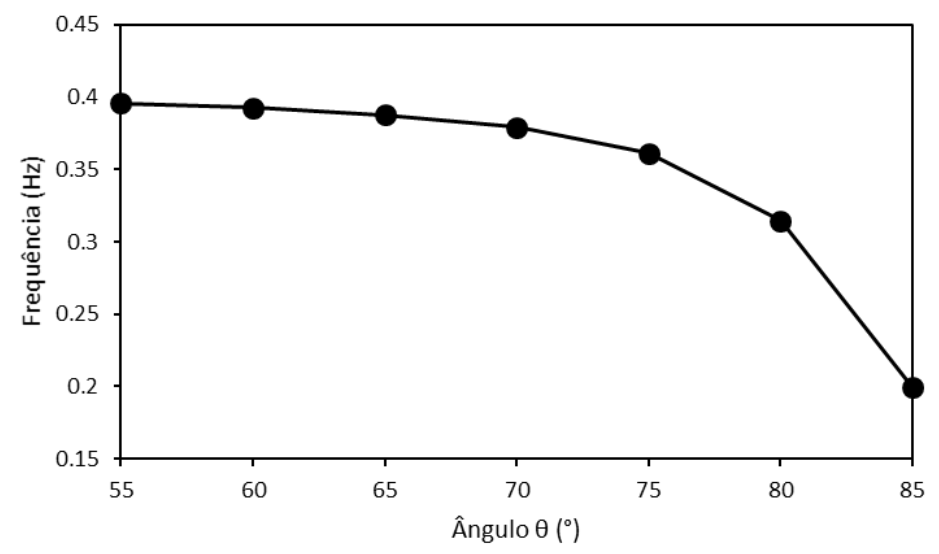

Figura 5.4 - Relação frequência fundamental com o ângulo $\theta, 55^{\circ} \leq \theta \leq 85^{\circ}$.

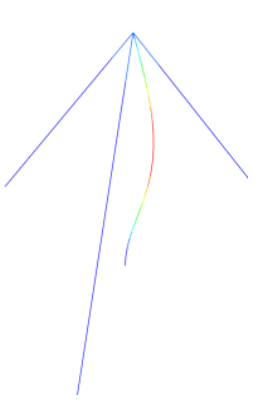

(a) $\theta=55^{\circ}$

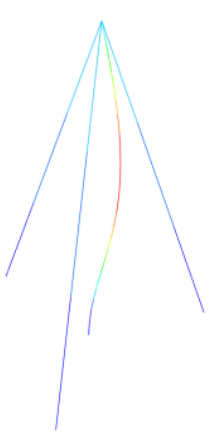

(d) $\theta=70^{\circ}$

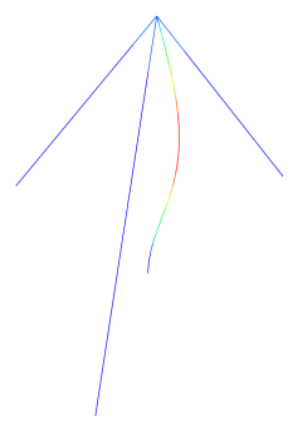

(b) $\theta=60^{\circ}$

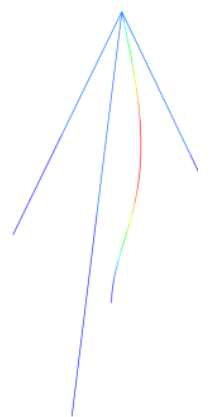

(c) $\theta=65^{\circ}$

Figura 5.5 - Primeiro modo normal de vibração para uma torre com $55^{\circ} \leq \theta \leq 85^{\circ}$.

\subsubsection{4.}

\section{Pré-tensão nos cabos}

Uma característica desse tipo de estrutura que necessita de uma atenção maior é a de pré-tensão dos cabos. Se por um lado cabos sem pré-tensão possuem uma rigidez significativamente menor do que um tracionado, por outro lado, uma prétensão inicial elevada aumenta a compressão no mastro, o que leva a uma perda de rigidez efetiva. Para avaliar o efeito da pré-tensão na frequência fundamental da 
torre, no presente trabalho foram utilizados valores de pré-tensão variando entre $10 \%$ e $30 \%$ da força de ruptura do cabo com $\phi=48 \mathrm{~mm}$. O resultado é uma relação linear com a frequência fundamental decrescendo de $0.3926 \mathrm{~Hz}$ para $0.3574 \mathrm{~Hz}$ para forças de tração de $125 \mathrm{kN}$ e $375 \mathrm{kN}$, respectivamente, para os valores de $10 \%$ e $30 \%$, da força de ruptura desse cabo, como pode ser observado na Figura 5.6.

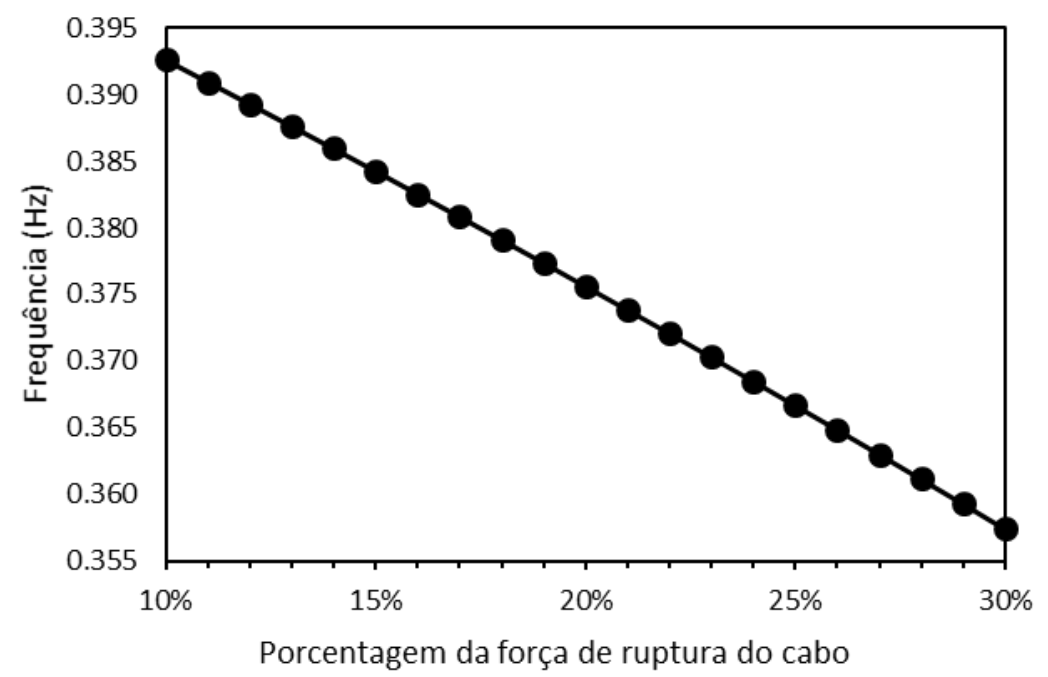

Figura 5.6 - Relação frequência natural $x$ porcentagem da força de ruptura do cabo, para o modelo sintético padrão.

\subsection{3. Influência de imperfeições iniciais}

Imperfeições usualmente possuem um importante efeito nas características de flambagem e vibração de estruturas esbeltas. Buscando um entendimento de como imperfeições de cargas ou imperfeições geométricas iniciais influenciam a frequência natural de torres estaiadas, foi considerada uma carga lateral uniformemente distribuída no mastro, atuando em conjunto com o peso próprio da estrutura e as tensões iniciais dos cabos. Variando as cargas laterais de 0,02 kN/m até 2,5 kN/m, foram obtidas as dez primeiras frequências naturais do modelo.

As condições iniciais de deformação impostas ao modelo, geraram uma configuração inicial similar ao primeiro modo de vibração, além de pequenas variações no pré-tensionamento dos cabos. As imperfeições geométricas ocasionam a quebra de simetria do modelo, não se obtendo frequências naturais iguais, como mostra a Tabela 5.6, eliminando. a ressonância interna 1:1. A diferença entre as frequências, depende do nível de carregamento. 
Tabela 5.6 - Frequências naturais da torre em função de carregamentos laterais estáticos uniformemente distribuídos $-\phi=48 \mathrm{~mm}-\mathrm{T}=125 \mathrm{kN}$.

\begin{tabular}{c|c|c|c|c|c|c|c|c}
\hline \multirow{2}{*}{ Modo } & \multicolumn{7}{|c}{ Carregamento lateral estático e deslocamento no topo da torre } \\
\cline { 2 - 10 } & $\mathbf{0 . 0 2 k N / m}$ & $\mathbf{0 . 1 k N / m}$ & $\mathbf{0 . 5 k N / m}$ & $\mathbf{0 . 8 k N / m}$ & $\mathbf{1 k N / m}$ & $\mathbf{1 . 5 k N / m}$ & $\mathbf{2 k N / \mathbf { m }}$ & $\mathbf{2 . 5 k N / m}$ \\
\cline { 2 - 9 } & $\mathbf{0 . 9 7} \mathbf{~ m m}$ & $\mathbf{4 . 8 5} \mathbf{~ m m}$ & $\mathbf{2 4 . 2 7} \mathbf{~ m m}$ & $\mathbf{3 8 . 8 4} \mathbf{~ m m}$ & $\mathbf{4 8 . 5 5} \mathbf{~ m m}$ & $\mathbf{7 2 . 8 8} \mathbf{~ m m}$ & $\mathbf{9 7 . 2 6} \mathbf{~ m m}$ & $\mathbf{1 8 7 . 0 3} \mathbf{~ m m}$ \\
\hline $\mathbf{1}$ & 0,39262 & 0,39262 & 0,39277 & 0,39301 & 0,39323 & 0,39398 & 0,39501 & 0,34255 \\
\hline $\mathbf{2}$ & 0,39262 & 0,39264 & 0,39308 & 0,3938 & 0,39444 & 0,39667 & 0,39969 & 0,39198 \\
\hline $\mathbf{3}$ & 1,1577 & 1,1577 & 1,1578 & 1,1579 & 1,158 & 1,1585 & 1,1592 & 0,90173 \\
\hline $\mathbf{4}$ & 1,1577 & 1,1577 & 1,1579 & 1,1582 & 1,1584 & 1,1591 & 1,16 & 1,1568 \\
\hline $\mathbf{5}$ & 1,9265 & 1,9265 & 1,9266 & 1,9268 & 1,927 & 1,9278 & 1,9289 & 1,7066 \\
\hline $\mathbf{6}$ & 1,9265 & 1,9266 & 1,927 & 1,9275 & 1,928 & 1,9295 & 1,9317 & 1,9251 \\
\hline $\mathbf{7}$ & 3,2672 & 3,2672 & 3,2674 & 3,2677 & 3,268 & 3,2691 & 3,2705 & 3,193 \\
\hline $\mathbf{8}$ & 3,2672 & 3,2672 & 3,2674 & 3,2678 & 3,2681 & 3,2691 & 3,2705 & 3,266 \\
\hline $\mathbf{9}$ & 5,2946 & 5,2946 & 5,2948 & 5,2951 & 5,2954 & 5,2964 & 5,2978 & 5,2677 \\
\hline $\mathbf{1 0}$ & 5,2946 & 5,2946 & 5,2948 & 5,2951 & 5,2954 & 5,2964 & 5,2979 & 5,2935 \\
\hline
\end{tabular}

A quebra de simetria pode ser introduzida no sistema como um carregamento estático inicial, como uma imperfeição geométrica ou por uma mudança nas propriedades de algum cabo, por exemplo, um comprimento ou tensão inicial distinta das demais. Quando há a adição de pequenas imperfeições, esta elimina a singularidade, resultando em duas frequências naturais diferentes, porém próximas, e dois autovetores ortogonais linearmente independentes, Figura 5.7.

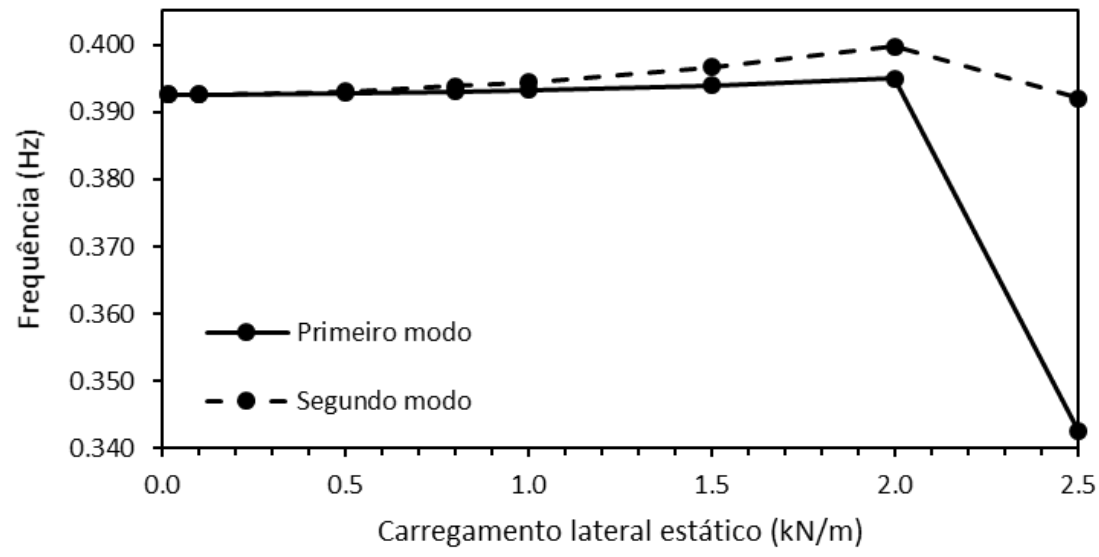

Figura 5.7 - Relação entre carregamento lateral estático e frequências dos dois primeiros modos de uma torre estaiada. 


\subsection{4.}

\section{Influência da quantidade de níveis de estais}

A configuração dos níveis de estais em uma torre altera sua rigidez, já que aumenta as restrições laterais ao longo do eixo longitudinal do mastro. Para avaliar como os níveis de estais alteram as frequências naturais do sistema, foi desenvolvida uma análise dinâmica linear para cinco tipos de distribuições dos cabos ao longo da torre. O primeiro modelo é o modelo sintético padrão utilizado nas investigações ao longo deste capítulo. Este modelo é comparado com os modelos considerando dois e três níveis de estão, podendo ser os cabos paralelos ou em leque, como visto nos capítulos anteriores ver Figura 3.4.

O aumento da frequência natural com o nível e configuração dos cabos pode ser observado na Tabela 5.7. Nota-se que, devido a simetria do modelo, também há a simetria dos modos apresentando-se em pares. Observa-se que as frequências de uma torre com três níveis de estais chegam a triplicar o seu valor quando comparado com o modelo com apenas um nível de estais, o que ressalta o aumento na rigidez da estrutura. Também se observa que para um certo número de níveis de estais, cabos em leque levam a frequências maiores que cabos em paralelo; isto em virtude da influência do ângulo $\theta$ na rigidez da estrutura, como mostrado anteriormente.

Tabela 5.7 - Frequências naturais para diferentes configurações de cabos ao longo da torre.

\begin{tabular}{|c|c|c|c|c|c|}
\hline \multicolumn{6}{|c|}{ Frequências (Hz) - Níveis de estais } \\
\hline \multirow[b]{2}{*}{ Modo } & 1 Nível & 2 Níveis & 2 Níveis & 3 Níveis & 3Níveis \\
\hline & $\begin{array}{c}\text { Cabos } \\
\text { Individuais }\end{array}$ & Cabos paralelos & $\begin{array}{c}\text { Cabos } \\
\text { em leque }\end{array}$ & Cabos paralelos & $\begin{array}{c}\text { Cabos } \\
\text { em leque }\end{array}$ \\
\hline 1 & 0,3926 & 0,9119 & 0,9679 & 1,1771 & 1,2956 \\
\hline 2 & 0,3926 & 0,9119 & 0,9679 & 1,1771 & 1,2956 \\
\hline 3 & 1,1577 & 1,3998 & 1,5898 & 1,5669 & 1,7449 \\
\hline 4 & 1,1577 & 1,3998 & 1,5898 & 1,5669 & 1,7449 \\
\hline 5 & 1,9265 & 1,9476 & 1,9668 & 2,3744 & 2,6551 \\
\hline 6 & 1,9265 & 1,9476 & 1,9668 & 2,3744 & 2,6551 \\
\hline 7 & 3,2672 & 3,4108 & 3,5287 & 3,3139 & 3,3504 \\
\hline 8 & 3,2672 & 3,4108 & 3,5287 & 3,3139 & 3,3504 \\
\hline 9 & 5,2946 & 5,3538 & 5,3563 & 5,3504 & 5,3988 \\
\hline 10 & 5,2946 & 5,3538 & 5,3563 & 5,3504 & 5,3988 \\
\hline
\end{tabular}




\section{3.}

\section{Comentários finais}

A partir da análise paramétrica pode-se constatar que os cabos influem de forma significativa nas características dinâmicas da torre. Observa-se que o modelo utilizado como base do estudo apresenta uma alta sensibilidade aos efeitos dos cabos, como peso próprio, inclinação $\theta$, sua pré-tensão, quantidade de cabos na estrutura e a imperfeições iniciais.

A norma ASCE [119] classifica uma estrutura como sensível dinamicamente, ou "flexível" se sua frequência natural mais baixa for menor que $1 \mathrm{~Hz}$; caso contrário, é considerada "rígida". A classificação usada pela norma ASCE é amplamente aceita como um limite razoável entre comportamento flexível e nãoflexível. Conforme observado ao longo das análises desenvolvidas neste capítulo, várias frequências da torre com um nível de estais são inferiores a $1 \mathrm{~Hz}$. Assim, a estrutura é dinamicamente sensível a cargas laterais dependentes do tempo e é necessária uma análise dinâmica não linear para garantir um projeto seguro. 


\section{6 Análise dinâmica não-linear}

A investigação numérica do comportamento dinâmico não-linear de torres estaiadas, neste trabalho, é abordada utilizando o modelo em elementos finitos para uma torre com 1 nível de estais, a mesma apresentada nos capítulos anteriores. São realizadas análises de vibração livre amortecida e vibração forçada amortecida do modelo da torre. As análises consideram os efeitos de diversos parâmetros da estrutura, possibilitando a análise do seu comportamento dinâmico em diversas situações. As respostas no domínio do tempo e da frequência bem como as seções de Poincaré, planos de fase e espectros de frequência, são obtidos, permitindo analisar a estabilidade dinâmica do sistema.

\section{1. \\ Parâmetros da análise numérica}

Para a análise das vibrações livres e forçadas amortecidas foram adotados parâmetros de amortecimento proporcional de Rayleigh com $\xi=1 \%$. Os parâmetros $\mathrm{A}$ e B, que multiplicam as matrizes de massa e rigidez do modelo são calculados em função das duas primeiras frequências naturais do modelo, sendo dados respectivamente por 0.0368432 e 0.00205318 [120]. Uma vez que para a torre em estudo as frequências naturais aparecem em pares, utilizou-se o primeiro e o terceiro valor encontrados pela análise modal do modelo sintético padrão, respectivamente $\omega_{1}=2,4669 \mathrm{rad} / \mathrm{s}$ e $\omega_{3}=7,2741 \mathrm{rad} / \mathrm{s}$. Tem-se, pois, para a matriz de amortecimento $\boldsymbol{C}$,

$$
C=0,0368432 \boldsymbol{M}+0,00205318 \boldsymbol{K}
$$

A integração das equações de movimento é realizada através do método Newmark- $\beta$ com um pequeno amortecimento numérico. Para isso são adotados os parâmetros alpha $=0$, beta $=0.3025$, gamma $=0.6$. 
O passo de tempo é fixado em um centésimo do período fundamental do modelo. Como o período é de 2,5 segundos, o passo é de $0,025 \mathrm{~s}$. O tempo total de análise foi fixado em 300s, o que resulta em um total de 12000 incrementos.

\section{2 .}

\section{Modos normais não lineares}

Os modos normais não-lineares de um modelo discreto com dois graus de liberdade de um pêndulo estaiado, proposto por Thompson e Gaspar, [20], como modelo conceitual para uma torre estaiada, é investigado por Orlando et al.[82], [83], utilizando seções de Poincaré [121]. Nesses estudos, a análise da seção de Poincaré do sistema Hamiltoniano para níveis crescentes de energia mostrou que as simetrias características do sistema levam a uma superabundância dos modos normais não lineares, incluindo modos similares e não similares. Os trabalhos destacam a troca contínua de energia na interação entre estes modos. Para se obter expressões analíticas desses modos, Gavassoni et al. [84] aplicou uma abordagem por variedades invariantes, proposta por Shaw e Pierre [76]-[78], às equações não lineares de movimento desse modelo, resolvendo as equações através de expansões assintóticas.

A Figura 6.1(a), mostra a seção de Poincaré do sistema Hamiltoniano para o pêndulo estaiado, com a identificação de cinco modos não lineares estáveis (centros) e dois instáveis (selas), [19], [21], [82]. A Figura 6.1(b) apresenta os modos associados aos pontos P01, P11 e P21 correspondentes a três modos não lineares similares estáveis na direção dos três cabos do modelo (modos similares são representados por uma trajetória retilínea na configuração do espaço). Os pontos P31 e P41 correspondem a modos normais não similares (curvas na configuração do espaço) em fase e fora de fase, Figura 6.1(c). As figuras referentes aos modos normais mostram o movimento do topo da torre no espaço. Neste caso a forma Hamiltoniana adimensional é expressa por [21].

$$
\begin{gathered}
H\left(u_{1}, \dot{u}_{1}, u_{2}, \dot{u}_{2}\right)=\left[\dot{u}_{1}^{2}+\dot{u}_{2}^{2}+\frac{\left(u_{1} \dot{u}_{1}+u_{2} \dot{u}_{2}\right)}{1-u_{1}^{2}-u_{2}^{2}}\right]-\frac{4 \omega_{P}^{2}}{3 \lambda}\left[\frac{3 \lambda}{4}\left(1-\sqrt{1-u_{1}^{2}-u_{2}^{2}}\right)\right]- \\
6+2 \sqrt{1-u_{2}}+\sqrt{2} \sqrt{4-2 \sqrt{3 u_{1}}+2 u_{2}}+\sqrt{2} \sqrt{2-\sqrt{3 u_{1}}+u_{2}}
\end{gathered}
$$

onde $\omega_{P}=\sqrt{g / l}$, representa a frequência natural de um pêndulo e $\lambda$ é referente a um parâmetro de carregamento estático entre zero e um. 


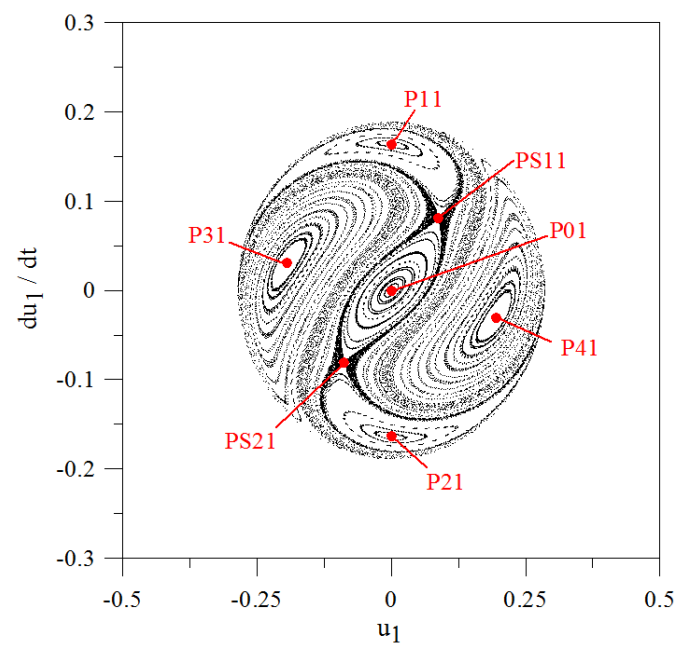

(c) Seção de Poincaré do sistema Hamiltoniano

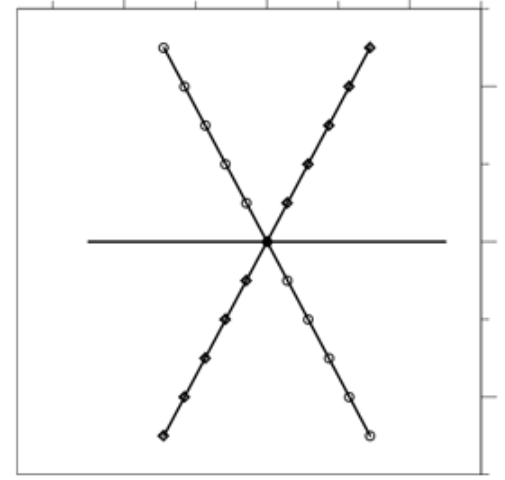

(d) Três modos não-lineares similares

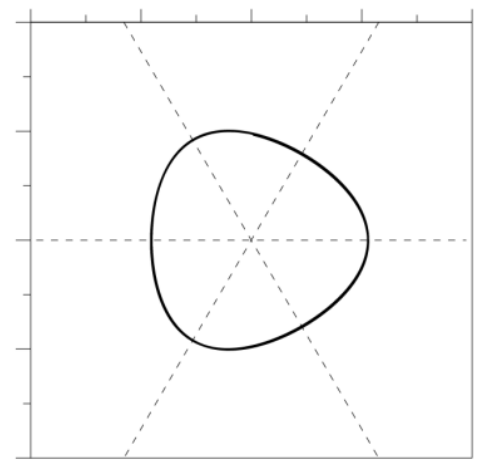

(e) Duas soluções multimodais

Figura 6.1 - Seção de Poincaré do sistema Hamiltoniano,(a), [19], e modos normais não-lineares para um modelo de Pêndulo estaiado,(b) e (c),[21].

\section{3.}

\section{Vibração livre amortecida}

Com a finalidade de verificar a existência de modos normais não lineares e multimodos, analisam-se inicialmente as vibrações livres amortecidas para o modelo sintético padrão. As propriedades desse modelo são apresentadas na seção 3.3.1.3 e adotam-se cabos de $48 \mathrm{~mm}$ de diâmetro.

\subsection{1.}

\section{Vibração livre amortecida - Ângulo $\beta$}

Para essas análises são consideradas perturbações iniciais transversais à torre, como ilustra a Figura 6.2. Essa perturbação inicial é introduzida no modelo como 
um pequeno pulso lateral aplicado a um ângulo $\beta$ em relação ao eixo $X$. Este pulso corresponde a uma força lateral de $20 \mathrm{kN} / \mathrm{m}$, atuando no mastro da estrutura durante um período de 0,05 segundos, gerando uma perturbação cinematicamente admissível.

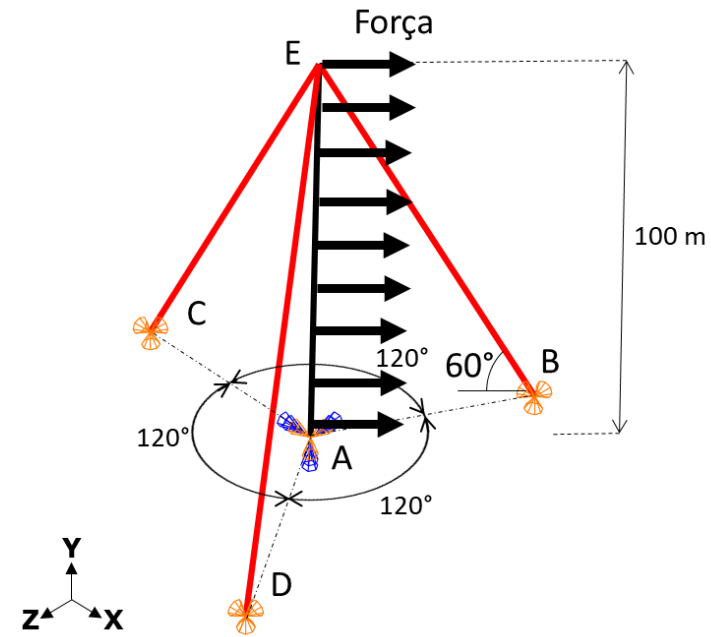

(a)

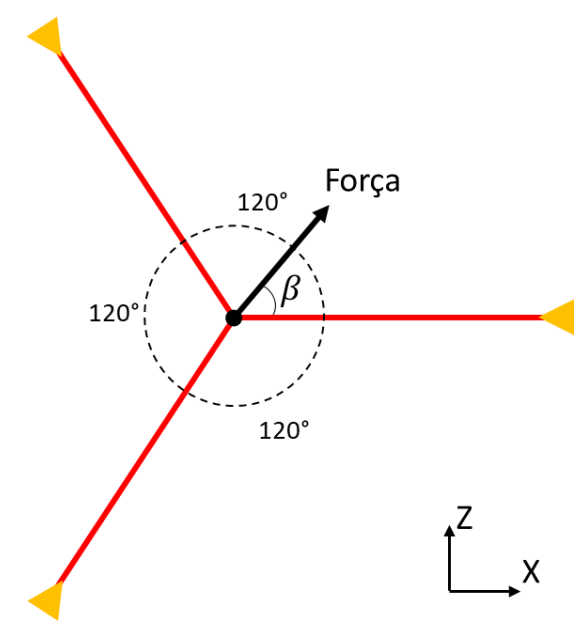

(b)

Figura 6.2 - Vistas do modelo sintético padrão com uma perturbação inicial atuando em um ângulo $\beta$ em relação ao eixo X. (a) Perspectiva da torre com carregamento distribuído; (b) Vista de topo da torre com perturbação com orientação $\beta$.

Para os estudos foram selecionados os seguintes valores de $\beta: 0^{\circ}, 15^{\circ}, 30^{\circ}$, $45^{\circ}, 60^{\circ}$ e $120^{\circ}$. A Figura 6.3 mostra o movimento do topo da torre no plano XZ para os diferentes valores de $\beta$. A figura também apresenta linhas de referência indicando as posições dos cabos. Para $\beta=0^{\circ}, \beta=60^{\circ}$ e $\beta=120^{\circ}$ tem-se um movimento retilíneo no sentido dos cabos, representado por uma reta no plano XZ. Para $\beta=180^{\circ}, \beta=240^{\circ}$ e $\beta=300^{\circ}$, o mesmo movimento é constatado, já que também o movimento ocorre na direção dos cabos. É importante ressaltar que, todos os outros nós ao longo do mastro da torre seguem o mesmo padrão de movimento, e passam pelo zero ao mesmo tempo, indicando uma sincronia do movimento.

Os modos encontrados para esse modelo são compatíveis com o conceito inicial de modos normais não lineares introduzido por Rosenberg [75], [122], [123] que definiu estes modos como vibrações em uníssono e classificou-os em modos similares ou não-similares, [21]. São também compatíveis com a classificação de Montaldi et al., [124] para as famílias de oscilações periódicas que tendem aos 
modos normais lineares do sistema dinâmico linearizado em torno da posição de equilíbrio, Gavassoni [21], [124].

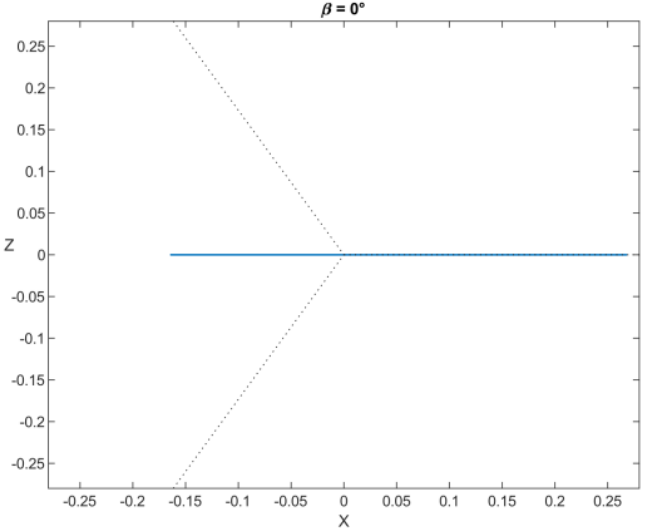

(a) $\beta=0^{\circ}$

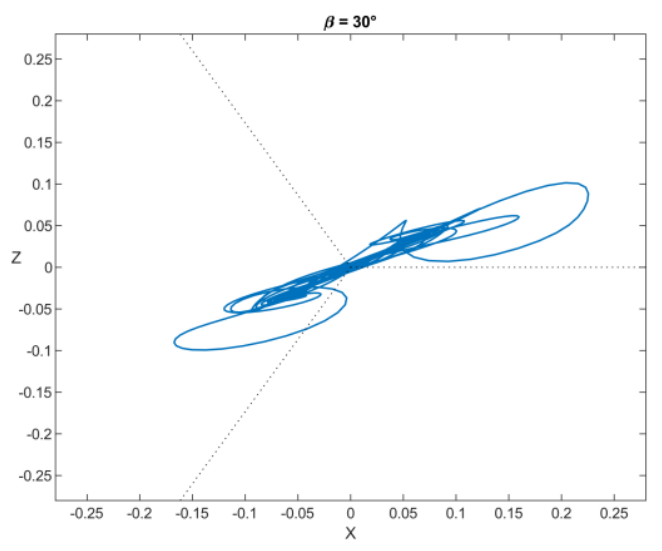

(c) $\beta=30^{\circ}$

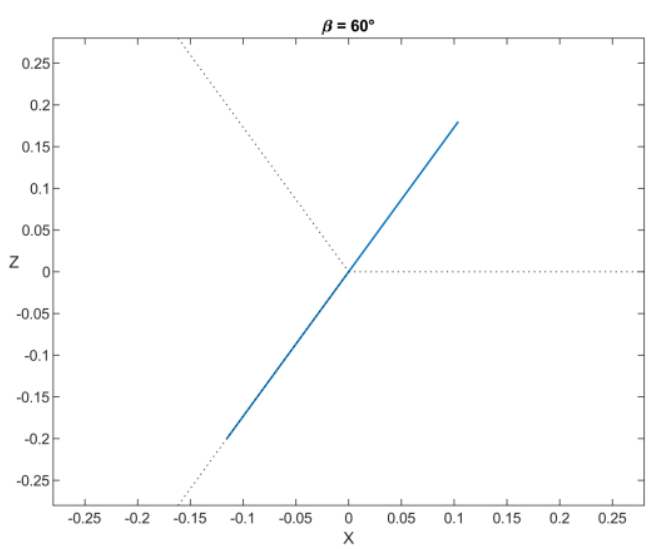

(e) $\beta=60^{\circ}$

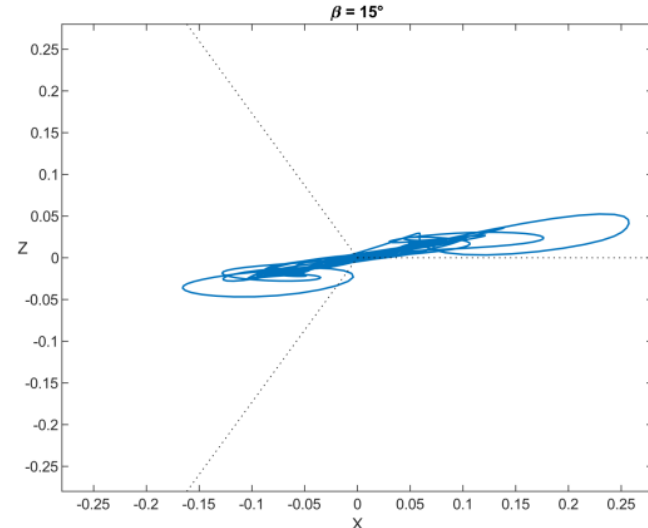

(b) $\beta=15^{\circ}$

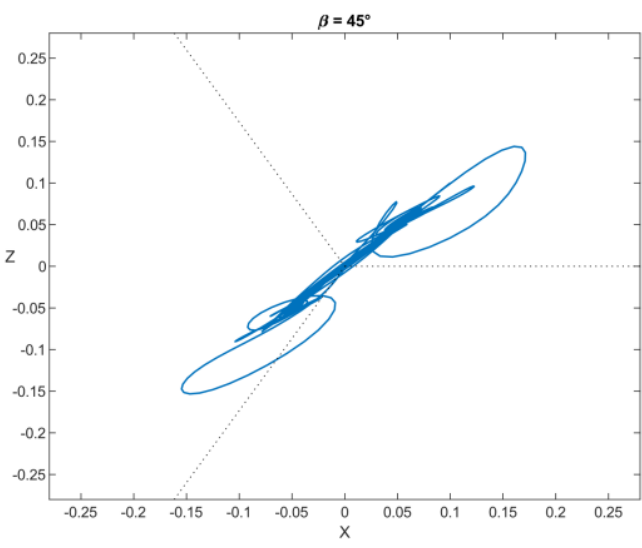

(d) $\beta=45^{\circ}$

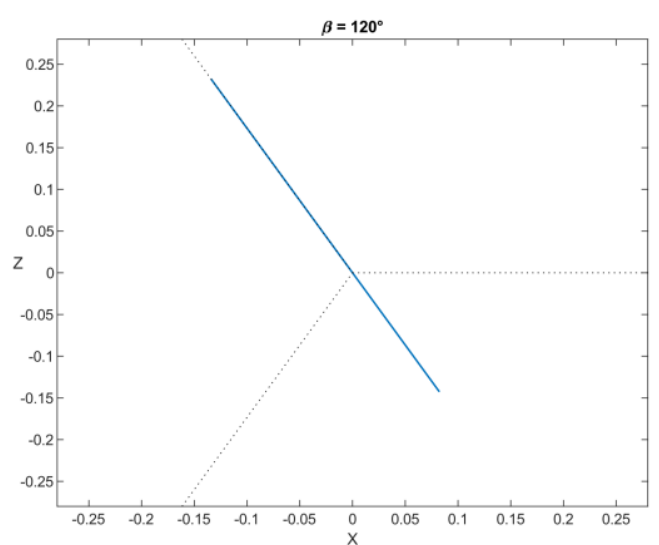

(f) $\beta=120^{\circ}$

Figura 6.3 - Movimento horizontal do topo da torre no espaço em função das perturbações nas direções $\beta$. 
Ao se comparar os modos normais não lineares do modelo conceitual, Figura 6.1(b), às respostas obtidas para o modelo sintético padrão (Figura 6.3(a), Figura 6.3(e) e Figura 6.3(f)), nota-se que os três modos lineares similares são idênticos, resultando em três modos normais não lineares desacoplados para a torre nessas direções. Na Figura 6.3 também se pode observar movimentos acoplados, soluções multimodais, para $\beta=15^{\circ}, 30^{\circ}$ e $45^{\circ}$.

Para uma melhor compreensão desses movimentos acoplados é apresentada na Figura 6.4 a resposta no tempo para $\beta=30^{\circ}$ e tos planos de fase relacionando velocidade e deslocamento nos eixos $\mathrm{X}$ e $\mathrm{Z}$ do topo da estrutura. Pode-se observar o movimento acoplado.
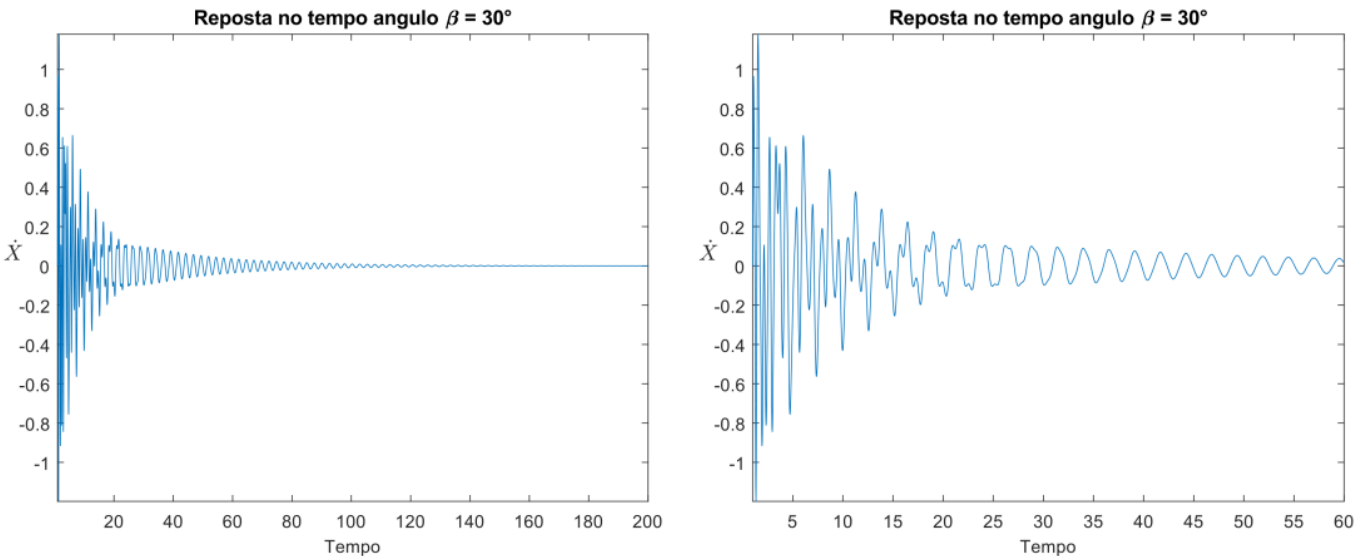

(a) Resposta no tempo para pulso atuando a $30^{\circ}$.

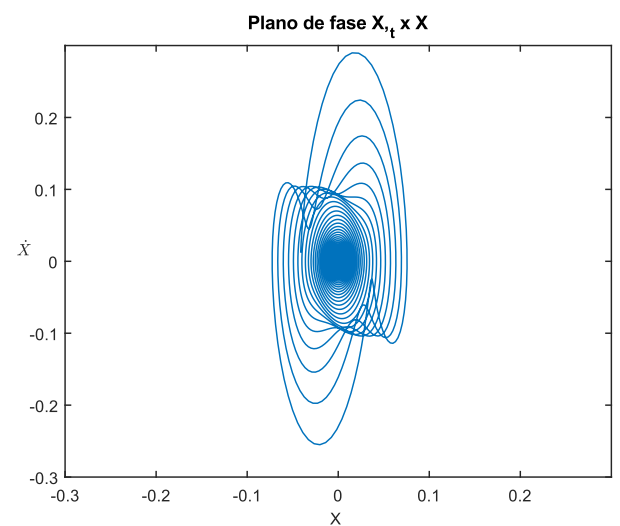

(b) Plano de fase velocidade $x$ deslocamento - direção X.

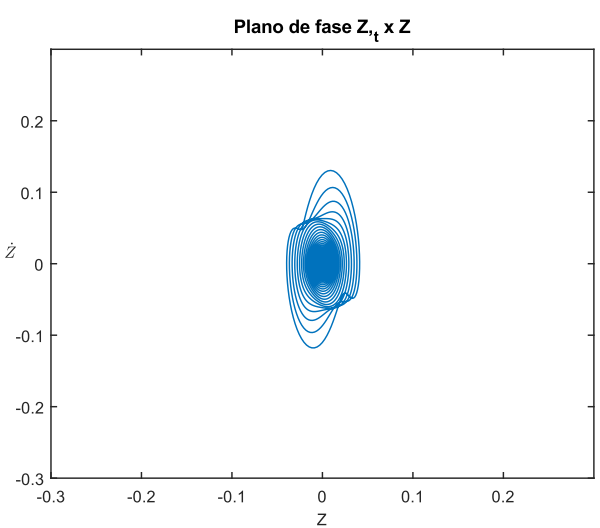

(c) Plano de fase velocidade $x$ deslocamento - direção Z.

Figura 6.4 - Resposta no tempo, (a), e projeções dos planos de fase para o angulo $\beta=30^{\circ}$, para 200 s e 60 s. (b) Plano de fase velocidade $x$ deslocamento no eixo X; (c) Plano de fase velocidade $x$ deslocamento no eixo $\mathrm{Z}$. 
Observa-se uma assimetria na resposta do sistema em virtude da não linearidade quadrática originada pelo afrouxamento dos cabos durante o movimento. Isto é, quando a torre se move na direção de um dos cabos, a tensão no cabo dessa direção diminui, enquanto as tensões dos outros dois aumentam. Quando a torre se movimenta na direção contrária a um dos cabos, ocorre o oposto.

Gavassoni [21] uma expansão assintótica dos modos não lineares similares. Para o modo P01, a aproximação contendo termos não lineares até quarta ordem resulta em.

$$
\begin{gathered}
\ddot{u}+2 \xi \omega_{P} \sqrt{\frac{1}{\lambda}-1 \dot{u}}+(1-\lambda) \frac{\omega_{P}^{2}}{\lambda} u+\frac{3}{8} \frac{\omega_{P}^{2}}{\lambda} u^{2}+(16 \lambda-17) \frac{\omega_{P}^{2}}{32 \lambda} u^{3}+u \dot{u}^{2}-\frac{17}{512} \frac{\omega_{P}^{2}}{\lambda} u^{4} \\
=\Gamma \cos (\omega t)
\end{gathered}
$$

Observa-se a existência de termos não lineares quadráticos, cúbicos associados à não-linearidade geométrica, além de um termo cúbico associado às não linearidades inerciais.

Utilizando conceitos da teoria da vibração linear, se pequenas perturbações são impostas à estrutura (pequeno pulso), a resposta da torre é praticamente linear e o movimento do nó do topo é descrito como uma reta no plano XZ, para qualquer valor de $\beta$. Entretanto, à medida que as perturbações crescem, o efeito da não linear da torre estaiada se torna mais importante e aparece os acoplamentos modais.

\subsection{2.}

\section{Vibração livre amortecida - ângulo $\beta$ com imperfeição inicial}

Como observado anteriormente, imperfeições iniciais levam a uma quebra de simetria, influindo no número e estabilidade dos modos normais não lineares .[82], [83] Para avaliar o efeito de uma imperfeição inicial na vibração não-linear livre amortecida, aplica-se uma carga estática lateral inicial de $2 \mathrm{kN} / \mathrm{m}$ atuando a $45^{\circ}$. Com a estrutura deformada, aplica-se um pulso de $20 \mathrm{kN} / \mathrm{m}$ durante $0,05 \mathrm{~s}$. Variase o ângulo $\beta$ de forma semelhante à análise anterior sem a imperfeição.

Na Figura 6.5 é apresentada a resposta do nó do topo da estrutura no plano $X Z$. Nota-se que a quebra de simetria pela carga estática inicial, leva a movimentos complexos para qualquer valor de $\beta$, mas as simetrias do modelo original ainda 
podem ser observadas no movimento acoplado. O mesmo tipo de comportamento é observado quando se consideram outros tipos de imperfeição, como as imperfeições geométricas da coluna e dos cabos.

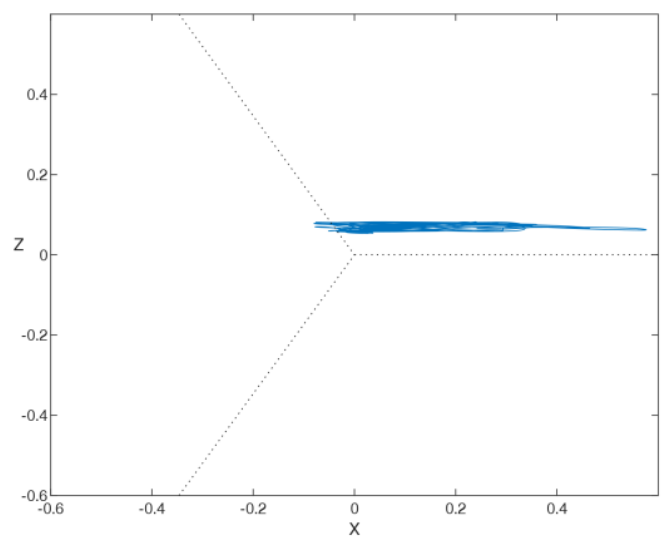

(a) $\beta=0^{\circ}$

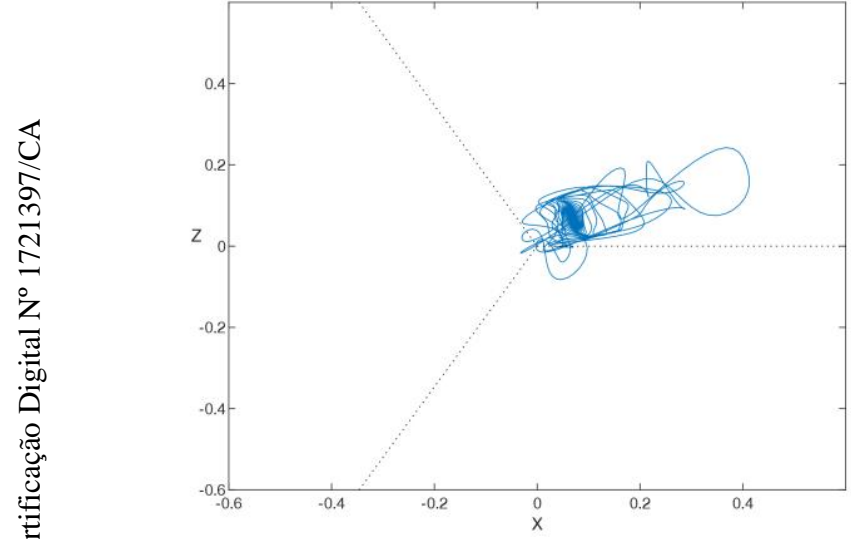

(c) $\beta=60^{\circ}$

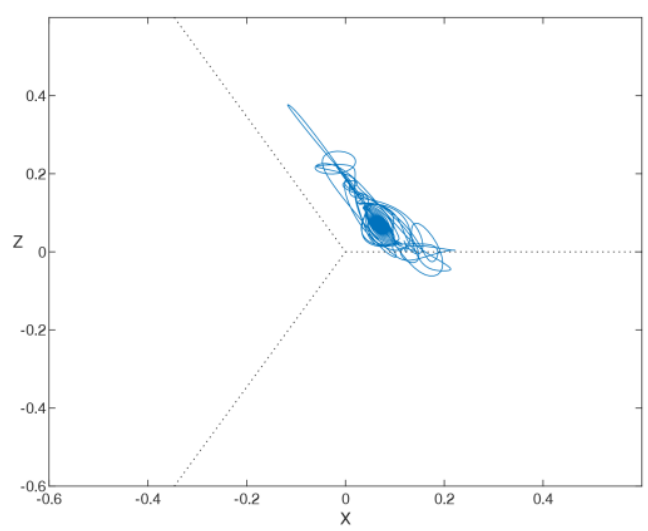

(e) $\beta=120^{\circ}$

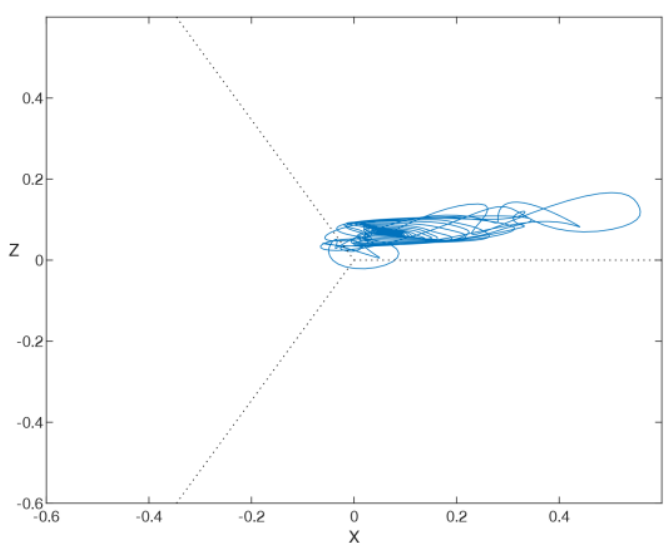

(b) $\beta=30^{\circ}$

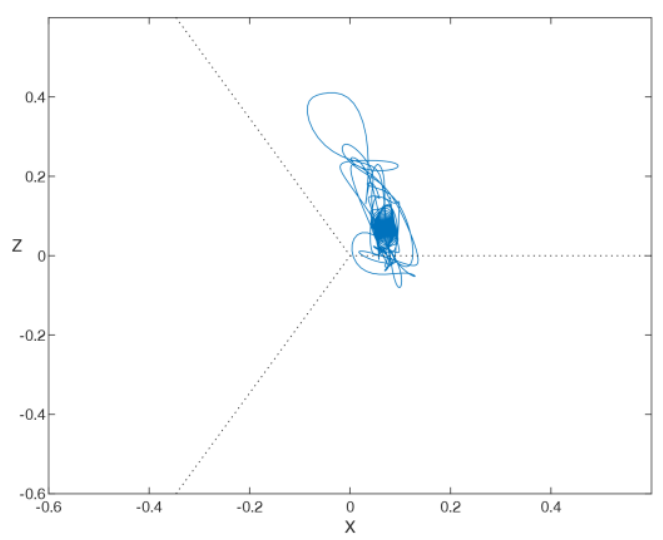

(d) $\beta=90^{\circ}$

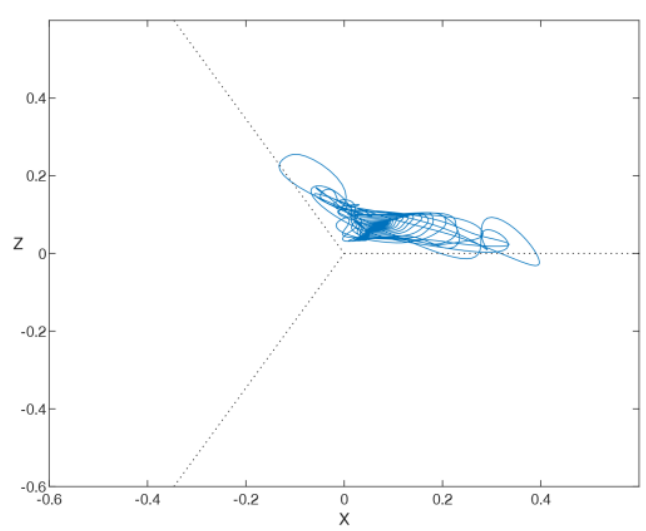

(f) $\beta=150^{\circ}$

Figura 6.5 - Movimento do topo da torre em função da perturbação na direção $\beta$ com imperfeição inicial a $45^{\circ}$. 


\section{4 . Vibração não-linear forçada amortecida}

Cargas de vento são predominantes em mastros, torres e chaminés e seus efeitos são investigados pela simulação de vibrações induzidas por rajadas na direção do vento, e vibrações induzidas por vórtices perpendicularmente à direção do vento. Para seções transversais circulares e outras seções fechadas, a excitação por desprendimento de vórtices é normalmente preponderante. Esta excitação é periódica e pode ser descrita como uma carga harmónica. Postes metálicos altos são exemplos de estruturas sujeitas a consideráveis oscilações induzidas por desprendimento de vórtices [125].

Torres estaiadas com $\omega_{1}<1 \mathrm{~Hz}$, requerem uma análise dinâmica sob ação do vento. Este é o caso do modelo adotado como padrão para as análises desse trabalho. Para as análises dinâmicas, dois modelos de carregamentos são usualmente adotados: excitações senoidais e excitações randômicas. O modelo de excitação senoidal com amplitude constate da força de flutuação é usado para simular a parcela da força do vento transversal. Para estruturas muito esbeltas e altas, uma correlação total dos modelos de excitação para as forças de vento atuantes sobre o sistema é geralmente adotado para as análises. A torre é então submetida a uma carga horizontal periódica uniformemente distribuída expressa por $f(t)=F \operatorname{sen}(\Omega t)+F_{0}$, onde $F$ é a magnitude da força, $\Omega$ é a frequência de excitação, e $F_{0}$ é a carga constante atuando em uma direção $\beta$, caso ilustrado na Figura 6.2.

Assume-se que a pressão de vento usualmente encontra-se no intervalo de 0 a $3 \mathrm{kN} / \mathrm{m}$ [24], [31], [32], [59]-[62].Com o intuito de entender o efeito da nãolinearidade e do acoplamento modal, foram desenvolvidos estudos com carga lateral harmônica distribuída variando de 0 a $8 \mathrm{kN} / \mathrm{m}$. A intensão de elevar um pouco o intervalo máximo de carregamento de harmônico, é para avaliar o efeito de cargas harmônicas de magnitudes mais elevadas que as usuais, excitando a estrutura na ressonância. Isto possibilita a observação de um espectro mais amplo de comportamentos não lineares. 


\subsection{1.}

\section{Análise Paramétrica}

Em um problema linear, espera-se que a resposta do sistema esteja na direção da força harmônica e que sua magnitude tenha uma relação linear com o nível de carregamento. Embora a estrutura analisada apresente um alto índice de nãolinearidade, uma análise linear pode ser empregada para níveis baixos de carregamentos. Para verificar tais suposições, uma análise paramétrica da magnitude da força é desenvolvida.

Todas as análises paramétricas são para o modelo sintético padrão com cabos de $48 \mathrm{~mm}$, com uma força de pré-tensão de $\mathrm{T}=125 \mathrm{kN}$. Além disso, como as investigações são para parâmetros de carregamentos harmônicos, a frequência forçada é de $2,5 \mathrm{rad} / \mathrm{s}(0.40 \mathrm{~Hz})$, valor próximo a região principal de ressonância da estrutura pré-carregada.

\subsubsection{1.}

\section{Vibração forçada amortecida - ângulo $\beta$}

Como ponto de partida para as investigações, adota-se uma força de magnitude $F=2 \mathrm{kN} / \mathrm{m}$, onde se varia o ângulo $\beta$ com o eixo X. Para isto, faz-se a decomposição da força em função de $\beta: F_{x}=F \cos \beta$ e $F_{z}=F \operatorname{sen} \beta$ e as duas componentes são inseridas como dados de entrada no ABAQUS, Figura 6.6.

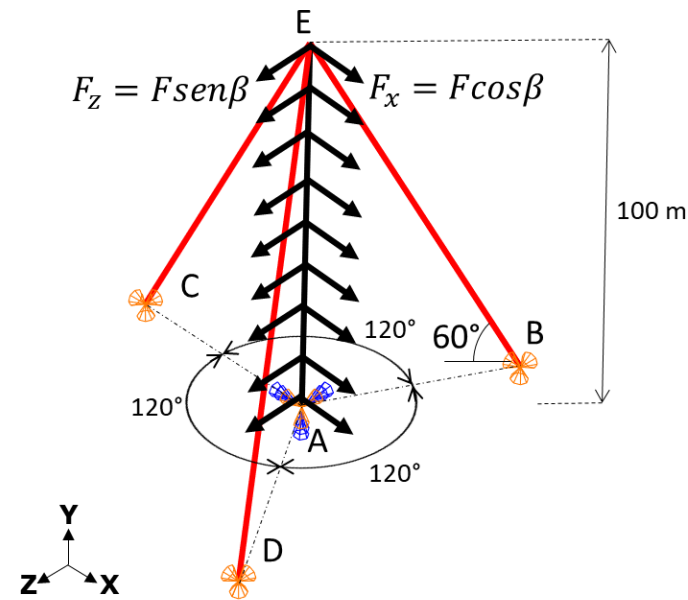

(a) Perspectiva da torre com carregamento decomposto.

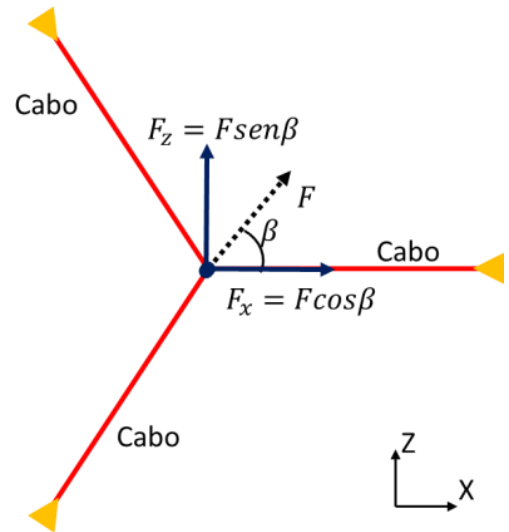

(b) Vista do topo da torre com carregamento decomposto.

Figura 6.6 - Vistas da torre com as componentes da carga harmônica nas direções X e Z. 
Para as análises foram escolhidos ângulos entre $0^{\circ}$ e $360^{\circ}$, espaçados de $30^{\circ}$. Assim, pode-se observar o comportamento para nove ângulos diferentes. Devido o sistema não linear apresentar transientes muito longos e com participação de vários modos, despreza-se nas projeções no espaço de fase a resposta transiente. Projeções da resposta permanente correspondente aos 70 últimos períodos da análise (um tempo de 175 s de observação) para valores selecionados de $\beta$ no plano $\mathrm{XZ}$ são apresentadas na Figura 6.7.

As respostas observadas na Figura 6.7 (b, d e f), mostram o mesmo comportamento com uma simetria de rotação, onde há uma evidente influência de dois modos normais não lineares. Quanto aos ângulos com direções coincidentes às dos cabos, nota-se que a resposta é complexa (possivelmente caótica) com a influência de três modos normais não lineares, com movimentos predominantes na direção do carregamento quando o movimento ocorre no sentido do cabo e governado pelos outros dois MNNLs quando o movimento se dá no sentido oposto ao cabo. Novamente observa-se a assimetria do movimento em função da não linearidade quadrática.

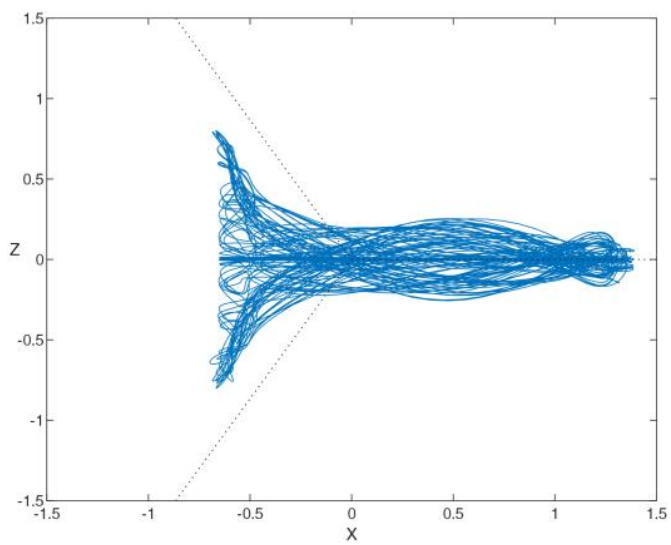

(a) $\beta=0^{\circ}, \beta=180^{\circ}$ e $\beta=360^{\circ}$

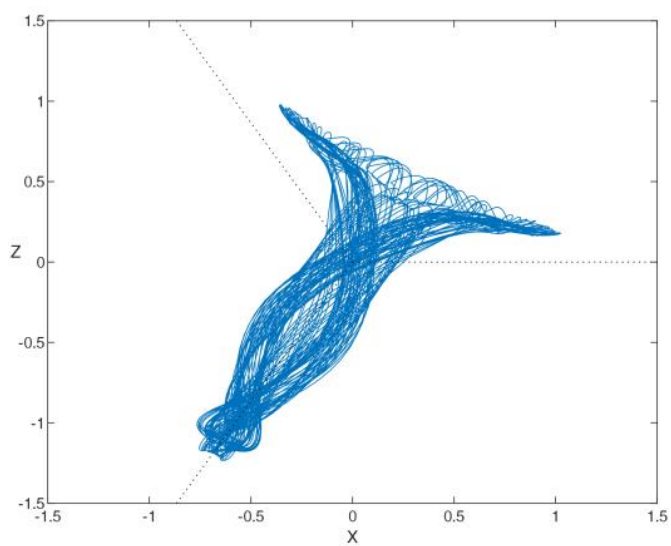

(c) $\beta=60^{\circ}$ e $\beta=240^{\circ}$

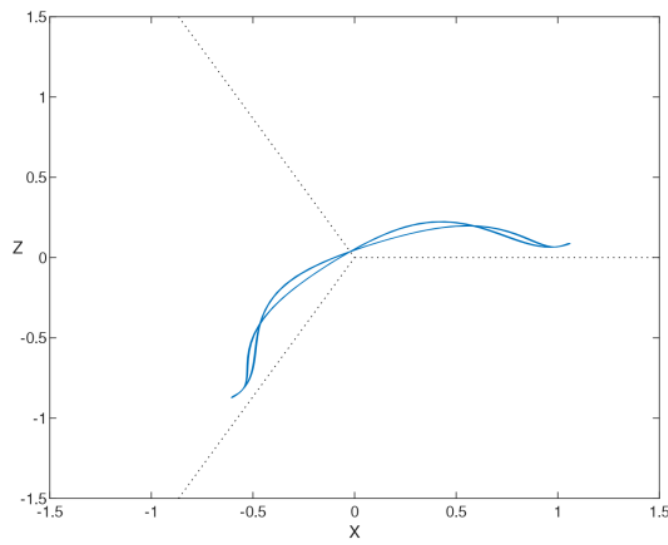

(b) $\beta=30^{\circ}$ e $\beta=120^{\circ}$

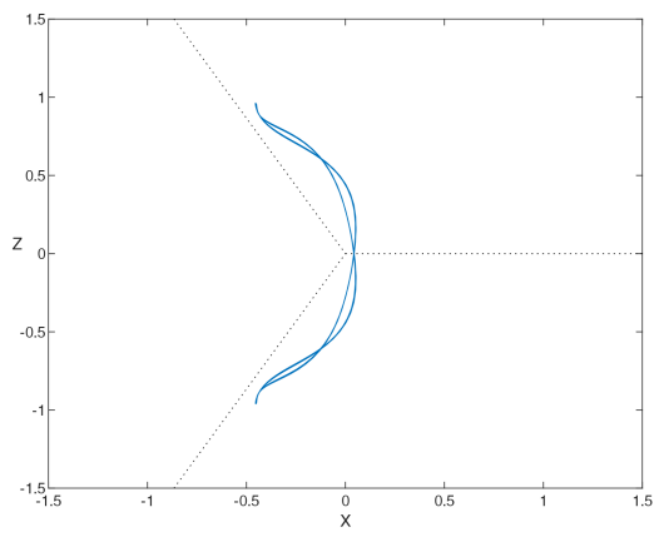

(d) $\beta=90^{\circ}$ e $\beta=270^{\circ}$ 


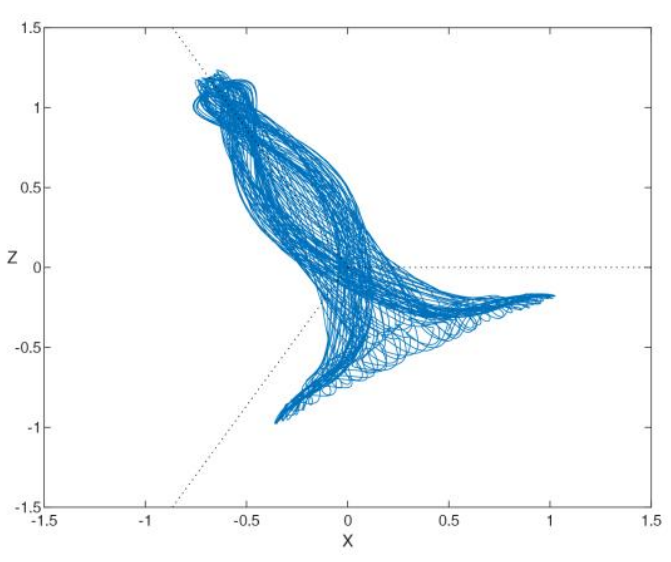

(e) $\beta=120^{\circ}$ e $\beta=300^{\circ}$

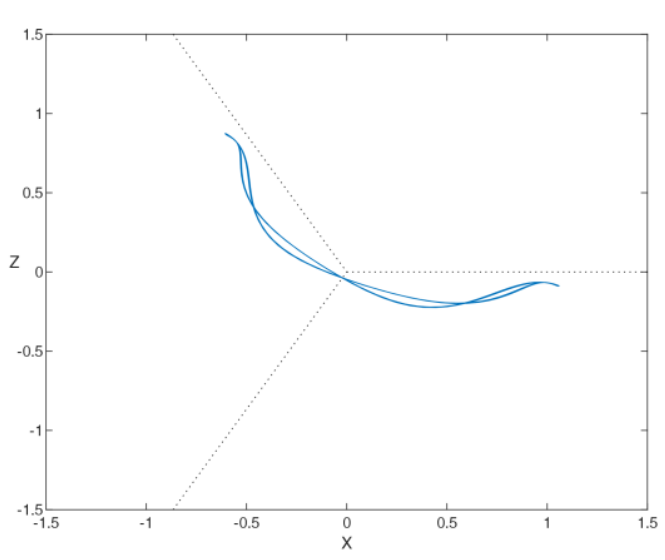

(f) $\beta=150^{\circ}$ e $\beta=330^{\circ}$

Figura 6.7 - Influência da direção do carregamento $\beta$ na resposta permanente da torre. $F=$ $2 \mathrm{kN} / \mathrm{m}$.

\subsubsection{2.}

\section{Vibração forçada amortecida - ângulo $\beta=60^{\circ}$ e $F$ variável}

Para a investigar o efeito da magnitude do carregamento na resposta do sistema analisa-se inicialmente a resposta para $\beta=60^{\circ}$. Além da resposta no tempo, para cada nível de carregamento selecionado foi obtida a Transformada Rápida de Fourier (FFT) da solução permanente e o espectrograma, levando a uma melhor compreensão da resposta da torre estaiada. Na Figura 6.8, são apresentadas as respostas dos planos de fase para o movimento de topo da estrutura no plano XZ. Os espectros de frequência e os espectrogramas referentes as estas análises são apresentados na Figura 6.9.

Para níveis de carregamento abaixo de $0.5 \mathrm{kN} / \mathrm{m}$ (Figura $6.8(\mathrm{a}-\mathrm{c})$ ) a resposta corresponde a uma reta no plano, sendo a resposta praticamente linear. Nesse intervalo a resposta está contida na variedade invariante associada ao modo normal não linear nessa direção. Isso pode ser verificado quando se observa a Figura 6.9(a) nota-se a presença de apenas um pico corresponde à frequência de excitação.

À medida que a carga aumenta acima de $0,5 \mathrm{kN} / \mathrm{m}$, a complexidade da resposta aumenta e não se pode mais usar um modelo desacoplado. Para esse valor, a resposta flutua ligeiramente ao redor da linha de referência a $60^{\circ}$. Isso pode ser explicado, pela influência de outros modos normais não lineares presentes na resposta. Nota-se também uma participação dos modos mais altos, em particular do terceiro modo, como pode ser observado no espectro de resposta e no 
espectrograma, Figura 6.9. Observa-se que há um pico intermediários entre aqueles do primeiro e terceiro modo, que corresponde a uma frequência combinada, $\left(\omega_{1}+\omega_{3}\right) / 2$, resultante da não linearidade do sistema [126].

Pode-se observar um aumento no número de frequências excitadas para cada tipo de carregamento. Nas cargas mais baixas há a presença apenas das duas primeiras frequências naturais e de uma combinação entre elas, mas, à medida que se aumenta a carga, mais frequências são excitadas.

Para as cargas de $1,6 \mathrm{kN} / \mathrm{m}$ e $2 \mathrm{kN} / \mathrm{m}$ a resposta mostra claramente a influência dos modos similares na resposta da torre, com o movimento de topo alternando entre a direção dos três cabos. Observa-se também a presença de um grande número de picos, indicando ressonâncias sub e super-harmônicas. O espectro de frequências e o espectrograma são típicos de um movimento caótico [127]. Entretanto, para uma magnitude de carregamento de $4 \mathrm{kN} / \mathrm{m}$ a resposta volta a retilínea no plano $\mathrm{XZ}$, indicando uma bifurcação e volta-se a ter um espectro com picos bem definidos. $\mathrm{O}$ mesmo comportamento permanece para um carregamento de $5 \mathrm{kN} / \mathrm{m}$. Porém quando a carga passa para $8 \mathrm{kN} / \mathrm{m}$, o comportamento do sistema volta a ser caótico (Figura $6.8(\mathrm{f}-\mathrm{g})$ ), indicando uma nova bifurcação.

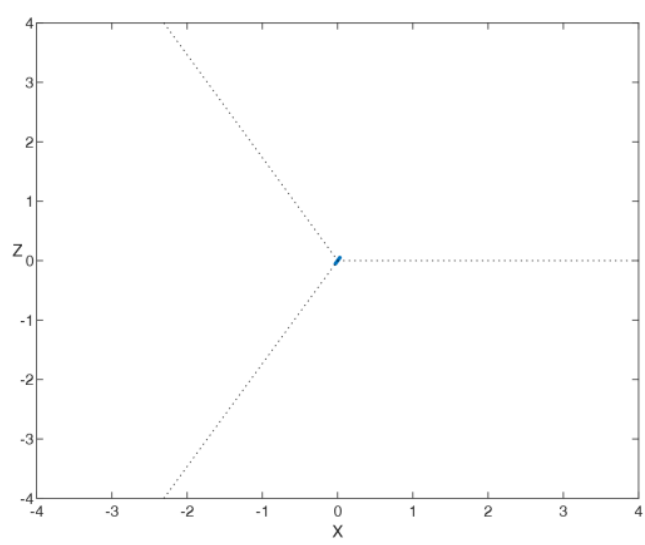

(a) $F=0,05 \mathrm{kN} / \mathrm{m} \operatorname{com} \beta=60^{\circ}$

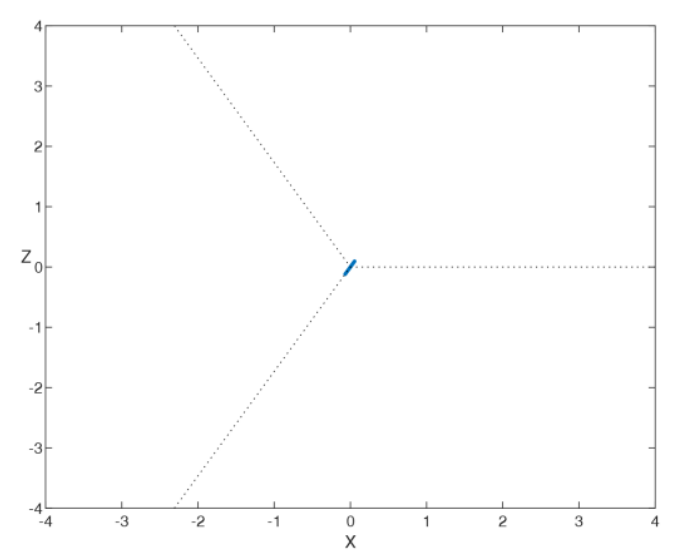

(b) $F=0,1 \mathrm{kN} / \mathrm{m} \operatorname{com} \beta=60^{\circ}$ 


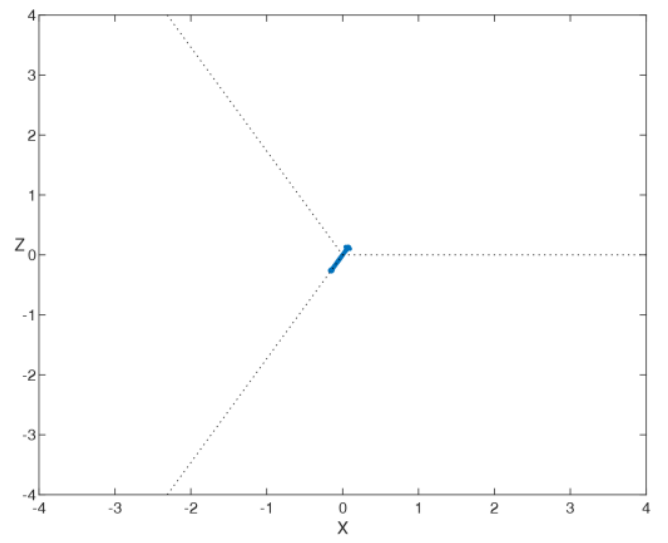

(c) $F=0,25 \mathrm{kN} / \mathrm{m} \operatorname{com} \beta=60^{\circ}$

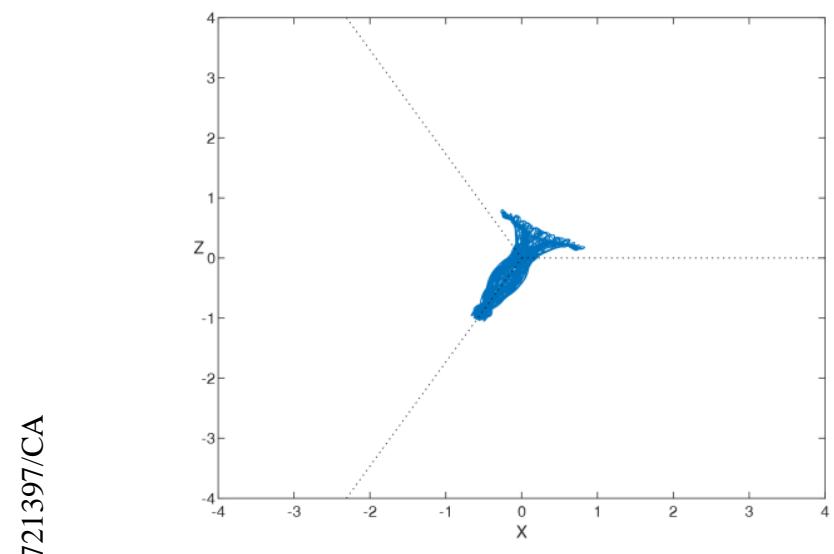

(e) $F=1,6 \mathrm{kN} / \mathrm{m} \operatorname{com} \beta=60^{\circ}$

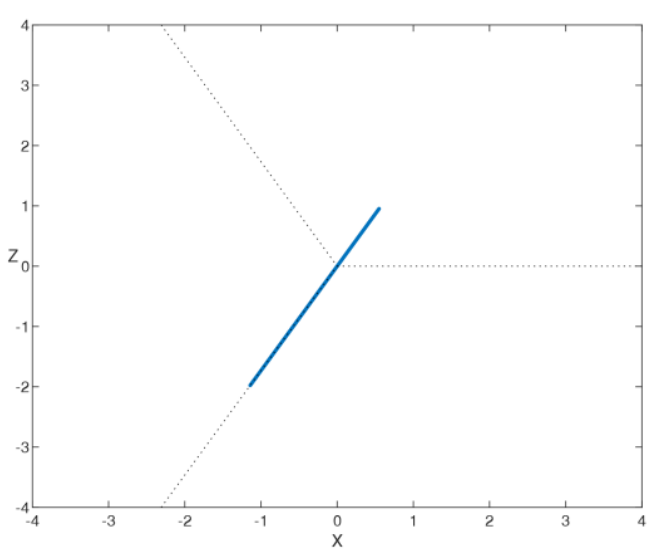

(g) $F=4 \mathrm{kN} / \mathrm{m} \operatorname{com} \beta=60^{\circ}$

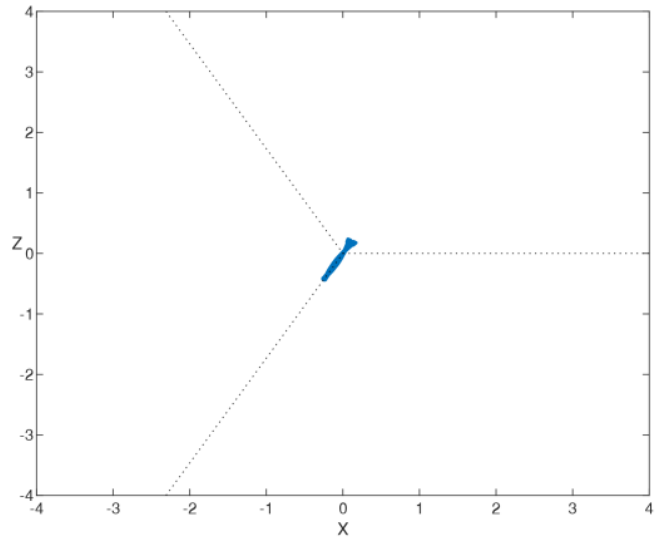

(d) $F=0,5 \mathrm{kN} / \mathrm{m} \operatorname{com} \beta=60^{\circ}$

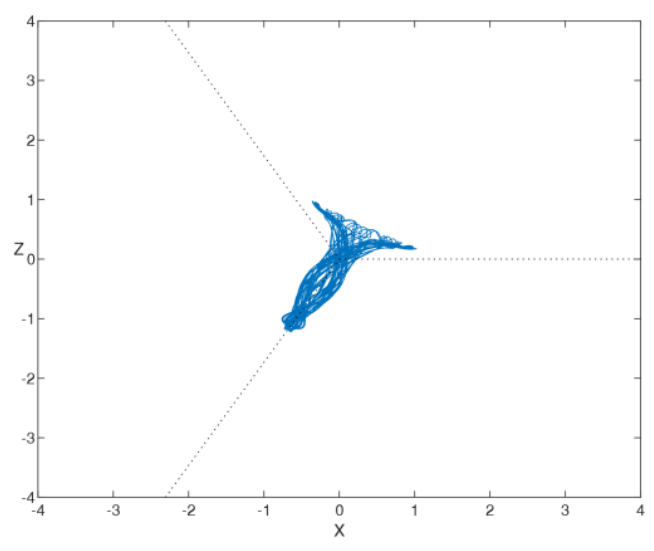

(f) $F=2 \mathrm{kN} / \mathrm{m} \operatorname{com} \beta=60^{\circ}$

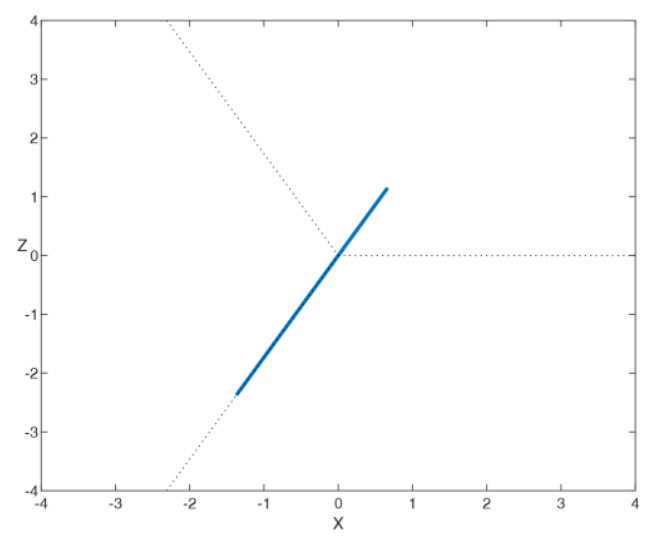

(h) $=5 \mathrm{kN} / \mathrm{m} \operatorname{com} \beta=60^{\circ}$ 


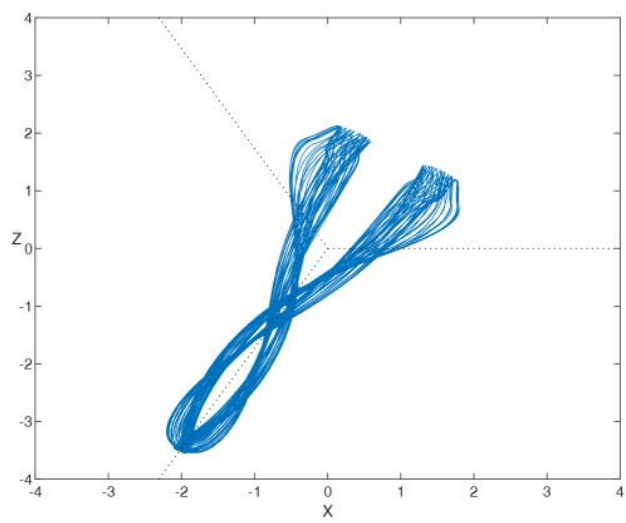

(i) $F=8 \mathrm{kN} / \mathrm{m} \operatorname{com} \beta=60^{\circ}$

Figura 6.8 - Influência da magnitude da força na resposta do regime permanente para $\beta=60^{\circ}$, plano de fase XZ.
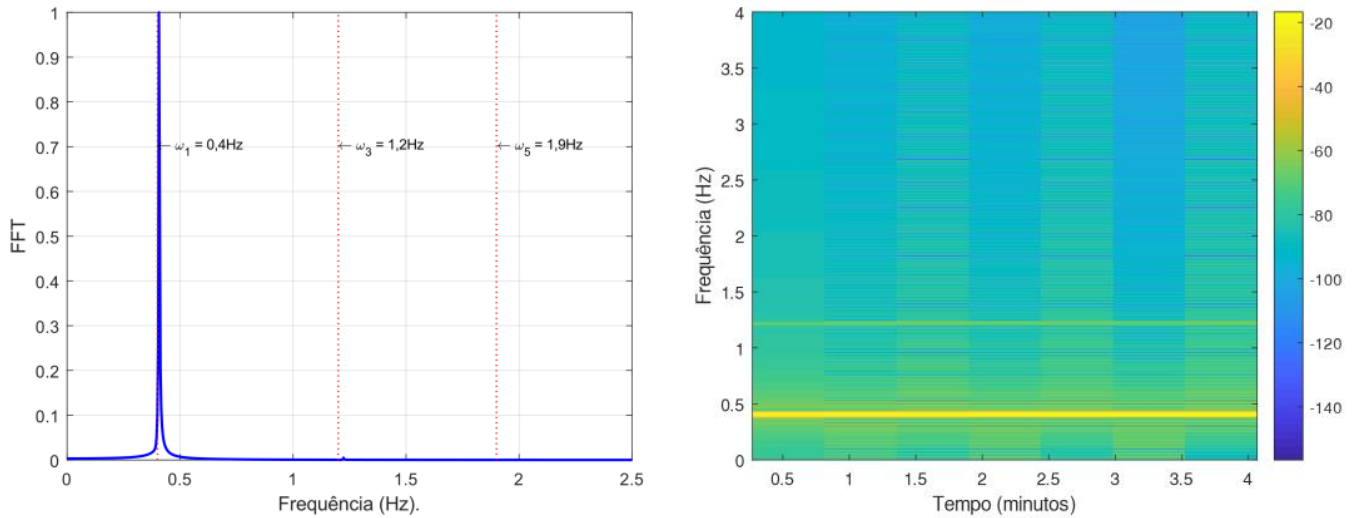

(a) $F=0,05 \mathrm{kN} / \mathrm{m} \operatorname{com} \beta=60^{\circ}$.
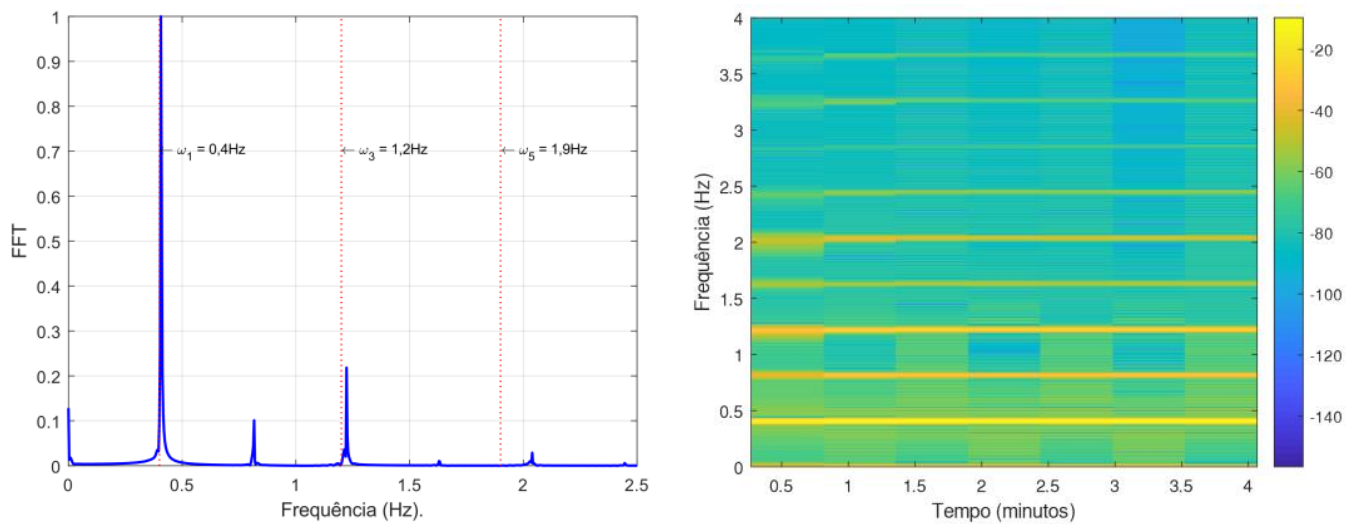

(b) $F=0,1 \mathrm{kN} / \mathrm{m} \operatorname{com} \beta=60^{\circ}$. 

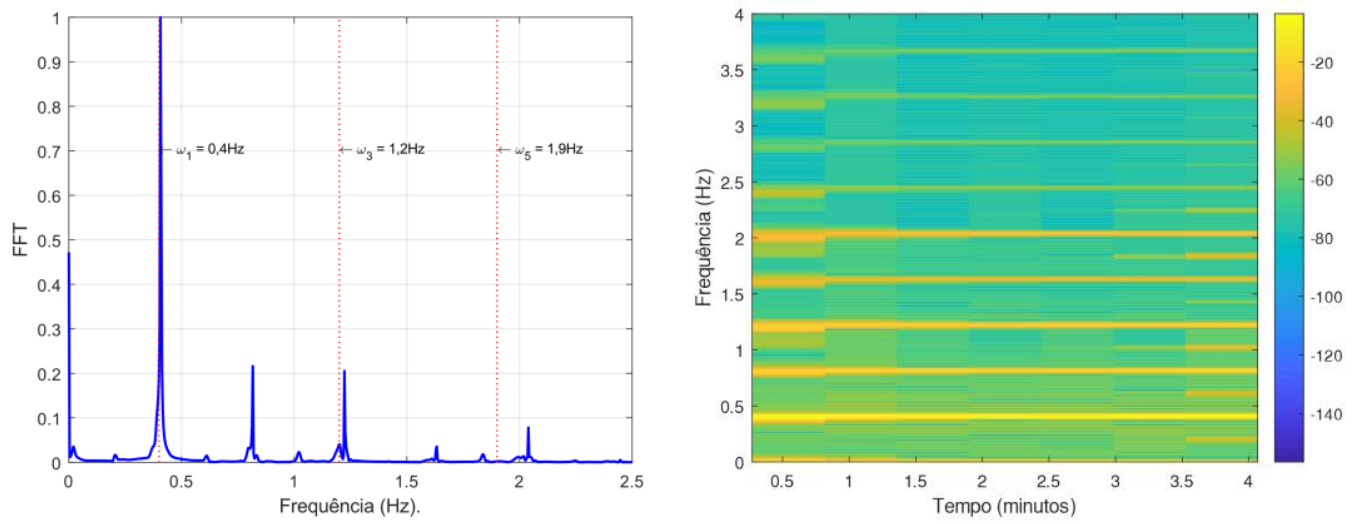

(c) $F=0,25 \mathrm{kN} / \mathrm{m} \operatorname{com} \beta=60^{\circ}$.
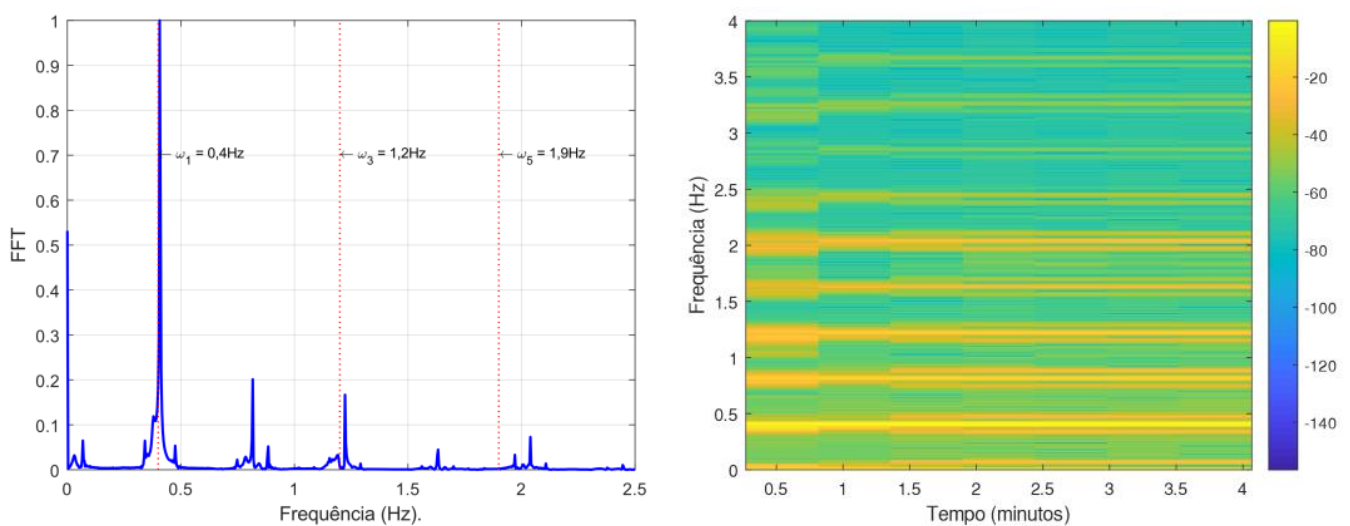

(d) $F=0,5 \mathrm{kN} / \mathrm{m} \operatorname{com} \beta=60^{\circ}$.
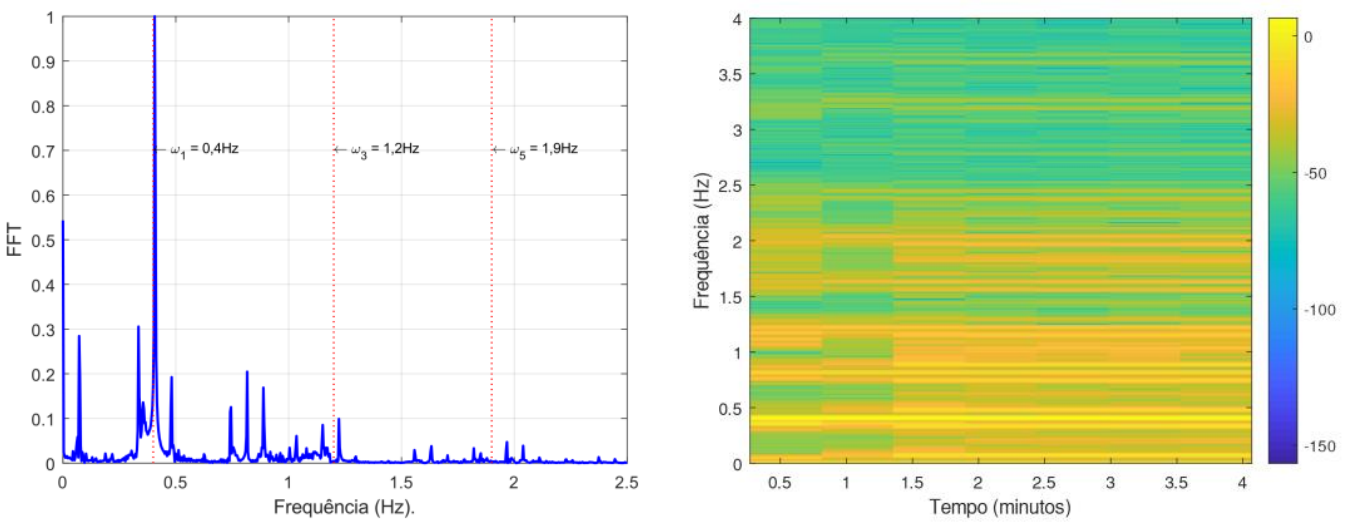

(e) $F=1,6 \mathrm{kN} / \mathrm{m} \operatorname{com} \beta=60^{\circ}$.
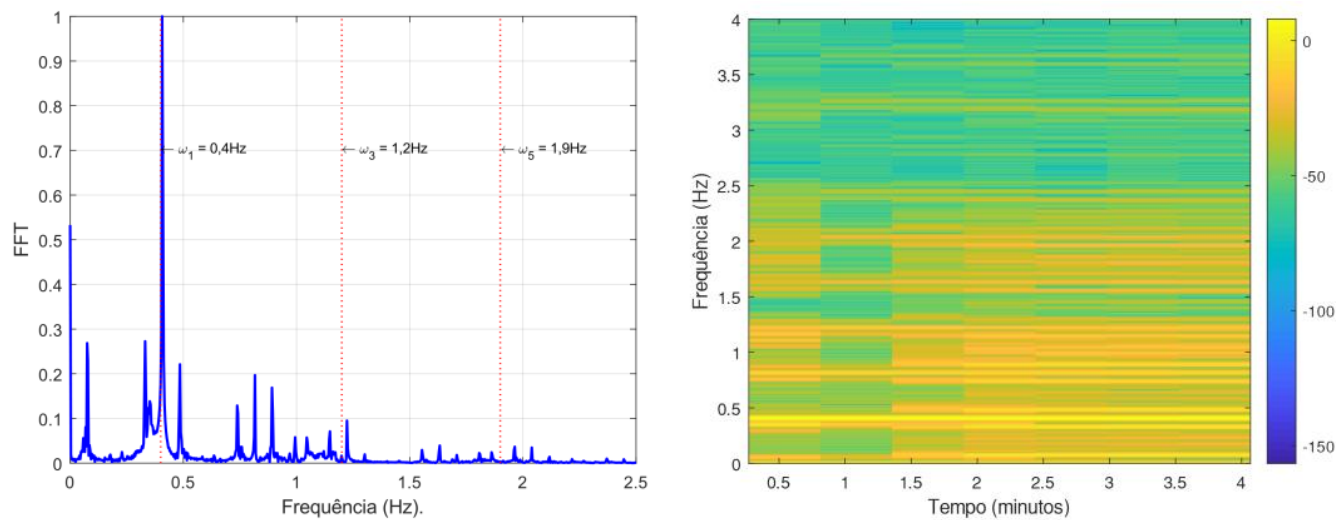
(f) $F=2 \mathrm{kN} / \mathrm{m} \operatorname{com} \beta=60^{\circ}$.
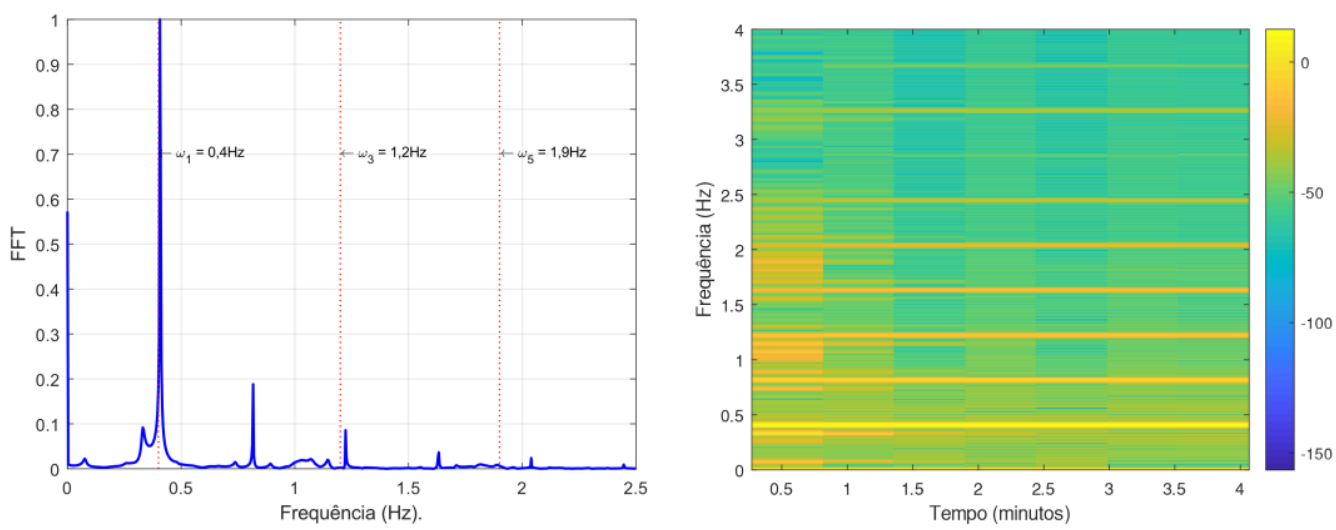

(g) $F=4 \mathrm{kN} / \mathrm{m} \operatorname{com} \beta=60^{\circ}$.
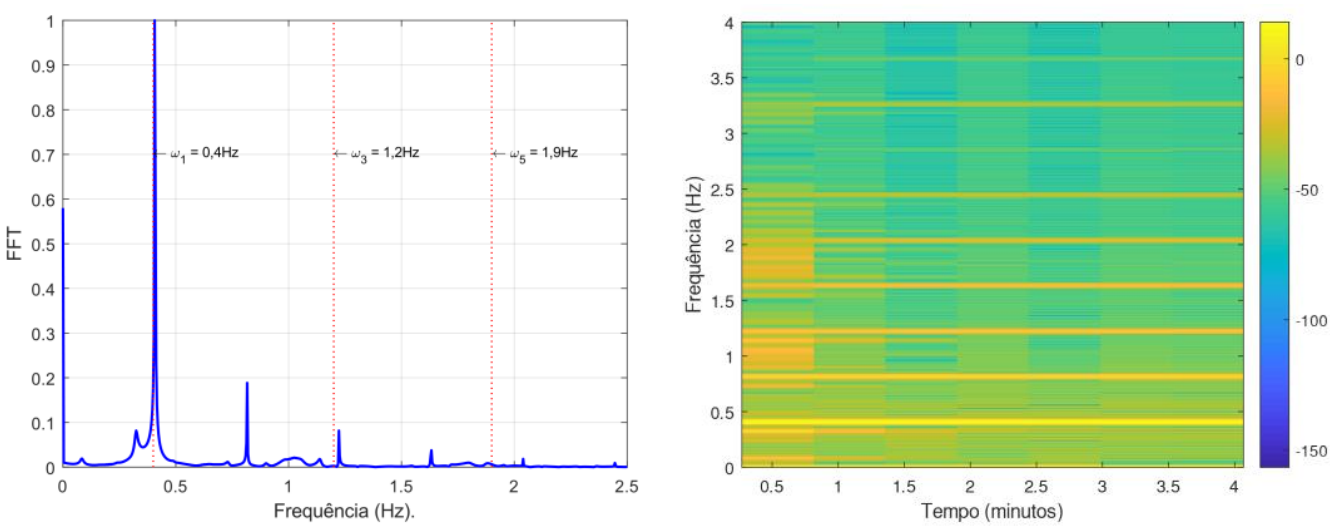

(h) $F=5 \mathrm{kN} / \mathrm{m} \operatorname{com} \beta=60^{\circ}$.
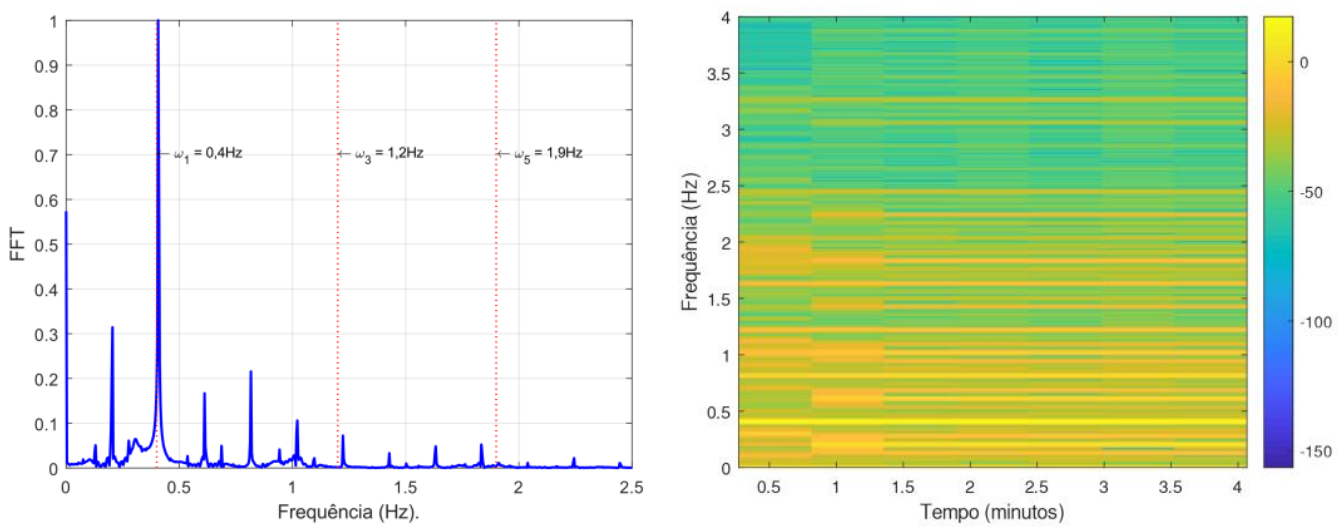

(i) $F=8 \mathrm{kN} / \mathrm{m} \operatorname{com} \beta=60^{\circ}$.

Figura 6.9 - Influência da magnitude da força na resposta do regime permanente para $\beta=60^{\circ}$, análise de frequências e análise espectral.

Para ilustrar o comportamento do sistema durante a fase transiente e permanente, mostra-se na Figura 6.10 a resposta no tempo dos deslocamentos nó do topo da torre nas direções X e Z, para os valores de carga de $2 \mathrm{kN} / \mathrm{m}, 4 \mathrm{kN} / \mathrm{m}, 5$ 
$\mathrm{kN} / \mathrm{m}$, e $8 \mathrm{kN} / \mathrm{m}$. Também são apresentadas as seções do mapa de Poincaré dos atratores caóticos, Figura 6.11.
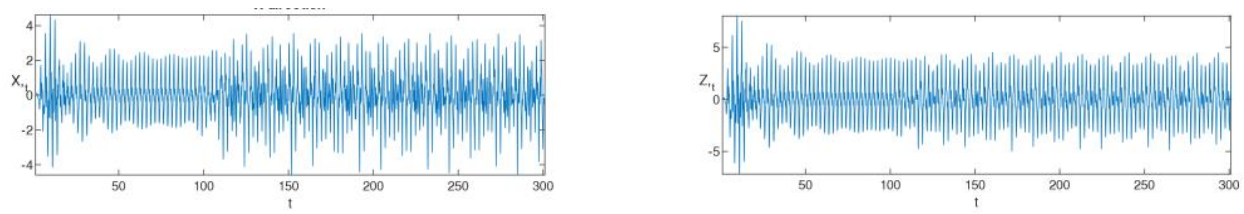

(a) $2 \mathrm{kN} / \mathrm{m}$
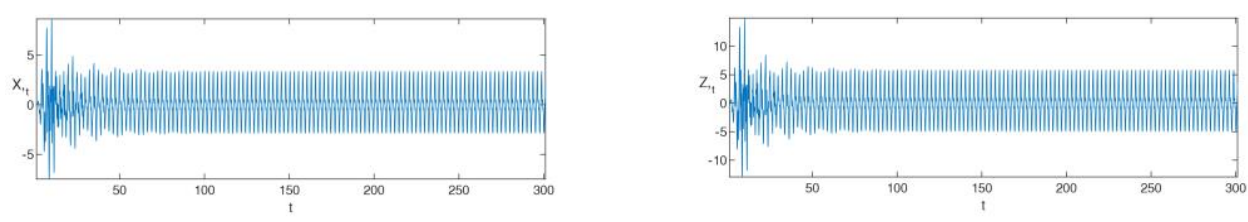

(b) $4 \mathrm{kN} / \mathrm{m}$
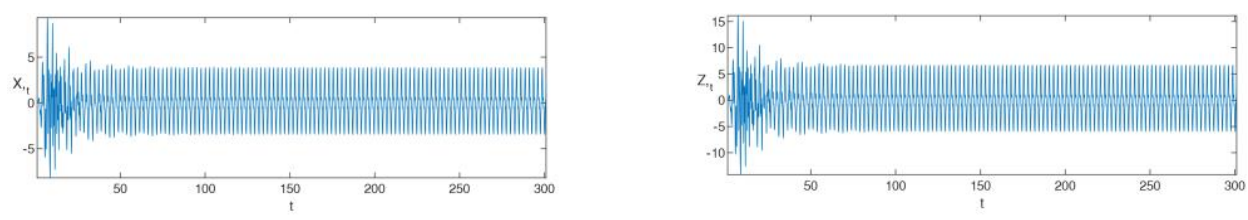

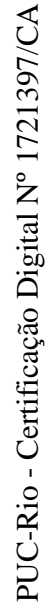

(c) $5 \mathrm{kN} / \mathrm{m}$
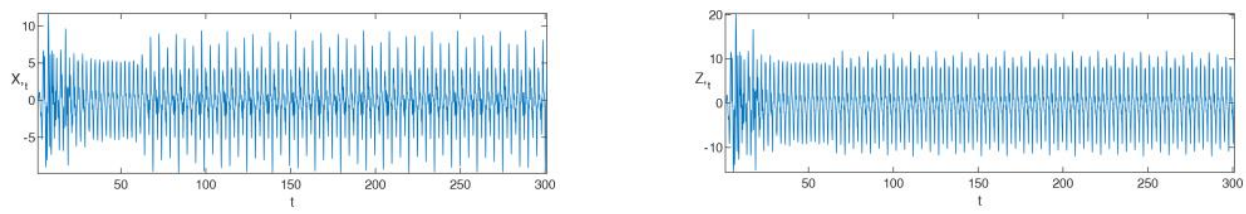

(d) $8 \mathrm{kN} / \mathrm{m}$

Figura 6.10 - Resposta no tempo nos eixos X e Z.

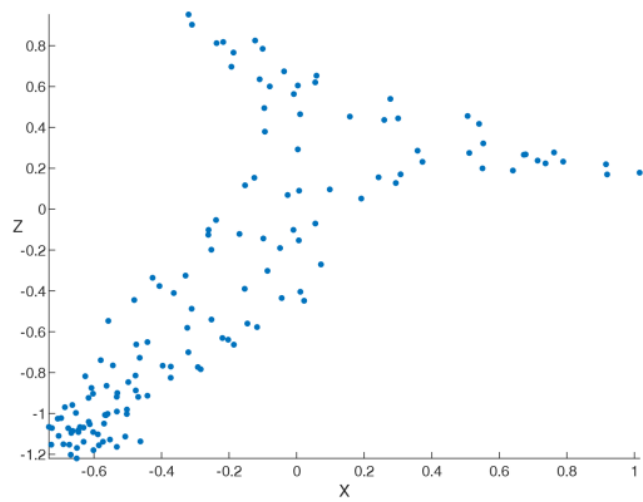

(a) $2 \mathrm{kN} / \mathrm{m}$

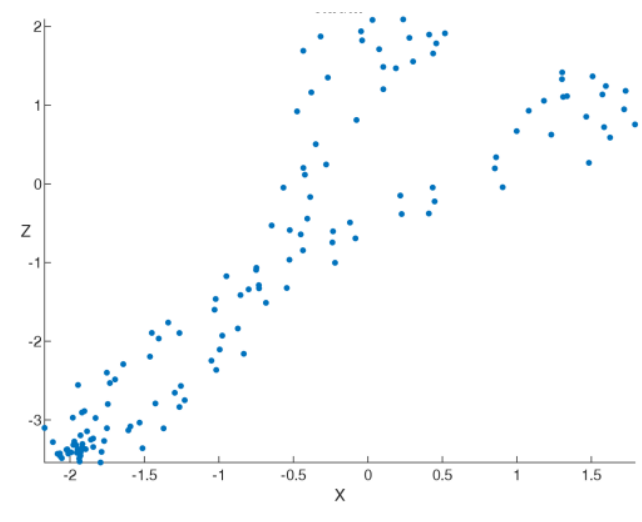

(b) $8 \mathrm{kN} / \mathrm{m}$

Figura 6.11 - Seções de mapeamento de Poincaré, plano XZ, dos atratores caóticos, para $\beta=60^{\circ}$.

Para entender melhor o aumento da complexidade da resposta do regime estacionário, são apresentados os planos de fase relacionando velocidade e 
deslocamento, para todos os níveis de carga abordados nesse estudo, Figura 6.12. Nota-se que para o nível de até $0,1 \mathrm{kN} / \mathrm{m}$ o sistema apresenta uma projeção elipsoidal, característica de uma resposta linear. Para um nível acima de $0,25 \mathrm{kN} / \mathrm{m}$, a presença de harmônicos mais elevados já é detectada na análise de Fourier juntamente com um aumento significativo na amplitude de vibração e na geometria da projeção até um carregamento de $2 \mathrm{kN} / \mathrm{m}$, onde se observa claramente o comportamento caótico. Para cargas de $4 \mathrm{kN} / \mathrm{m}$ e $5 \mathrm{kN} / \mathrm{m}$ obtém-se novamente uma resposta regular, voltando a ser caótica para uma carga de $8 \mathrm{kN} / \mathrm{m}$. Esta sequência mostra que a torre apresenta uma série de bifurcações à medida que cresce o carregamento.

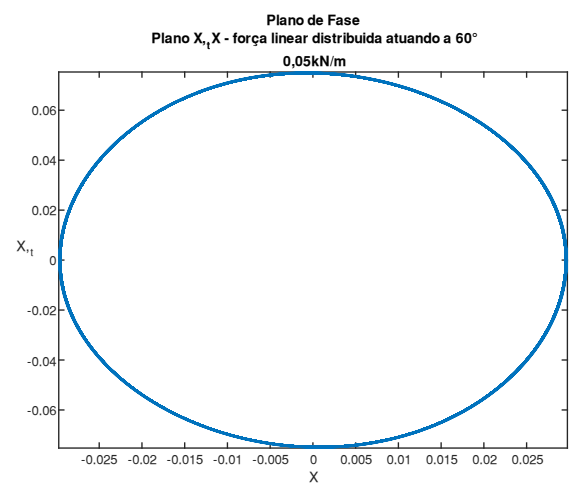

(a) $F=0,05 \mathrm{kN} / \mathrm{m} \operatorname{com} \beta=60^{\circ}$.

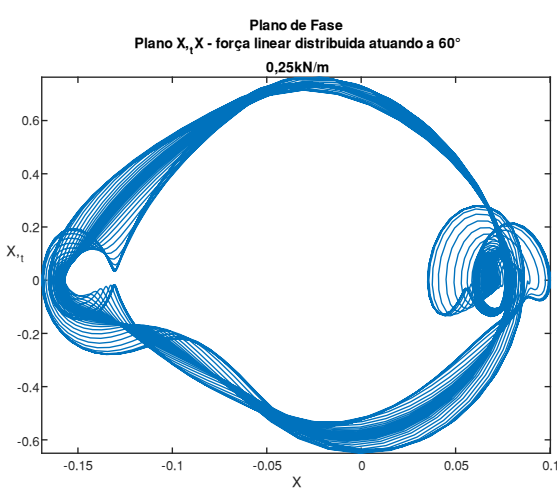

(c) $F=0,25 \mathrm{kN} / \mathrm{m} \operatorname{com} \beta=60^{\circ}$.

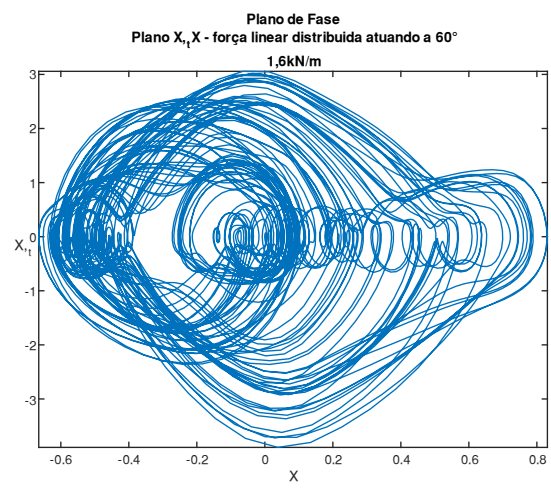

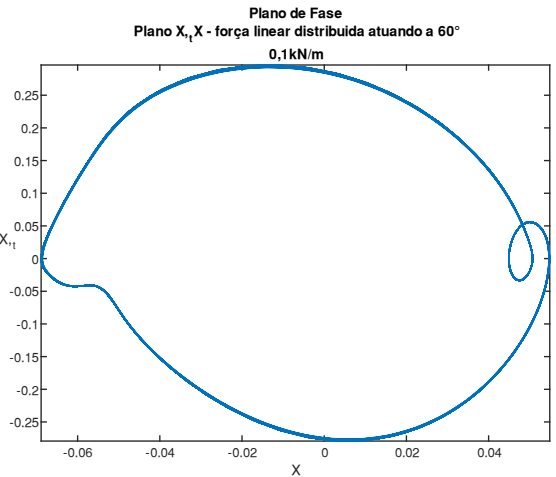

(b) $F=0,1 \mathrm{kN} / \mathrm{m} \operatorname{com} \beta=60^{\circ}$.

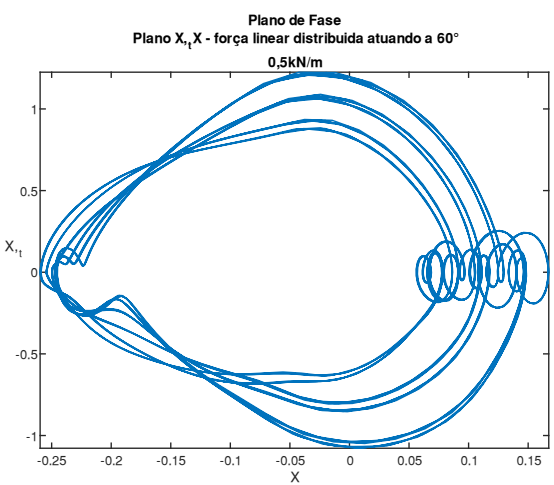

(d) $F=0,5 \mathrm{kN} / \mathrm{m} \operatorname{com} \beta=60^{\circ}$.

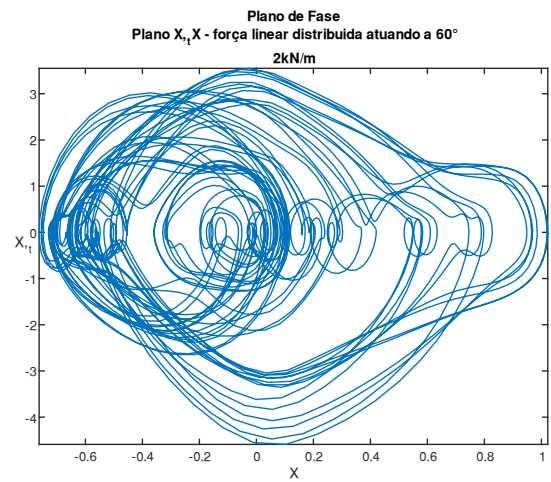


(e) $F=1,6 \mathrm{kN} / \mathrm{m} \operatorname{com} \beta=60^{\circ}$.

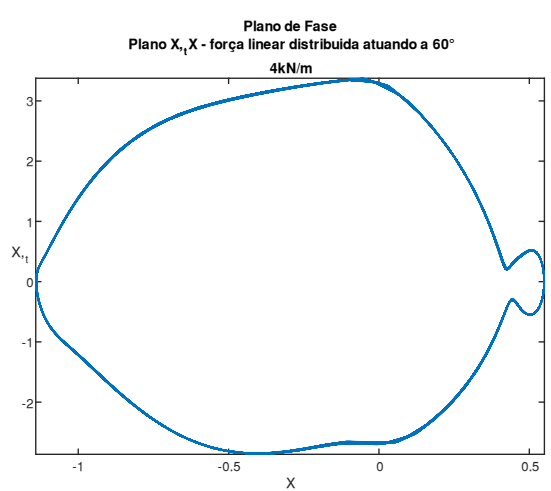

(g) $F=4 \mathrm{kN} / \mathrm{m} \operatorname{com} \beta=60^{\circ}$. Plano de Fase
Plano $X, \mathrm{X}$ - força linear distribuida atuando a $60^{\circ}$

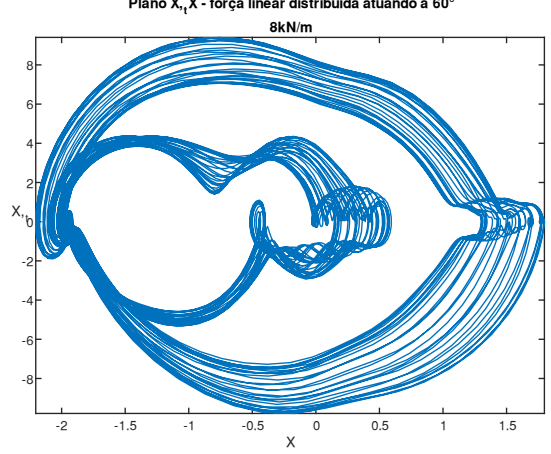

(i) $F=8 \mathrm{kN} / \mathrm{m} \operatorname{com} \beta=60^{\circ}$.

Figura 6.12 - Planos de fase relacionado velocidade $x$ deslocamento eixo X.

\subsubsection{3.}

\section{Vibração forçada amortecida - Pequenas perturbações}

Para verificar como a resposta obtida para $\beta=0^{\circ}$ se comporta na presença de perturbações, considera-se uma carga lateral de $2 \mathrm{kN} / \mathrm{m}$ com uma inclinação de $2^{\circ}$ e $5^{\circ}$. A resposta obtida foi similar à resposta a $0^{0}$, com comportamento caótico, como ilustra a Figura 6.13.
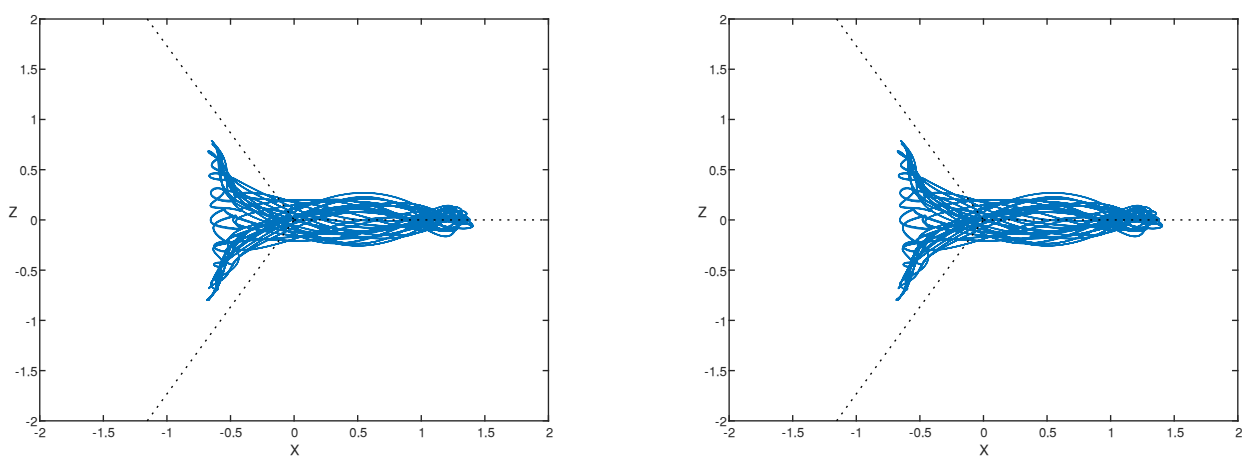

(a) $F=2 \mathrm{kN} / \mathrm{m} \operatorname{com} \beta=0^{\circ} \mathrm{e}$
(b) $F=2 \mathrm{kN} / \mathrm{m} \operatorname{com} \beta=0^{\circ} \mathrm{e}$ perturbação a $2^{\circ}$. perturbação a $5^{\circ}$.

Figura 6.13 - Resposta do regime estacionário para $\beta=0^{\circ}$ e $F=2 \mathrm{kN} / \mathrm{m}$ considerando uma perturbação de $2^{\circ}$ e $5^{\circ}$.

\subsubsection{4.}

\section{Comportamento caótico da torre}

Para verificar a consistência dos resultados obteve-se para $\beta=0^{\circ}$. a solução permanente não linear para os mesmos níveis de carregamento foram aplicados para $\beta=60^{\circ}$ Nas Figura 6.14, Figura 6.15, Figura 6.16, são apresentados os planos de fase no plano XZ, os espectros de frequência e espectrogramas, bem como os planos de fase e o mapeamento de Poincaré dos resultados. Observa-se a mesma sequência de bifurcações detectada para $\beta=60^{\circ}$

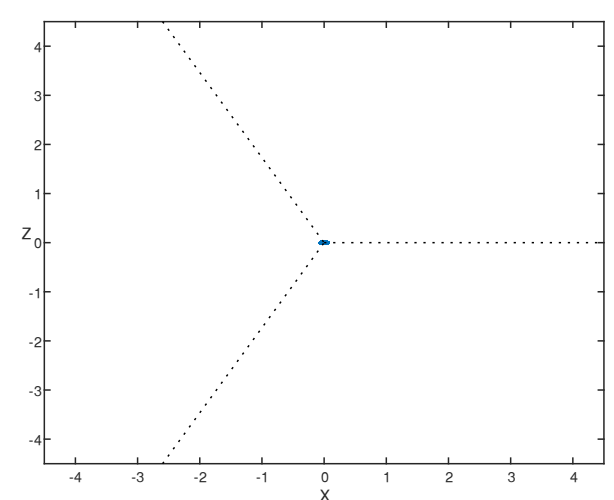

(a) $F=0,05 \mathrm{kN} / \mathrm{m} \operatorname{com} \beta=0^{\circ}$.

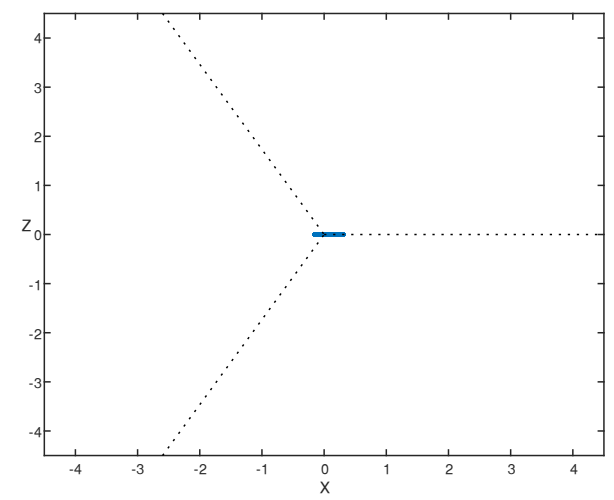

(c) $F=0,25 \mathrm{kN} / \mathrm{m} \operatorname{com} \beta=0^{\circ}$.

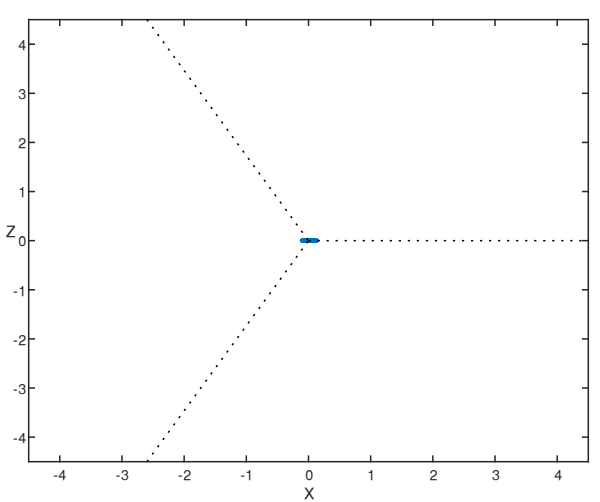

(b) $F=0,1 \mathrm{kN} / \mathrm{m} \operatorname{com} \beta=0^{\circ}$.

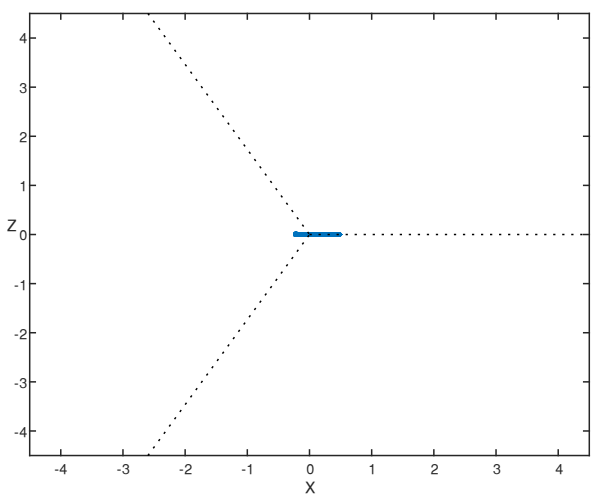

(d) $F=0,5 \mathrm{kN} / \mathrm{m} \operatorname{com} \beta=0^{\circ}$. 


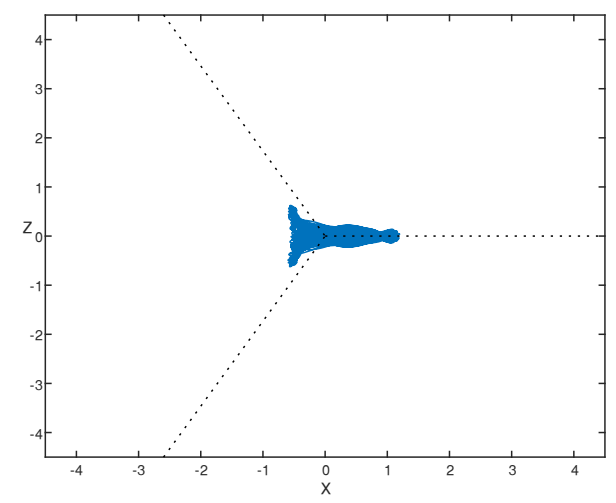

(e) $F=1,6 \mathrm{kN} / \mathrm{m} \operatorname{com} \beta=0^{\circ}$.

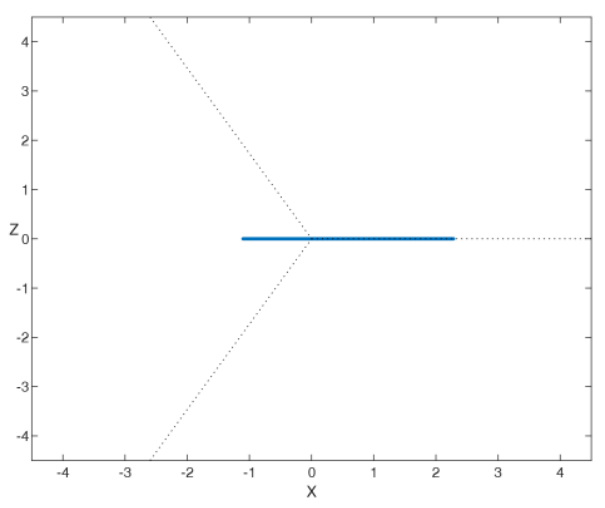

(g) $F=4 \mathrm{kN} / \mathrm{m} \operatorname{com} \beta=0^{\circ}$.

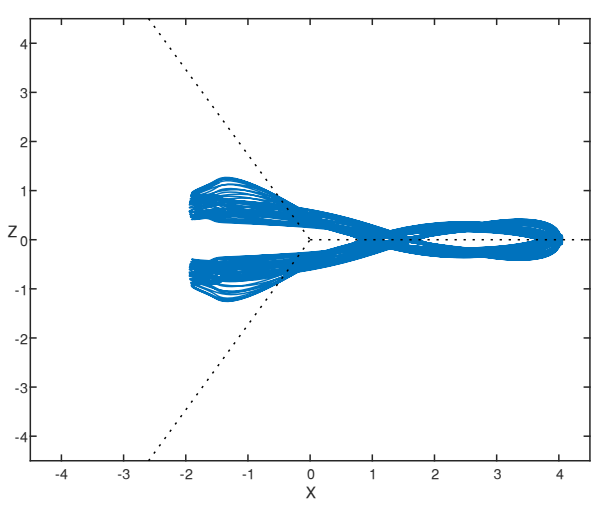

(i) $F=8 \mathrm{kN} / \mathrm{m} \operatorname{com} \beta=0^{\circ}$.

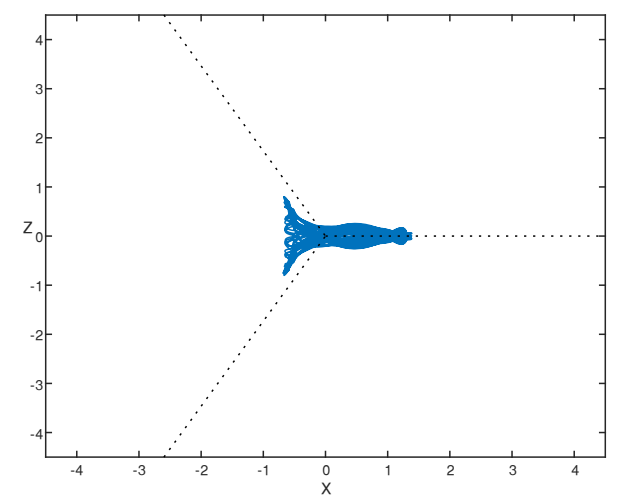

(f) $F=2 \mathrm{kN} / \mathrm{m} \operatorname{com} \beta=0^{\circ}$.

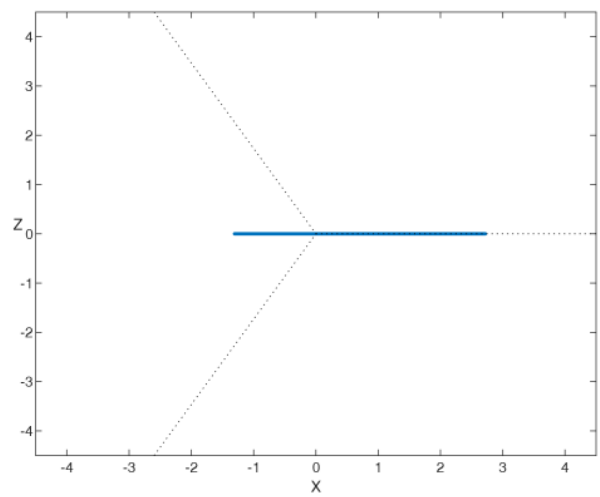

(h) $F=5 \mathrm{kN} / \mathrm{m} \operatorname{com} \beta=0^{\circ}$.

Figura 6.14 - Influência da magnitude da força na resposta do regime permanente com $\beta=0^{\circ}$, plano de fase XZ. 

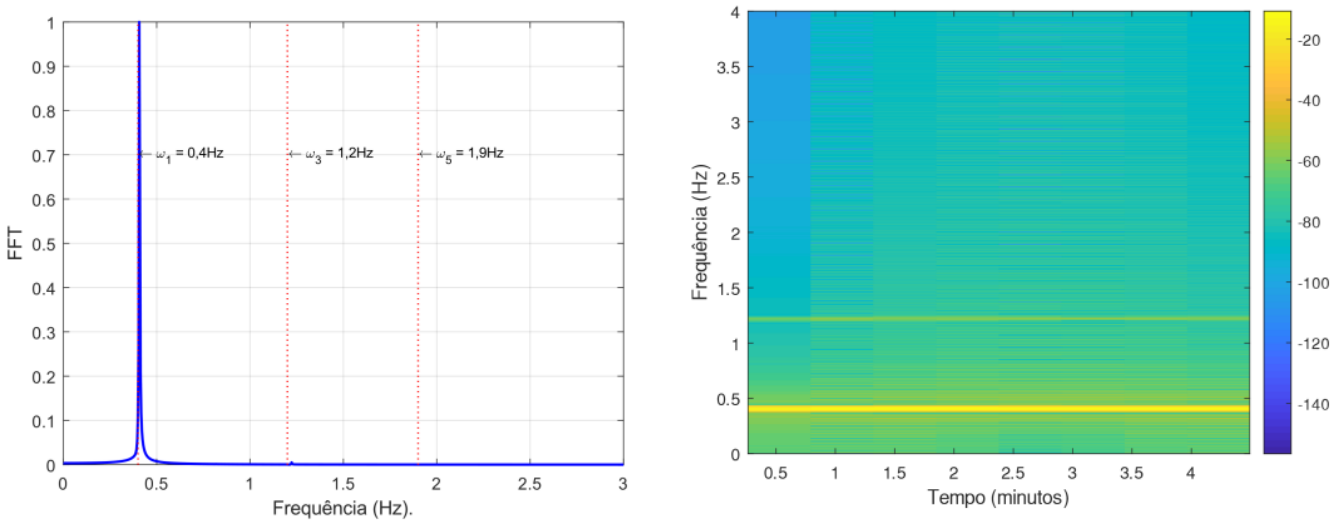

(a) $F=0,05 \mathrm{kN} / \mathrm{m} \operatorname{com} \beta=0^{\circ}$.
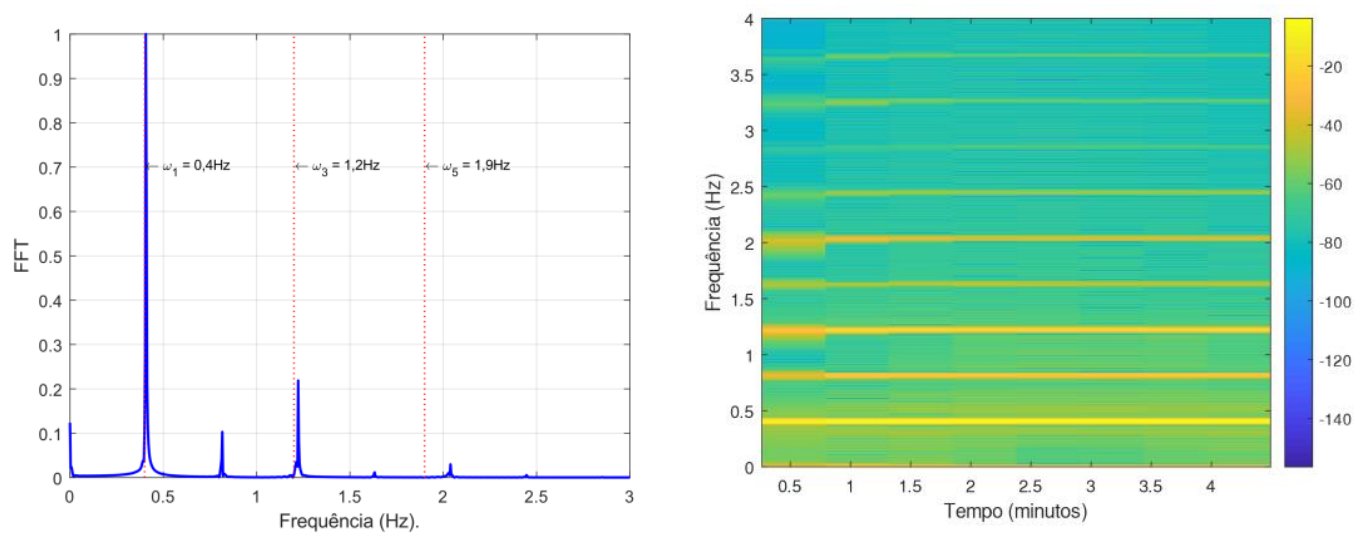

(b) $F=0,1 \mathrm{kN} / \mathrm{m} \operatorname{com} \beta=0^{\circ}$.
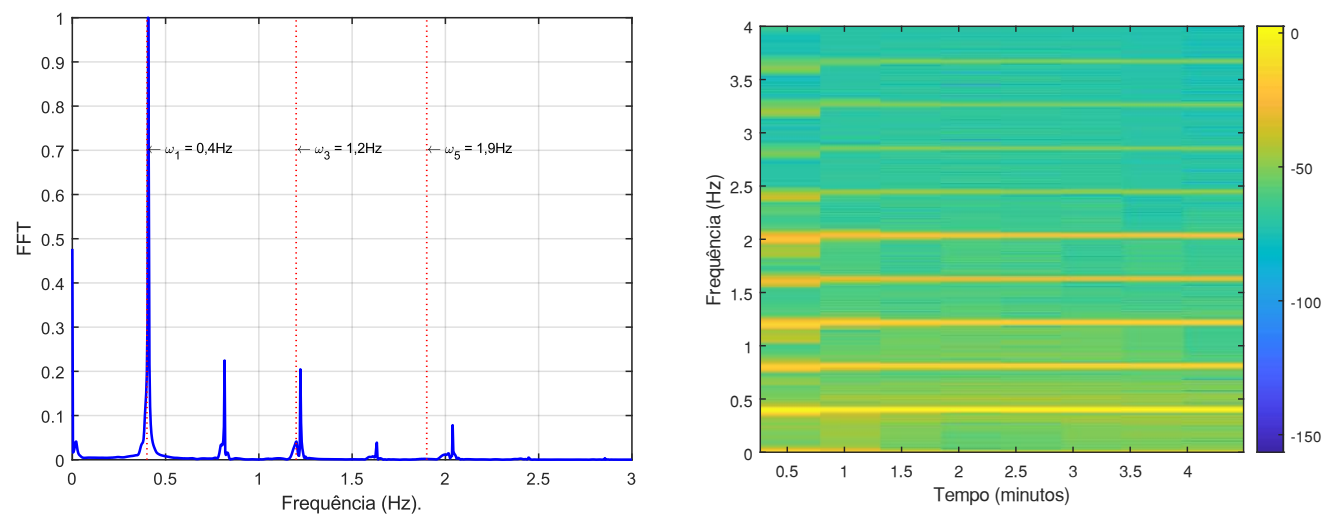

(c) $F=0,25 \mathrm{kN} / \mathrm{m} \operatorname{com} \beta=0^{\circ}$. 

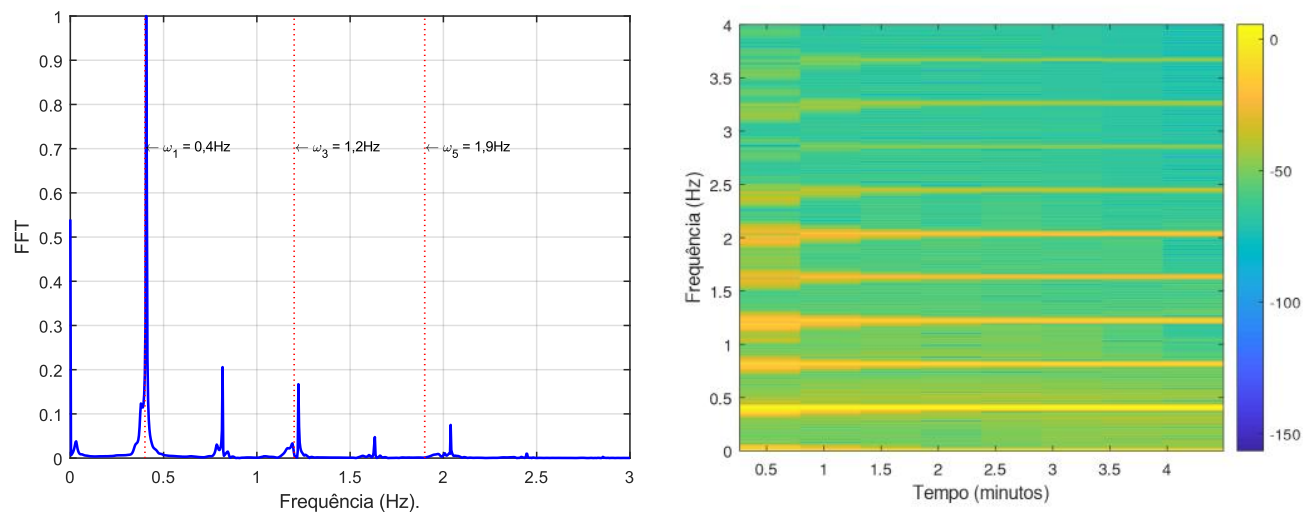

(d) $F=0,5 \mathrm{kN} / \mathrm{m} \operatorname{com} \beta=0^{\circ}$.
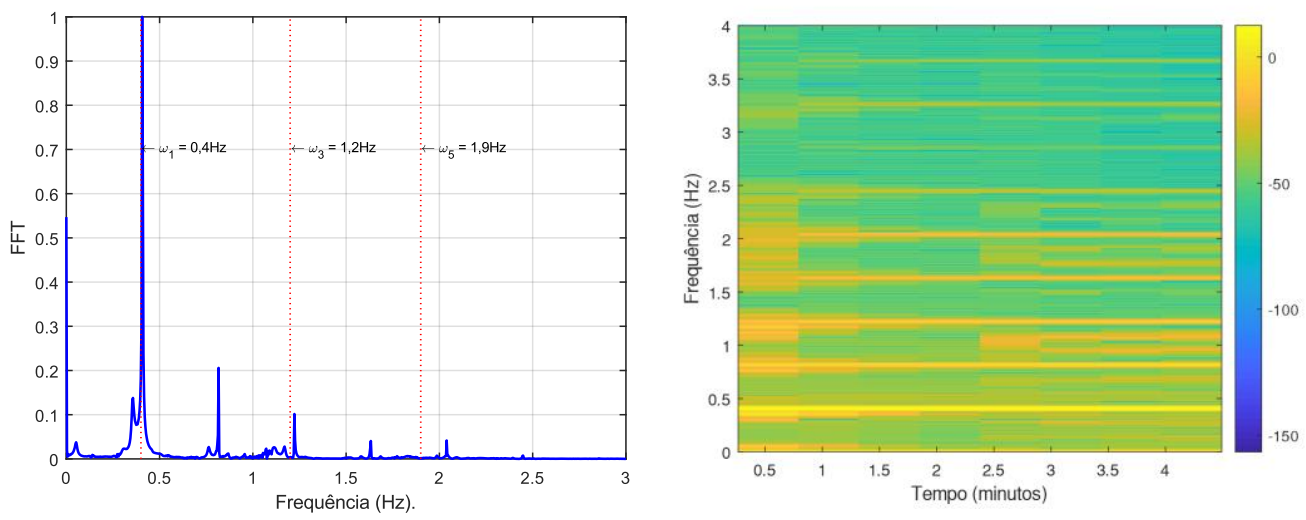

(e) $F=1,6 \mathrm{kN} / \mathrm{m} \operatorname{com} \beta=0^{\circ}$.
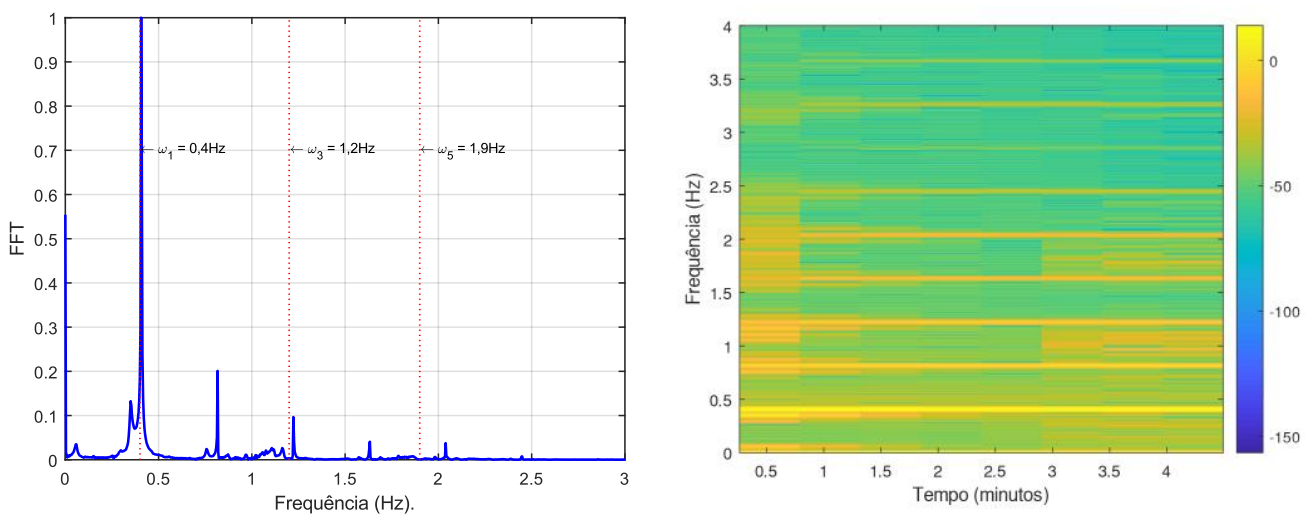

(f) $F=2 \mathrm{kN} / \mathrm{m} \operatorname{com} \beta=0^{\circ}$. 

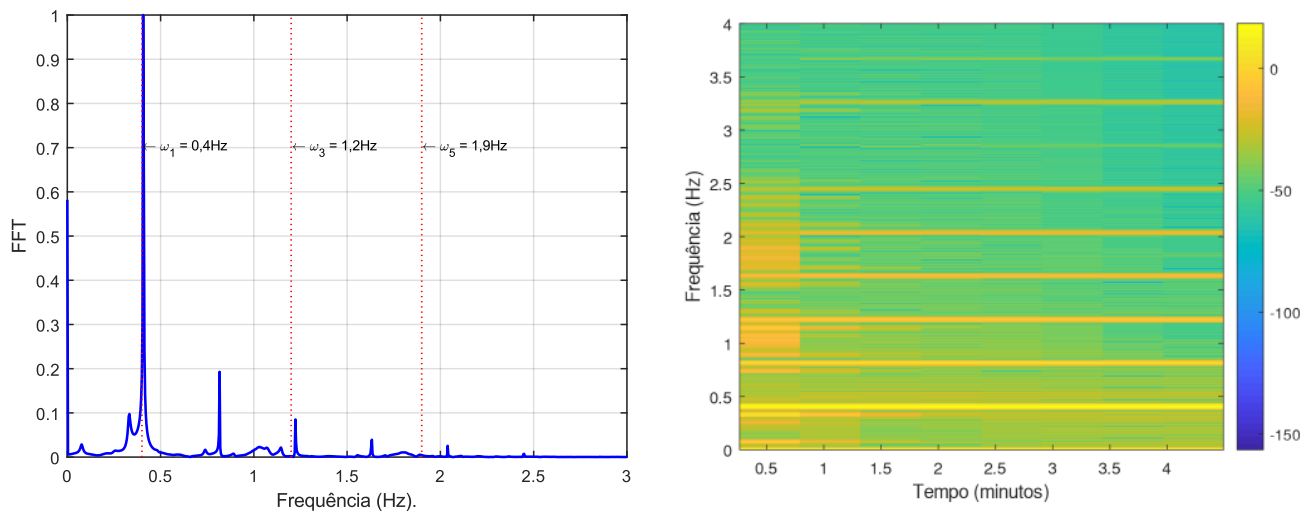

(g) $F=4 \mathrm{kN} / \mathrm{m} \operatorname{com} \beta=0^{\circ}$.
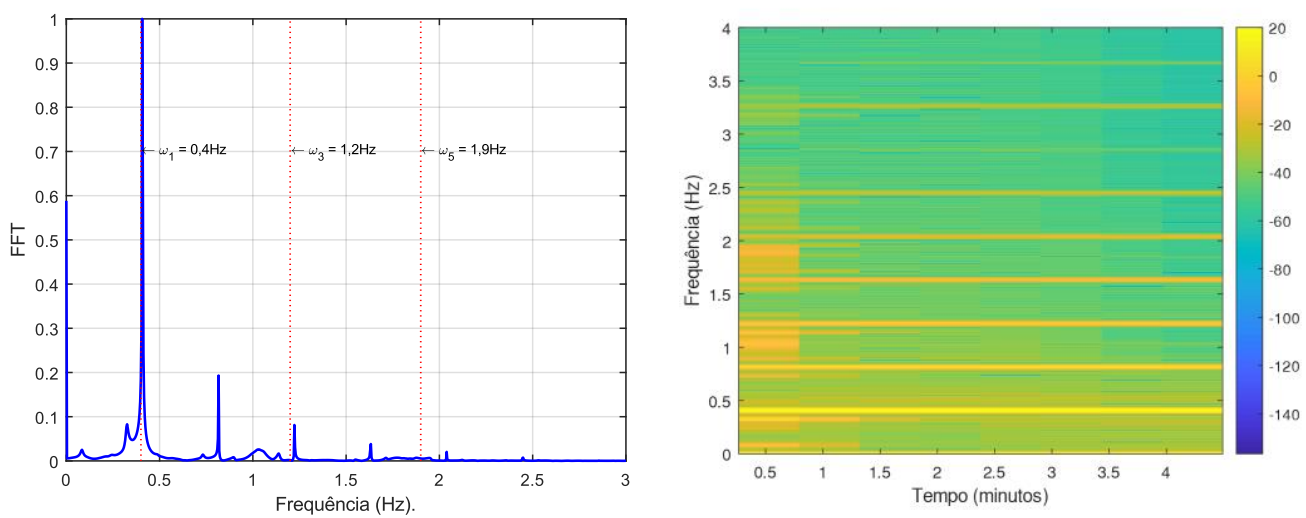

(h) $F=5 \mathrm{kN} / \mathrm{m} \operatorname{com} \beta=0^{\circ}$.
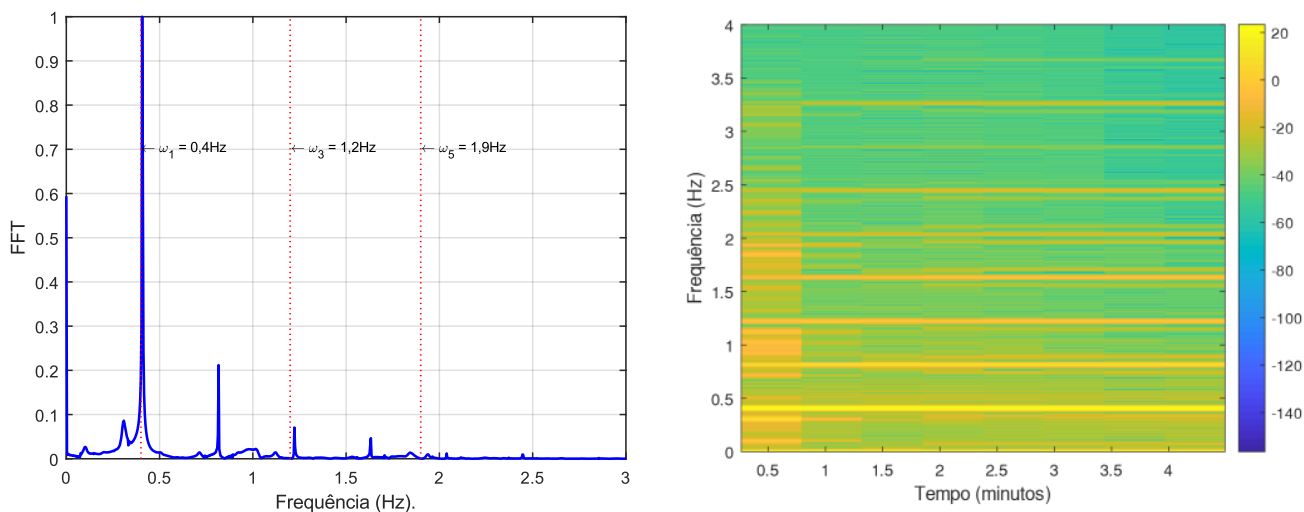

(i) $F=8 \mathrm{kN} / \mathrm{m} \operatorname{com} \beta=0^{\circ}$.

Figura 6.15 - Influência da magnitude da força na resposta permanente $\operatorname{com} \beta=0^{\circ}$, análise de frequências e análise espectral. 


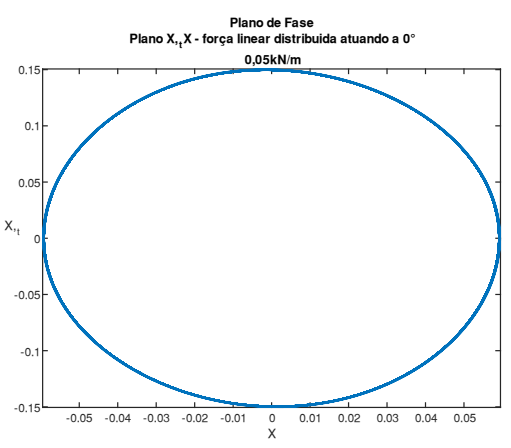

(a) $F=0,05 \mathrm{kN} / \mathrm{m} \operatorname{com} \beta=0^{\circ}$.

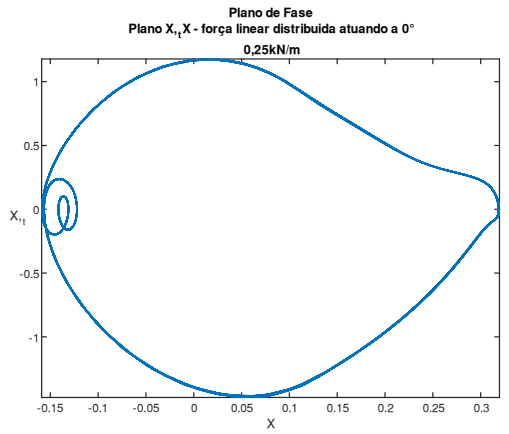

(c) $F=0,25 \mathrm{kN} / \mathrm{m} \operatorname{com} \beta=0^{\circ}$.

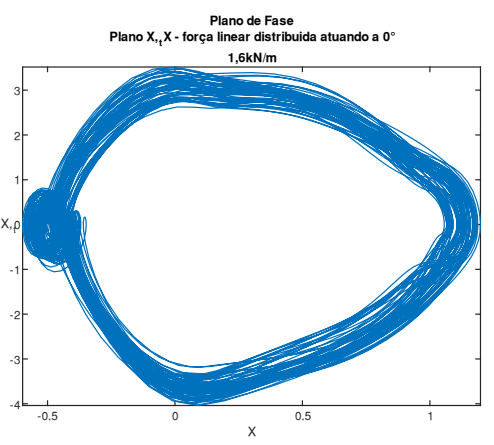

(e) $F=1,6 \mathrm{kN} / \mathrm{m} \operatorname{com} \beta=0^{\circ}$.

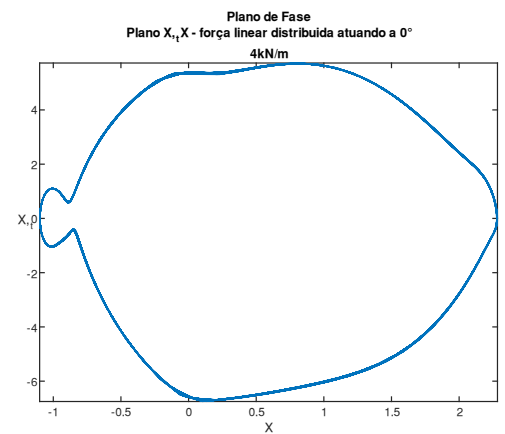

(g) $F=4 \mathrm{kN} / \mathrm{m} \operatorname{com} \beta=0^{\circ}$.

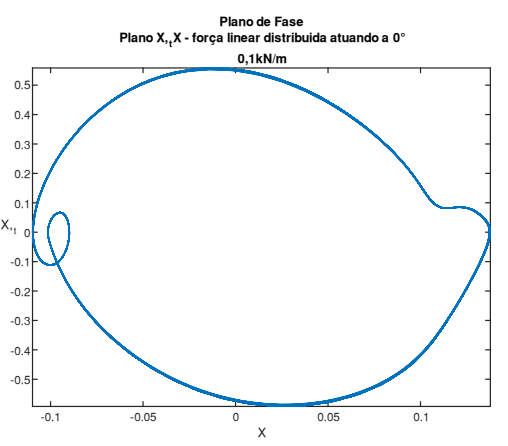

(b) $F=0,1 \mathrm{kN} / m \operatorname{com} \beta=0^{\circ}$.

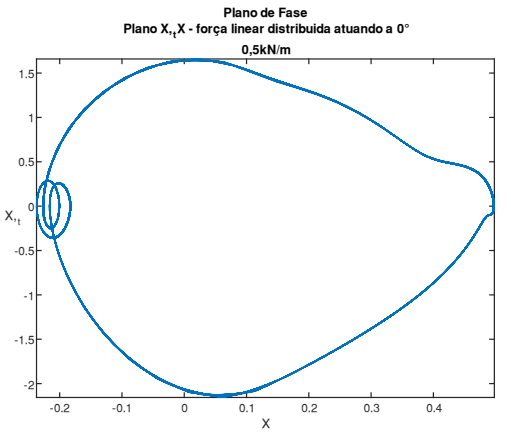

(d) $F=0,5 \mathrm{kN} / \mathrm{m} \operatorname{com} \beta=0^{\circ}$.

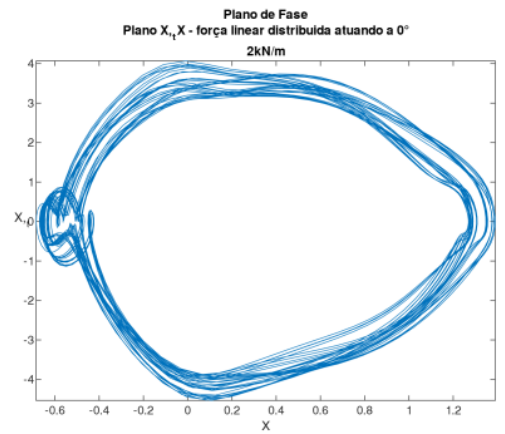

(f) $F=2 \mathrm{kN} / \mathrm{m} \operatorname{com} \beta=0^{\circ}$.

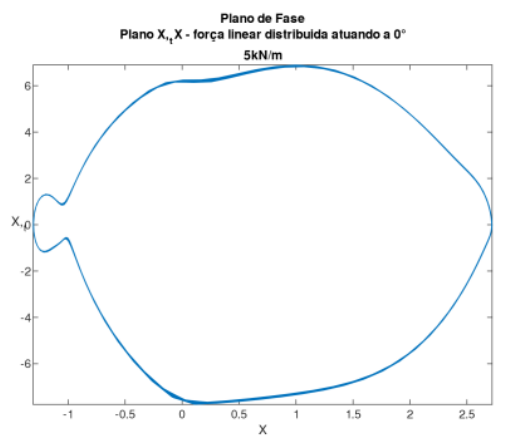

(h) $F=5 \mathrm{kN} / \mathrm{m} \operatorname{com} \beta=0^{\circ}$. 


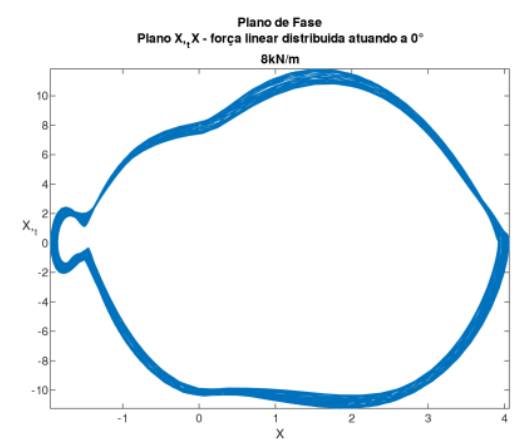

(i) $F=8 \mathrm{kN} / \mathrm{m} \operatorname{com} \beta=0^{\circ}$.

Figura 6.16 - Planos de fase velocidade $x$ deslocamento no eixo X, para regime permanente com

$$
\beta=0^{\circ} \text {. }
$$

\subsubsection{5.}

\section{Comportamento acoplado do movimento}

Como pode-se observar ao longo das análises desenvolvidas, a estrutura estaiada com um nível de estais apresenta um comportamento caótico em função da magnitude e da direção de aplicação do carregamento. Para um melhor entendimento desse comportamento, foram realizadas análises para ângulo $\beta=0^{\circ}$ e $\beta=60^{\circ}$. Entretanto, essas direções são correspondentes às direções dos cabos.

Um estudo do comportamento da estrutura para um carregamento forçado a $30^{\circ}$ para uma carga de $2 \mathrm{kN} / \mathrm{m}$, seção 6.4.1.1, apresentou um movimento acoplado do topo da torre, evidenciando a influência dos modos normais não-lineares no comportamento. Apresenta-se aqui os resultados para $50 \mathrm{kN} / \mathrm{m}, 500 \mathrm{kN} / \mathrm{m}$ e $8 \mathrm{kN} / \mathrm{m}$. A Figura 6.17, apresenta o movimento do topo da torre no plano XZ. Adicionalmente, é apresentada a resposta da torre obtida por FFT para esses carregamentos.

O movimento acoplado do topo da torre apresenta, para pequenas magnitudes de força um comportamento praticamente linear, tendo a FFT apenas um pico coincidente com a primeira frequência natural. Porém, à medida que a magnitude do carregamento aumenta, observa-se que o movimento passa a ser mais influenciado por dois modos normais não lineares, com a torre movendo-se alternadamente na direção de dois cabos com três frequências dominantes na resposta do sistema. Para uma magnitude de $8 \mathrm{kN} / \mathrm{m}$ o movimento passa a ser caótico, mas mostrando ainda um movimento predominante nos sentidos de dois dos cabos. 

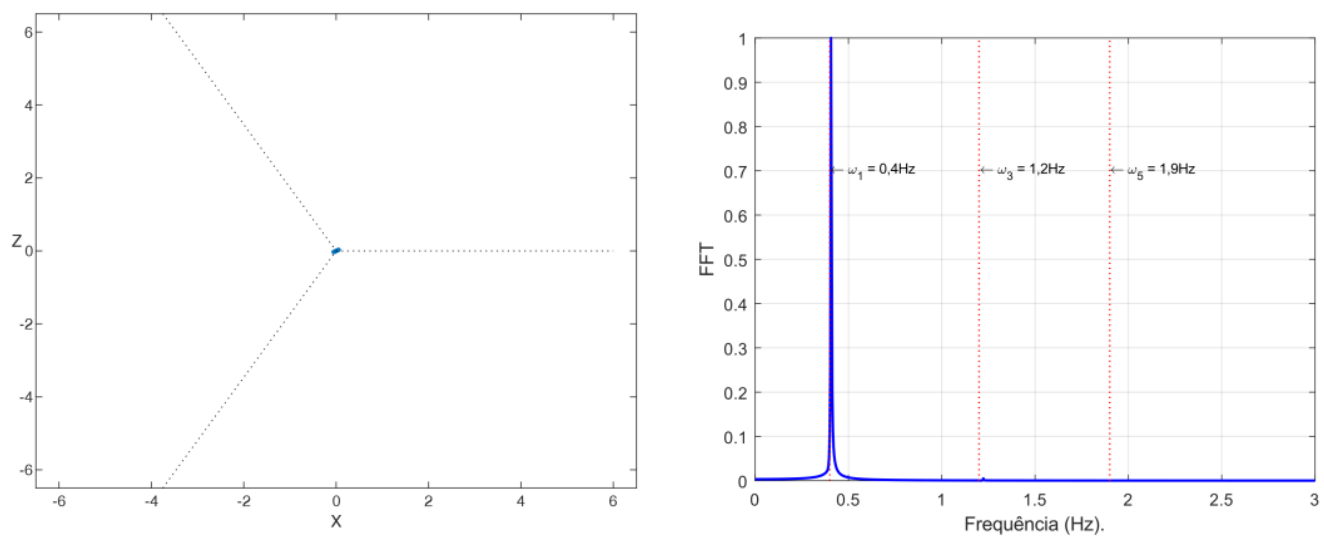

(a) $F=0,05 \mathrm{kN} / \mathrm{m} \operatorname{com} \beta=30^{\circ}$.
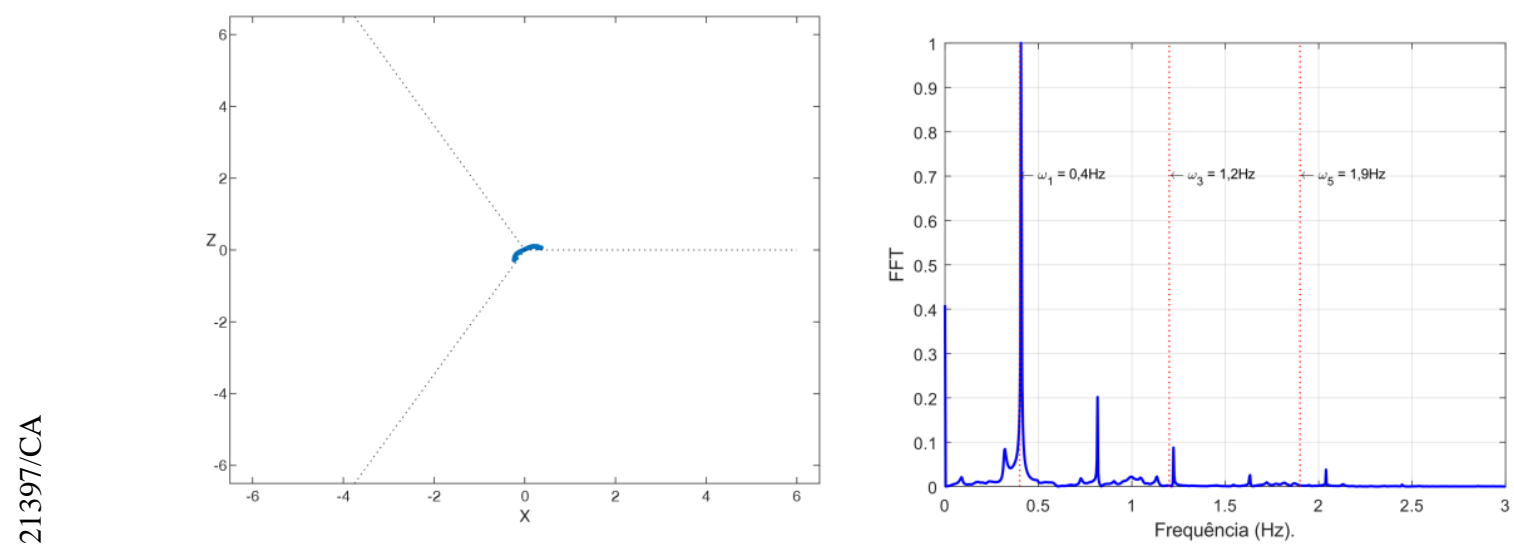

(b) $F=0,5 \mathrm{kN} / \mathrm{m} \operatorname{com} \beta=30^{\circ}$.
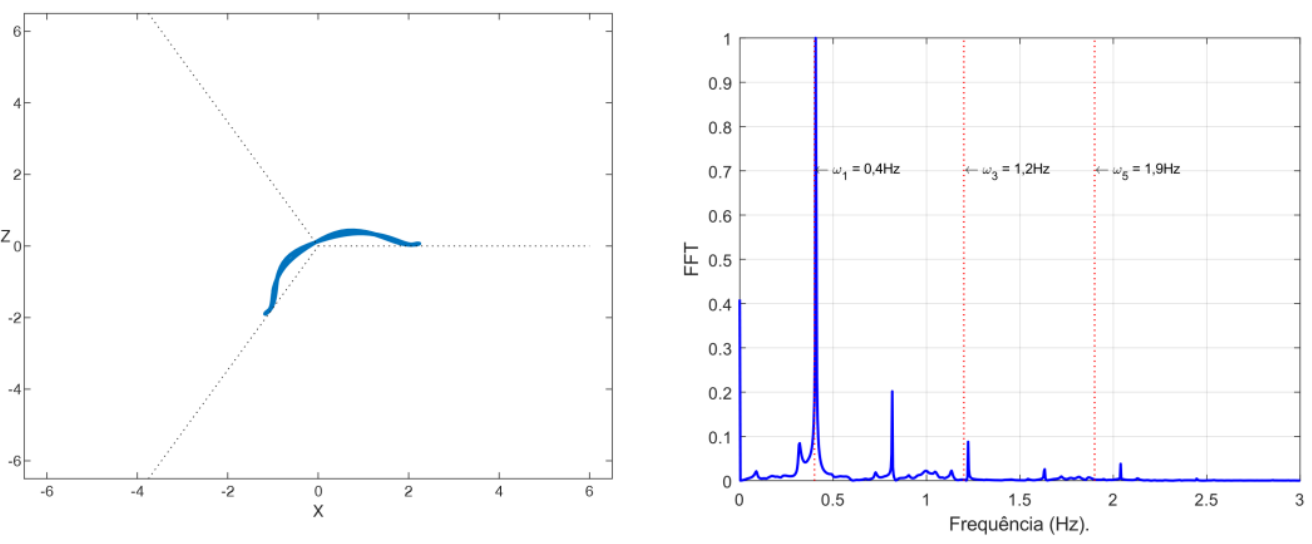

(c) $F=5 \mathrm{kN} / \mathrm{m} \operatorname{com} \beta=30^{\circ}$. 

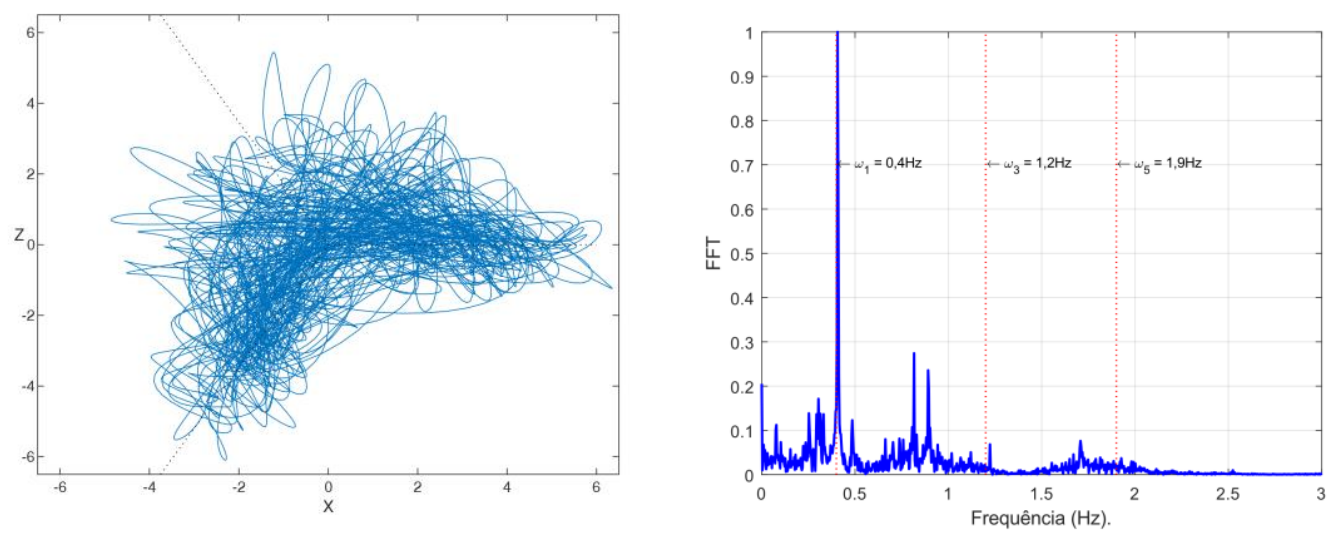

(d) $F=8 \mathrm{kN} / \mathrm{m} \operatorname{com} \beta=30^{\circ}$.

Figura 6.17 - Influência da magnitude da força na resposta do regime permanente com $\beta=30^{\circ}$, plano de fase XZ e análise de frequências. 


\section{7}

\section{Estudo de caso}

\section{1. Introdução}

Para fins de comparação dos resultados obtidos a partir das investigações dos modelos sintéticos desenvolveram-se algumas análises em uma torre estaiadas com vários níveis de cabos adaptada de uma torre real, denominada neste trabalho de "modelo real".

O modelo de torre real representa uma torre treliçada de seção triangular, com dez níveis de estais. Para efeitos de simplificação do modelo e para uma melhor comparação com o modelo sintético padrão, desenvolveu-se um modelo equivalente para essa torre treliçada. Para o desenvolvimento do modelo equivalente primeiro modelou-se a torre completa sem os estais no ABAQUS e, após análises estáticas de compressão axial, flexão e torção foi possível determinar uma seção equivalente e uma densidade equivalente, possibilitando gerar um modelo de viga-coluna para representação do mastro central da torre.

\subsection{1. Modelo Treliçado}

A torre é composta por uma estrutura treliçada triangular com altura de $93 \mathrm{~m}$, Figura 7.1. Todos os elementos possuem seções circulares, os verticais seções vazadas e as diagonais e barras horizontais seções cheias. Os elementos verticais são tubulares com diâmetro externo de 48,3 mm e espessura de 3,6 mm, [128]. As barras horizontais e diagonais da treliça possuem seção transversal de $12,7 \mathrm{~mm}$, [129]. As propriedades físicas dos elementos que compõe a torre são as mesmas para todos os elementos, com modulo de elasticidade (E) de $200 \mathrm{GPa}$, módulo de cisalhamento $(\mathrm{G})$ de $75 \mathrm{GPa}$ e densidade $(\rho)$ de $7850 \mathrm{~kg} / \mathrm{m}^{3}$. 


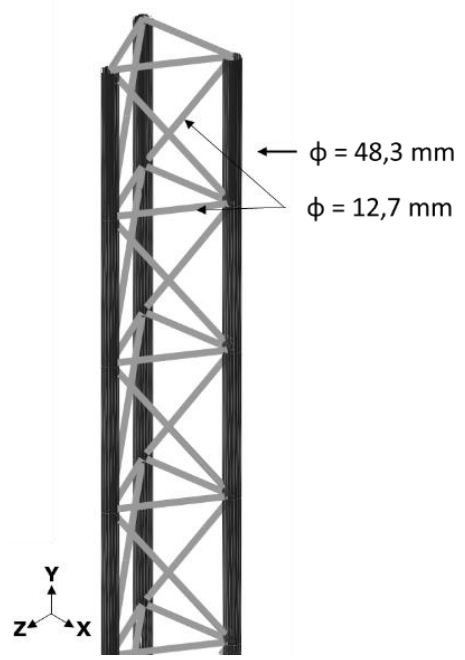

(a) Vista 3D da torre.

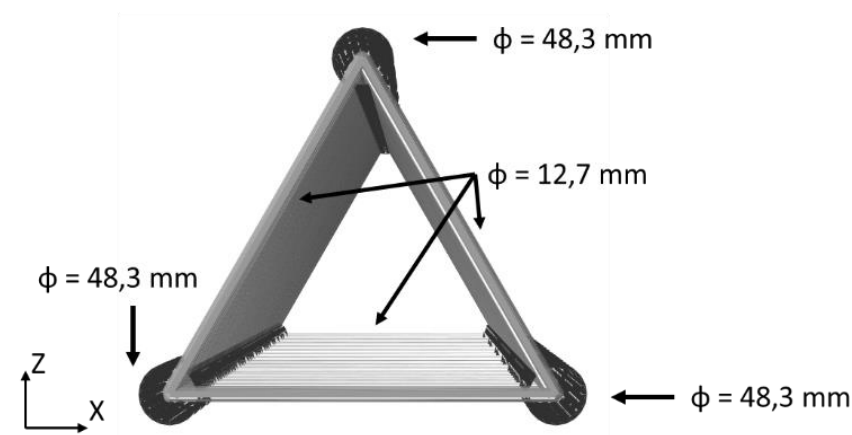

(b) Vista do topo da torre.

Figura 7.1 - Vistas da torre treliçada com indicações dos diâmetros dos elementos.

O modelo completo possui dez níveis de estais, espaçados a cada $9 \mathrm{~m}$ ao longo da altura, que são ancorados no solo em três bases a cada 17 m, Figura 7.2. Esta estrutura foi modelada no ABAQUS, com elementos de vigas tridimensionais para as barras verticais e de treliça para as demais barras. Quanto à discretização destes elementos, cada trecho foi discretizado com 2 elementos. No primeiro momento os cabos não foram incluídos no modelo, visto que a ideia central da modelagem do mastro com todas as suas barras é a determinação de uma seção equivalente.

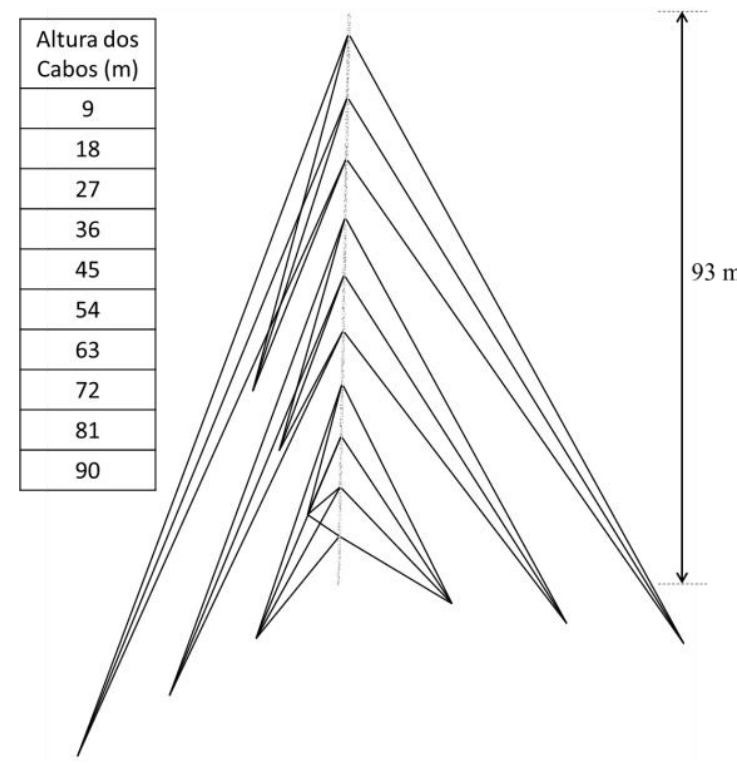

(a) Vista de perspectiva da torre completa

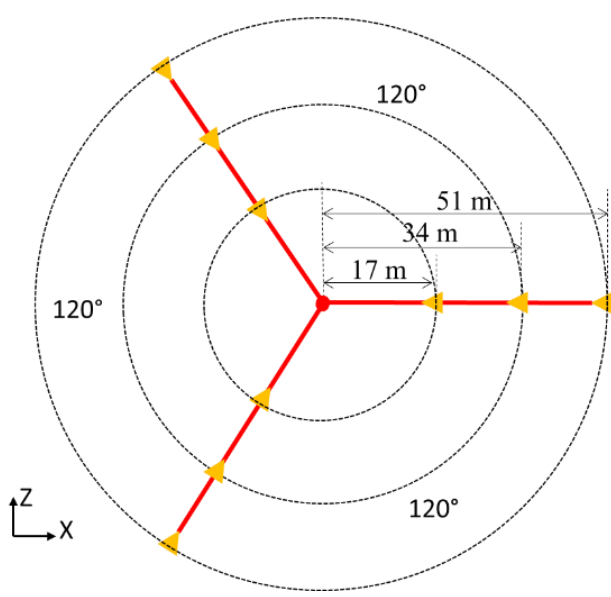

(b) Vista superior da torre

Figura 7.2 - Esquema de distribuição dos cabos ao longo da torre, (a) Distribuição vertical; (b) vista em planta. 


\subsection{2.}

\section{Desenvolvimento do modelo equivalente}

Como o modelo real é uma estrutura triangular composta por três componentes verticais, as cargas foram aplicadas em um nó no centro geométrico da seção plana no topo da estrutura, e esse nó transfere a carga para os nós de topo das barras verticais da treliça.

Para a determinação da área transversal equivalente foi aplicado uma carga axial de $1 \mathrm{~N}$ no baricentro da seção da torre e obteve-se os deslocamentos no eixo Y, ocasionados por essa carga, Figura 7.3(a). Em uma nova análise, ainda para o mesmo ponto foi aplicada uma carga concentrada de $1 \mathrm{~N}$, decomposta nas direções $\mathrm{X}$ e $\mathrm{Z}$ para que a resultante incidisse em uma das faces da torre. Com isso pode-se coletar os deslocamentos no eixo X e determinar o momento de inércia, Figura 7.3(b). Para determinação da inercia polar do modelo equivalente, aplicou-se no baricentro da seção um momento de 1N.m no eixo Y, Figura 7.3(c).

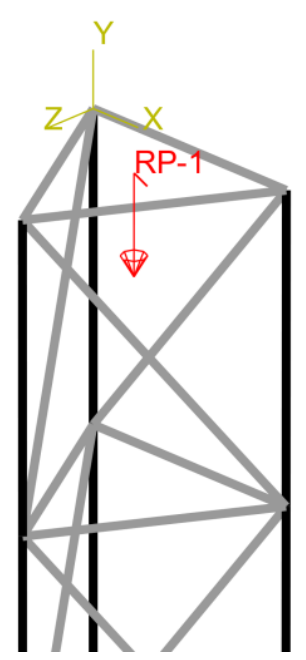

(a) Força vertical.

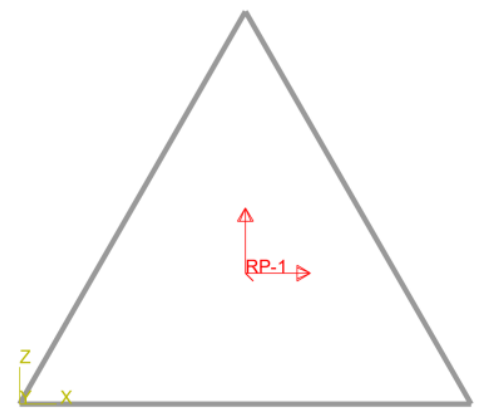

(b) Força horizontal, com componentes em X e Z,

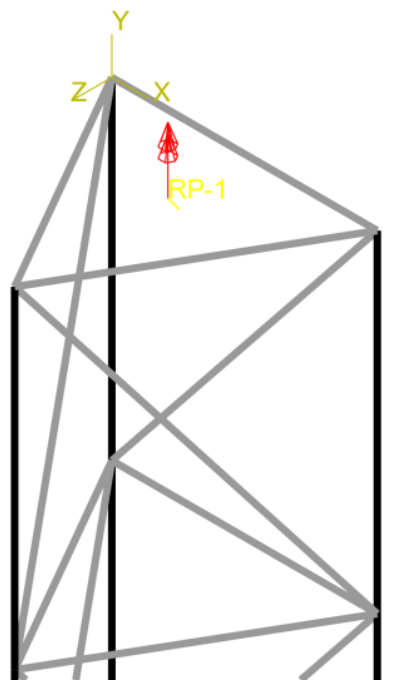

(c) Momento em Y.

Figura 7.3 - Ilustrações das forças e momento aplicados a estrutura para obtenção das propriedades equivalentes da seção.

O carregamento de compressão axial resultou em um deslocamento em Y de 2,98E-07 m; para a flexão o deslocamento foi de $0,058 \mathrm{~m}$ e para a de torção a rotação da torre foi de 4,94E-4 rad. O volume da estrutura, calculada pelo 
ABAQUS, foi de $0,22 \mathrm{~m}^{3}$. Relacionando estes valores e as propriedades da estrutura através das expressões

$$
\begin{gathered}
A_{e q}=P_{\text {Vertical }} L / L \delta_{\text {Vertical }} \\
I_{e q}=P_{\text {Horizontal }} L^{3} / 3 E \delta_{\text {Horizontal }} \\
J_{e q}=M L / G \Phi \\
\rho_{e q}=\rho V_{\text {real }} / A_{e q} L
\end{gathered}
$$

têm-se os valores apresentados na Tabela 7.1.

Tabela 7.1 - Propriedades geométricas para seção equivalente

\begin{tabular}{c|c|c}
\hline \multicolumn{3}{c}{ Seção equivalente } \\
\hline$A_{e q}$ & $1.561 \mathrm{E}-03$ & $\mathrm{~m}^{2}$ \\
$I_{e q}$ & $2.313 \mathrm{E}-05$ & $\mathrm{~m}^{4}$ \\
$J_{e q}$ & $2.509 \mathrm{E}-06$ & $\mathrm{~m}^{4}$ \\
$\rho_{e q}$ & $1.161 \mathrm{E}+04$ & $\mathrm{~kg} / \mathrm{m}^{3}$ \\
\hline
\end{tabular}

Logo, com as propriedades geométricas equivalentes e a densidade equivalente do modelo, pode-se desenvolver no ABAQUS um modelo de vigacoluna com uma seção genérica com estas propriedades e discretização de 93 elementos, ou seja, cada elemento tem um metro de comprimento.

As mesmas análises com cargas e momento unitário foram realizadas com o modelo equivalente. A Tabela 7.2 apesenta uma comparação entre o modelo equivalente e o modelo real. Os resultados obtidos para as análises efetuadas são idênticos, comprovando que o modelo equivalente possui o mesmo comportamento do modelo real.

Tabela 7.2 - Deslocamentos obtidos pelas análises para os dois modelos

\begin{tabular}{c|c|c}
\hline Deslocamentos & Real & Idealizado \\
\hline Axial $(\mathbf{m})$ & $2.98 \mathrm{E}-07$ & $2.98 \mathrm{E}-07$ \\
Transversal (m) & $5.80 \mathrm{E}-02$ & $5.80 \mathrm{E}-02$ \\
Rotação $(\mathbf{r a d})$ & $4.94 \mathrm{E}-04$ & $4.94 \mathrm{E}-04$ \\
\hline
\end{tabular}




\section{2.}

\section{Análise linear}

Análises estáticas e dinâmicas lineares foram desenvolvidas para o modelo equivalente e para o modelo real com e sem cabos, para verificar a compatibilidade entre modelos e também a influência dos cabos. Para essas análises foram aplicadas as mesmas metodologias utilizadas anteriormente neste trabalho.

Os cabos foram modelados como barras de treliça trabalhando apenas a tração. Estes cabos são cordoalhas de 7 fios com diâmetro de $6,35 \mathrm{~mm}$, densidade de $5683,75 \mathrm{~kg} / \mathrm{m}^{3}$, módulo de elasticidade de $147 \mathrm{GPa}$ e carga de ruptura $21,2 \mathrm{kN}$, o que corresponde a uma tensão de ruptura de $6,691 \mathrm{E}+05 \mathrm{kN} / \mathrm{m}^{2}$, [3, 4]. A pré-tensão utilizada para os cabos é de $10 \%$ da carga de ruptura.

\subsection{1.}

\section{Análise Estática Linear}

A análise de carga crítica desses modelos gera os resultados da Tabela 7.3. Pode-se observar que, com a presença dos cabos, os modelos passam a suportar mais carga, isto é, o valor da carga crítica do modelo aumenta conforme foi constatado nas análises da estrutura sintética com uma menor quantidade de estais. Observa-se que para a estrutura completa com cabos, o valor da carga crítica é quase 80 vezes maior a da estrutura sem cabos, algo semelhante acontece para o modelo equivalente. Mais uma vez devido à simetria do modelo os modos de flambagem e cargas críticas apresentam-se em pares.

Tabela 7.3 - Cargas Críticas para modelos reais e equivalentes com e sem cabos.

\begin{tabular}{c|c|c|c|c}
\hline \multicolumn{4}{c}{ Carga Crítica (kN) } \\
\hline \multirow{3}{*}{ Modos } & \multicolumn{4}{c}{ Modelos } \\
\cline { 2 - 5 } & $\begin{array}{c}\text { Real Sem } \\
\text { Cabos }\end{array}$ & $\begin{array}{c}\text { Real Com } \\
\text { Cabos }\end{array}$ & $\begin{array}{c}\text { Equivalente } \\
\text { Sem Cabos }\end{array}$ & $\begin{array}{c}\text { Equivalente } \\
\text { Com Cabos }\end{array}$ \\
\hline $\mathbf{1}$ & 1,32 & 106,41 & 1,32 & 101,93 \\
$\mathbf{2}$ & 1,32 & 106,41 & 1,32 & 101,93 \\
$\mathbf{3}$ & 11,87 & 258,53 & 11,88 & 261,40 \\
$\mathbf{4}$ & 11,87 & 258,53 & 11,88 & 261,40 \\
$\mathbf{5}$ & 32,89 & 284,89 & 32,99 & 285,89 \\
$\mathbf{6}$ & 32,89 & 284,89 & 32,99 & 285,89 \\
$\mathbf{7}$ & 64,24 & 341,50 & 64,63 & 348,71 \\
$\mathbf{8}$ & 64,24 & 341,50 & 64,63 & 348,71 \\
$\mathbf{9}$ & 105,73 & 367,36 & 106,80 & 424,20 \\
$\mathbf{1 0}$ & 105,73 & 414,21 & 106,80 & 424,20 \\
\hline
\end{tabular}


Da comparação entre cargas críticas dos modelos reais e modelos equivalentes, observam-se valores iguais para os mastros isolados e uma pequena diferença quando são considerados os cabos nos dois modelos, o que valida o emprego do modelo equivalente para os estudos subsequentes.

\subsection{2.}

\section{Análise Dinâmica}

Assim como para as análises estáticas lineares, pode-se desenvolver um estudo comparativo entre as frequências naturais para cada um dos modelos, Tabela 7.4. De modo análogo às análises dinâmicas lineares desenvolvidas no modelo sintético dos capítulos anteriores, nota-se que a presença dos cabos aumenta a rigidez da estrutura e, portanto, aumenta suas frequências naturais. Como a quantidade de níveis de cabos é elevada, observa-se que as frequências dos modelos com cabos são aproximadamente 49 vezes maiores que as do modelo sem cabos. As frequências também se apresentam em pares devido à simetria do modelo. Quando comparados modelos equivalentes e reais, tem-se que estes possuem frequências naturais na mesma ordem de grandeza e faixas de valores.

Tabela 7.4 - Frequências naturais para modelos reais e equivalentes com e sem cabos.

\begin{tabular}{c|c|c|c|c}
\hline \multicolumn{4}{c}{ Frequências Naturais (Hz) } \\
\hline \multirow{3}{*}{ Modos } & \multicolumn{4}{c}{ Modelos } \\
\cline { 2 - 5 } & $\begin{array}{c}\text { Real Sem } \\
\text { Cabos }\end{array}$ & $\begin{array}{c}\text { Real Com } \\
\text { Cabos }\end{array}$ & $\begin{array}{c}\text { Equivalente } \\
\text { Sem Cabos }\end{array}$ & $\begin{array}{c}\text { Equivalente } \\
\text { Com Cabos }\end{array}$ \\
\hline $\mathbf{1}$ & 0,0327 & 1,6099 & 0,0327 & 1,5857 \\
$\mathbf{2}$ & 0,0327 & 1,6732 & 0,0327 & 1,6359 \\
$\mathbf{3}$ & 0,2046 & 1,6732 & 0,2048 & 1,6359 \\
$\mathbf{4}$ & 0,2046 & 1,9145 & 0,2048 & 1,8729 \\
$\mathbf{5}$ & 0,5723 & 1,9145 & 0,5735 & 1,8729 \\
$\mathbf{6}$ & 0,5723 & 2,3507 & 0,5735 & 2,2904 \\
$\mathbf{7}$ & 1,1194 & 2,3507 & 1,1236 & 2,2904 \\
$\mathbf{8}$ & 1,1194 & 2,6458 & 1,1236 & 2,5399 \\
$\mathbf{9}$ & 1,7247 & 2,6458 & 1,5911 & 2,5399 \\
$\mathbf{1 0}$ & 1,8461 & 3,3617 & 1,8568 & 3,2273 \\
\hline
\end{tabular}

Um ponto a se ressaltar é que a primeira frequência natural das estruturas com cabos corresponde a um modo axial de vibração ocasionado pela compressão 
induzida pelos cabos. Os demais modos seguem o padrão convencional para uma viga coluna com restrições ao longo do seu eixo longitudinal.

\section{3.}

\section{Análises Não Lineares}

As análises não lineares foram realizadas apenas para o modelo equivalente, visto que esse modelo representa de forma satisfatória o comportamento da estrutura completa. Estas análises seguem a mesma metodologia dos demais estudos apresentados nesse trabalho.

\subsection{1.}

\section{Análise Estática Não-Linear}

Para a estrutura em questão foi desenvolvida uma análise estática não linear a fim de determinar o caminho pós-crítico da estrutura, Figura 7.4, onde se relaciona o parâmetro de carga $\alpha$ com o deslocamento transversal normalizado U1/L, Notase que com a presença de vários níveis de cabos a estrutura possui capacidade de carga elevada. Entretanto a estrutura apresenta um caminho pós-crítico instável com declividade inicial bastante acentuada, o que resulta em uma grande sensibilidade a imperfeições.

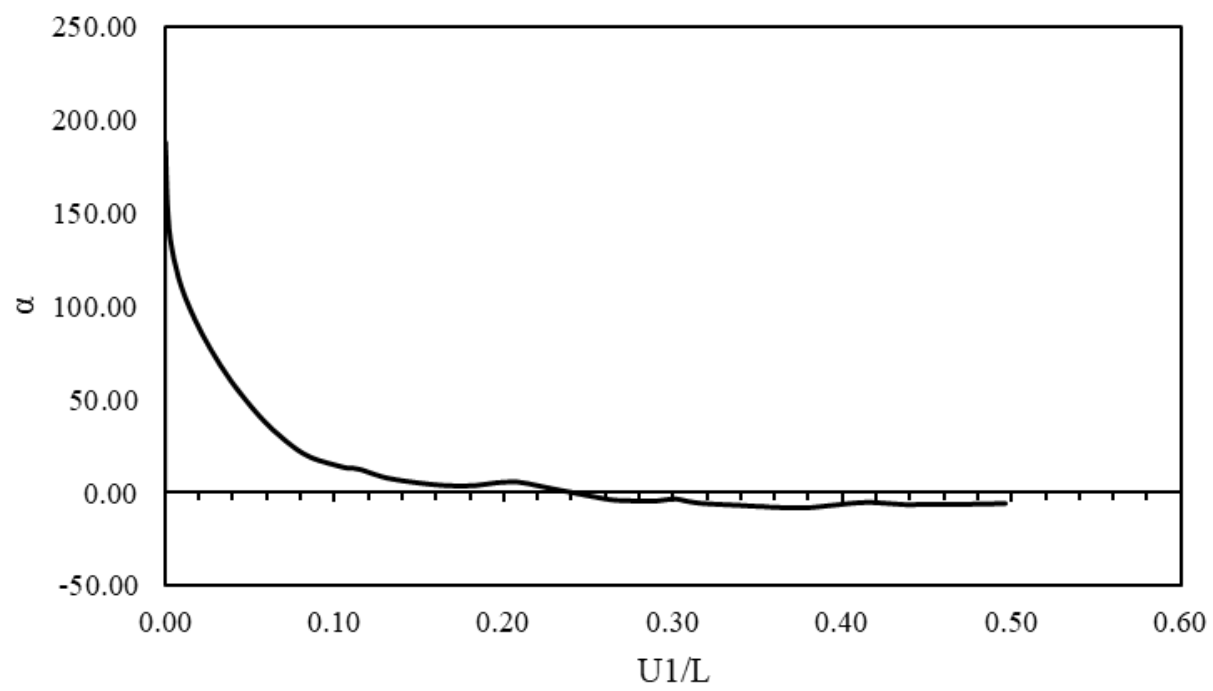

Figura 7.4 - Caminho de equilíbrio pós-crítico para o modelo de equivalente. 


\subsection{2.}

\section{Análise Dinâmica Não Linear}

A seguir procedeu-se a análise linear e não linear da vibração forçada sob carga harmônica. Para o desenvolvimento das análises dinâmicas lineares e não lineares, foi aplicada a mesma metodologia utilizada no modelo sintético padrão. $\mathrm{Na}$ análise linear, não foi contabilizada a não linearidade geométrica do modelo. A única diferença é que na integração numérica usa-se um passo adaptativo. Para isso foram inseridos parâmetros de controle no programa como o tempo total, número máximo de incrementos, tamanho do incremento inicial e o tamanho máximo e mínimo do incremento, Tabela 7.5. Esta mudança se deve ao fato da integração numérica com passo constante apresentar instabilidade numérica mesmo se usando um passo de um milésimo do período fundamental.

Tabela 7.5 - Parâmetros de controle para análise dinâmica linear e não linear.

\begin{tabular}{c|c}
\hline \multicolumn{2}{c}{ Parâmetros d e Controle análise dinâmica. } \\
\hline Tempo total & 300 \\
Número máximo de incrementos & 700.000 \\
Incremento inicial & 0,0005 \\
Tamanho máximo do incremento & 0,006 \\
Tamanho mínimo do incremento & 1E-05 \\
\hline
\end{tabular}

Os parâmetros inseridos como tamanho máximo e incremento inicial, são respectivamente um valor próximo a um milésimo e um centésimo do segundo período fundamental da estrutura, 0,61 segundos.

Visando determinar como a estrutura completa se comporta sob diversos aspectos, foram aplicadas várias magnitudes de carreamento lateral. Durante as análises essa estrutura é submetida a um carregamento harmônico com frequência próxima à segunda frequência natural do sistema, 10,3 rad/s (primeiro modo de flexão). Na Figura 7.5 é apresenta a resposta no tempo para três níveis de carga: $50 \mathrm{~N}, 500 \mathrm{~N}$ e $1000 \mathrm{~N}$, para as análises lineares e não lineares. Nota-se que para níveis baixos de carregamento a estrutura apresenta um comportamento muito semelhante 
para os dois tipos de análises. Entretanto, com o aumento da magnitude do carregamento cresce a diferença entre a resposta linear e não linear.

Todos os resultados de resposta no tempo para esse estudo não chegaram ao tempo de 300s, pois a resposta diverge antes disso. Pode-se observar que, com o aumento do carregamento, a resposta passa a apresentar grandes amplitudes de deslocamento do topo da estrutura. Isso denota uma sensibilidade muito alta da estrutura à magnitude da força aplicada quando entra em ressonância.

Para avaliar a influência dos modos durante este regime de vibração forçada, foi obtido o espectro de frequência para cada resposta. Cabe comentar que, devido à simetria do modelo, as frequências naturais se apresentam em pares e por isso os índices variam de dois em dois. Outro ponto a se ressaltar é que, como o primeiro modo é um modo axial, não é excitado por um carregamento lateral. Para o carregamento $50 \mathrm{~N}$, a resposta para as duas análises é praticamente a mesma, com participação preponderante do primeiro modo de flexão. Para $500 \mathrm{~N}$ nota-se na resposta linear uma excitação de vários modos, com vários picos abaixo da segunda frequência modo o que resulta em uma resposta complexa, o que não é observado na análise não linear onde o segundo modo é dominante. O mesmo ocorre para o a resposta não linear com magnitude de carregamento de $1 \mathrm{kN}$, enquanto a resposta linear rapidamente diverge.

Nota-se que a estrutura é bastante sensível a carregamentos quando em ressonância e que mesmo para níveis muito baixos de carregamentos há uma presença de outros modos atuando no sistema. Para uma melhor análise do comportamento dessa estrutura, mais estudos com variações de parâmetros do algoritmo de integração e da estrutura necessitam ser realizados. 


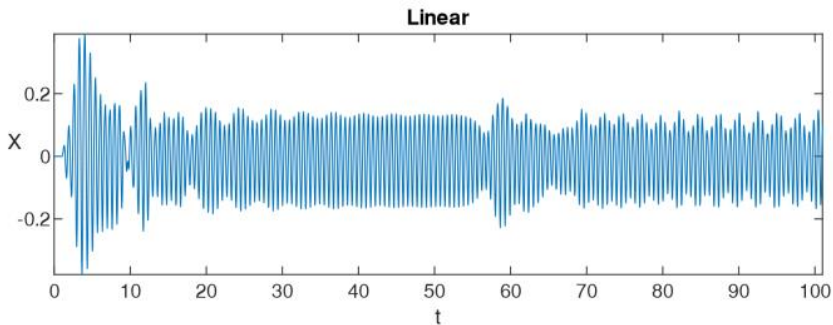

Não-Linear

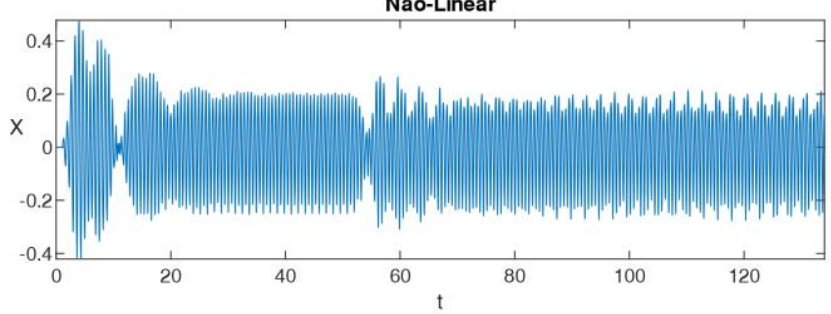

(a) Resposta no tempo carregamento de $50 \mathrm{~N}$.
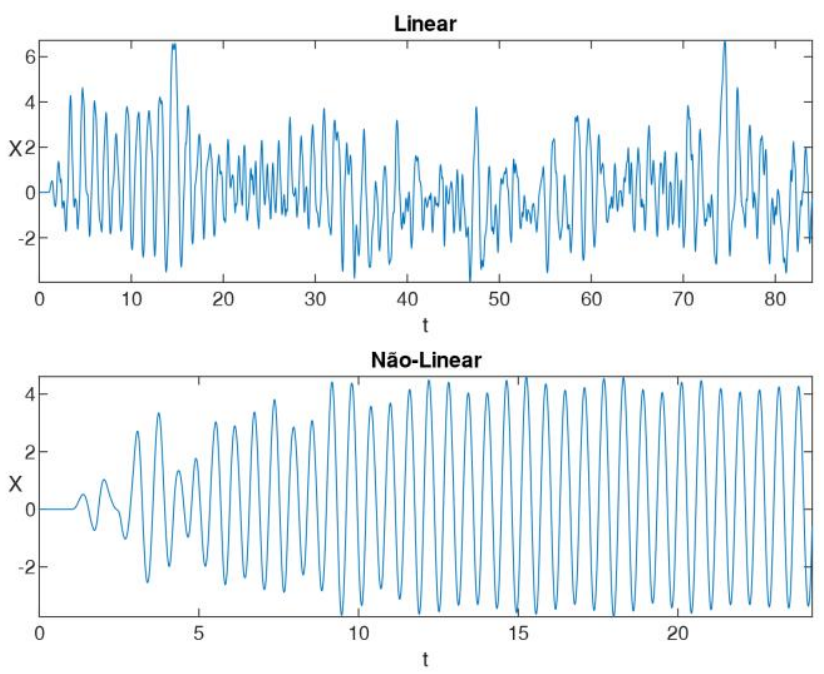

(b) Resposta no tempo carregamento de $500 \mathrm{~N}$.
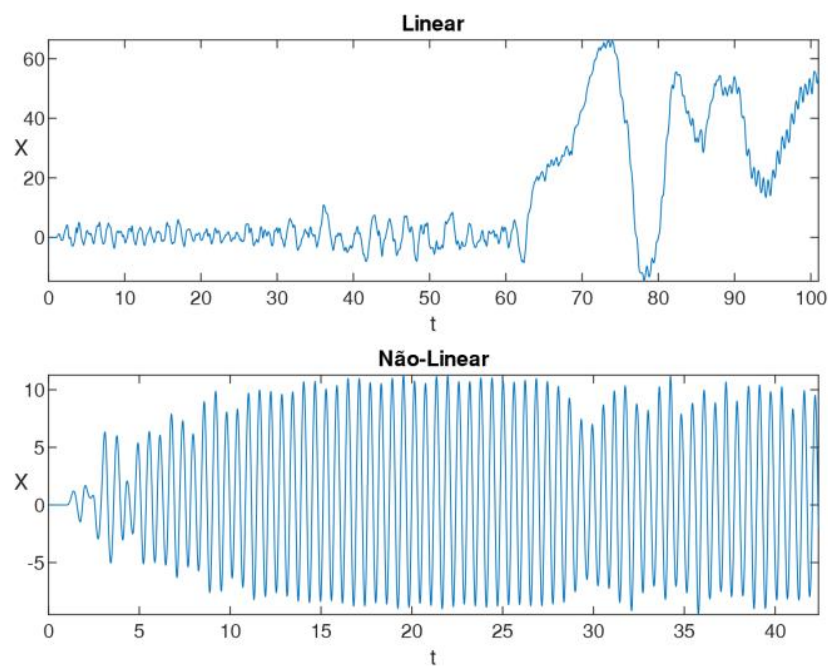

(c) Resposta no tempo carregamento de $1000 \mathrm{~N}$.

Figura 7.5 - Resposta no tempo, linear e não linear, amplitude (m) x tempo (s) do modelo real para diferentes níveis de carregamento. 

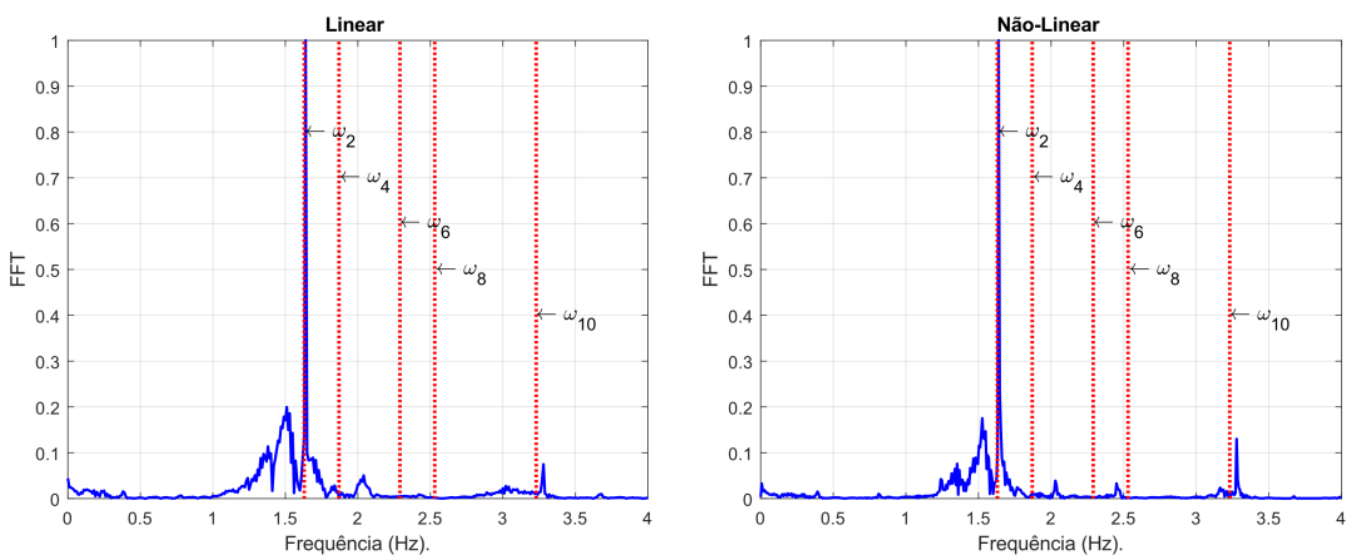

(a) Espectro de frequências - carregamento de 50N.
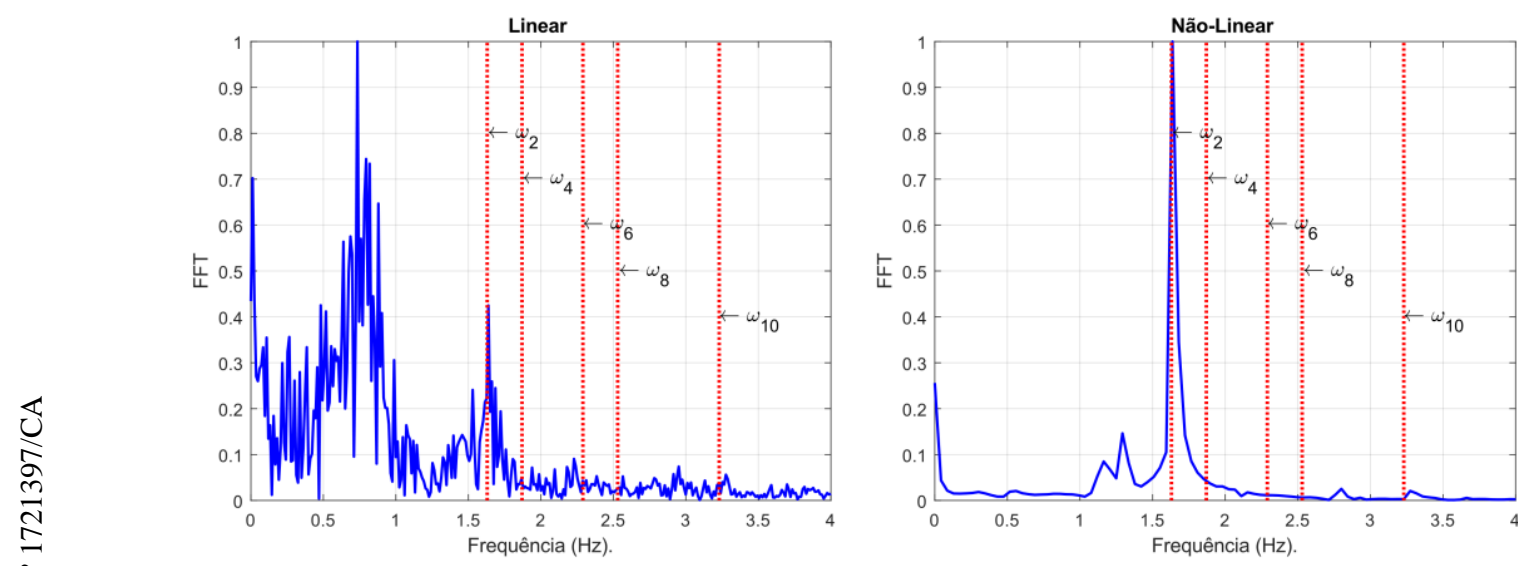

(b) Espectro de frequências - carregamento de 500N.
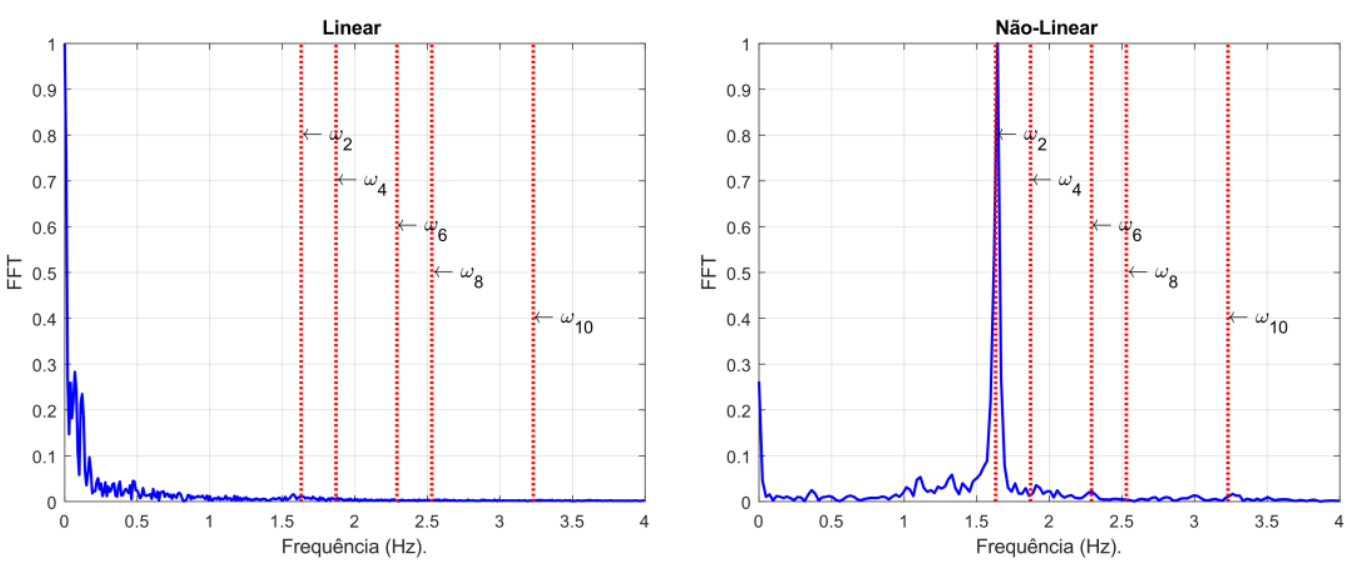

(c) Espectro de frequências carregamento de $1000 \mathrm{~N}$.

Figura 7.6 - Espectro de frequências para análise de vibração forcada amortecida, linear e não linear para diferentes níveis de carregamentos, modelo real. 


\section{8 \\ Conclusões e Sugestões}

\section{1.}

\section{Conclusões}

Esse trabalho busca investigar através de modelos de elementos finitos não lineares características de estabilidade e vibrações não lineares de uma torre estaiada, comparam-se as respostas do comportamento dos modelos contínuos ao de um modelo discreto de uma torre estaiada de dois graus de liberdade.

Os modelos contínuos utilizados apresentam três planos de simetria de modo que as frequências naturais e cargas críticas ocorrem em pares. Essa condição pode levar a uma ressonância interna 1:1 e a uma interação entre modos de flambagem. Quando há uma quebra de simetria por influência quer de imperfeições geométricas quer de cargas, os resultados encontrados para as frequências naturais passam a ser distintos, ainda que com valores muito próximos, o que não previne a interação modal. Mesmo em condições de pequena quebra de simetria o sistema apresenta um comportamento não linear complexo.

Um dos destaques desse trabalho são as análises paramétricas da participação dos cabos e do peso próprio da estrutura em sua resposta. A partir desses estudos verifica-se uma influência benéfica dos cabos, que contribuem para aumentar as frequências naturais do sistema. Quanto mais níveis de cabos ao longo da torre, maior a frequência fundamental. Os cabos apresentam ainda uma influência significativa na carga crítica do sistema aumentando em aproximadamente 11 vezes a carga crítica entre o modelo sem estais e o modelo com um nível de estais, e de aproximadamente 4 vezes, entre modelos com um nível e o modelo com três níveis de estais. Em relação ao peso próprio da estrutura, constata-se que sua incorporação a diretrizes de projeto e análise é crucial, visto que, sendo a estrutura muito esbelta, a contribuição do peso próprio de todos os elementos que a compõe, reduz a sua capacidade de suporte.

Nota-se ainda que as estruturas estaiadas, apresentam uma alta sensibilidade a imperfeições, pois é constatado que a trajetória de equilíbrio pós-crítico é instável 
e possui uma alta declividade inicial, apresentando um mínimo pós-crítico menor do que a carga crítica de uma torre engastada e livre sem cabos. Isso é decorrente da interação modal observada nesse tipo de sistema, ocasionada por bifurcações múltiplas. Outro ponto a ser realçado é a importância dos cabos nesse comportamento, pois estes influenciam na direção da trajetória de acordo com o tipo e direção da quebra de simetria.

Os resultados obtidos pelas análises não lineares em elementos finitos para o sistema em vibração livre amortecida mostram a existência de três modos normais não lineares simétricos e soluções multimodais, reafirmando o comportamento não linear encontrado para um modelo simplificado de dois graus de liberdade.

As análises não lineares de vibração forçada amortecida da torre apresentam grande influência das simetrias e dos modos normais não lineares na faixa de ressonância. É evidenciado que o comportamento é regido pelas simetrias de rotação e que o comportamento dessas estruturas varia de acordo com a direção do carregamento forçado. Quando os ângulos de incidência do carregamento harmônico coincidem com as direções dos cabos, a resposta é complexa (possivelmente caótica) com a influência de três modos normais não lineares. Isso leva a movimentos nos sentidos dos três cabos e quando o movimento se dá em outra direção nota-se que este é governado por dois outros MNNLs. A assimetria do movimento em função da não linearidade quadrática é evidenciada. Quando se aumenta a magnitude do carregamento lateral harmônico, vários modos participam na resposta, com frequências combinadas, e ressonâncias sub e super-harmônicas, típicas de um movimento caótico. Nota-se ainda presença de bifurcações dinâmicas com mudanças brusca na resposta do sistema que varia entre caótica e periódica. Isto comprova que estas estruturas possuem uma alta sensibilidade à magnitude $\mathrm{e}$ direção dos carregamentos.

O estudo de uma torre estaiada com características semelhantes a uma torre de telecomunicações real levou a observações semelhantes. Pode-se reafirmar a forte não linearidade da estrutura e a interação entre vários modos quando submetida a cargas harmônicas, mesmo para níveis baixos de carregamentos.

Estes resultados nos levam a compreender melhor as causas das diversas falhas catastróficas desse tipo de estrutura relatadas na literatura técnica. 


\section{2. \\ Sugestões}

Este trabalho despertou algumas questões adicionais a serem investigadas em trabalhos subsequentes. Algumas sugestões para trabalhos futuros são apresentadas a seguir:

1. Refinar os estudos considerando um modelo de torre com mais níveis de cabos, com a mesma seção tubular ou outras seções transversais;

2. Analisar uma torre com outros tipos de simetrias de distribuição de cabos, aumentando a quantidade de planos de simetria;

3. Utilizar outros métodos de integração numérica para solução não linear das equações;

4. Desenvolver uma solução analítica para esse tipo de modelo contínuo levando em consideração a sua distribuição de cabos;

5. Estudar a influência da ruptura de um dos cabos no comportamento dinâmico da estrutura;

6. Desenvolver análises com um modelo mais discretizado e mais complexo dos cabos, levando em consideração a catenária e sua não linearidade;

7. Considerar na modelagem uma possível plastificação dos elementos na presença de cargas elevadas; 


\section{Referências Bibliográficas}

[1] "Wolfsheim Mobile Telephone Transmitter - Structurae [en]: ImageID:185318," 2011. [Online]. Available: https://structurae.net/en/photos/185318-wolfsheim-mobiletelephone-transmitter?download=1. [Accessed: 03-Dec-2019].

[2] "Ulm-Jungingen Transmission Mast - Structurae [en]: ImageID:181571," 2011. [Online]. Available: https://structurae.net/en/photos/181571-ulm-jungingen-transmissionmast. [Accessed: 03-Dec-2019].

[3] J. R. Malli, P. D. Jivani, and D. R. G. Dhamsaniya, "A parametric study on guyed mast tower," J. Emerg. Technol. Innov. Res., vol. 4, no. 11, pp. 41-48, 2017.

[4] "Ausblendmast Mühlacker - Structurae [en]: Image-ID:196636." [Online]. Available: https://structurae.net/en/photos/196636ausblendmast-muhlacker. [Accessed: 03-Dec-2019].

[5] photographer: Christian Brinkmann, "Military Transmitter at Saterland-Ramsloh - Structurae [en]: Image-ID:106060," 2007. [Online]. Available: https://structurae.net/en/photos/106060-militarytransmitter-at-saterland-ramslohphotographer-christian-brinkmann. [Accessed: 03-Dec-2019].

[6] "WOI Television Tower (Alleman, 1972) - Structurae [en]: ImageID:53858," $2005 . \quad$ [Online]. Available: https://structurae.net/en/photos/53858-woi-television-tower-alleman1972. [Accessed: 03-Dec-2019].

[7] M. G. Nielsen, "The Analysis of Masts and Towers," Int. J. Sp. Struct., vol. 24, no. 4, pp. 97-102, 2009.

[8] J. Laiho, "Some known mast failures," J. Int. Assoc. Shell Spat. Struct., vol. 125, no. 3, pp. 197-200, 1997.

[9] D. K. Davies, "North American tower falilures:Causes and cures," 2011. 
[10] M. H. Magued, M. Bruneau, and R. B. Dryburgh, "Evolution of design standards and recorded failures of guyed towers in Canada," Can. J. Civ. Eng., vol. 16, no. 5, pp. 725-732, Oct. 1989.

[11] U. S. Coast Guard, "Tower manual," no. January. U.S. Departament of Transportation, Washington, DC, p. 214, 2002.

[12] Wikipedia contributors, "List of catastrophic collapses of broadcast masts and towers," Wikipedia, The Free Encyclopedia., 2019. [Online].

Available: https://en.wikipedia.org/w/index.php?title=List_of_catastrophic_colla pses_of_broadcast_masts_and_towers\&oldid=887975760. [Accessed: 08-May-2019].

[13] V. E. Parnás, fallas estructurales eN TORRES RETICULADAS PARA TELECOMUNICACIONES. Havana, Cuba: Facultad de Arquitectura. Universidad Tecnológica de La Habana José Antonio Echeverría, 2008.

[14] "Nebraska Television Tower Collapse | Knott Laboratory, LLC." [Online]. Available: https://knottlab.com/cases/nebraska-televisiontower-collapse/. [Accessed: 03-Dec-2019].

[15] C. Summary and C. Factors, "Tower Technician Killed When Guyed Tower Collapsed Case Report 09NY095,” 2009.

[16] F. K. Abbas, A. Abdul, and J. Al-Waily, "Computer Aids To Analysis Of Semi -Rigid Steel Space Frames," 2000.

[17] "Com queda de torre de energia, rodovia no Ceará permanece interditada | Agência Brasil." [Online]. Available: http://agenciabrasil.ebc.com.br/geral/noticia/2019-01/com-queda-detorre-de-energia-rodovia-no-ceara-permanece-interditada.

[Accessed: 03-Dec-2019].

[18] E. Pasquetti, "Estabilidade Estática e Dinâmica de Torres Estaiadas," PUC-Rio, 2003.

[19] D. Orlando, "Dinâmica Não-Linear, Instabilidade e Controle de Sistemas Estruturais com Interação Modal," Pontifícia Universidade Católica do Rio de Janeiro, 2010.

[20] J. M. T. Thompson and Z. Gaspar, "A buckling model for the set of 
umbilic catastrophes," Math. Proc. Cambridge Philos. Soc., vol. 82, no. 3, pp. 497-507, 1977.

[21] E. Gavassoni Neto, "Aplicação dos modos de vibração não lineares a modelos conceituais de estruturas offshore," Pontifícia Univerdiade Católica do Rio de Janeiro - PUC-Rio, 2012.

[22] W. H. Greene, "Minimum Weight Sizing of Guyed Antenna Towers," J. Struct. Eng., vol. 111, no. 10, pp. 2121-2137, Oct. 1985.

[23] H. A. El-Ghazaly and H. A. Al-Khaiat, "Analysis and design of guyed transmission towers-Case study in Kuwait," Comput. Struct., vol. 55, no. 3, pp. 413-431, May 1995.

[24] TIA-222-G, "Structural Standard for Antenna Supporting Structures and Antennas." TELECOMMUNICATIONS INDUSTRY ASSOCIATION Standards and Technology Department, Arlington, Virgínia, 2005.

[25] "Assembling your antenna system." [Online]. Available: http://www.astrosurf.com/luxorion/qsl-tower-assembly5.htm. [Accessed: 03-Dec-2019].

[26] "Land Requirements for Guyed Towers | Sabre Towers and Poles." [Online]. Available: http://www.sabre-stp.com/LandRequirements.aspx. [Accessed: 03-Dec-2019].

[27] C. Ryan, Handbook of Genetic Programming Applications. 2015.

[28] I. Woofenden, "Wind Generator Tower Basics." Home Power, Ashland, Oregon, pp. 64-68, 2005.

[29] "Rural Interstate Corridor Communications Study Report to States: Appendix A - Towers/Facilities - FHWA Operations." [Online]. Available:

https://ops.fhwa.dot.gov/publications/fhwahop09021/app_a/a_sec3.h tm. [Accessed: 03-Dec-2019].

[30] B. Windpower Co., "Installation Manual -BWC EXCEL 5k Wind Turbine Guyed-Lattice and Towers." Norman, Oklahoma, p. 71, 2012.

[31] CSA, "Antennas, towers, and antenna supporting structures." Standard CAN/CSA-S37-01, Canadian Standards Association, Rexdale, Canadá, 2001. 
[32] TIA/EIA 222 - F, "Structural Standards For Steel Antenna Towers And Supporting Structures." TELECOMMUNICATIONS INDUSTRY ASSOCIATION Standards and Technology Department, Arlington, Virgínia, 1996.

[33] M. K. S. (Ed. . Madugula, Dyanamic Response of Lattice Towers and Guyed Masts. Reston, Viginia, E.U.A: ASCE Publications, 2001.

[34] C. Mendonça and R. Carneiro De Barros, "METHODS TO DESIGN A GUIDED TOWER CONCERNING DYNAMIC BEHAVIOR METHODS TO DESIGN A GUIDED TOWER CONCERNING DYNAMIC BEHAVIOUR," in COMPDYN 2013 4th ECCOMAS Thematic Conference on Computational Methods in Structural Dynamics and Earthquake Engineering, 2014.

[35] G. G. Amiri, "Seismic Response of Guyed Telecommunication Towers," Montreal, Canadá, 1996.

[36] H. M. Irvine, Cable Structures. Cambridge, Massachusetts, e Londres, Inglaterra: Massachusetts Institute of Technology Press, 1981.

[37] J. W. Leonard, Tension Structures: Behavior and Anaivsis. McGrawHill, 1988.

[38] M. S. TRIANTAFYLLOU, "THE DYNAMICS OF TAUT INCLINED CABLES," Q. J. Mech. Appl. Math., vol. 37, no. 3, pp. 421-440, 1984.

[39] A. S. Veletsos and G. R. Darbre, "Dynamic stiffness of parabolic cables," Earthq. Eng. Struct. Dyn., vol. 11, no. 3, pp. 367-401, 1983.

[40] B. U. Starossek, "Dynamic stiffness $\mathrm{m}$ a $\mathrm{t} \mathrm{r}$ i $\mathrm{x}$ of sagging cable," J. Eng. Mech., vol. 117, no. 12, pp. 2815-2828, 1991.

[41] B. U. Starossek, "Reduction of Dynamic Cable Stiffness To," J. Eng. Mech., vol. 119, no. 10, pp. 2132-2136, 1993.

[42] F. G. A. Al-Bermani and S. Kitipornchai, "Nonlinear finite element analysis of latticed transmission towers," Eng. Struct., vol. 15, no. 4, pp. 259-269, 1993.

[43] F. G. A. Albermani and S. Kitipornchai, "Numerical simulation of structural behaviour of transmission towers," Thin-Walled Struct., vol. 41, no. 2-3, pp. 167-177, 2003. 
[44] F. Albermani, M. Mahendran, and S. Kitipornchai, "Upgrading of transmission towers using a diaphragm bracing system," Eng. Struct., vol. 26, no. 6, pp. 735-744, 2004.

[45] C. F. C. Junior, "Análise numérica e experimental do efeito dinamico do vento em torres metalicas treliçadas para telecomunicações," Escola Politécnica da Universidade de São Paulo - USP, 2000.

[46] N. Ben Kahla, "Dynamic analysis of guyed towers," Eng. Struct., vol. 16, no. 4, pp. 293-301, 1994.

[47] N. Ben Kahla, "Response of a guyed tower to a guy rupture under no wind pressure," Eng. Struct., vol. 22, no. 6, pp. 699-706, 2000.

[48] R. C. G. Menin, “Análise Estática E Dinâmica De Torres Metálicas Estaiadas," Universidade de Brasília, 2002.

[49] N. Prasad Rao and V. Kalyanaraman, "Non-linear behaviour of lattice panel of angle towers," J. Constr. Steel Res., vol. 57, no. 12, pp. 1337-1357, 2001.

[50] E. de C. Ribeiro, "ANÁLISE DE TORRES METÁLICAS ESTAIADAS SUBMETIDAS À AÇÃO DO VENTO," Universidade de Brasília, 2007.

[51] R. Saxena, N. Popplewell, P. G. S. Trainor, and A. H. Shah, "Vibrations of Complex Guyed Towers," in 12th Biennial Conference on Mechanical Vibration and Noise Control, 1989.

[52] Y. Wahba, M. Madugula, and G. Monforton, "Free Vibration of Guyed Antenna Towers," in Advances in Steel Structures - Proceedings of International Conference on Advances in Steel Structures, 1996, pp. 1095-1100.

[53] Y. M. F. Wahba, M. K. S. Madugula, and G. R. Monforton, "Evaluation of non-linear analysis of guyed antenna towers," Comput. Struct., vol. 68, no. 3, pp. 207-212, 1998.

[54] B. Sparling, "The Dynamic Behavior Of Guys And Guyed Masts In Turbulent Winds," The University of Western Ontario, 1995.

[55] B. E. ROHIT KAUL, "DYNAMIC ANALYSIS OF GUYED TOWERS SUBJECTED TO WIND LOADS INCORPORATING NONLINEARITY OF THE GUYS," Texas Tech University, 1999.

[56] M. K. S. Madugula, Y. M. F. Wahba, and G. R. Monforton, "Dynamic 
response of guyed masts," 1998.

[57] Y. M. F. Wahba, "Static and dynamic analyses of guyed antenna towers," University of Windsor, 1999.

[58] M. I. R. de Oliveira, J. G. S. da Silva, P. C. G. da S. Vellasco, S. A. L. de Andrade, and L. R. O. de Lima, "Structural analysis of guyed steel telecommunication towers for radio antennas," J. Brazilian Soc. Mech. Sci. Eng., vol. 29, no. 2, pp. 185-195, Jun. 2007.

[59] British Standards Institution. Lattice towers and towers Part 4, "Code of practice for loading of guyed tower." BS 8100-4:1995, London, UK, 1995.

[60] American Society for Civil Engineers, "Dynamic Response of Lattice Towers and Guyed Masts." American Society of Civil Engineers Task Committee on the Dynamic Response of Lattice Towers, ASCE Press, Reston, VA, 2002.

[61] C. E. De Normalisation, "European Standard EN 1993-3-1:2006: Eurocode 3 - Design of steel structures - Part 3-1: Towers, masts and chimneys - Towers and masts." CEN, Brussels, 2006.

[62] C. E. De Normalisation, "European Standard EN 1993-3-2:2006 (Eurocode 3: Design of steel structures - Part 3-2: Towers, towers and chimneys - Chimneys." CEN, Brussels, 2006.

[63] T. B. Carlos, "Análise dinâmica de torres estaiadas de linhas de transmissão submetidas à ruptura de cabos," Universidade Federal de Santa Maria (UFSM, RS), 2015.

[64] B. Sparling, B. Smith, and A. Davenport, "Simplified dynamic analysis methods for guyed towers in turbulent winds," J. Int. Assoc. Shell Sp. Struct., vol. 37, no. 2, pp. 89-106, 1996.

[65] H. Meshmesha, K. Sennah, and J. B. Kennedy, "Simple method for static and dynamic analyses of guyed towers," Struct. Eng. Mech., vol. 23, no. 6, pp. 635-649, 2006.

[66] H. Shi and H. Salim, "Geometric nonlinear static and dynamic analysis of guyed towers using fully nonlinear element formulations," Eng. Struct., vol. 99, pp. 492-501, Sep. 2015.

[67] F. Albermani, S. Kitipornchai, and R. W. K. Chan, "Failure analysis of 
transmission towers," Eng. Fail. Anal., vol. 16, no. 6, pp. 1922-1928, Sep. 2009.

[68] J. Ballaben, M. Rosales, and S. Preidikman, "Nonlinear dynamic response of a three-dimensional guyed mast," in $X$ International Conference on Structural Dynamics, EURODYN 2017, 2017, vol. 199, pp. 814-819.

[69] A. C. Luzardo, V. E. Parnaś, and P. M. Rodríguez, "Guy tension influence on the structural behavior of a guyed mast," J. Int. Assoc. Shell Spat. Struct., vol. 53, no. 172, pp. 111-116, 2012.

[70] J. S. Ballaben et al., "PARAMETRIC STUDIES OF GUYED TOWERS UNDER WIND AND SEISMIC LOADS," 2011.

[71] J. S. Ballaben, M. B. Rosales, and R. Sampaio, "DYNAMIC ANALYSIS OF A GUYED MAST WITH UNCERTAINTIES ON THE STIFFNESS AND THE NOMINAL WIND VELOCITY," 2015.

[72] J. S. Ballaben, A. M. Guzmán, and M. B. Rosales, "Nonlinear dynamics of guyed masts under wind load: Sensitivity to structural parameters and load models," J. Wind Eng. Ind. Aerodyn., vol. 169, pp. 128-138, Oct. 2017.

[73] J. S. Ballaben, R. Sampaio, and M. B. Rosales, "Uncertainty quantification in the dynamics of a guyed mast subjected to wind load," Eng. Struct., vol. 132, pp. 456-470, Feb. 2017.

[74] A. M. Ismail and S. H. M. Hassnien, "Non-Linear Dynamic Analysis of Guyed Towers to Wind Loading," IOSR J. Mech. Civ. Eng. e-ISSN, vol. 15, no. 1, pp. 21-29.

[75] R. M. Rosenberg, "On normal vibrations of a general class of nonlinear dual-mode systems," J. Appl. Mech. Trans. ASME, vol. 29, no. 1, pp. 216-217, 1961.

[76] S. Shaw and C. Pierre, "Non-linear normal modes and invariant manifolds To cite this version : HAL Id : hal-01310674," J. Sound Vib., vol. 150, no. 1, pp. 170-173, 1991.

[77] N. Boivin, C. Pierre, and S. W. Shaw, "Non-linear modal analysis of structural systems featuring internal resonances," J. Sound Vib., vol. 182, no. 2, pp. 336-341, 1995. 
[78] E. Pesheck et al., "Nonlinear Modal Analysis of Structural Systems Using Multi-Mode Invariant Manifolds," Nonlinear Dyn., vol. 25, no. 13, pp. 183-205, 2001.

[79] M. Peeters, R. Viguié, G. Sérandour, G. Kerschen, and J. C. Golinval, "Nonlinear normal modes, Part II: Practical computation using numerical continuation techniques," in Mechanical Systems and Signal Processing, 2009, pp. 195-216.

[80] A. F. Vakakis and R. H. Rand, "Normal modes and global dynamics of a two-degree-of-freedom non-linear system-II. High energies," Int. J. Non. Linear. Mech., vol. 27, no. 5, pp. 875-888, Sep. 1992.

[81] T. Yang, "Symmetry properties and normal mode vibrations," Int. J. Non. Linear. Mech., vol. 3, no. 3, pp. 367-381, Sep. 1968.

[82] D. Orlando, P. B. Gonçalves, G. Rega, and S. Lenci, "Influence of symmetries and imperfections on the non-linear vibration modes of archetypal structural systems," Int. J. Non. Linear. Mech., vol. 49, pp. 175-195, 2013.

[83] D. Orlando, P. B. Gonçalves, G. Rega, and S. Lenci, "Nonlinear dynamics and instability as important design concerns for a guyed mast," IUTAM Bookseries, vol. 32, pp. 223-234, 2013.

[84] E. Gavassoni, P. Batista Gonçalves, and D. De Mesquita Roehl, "Nonlinear vibration modes of an offshore articulated tower," Ocean Eng., vol. 109, pp. 226-242, 2015.

[85] G. Schmidt, "Thompson, J. M. T. / Hunt, G. W., Elastic Instability Phenomena. Chichester et al., John Wiley \&amp; Sons 1984. XII, 209 S., £ 17.50. ISBN 047190279 9," ZAMM - J. Appl. Math. Mech. / Zeitschrift für Angew. Math. und Mech., vol. 65, no. 11, pp. 576-576, Jan. 1985.

[86] E. C. Zeeman, "Catastrophe Theory," Sci. Am., vol. 234, no. 4, pp. 65-83, Apr. 1976.

[87] A. Andersson and R. Malm, "Measurement Evaluation and FEM Simulation of Bridge Dynamics - A Case Study of a Langer Beam Bridge," Stockholm, Sweden, 2004.

[88] Dassault Systems, “Abaqus Analysis User's Manual.” 2007. 
[89] Z. J. G. N. Del Prado, C. Carvalho, and P. B. Gonçalves, "DYNAMIC STABILITY OF IMPERFECT CABLE STAYED MASTS," in Asociación Argentina de Mecánica Computacional, 2010, pp. 15-18.

[90] Z. J. G. N. Del Prado, P. B. Gonçalves, and C. Carvalho, "NONLINEAR DYNAMICS OF CABLE-STAYED MASTS."

[91] E. H. Guimarães, S. A. G. Oliveira, and A. P. Clapis, "INFLUÊNCIA DAS CONDIÇÕES DE CONTORNO NA ANÁLISE MODAL DE TORRES ESTAIDAS PELO MÉTODO DE ELEMENTOS FINITOS," in $17^{\circ}$ Simpósio do Programa de Pós-graduação em Engenharia Mecânica, 2007.

[92] "The Complete Buyer's Guide to Wire Rope: Which Type is Best for Your Project? - US Rigging." [Online]. Available: https://usrigging.com/blog/wire-rope-buyers-guide/. [Accessed: 03Dec-2019].

[93] A. Tafreshi, "Buckling and post-buckling analysis of composite cylindrical shells with cutouts subjected to internal pressure and axial compression loads."

[94] E. Ramm, "Strategies for Tracing the Nonlinear Response Near Limit Points," Nonlinear Finite Elem. Anal. Struct. Mech., pp. 63-89, 1981.

[95] M. A. Crisfield, "A FAST INCREMENTAL/ITERATIVE SOLUTION PROCEDURE THAT HANDLES 'SNAP-THROUGH," Comput. Struct., vol. 13, pp. 55-62, 1981.

[96] G. POWELL and J. SIMONS, "Improved Iteration Strategy for Nonlinear Structures," Int. J. Numer. Methods Eng., vol. 17, pp. 14551467, 1981.

[97] H. M. Hilber, T. J. R. Hughes, and R. L. Taylor, "Algorithms in Structural Dynamics," Earthq. Eng. Struct. Dyn., vol. 5, no. June 1976, pp. 283-292, 1977.

[98] T. J. R. Hughes, "A note on the stability of Newmark's algorithm in nonlinear structural dynamics," Int. J. Numer. Methods Eng., vol. 11, no. 2, pp. 383-386, 1977.

[99] S. Krenk, "Energy conservation in Newmark based time integration algorithms," Comput. Methods Appl. Mech. Eng., vol. 195, no. 44-47, 
pp. 6110-6124, Sep. 2006.

[100] W. L. Wood, M. Bossak, and O. C. Zienkiewicz, "An alpha modification of Newmark's method," Int. J. Numer. Methods Eng., vol. 15, no. 10, pp. 1562-1566, 1980.

[101] NBR 6123, "NBR 6123: Forças devidas ao vento em edificações," Associação Brasilera de Normas Técnicas. p. 66, 1988.

[102] IASS, "Recommendations for Guyed Masts." International Association for Shell and Spatial Structures Working Group 4, Madrid, 1981.

[103] G. Ghodrati Amiri, "Seismic sensitivity indicators for tall guyed telecommunication towers," Comput. Struct., vol. 80, no. 3-4, pp. 349-364, Feb. 2002.

[104] Y. M. F. Wahba, "Static and dynamic analyses of guyed antenna towers.," Electron. Theses Diss., 1999.

[105] M. Grey, "Finite Element Seismic Analysis of Guyed Masts," University of Oxford, 2006.

[106] E. Pezo, P. Gonçalves, and D. Roehl, "Non-linear finite element analysis of the dynamics of a slender cable stayed tower," MATEC Web Conf., vol. 148, p. 03001, 2018.

[107] P. B. Gonçalves, D. L. B. R. Jurjo, C. Magluta, N. Roitman, and D. Pamplona, "Large deflection behavior and stability of slender bars under self weight," Struct. Eng. Mech., vol. 24, no. 6, pp. 709-725, 2006.

[108] W. H. Duan and C. M. Wang, "Exact Solution for Buckling of Columns Including Self-Weight," J. Eng. Mech., vol. 134, no. 1, pp. 116-119, Jan. 2008.

[109] S. P. Timoshenko and J. M. Gere, Theory of Elastic Stability, Second Edi. Mineola, New York: Dover Publications, INC., 2009.

[110] J. E. Goldberg and J. T. Gaunt, "Stability of Guyed Towers," J. Struct. Div., vol. 99, no. 4, pp. 741-756, 1973.

[111] F. W. Williams and W. P. Howson, "Concise buckling analysis of stayed columns," Int. J. Mech. Sci., vol. 20, no. 5, pp. 299-313, Jan. 1978. 
[112] E. CHAVES CARVALHO, "Análise Da Instabilidade Dinâmica De Estruturas Estaiadas," Universidade Federal de Goiás, 2008.

[113] Z. J. G. N. Prado, P. B. Gonçalves, and E. C. Carvalho, "NONLINEAR DYNAMICS OF CABLE-STAYED MASTS," in 11th PanAmerican Congress of Applied Mechanics, 2010.

[114] M. Matuszkiewicz, "Calculation of guyed masts in accordance with EN 1993-3-1 standard taking into account mast shaft geometrical imperfections," Eng. Struct., vol. 33, no. 6, pp. 2044-2048, Jun. 2011.

[115] M. Matuszkiewicz, "Imperfections In Calculations Of Guyed Lattice Masts," Arch. Civ. Eng., vol. 60, no. 4, pp. 409-420, Dec. 2014.

[116] A. Hartmann and A. Davenport, "Comparisons of the predicted and measured response of structures to wind." Rep. st-4-66, University of Western Ontario, London, Canada, 1966.

[117] R. D. Blevins, Formulas for Natural Frequency and Mode Shape, 1st ed. New York: Van Nostrand Reinbold Company, 1979.

[118] D. L. B. R. Jurjo, "Estabilidade de colunas sujeitas ao peso próprio," Pontifícia Universidade Católica do Rio de Janeiro, 2002.

[119] ASCE 7-05, "Minimum Design Loads for Buildings and Other Structures.” American Society of Civil Engineers (ASCE), 2005.

[120] I. Chowdhury and S. P. Dasgupta, "Computation of Rayleigh Damping Coefficients for Large Systems," Electron. J. Geotech. Eng., 2003.

[121] L. A. Month and R. H. Rand, "An application of the poincaré map to the stability of nonlinear normal modes," J. Appl. Mech. Trans. ASME, vol. 47, no. 3, pp. 645-651, 1980.

[122] R. M. Rosenberg, "Normal modes of nonlinear dual-mode systems," J. Appl. Mech. Trans. ASME, vol. 27, no. 2, pp. 263-268, 1960.

[123] R. Rosenberg, T. Normal, and N. Systems, "The Normal Modes of Nonlinear n-Degree-of-Freedom To cite this version: HAL Id: hal01344457 The Normal Modes of Nonlinear n-Degree-of-Freedom Systems," J. Appl. Mech. Am. Soc. Mech. Eng., vol. 29, no. 1, pp. 7$14,1962$.

[124] J. Montaldi, M. Roberts, and I. Stewart, "Existence of nonlinear normal modes of symmetric Hamiltonian systems," Nonlinearity, vol. 3, no. 3, 
pp. 695-730, Aug. 1990.

[125] T. Kitagawa, T. Wakahara, Y. Fujino, and K. Kimura, "An experimental study on vortex-induced vibration of a circular cylinder tower at a high wind speed," J. Wind Eng. Ind. Aerodyn., vol. 69-71, pp. 731-744, 1997.

[126] A. H. Nayfeh and D. T. Mook, Nonlinear oscillations. John Wiley \& Sons, Ltd, 2008.

[127] F. C. Moon, Chaotic and fractal dynamics : an introduction for applied scientists and engineers. John Wiley \& Sons, Ltd, 2008.

[128] Vallourec, "Tubos Estruturais Seção Circular, Quadrada e Retangular.".

[129] Gerdau, "Barras E Perfis." p. 8, 2019.

[130] SIVA CABOS DE AÇO, "Catálogos de Produtos - Cabos de Aço e Acessórios." pp. 49-188, 2014.

[131] CIMAF, "Manual Técnico de Cabos de Aço." 2012. 


\section{Apêndice A \\ Desenvolvimento de Análises dinâmicas lineares e não- lineares no ABAQUS}

Neste apêndice são descritas as etapas necessárias e os comandos correspondentes para o desenvolvimento do modelo de torre utilizado neste trabalho. São descritos também os passos para as análises modais de frequência e flambagem, análises de não-linear estática, análise não-linear dinâmica no ABAQUS®.

\section{A. 1 Definição do modelo de Torre Estaiada}

Para o desenvolvimento das análises estáticas e dinâmicas lineares e não lineares no programa ABAQUS®, utilizou-se a interface gráfica ABAQUS/CA. Nesta interface são geradas a topologia da estrutura, elementos de cabo e vigas e as suas respectivas propriedades físicas e geométricas.

As propriedades geométricas definias para cada modelo consiste em inserir as características da seção transversal. As propriedades físicas utilizadas pelas seções transversais de cada elemento são referentes ao módulo de elasticidade do material, densidade e amortecimento proporcional. Uma importante propriedade inserida nos elementos de cabo é a restrição deste a não trabalhar em regime de compressão, apenas à tração. Isso é inserido no programa apenas ativando uma propriedade no material, "NO COMPRESSION", Figura A. 1.

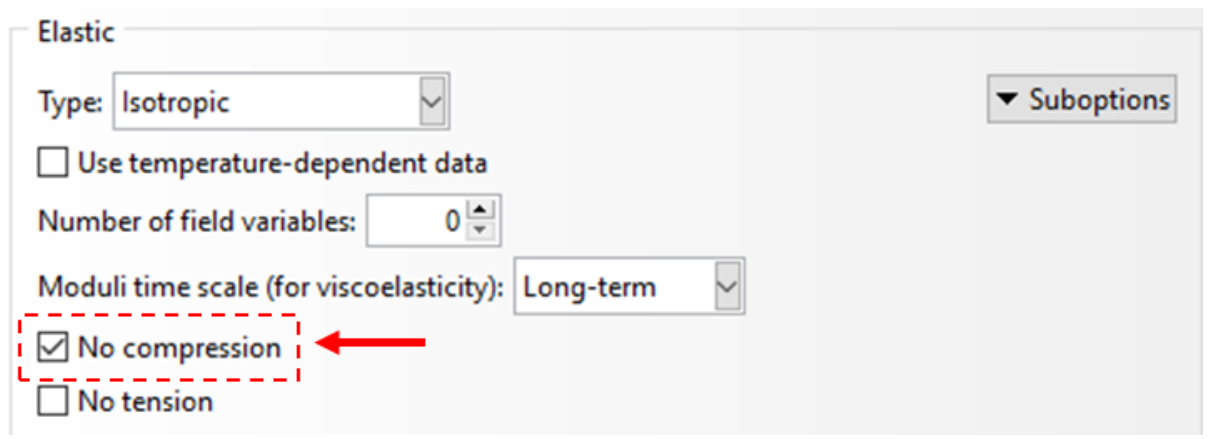

Figura A. 1 - Inserindo restrição à compressão no material. 


\section{A. 1.1 \\ Definindo amortecimento proporcional}

Para as análises dinâmicas não lineares e lineares de vibração livre e vibração forçada, há a necessidade de um amortecimento na estrutura. No programa ABAQUS esse amortecimento é inserido como amortecimento proporcional ou amortecimento de Rayleigh a partir dos parâmetros A e B. Esses parâmetros são calculados em função das frequências naturais da estrutura, $\omega_{i}$ e $\omega_{j}$, correspondentes aos i-ésimo e j-ésimo modos (modos escolhidos para a análise), e do fator de amortecimento, $\xi$, desejado. Logo deve-se conhecer os valores das frequências naturais do sistema. Nesse trabalho, como todos os dados são gerados numericamente, primeiro desenvolve-se a análise modal para determinar os autovalores e autovetores. Utilizam-se então as equações Eq.(13) e Eq.(14), para determinar esses valores. Os valores encontrados definem as propriedades dos materiais, como apresenta a Figura A. 2.

$$
\begin{aligned}
& A=\xi \frac{2 \omega_{i} \omega_{j}}{\omega_{i}+\omega_{j}} \\
& B=\xi \frac{2}{\omega_{i}+\omega_{j}}
\end{aligned}
$$

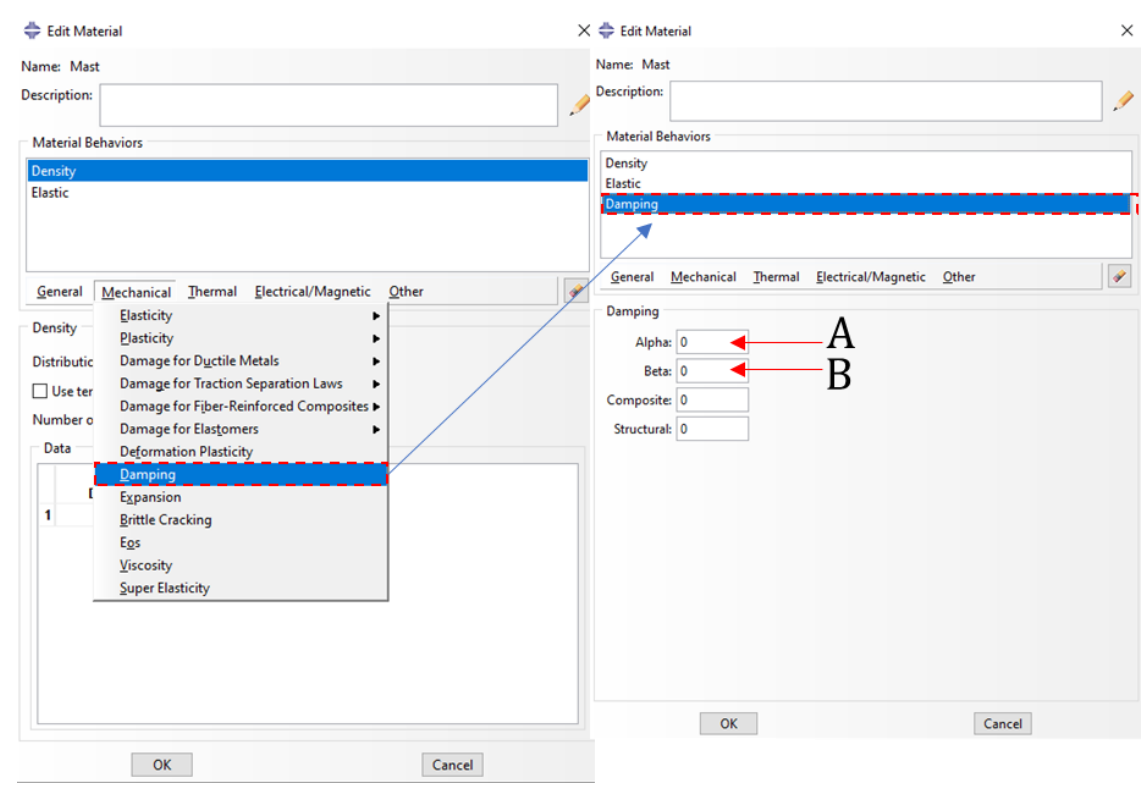

Figura A. 2 - Inserção do amortecimento da estrutura a partir dos parâmetros $\alpha$ e $\beta$ no programa ABAQUS®. 


\section{A. 1.2 \\ Definindo pré-tensão nos cabos}

Com todos os elementos com suas respectivas propriedades físicas e geométricas, agrupa-se o modelo gerando a estrutura completa. Com isso pode-se aplicar as condições de apoio aos nós e os carregamentos na estrutura.

Dentre as condições de contorno, para uma estrutura estaiada há a necessidade de pré-tensão nos cabos, como comentado ao longo do trabalho. Essa tensão inicial nos cabos é inserida como um campo predefinido de tensões, no programa. Inserese esse campo de tensões, como "Predefined Field" na categoria de procedimentos mecânicos, na etapa inicial da análise, e selecionam-se os elementos que necessitam dessa condição inicial. A seguir são inseridos os valores das tensões nas coordenadas locais do elemento. Como o elemento de cabo tem somente tensões normais, insere-se no campo "Sigma11" o valor da tensão para os cabos e os demais com zero, Figura A .3.

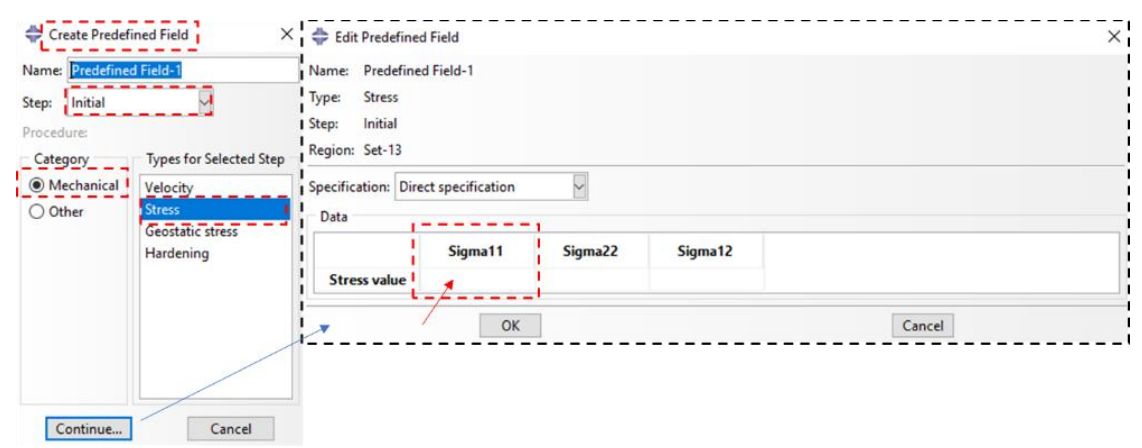

Figura A .3 - Inserindo pré-tensão nos cabos.

\section{A. 2}

\section{Análise geral estática}

Após a geração da estrutura com todas as propriedades definidas e as condições de contorno aplicadas, procedeu-se à análise do comportamento estático das torres. A organização dos passos de análise é apresentada na Figura A. 4. A etapa inicial é sempre uma análise estática geral, e nela são vinculadas todas as condições de contorno iniciais, carregamentos, condições de apoios e pré-tensão nos cabos. Com essa vinculação, estas condições são propagadas para as demais etapas, sendo computadas nas análises. 


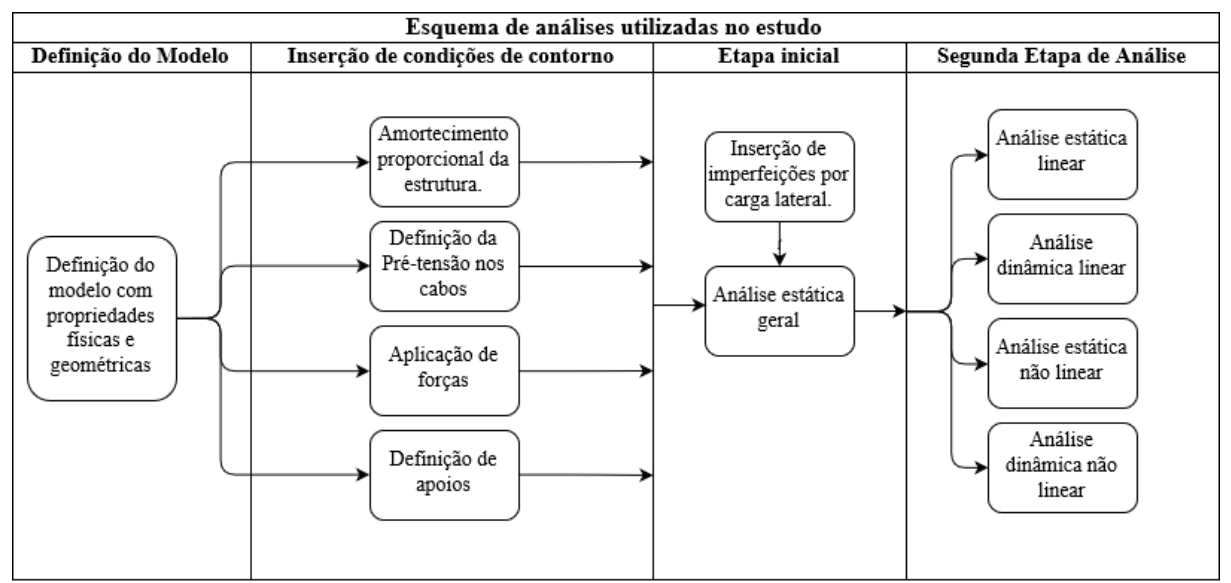

Figura A. 4 - Fluxograma esquemático das análises desenvolvidas no trabalho.

\section{A. 2.1}

\section{Peso Próprio}

Um carregamento importante para os estudos desenvolvidos neste trabalho é o peso próprio da estrutura. Essa carga é incluída no sistema como uma relação entre a gravidade, geometria e a densidade do material vinculadas a cada elemento. Para se inserir a gravidade no modelo, insere-se uma carga e escolhe-se o tipo dessa carga como gravidade, "GRAVITY" no ABAQUS. Após isso, basta inserir o valor da aceleração gravitacional na componente global desejada, Figura A. 5.

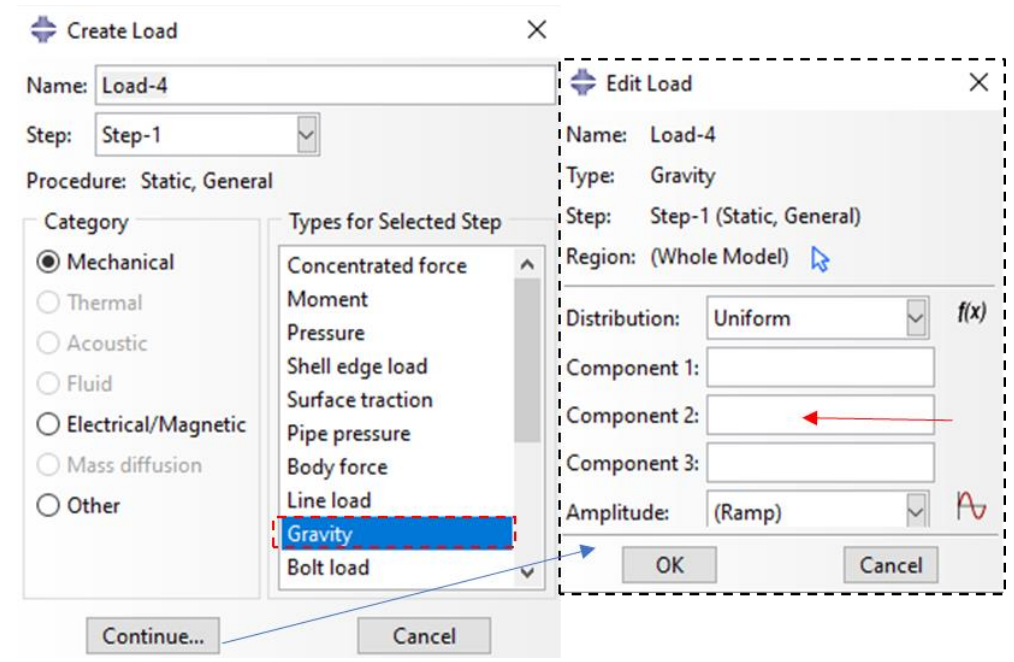

Figura A. 5 - Inserção da gravidade no modelo. 


\section{A. 2.2}

\section{Imperfeições e Carregamentos Estáticos}

Um outro tipo de carregamento importante vinculado a essa análise inicial, são as cargas laterais. Estas podem ser pontuais ou linearmente distribuídas ao longo da estrutura. Tais cargas são utilizadas nos modelos desenvolvidos neste trabalho para gerar deformações iniciais na estrutura. Para inseri-los seleciona-se o tipo de carregamento, a magnitude deste e em quais coordenadas ele atuará. Caso este não esteja atuando diretamente nos eixos do modelo, deve-se utilizar a decomposição trigonométrica correspondente.

\section{A. 2.3}

\section{Não Linearidade Geométrica}

Para contabilizar os efeitos da não linearidade geométrica do problema basta ligar em cada uma das etapas de análise essa função, Figura A. 6.

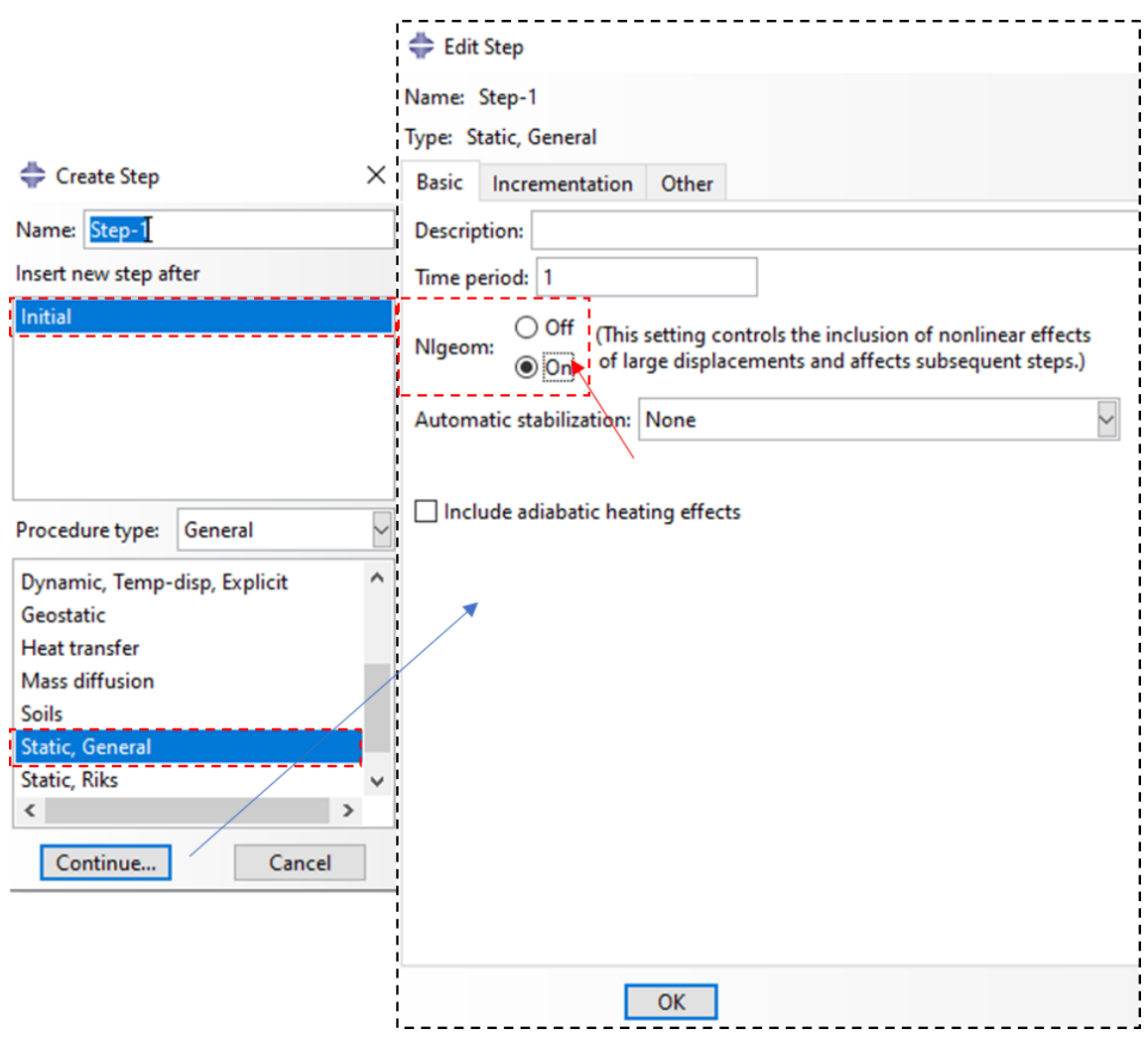

Figura A. 6 - Ativação da Não Linearidade Geométrica no modelo.

\section{A. 3}

\section{Análise Modal}

As propriedades dinâmicas, modos de vibração e frequências naturais, e as propriedades estáticas, modos de flambagem e cargas críticas, das torres estaiadas 
foram determinadas no programa ABAQUS através das análises de "FREQUENCY" e "BUCKLE', respectivamente. Para selecionar algum desses módulos, deve-se utilizar o tipo de procedimento como perturbação linear, Figura A. 7.

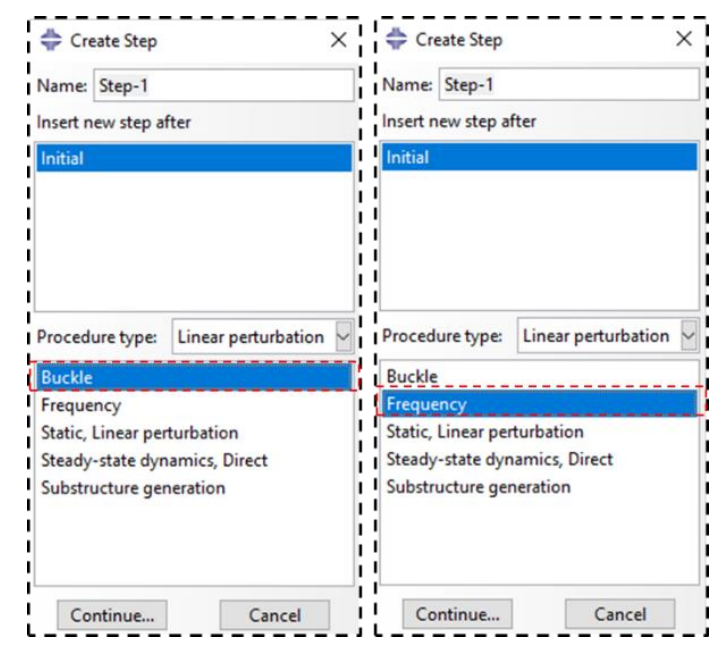

Figura A. 7 - Criação das etapas de "BUCKLE" e FREQUENCY".

\section{A. 3.1}

\section{Estática linear}

As análises estáticas lineares que correspondem à análise modal, obtendo-se os modos de flambagem e cargas críticas do modelo, foram desenvolvidas na etapa de "BUCKLE". Nessa etapa, o programa necessita de parâmetros de controle inseridos diretamente, para calcular o número de autovalores e autovetores. Os parâmetros de controle nessa etapa são o número de modos desejados e qual algoritmo de resolução deve ser empregado, Figura A. 8. No caso deste trabalho foi escolhido o Subspace. Após o processamento dessa etapa, pode-se visualizar cada modo de flambagem com sua respectiva carga. Como resultado além do apresentado na interface gráfica, pode-se coletar os valores dos autovalores no arquivo .dat gerado. 


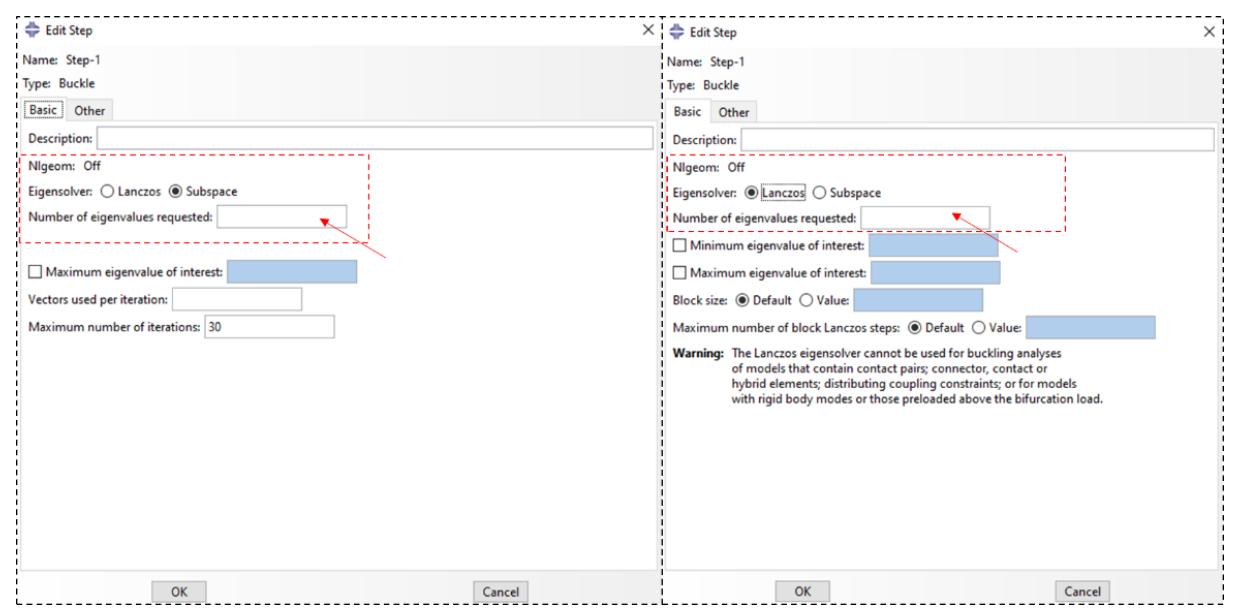

Figura A. 8 - Tipos de algoritmos de solução para etapa de "BUCKLE".

Outra necessidade desse módulo é a presença de alguma carga nessa etapa. Para a maioria das análises são utilizadas cargas unitárias no topo da estrutura, para que o autovalor seja diretamente o valor da carga crítica da estrutura. Mas em casos que se necessita avaliar a influência de algum tipo de carregamento isoladamente no modelo, deve-se inserir esse carregamento nessa etapa, como é o caso da avaliação da caga de peso próprio.

Para avaliar um modelo apenas com a carga de peso próprio, insere-se a gravidade apenas na etapa de "BUCKLE". Com isso o resultado será um fator proporcional que ao ser multiplicado pelo valor resultante do carregamento no modelo fornece a carga crítica.

\section{A. 3.2 Dinâmica linear}

De modo análogo à análise estática linear, para se obter os modos de vibração e frequências naturais do modelo, basta especificar a etapa como "FREQUENCY". Os parâmetros de controle para essa etapa são o número de autovalores e autovetores a serem calculados, assim como o algoritmo a ser utilizado. Para o trabalho, o algoritmo escolhido foi o Lanczos. Na Figura A. 9, são apresentadas as principais janelas do programa relativas a essa etapa de análise. Os resultados são apresentados tanto graficamente na interface, como no arquivo de texto dat gerado. Nesse arquivo pode-se encontrar as frequências naturais em radianos/segundo e em Hertz. 


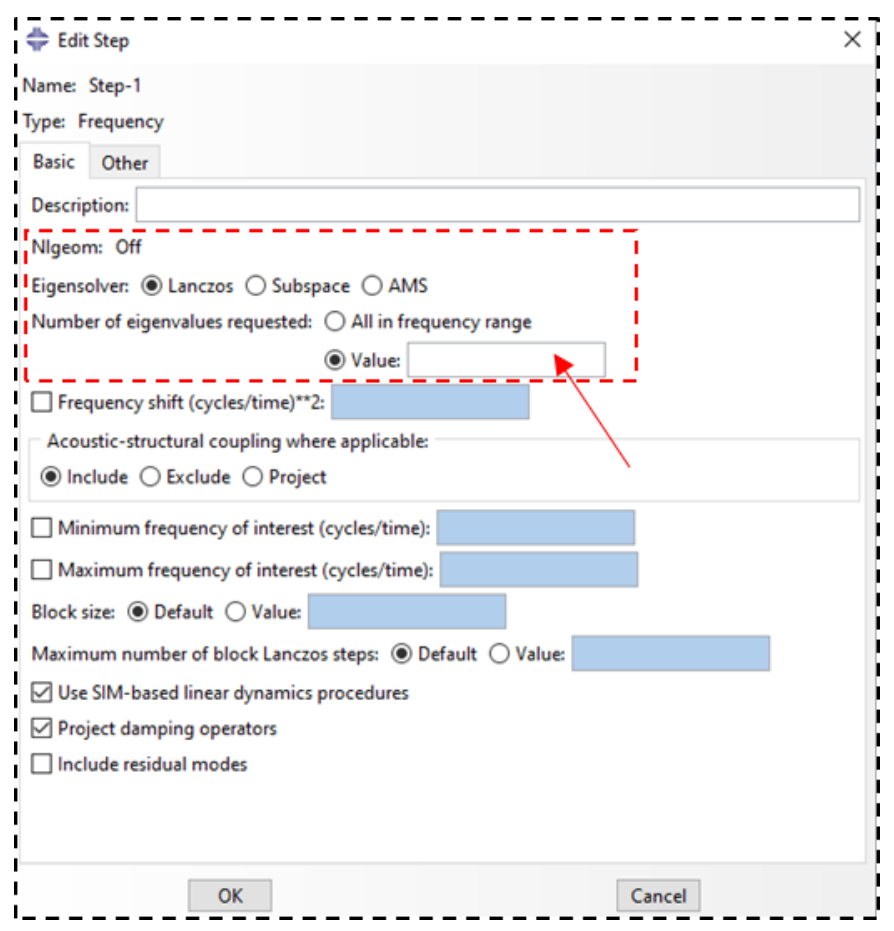

Figura A. 9 - Algoritmos de solução para etapa de "FREQUENCY".

Quando há a necessidade de contabilizar a influência de alguma carga inicial nessa etapa, deve-se ativar a não linearidade geométrica do modelo na etapa inicial.

\section{A. 4}

\section{Análise Não Linear}

Para as análises não lineares da torre, desenvolveram-se análises estáticas e dinâmicas. As estáticas consistem na utilização do método de Riks modificado para obtenção da envoltória de equilíbrio do caminho pós-crítico. E para as análises dinâmicas a metodologia utilizada foi o método HTT-alpha com parâmetros alterados para que esse método passasse a se comportar como o método de Newark$\beta$ com um pequeno amortecimento numérico. Estes módulos de análises são selecionados após a etapa inicial, estática geral, e são inseridos no modelo pelos módulos "Static,Riks" e "Dynamic, Implicit", Figura A. 10. 


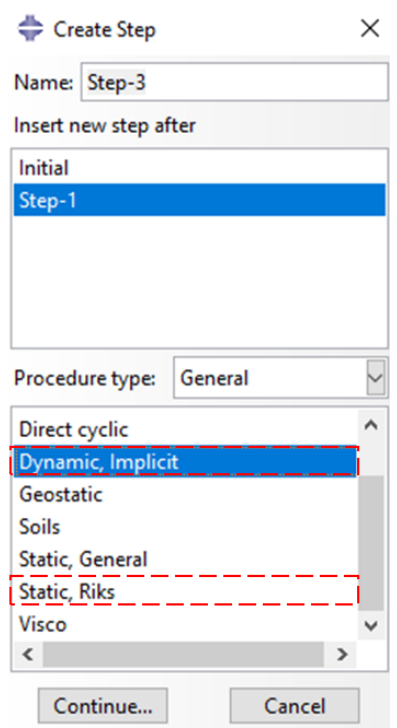

Figura A. 10 - Criação das etapas de análise não linear estática e dinâmica.

\section{A. 4.1}

\section{Análise Estática Não Linear}

Para o cálculo e obtenção da envoltória de equilíbrio pós-crítico, utilizou-se o método de Riks modificado, algoritmo do módulo "RIKS" no programa ABAQUS. Para que a envoltória de equilíbrio seja gerada, o modelo necessita de uma deformação inicial. Essa deformação pode ser aplicada no modelo de duas formas. Uma utilizando os carregamentos e com isso gerando uma deformação na estrutura. A outra forma é inserir uma imperfeição modal como parâmetro de deformação inicial do modelo.

\section{A. 4.1.1}

\section{Imperfeição Modal}

As imperfeições modais, são inseridas como porcentagens da deformação do modo de flambagem da estrutura. Então, antes de se processar uma análise de "RIKS" com esse tipo de imperfeição deve-se ter a etapa "BUCKLE" processada gerando um arquivo de saída contendo as coordenadas dos nós para os diferentes modos. Esse resultado será introduzido como imperfeição na análise de "RIKS", para obter a envoltória de equilíbrio, superando o problema de bifurcação. $\mathrm{Na}$ Figura A. 11, são apresentados os passos necessários para que o arquivo de saída com a informação dos nós, seja gerado ao fim do processamento do "BUCKLE". 


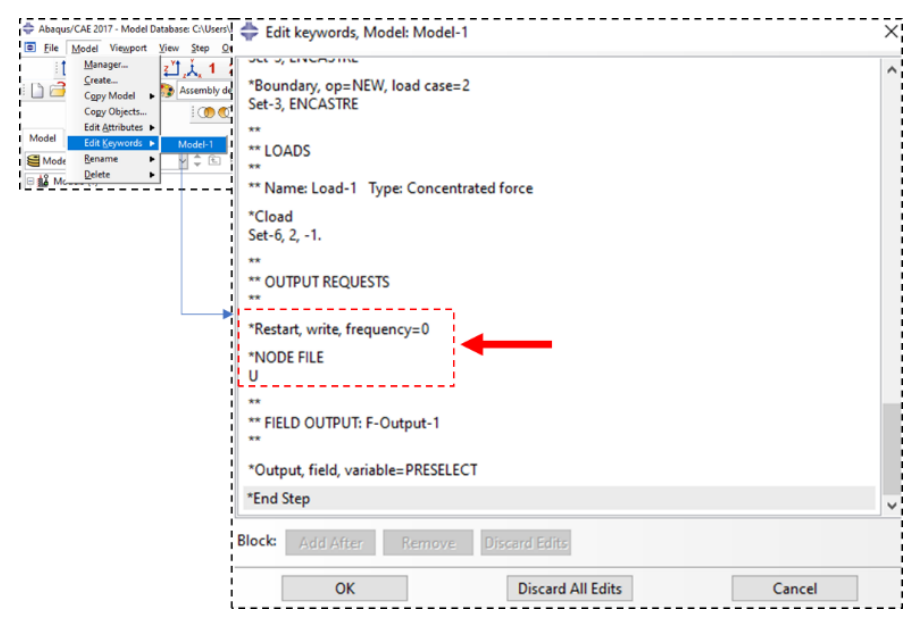

Figura A. 11 - Janela para geração de arquivo de saída com coordenadas dos nós para os modos de flambagem.

Então, cria-se um novo modelo com a etapa da análise de "RIKS", sem o "BUCKLE", e para que a análise seja efetuada, algumas modificações devem ser feitas no modelo. O indicador da não linearidade geométrica "NLGEOM" deve estar ativado, para que seja considerado os efeitos da não linearidade. Durante essa etapa deve-se existir uma carga na estrutura. Essa carga pode ser de qualquer valor, porém adota-se a carga como unitária ou a carga crítica do modelo, a justificativa de tal abordagem será comentada na próxima seção. Após a definição da carga do modelo, as imperfeições devem ser inseridas através das palavras-chave do modelo, Figura A. 12. Um ponto muito importante dessa etapa final é que quando se tem mais de uma etapa na análise a inserção das imperfeições deve se dar na primeira etapa. Um exemplo são as análises efetuadas nesse trabalho, a etapa inicial é sempre uma etapa estática geral, onde são computadas todas as condições iniciais como peso próprio e pré-tensão nos cabos, seguida da etapa de análise de "RIKS". A inserção das imperfeições se dá na etapa estática geral.

Um outro ponto a se salientar é a possibilidade de interações entre modos, onde são inseridas várias imperfeições cada uma em um modo diferente. 


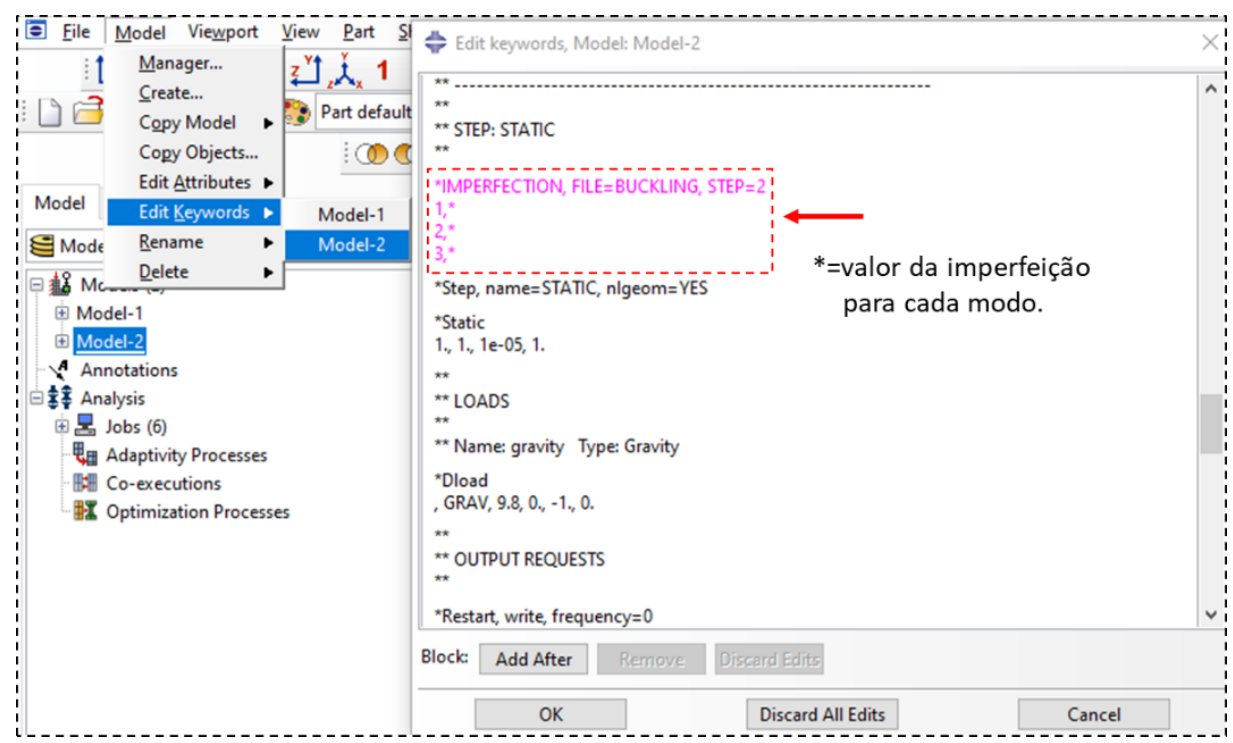

Figura A. 12 - Inserção das imperfeições modais.

\section{A. 4.1.2 \\ Parâmetros de Controle e Saída}

Após a escolha e inserção do tipo de imperfeição desejado, o processamento necessita da definição dos parâmetros de controle para o algoritmo. A integração numérica pode ser controlada por incrementos do tamanho do arco dos tipos fixos ou automáticos. A diferença basicamente é que no primeiro o usuário insere um incremento padrão que será seguido pelo algoritmo até o número máximo de incrementos fornecido pelo usuário. Na segunda opção, o tamanho do arco é variável e calculado pelo programa de acordo com parâmetros definidos pelo usuário, mas também respeita a quantidade máxima de incrementos. Esses dois tipos de controles são apresentados na Figura A. 13.

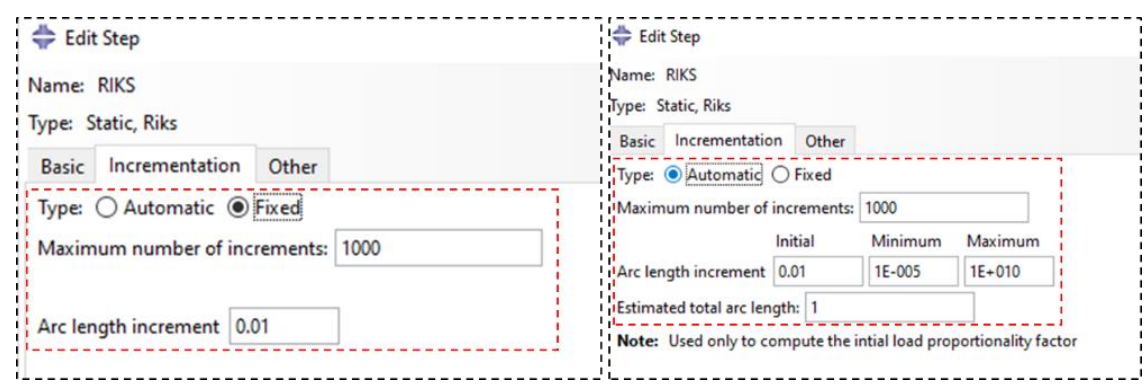

Figura A. 13 - Tipos de controle de integração "RIKS".

A resposta do modelo quanto ao carregamento, é um fator multiplicador "LPF", Figura A. 14. Então, ao se adotar a carga do modelo como unitária os valores de saída serão diretamente os valores de carga da análise. Em contrapartida, ao se 
adotar carga do modelo como a carga crítica, a saída será de fato um fator multiplicador e o resultado obtido no "LPF" deve ser multiplicado pelo $\mathrm{P}_{\mathrm{cr}}$.

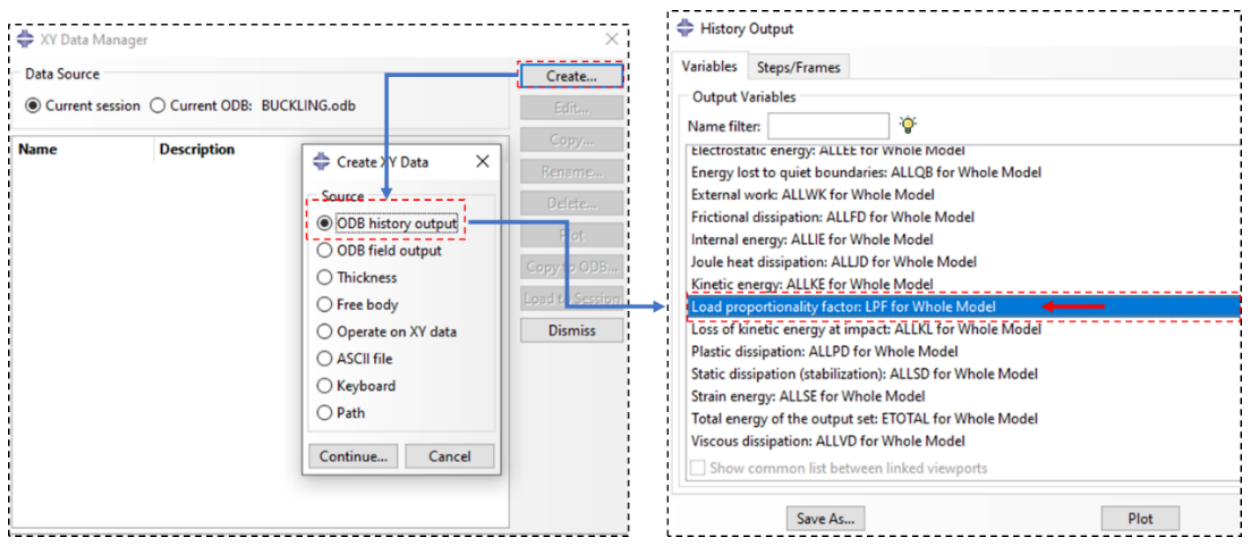

Figura A. 14 - Arquivos de saída para análise de "RIKS".

\section{A. 4.2 \\ Dinâmica Não Linear}

Para o cálculo das repostas dinâmicas dos modelos de torres estaiadas no programa $\mathrm{ABAQUS} \circledast$, os modelos foram submetidos a dois tipos de carregamentos nessa etapa. Incialmente, em algumas análises, aplicou-se uma imperfeição gerada por cargas estáticas na etapa de análise estática geral que é anterior a esta. Em todas as análises na etapa anterior à dinâmica, há a presença das cargas de pré-tensão e de peso próprio, sendo estas propagadas para a etapa dinâmica. Todas as análises dinâmicas possuem um amortecimento estrutural de 1\%, inserido como amortecimento proporcional em cada um dos materiais

\section{A. 4.2.1 Tipos de carregamentos}

$\mathrm{Na}$ etapa dinâmica as cargas aplicadas são de dois tipos, pulsos ou harmônicas. O carregamento de pulso é simulado por uma carga atuando na estrutura durante um curto período de tempo, durante as análises de vibração livre amortecida. No caso dos estudos abordados o período do pulso é de 0,05 segundos, inserido no programa como uma força que é função de uma amplitude. O tempo referente ao incremento desejado da existência da força, é inserido com amplitude unitária e logo após, no próximo incremento de tempo zera-se o valor da amplitude, Figura A. 15. 


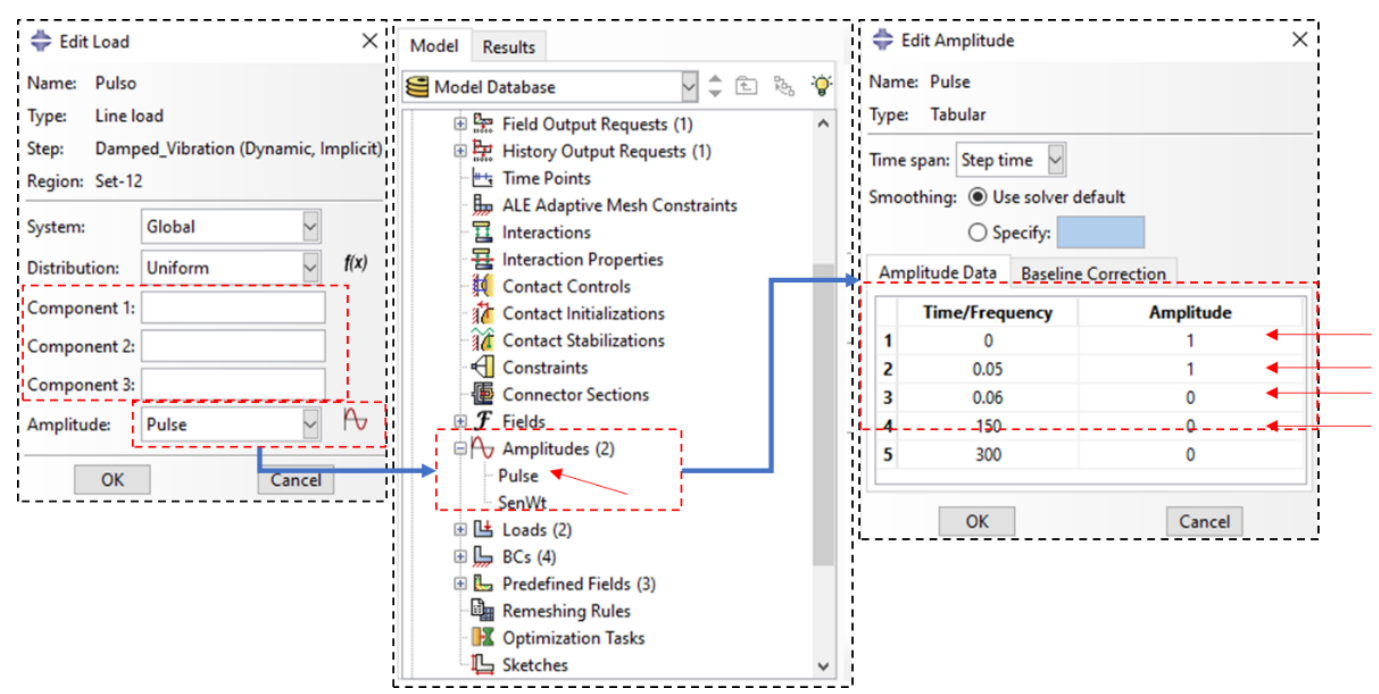

Figura A. 15 - Inserção de Força de Pulso.

Para o carregamento harmônico, a definição é basicamente a mesma: inserese o tempo e a amplitude da carga referente a cada tempo de integração, incremento de carga, fazendo com que a força aplicada seja um carregamento harmônico, Figura A. 16. Para os estudos da vibração forçada amortecida a frequência do harmônico da carga é muito próxima à frequência natural da estrutura, $\Omega$. $\mathrm{O}$ harmônico gerado é uma função seno, apresentada na Eq.(15).

$$
\mathrm{F}(\mathrm{t})=\operatorname{sen}(\Omega \mathrm{t})
$$

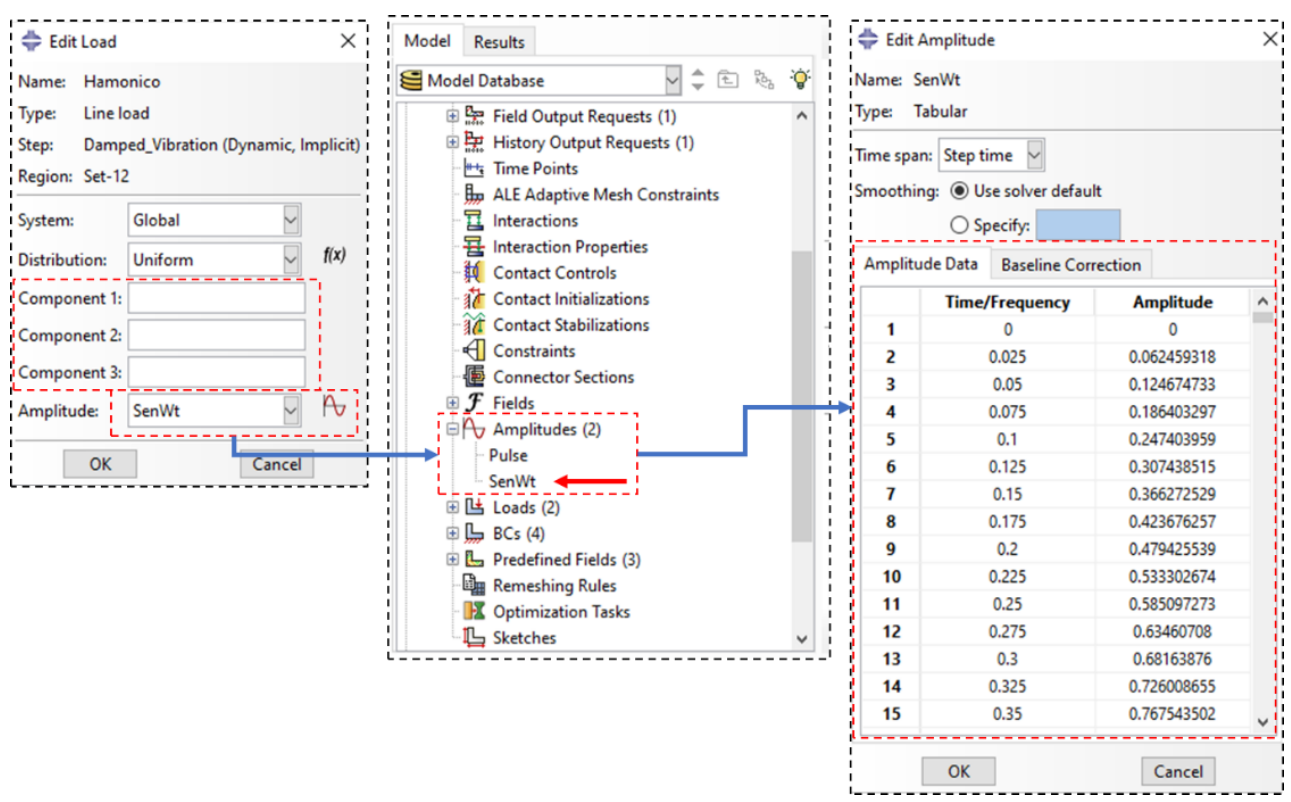

Figura A. 16 - Inserção de força harmônica. 
Para os dois casos de carga pulso e harmônico, quando há a necessidade da variação do ângulo de incidência da carga, a forca é decomposta em seno e cosseno do ângulo de incidência e aplicada nas componentes no eixo X e Z.

\section{A. 4.2.2}

\section{Parâmetros de controle}

Os primeiros parâmetros definidos para as análises dinâmicas dizem respeito à integração numérica. $\mathrm{O}$ módulo possibilita uma integração por incrementos fixos ou automáticos, Figura A. 17. No primeiro fixa-se o tamanho do passo de integração relacionando-o ao número máximo de incrementos como uma função do tempo total; no segundo não se controla o tamanho do incremento de tempo durante a análise. Neste trabalho foi adotado o incremento fixo.

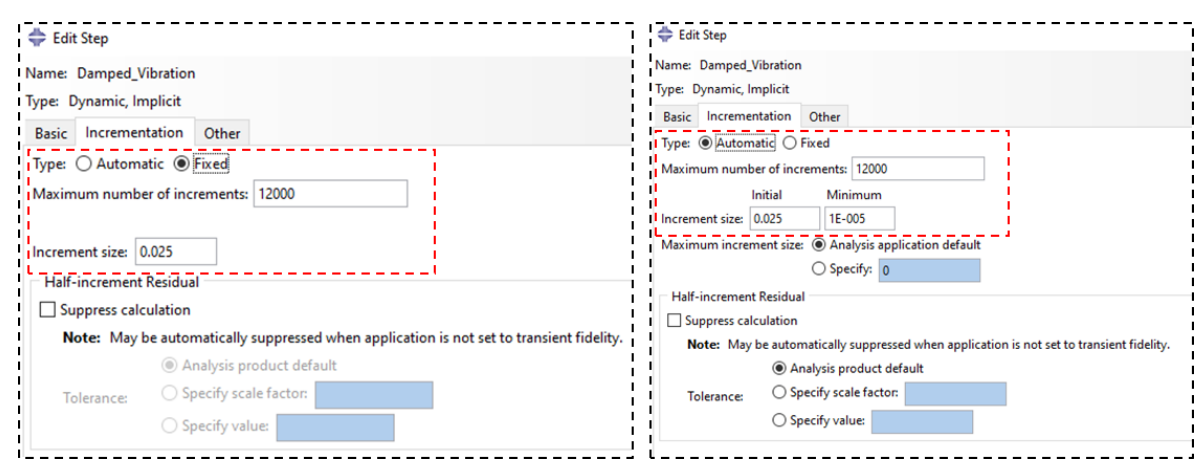

Figura A. 17 - Tipos de controle para análise dinâmica.

O tamanho do incremento de tempo $(\Delta t)$ é definido em relação ao período fundamental que é relacionado à frequência natural do modelo em $\mathrm{Hz}$ como um centésimo desse valor, Eq. (16). Todas as análises da torre do modelo sintético padrão são para um tempo de observação de 300s. Logo, a relação entre o tempo total, passo de tempo e número máximo de incrementos é encontrado pela relação apresentada na Eq. (17).

$$
\begin{gathered}
\Delta \mathrm{t}=\left(\frac{1}{\omega_{1}}\right) \frac{1}{100} \\
\mathrm{~N}_{\text {incrementos }}=300 / \Delta \mathrm{t}
\end{gathered}
$$

Com a definição dos passo e da carga aplicada no modelo, gera-se o arquivo .inp na seção de processamento. Nesse arquivo são alteradas as configurações do algoritmo de integração, onde o método HTT-alpha é modificado em função dos parâmetros alpha, beta e gamma para que o novo método seja Newmark- $\beta$ com um 
pequeno amortecimento. Esses parâmetros são inseridos com os respectivos valores de 0;0,3025 e 0,6. Para alterar procede-se como apresentado na Figura A. 18. Esta imagem apresenta o arquivo original e como ele fica após ser alterado.

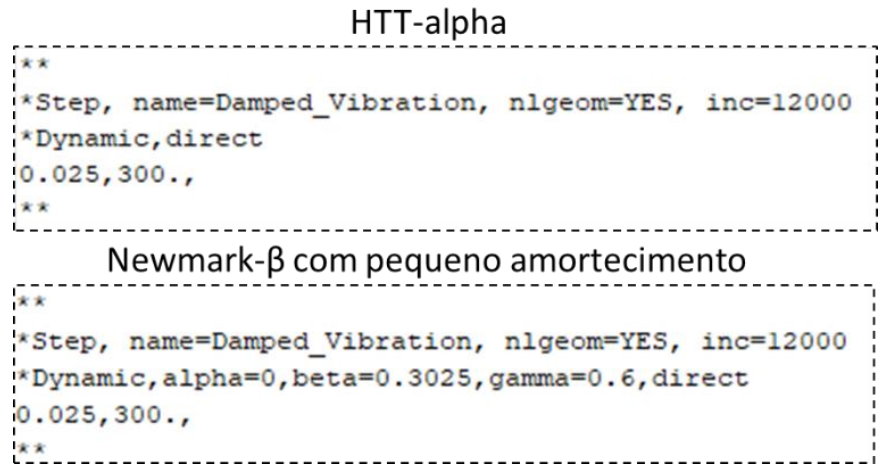

Figura A. 18 - Manipulação do método HTT-alpha para método Newmark- $\beta$.

\section{A. 4.2 .3 Respostas}

Após a inserção dos parâmetros de controle e do carregamento, a análise corre e são geradas as respostas no tempo. Para coletar os dados basta selecionar os dados de saída desejados em nós específicos. Para as análises deste trabalho foram coletados os dados de deslocamento e velocidade no topo da torre nas direções dos três eixos, X, Y e Z. O passo a passo desse processo é apresentado na Figura A. 19.

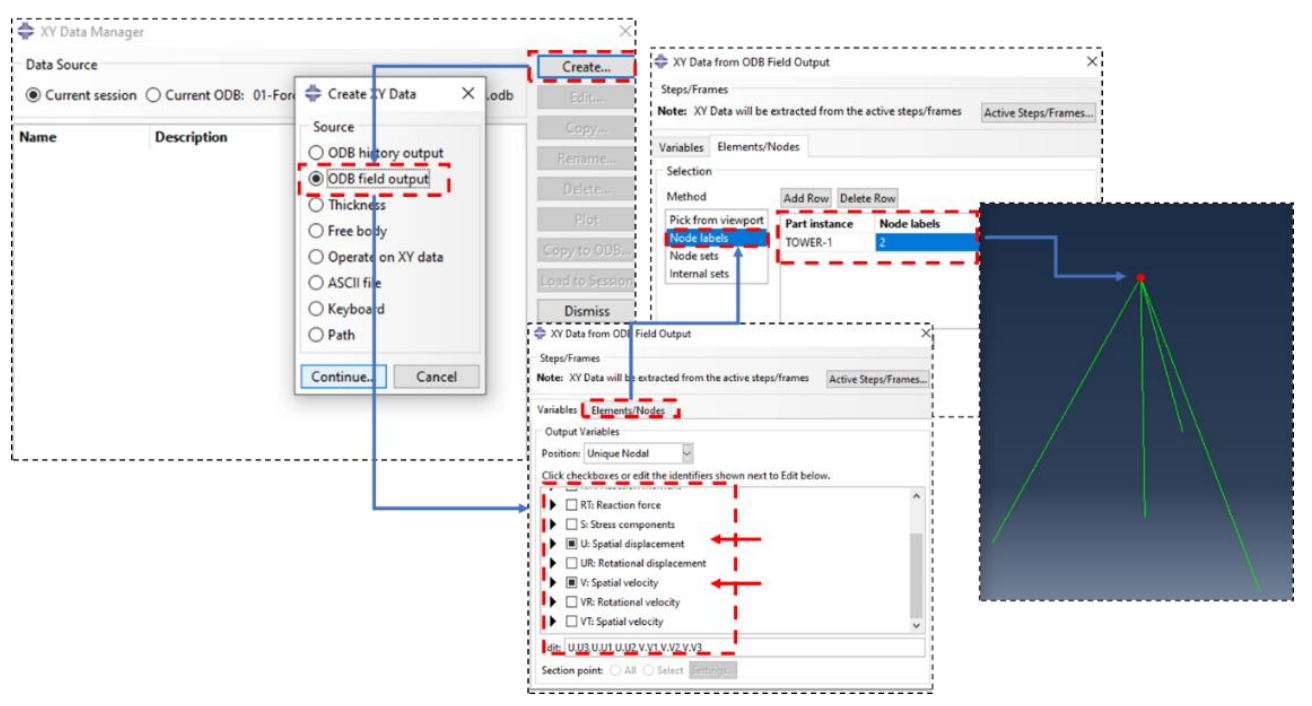

Figura A. 19 - Geração dos arquivos de resposta para análise dinâmica. 


\section{Apêndice B}

Respostas dinâmicas para $\beta=0^{\circ}$

Neste anexo são apresentadas todas as respostas dinâmicas para a estrutura quanto a variação da magnitude da força harmônica $\operatorname{com} \beta=0^{\circ}$. São expostas as respostas no tempo, análise FFT, análise no espectro de frequência por espectrograma no plano, análise no espectro de frequência por espectrograma no espaço, planos de fase relacionando Velocidade $x$ Deslocamento no eixo X,

Mapeamento de Poincaré no plano XZ, Mapeamento de Poincaré relacionando Velocidade $x$

Deslocamento no eixo X, respectivamente Figura B. 1, Figura B. 2, Figura B. 3, Figura B. 4,

Figura B. 5, Figura B. 6 e Figura B. 7.
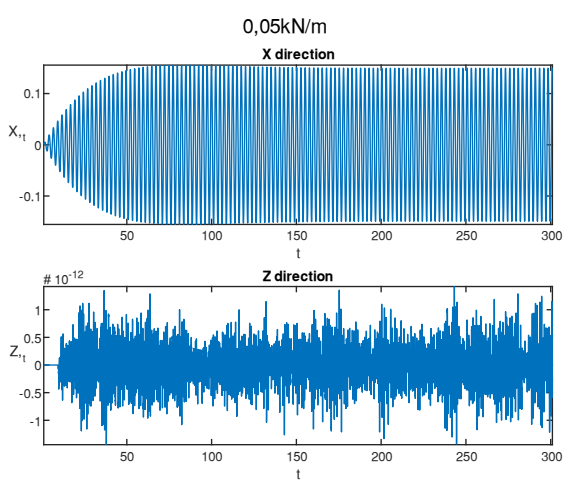

(a) $F=0,05 \mathrm{kN} / \mathrm{m} \operatorname{com} \beta=0^{\circ}$.
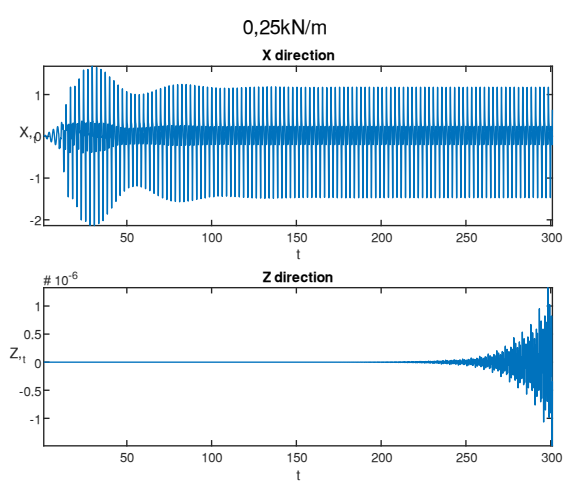

(c) $F=0,25 \mathrm{kN} / \mathrm{m} \operatorname{com} \beta=0^{\circ}$.
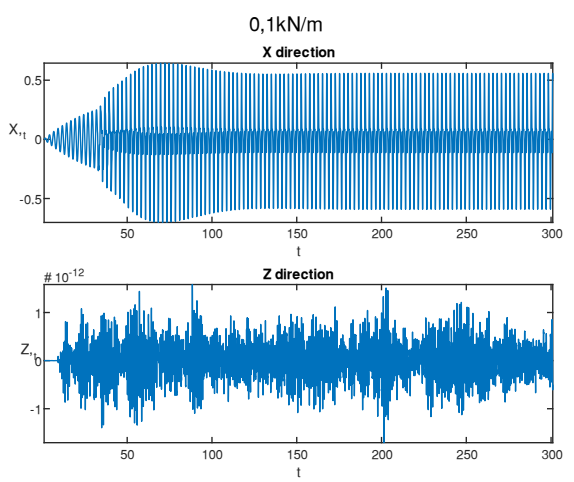

(b) $F=0,1 \mathrm{kN} / \mathrm{m} \operatorname{com} \beta=0^{\circ}$.

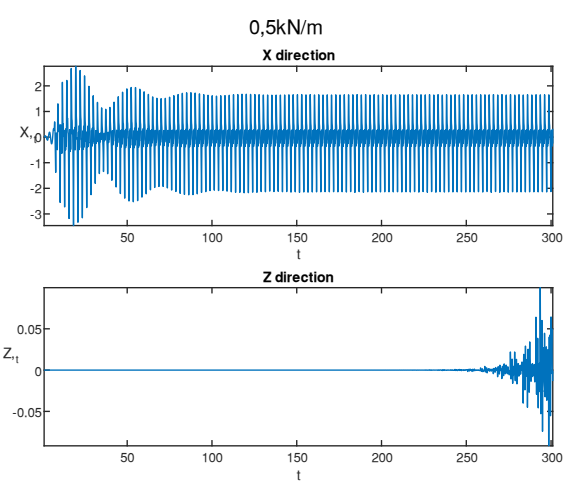

(d) $F=0,5 \mathrm{kN} / \mathrm{m} \operatorname{com} \beta=0^{\circ}$. 

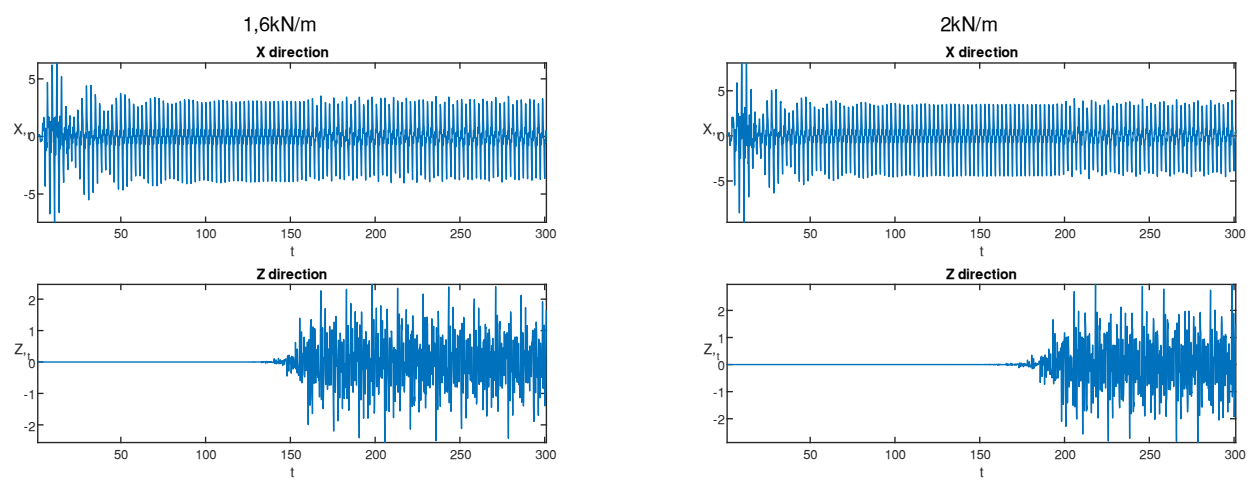

(e) $F=1,6 \mathrm{kN} / \mathrm{m} \operatorname{com} \beta=0^{\circ}$.

(f) $F=2 \mathrm{kN} / \mathrm{m} \operatorname{com} \beta=0^{\circ}$.
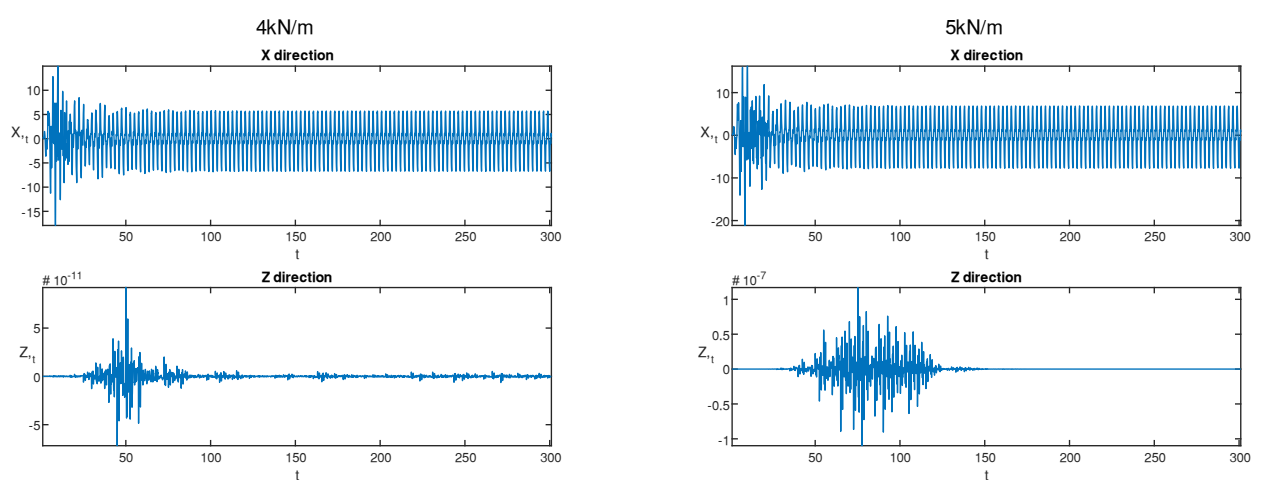

(g) $F=4 k N / m \operatorname{com} \beta=0^{\circ}$.

(h) $F=5 \mathrm{kN} / \mathrm{m} \operatorname{com} \beta=0^{\circ}$.

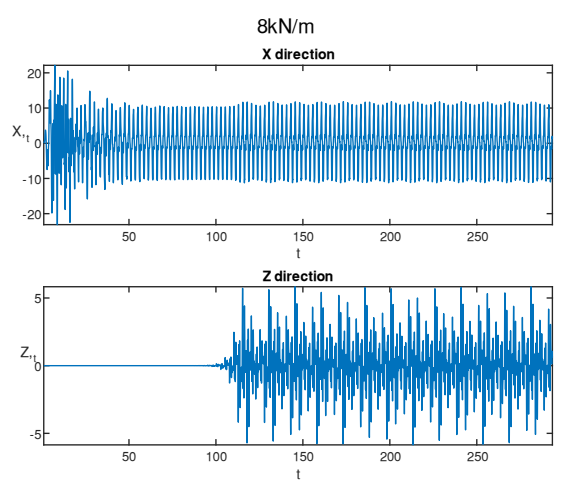

(i) $F=8 \mathrm{kN} / \mathrm{m} \operatorname{com} \beta=0^{\circ}$.

Figura B. 1 - Influência da magnitude da força na resposta em regime permanente com $\beta=0^{\circ}$, resposta no tempo. 


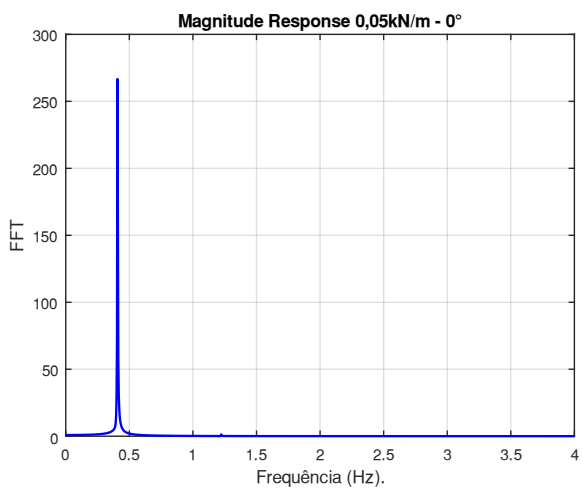

(a) $F=0,05 \mathrm{kN} / \mathrm{m} \operatorname{com} \beta=0^{\circ}$.

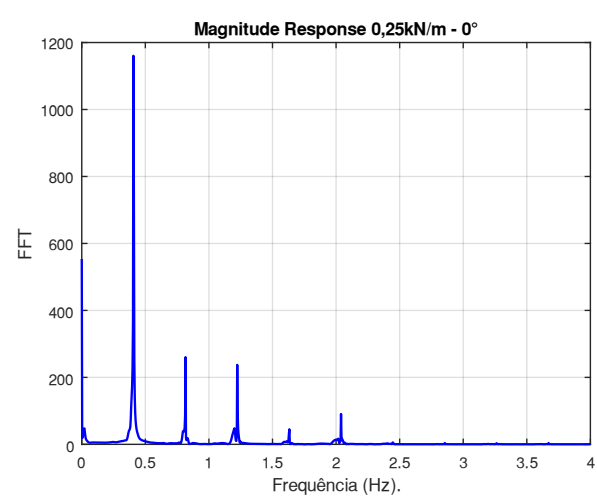

(c) $F=0,25 \mathrm{kN} / \mathrm{m} \operatorname{com} \beta=0^{\circ}$.

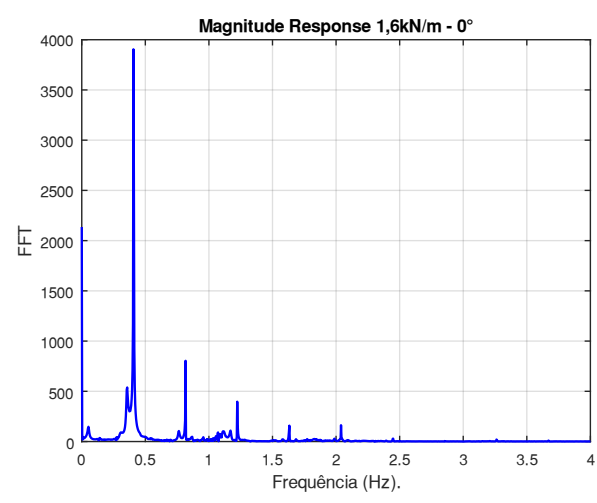

(e) $F=1,6 \mathrm{kN} / \mathrm{m} \operatorname{com} \beta=0^{\circ}$.

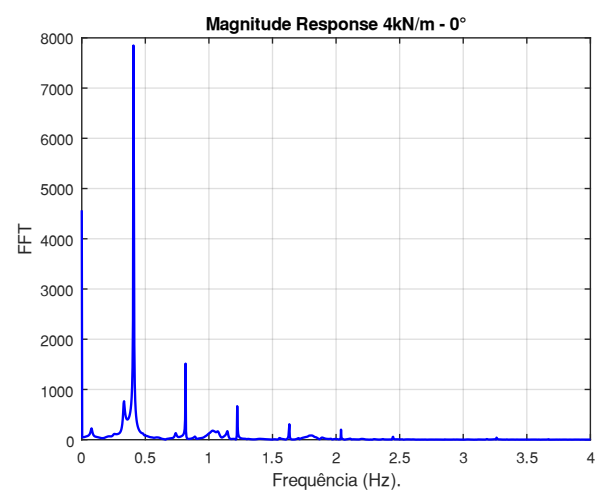

(g) $F=4 \mathrm{kN} / \mathrm{m} \operatorname{com} \beta=0^{\circ}$.

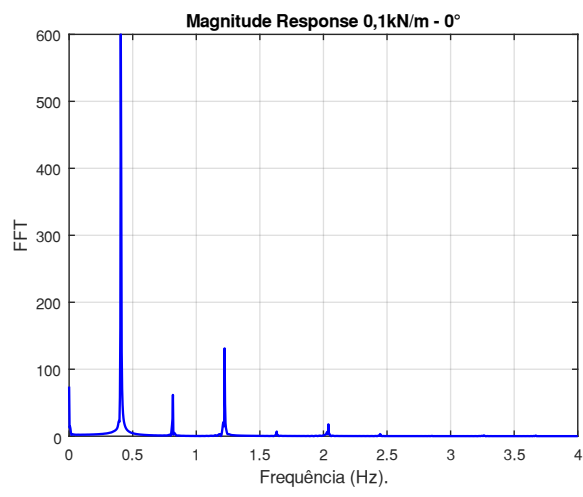

(b) $F=0,1 \mathrm{kN} / \mathrm{m} \operatorname{com} \beta=0^{\circ}$.

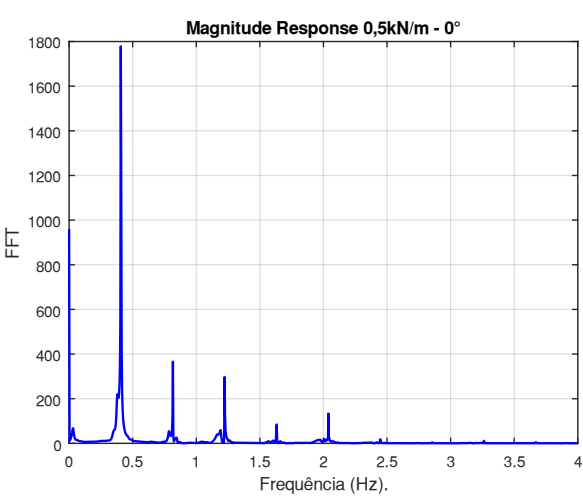

(d) $F=0,5 \mathrm{kN} / \mathrm{m} \operatorname{com} \beta=0^{\circ}$.

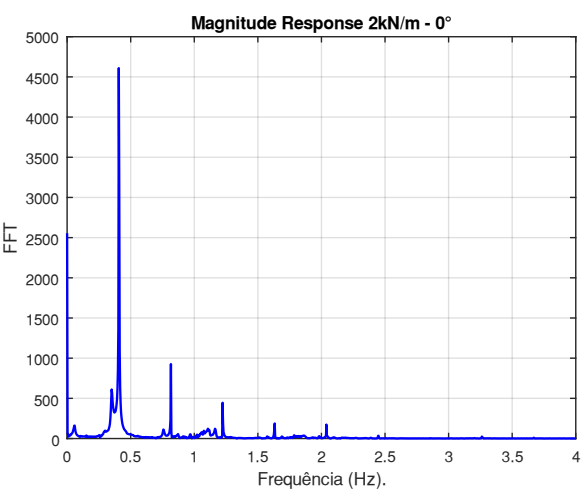

(f) $F=2 \mathrm{kN} / \mathrm{m} \operatorname{com} \beta=0^{\circ}$.

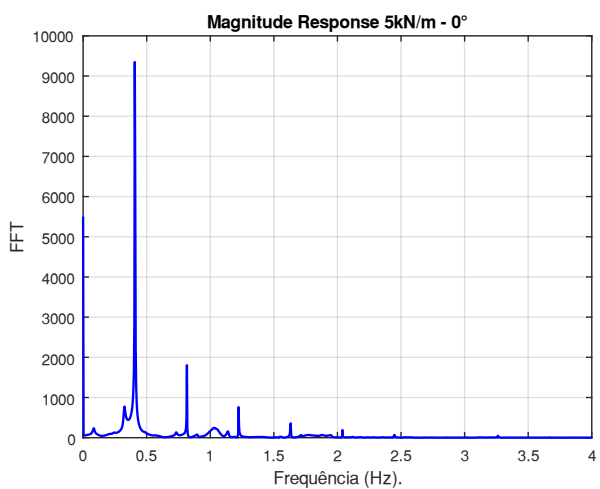

(h) $F=5 \mathrm{kN} / \mathrm{m} \operatorname{com} \beta=0^{\circ}$. 


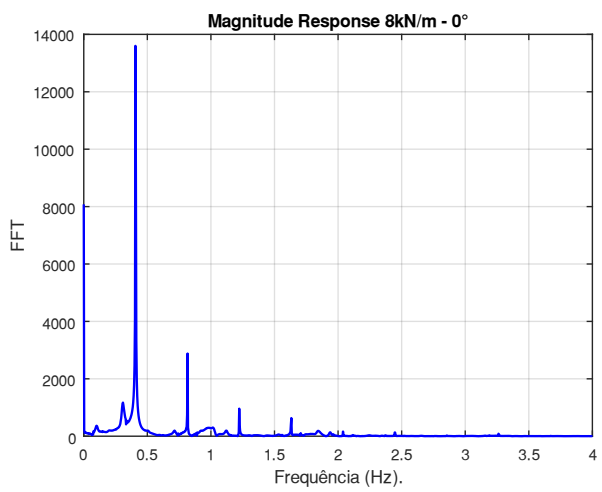

(i) $\quad F=8 \mathrm{kN} / \mathrm{m} \operatorname{com} \beta=0^{\circ}$.

Figura B. 2 - Influência da magnitude da força na resposta em regime permanente com $\beta=0^{\circ}$, análise de frequências FFT.

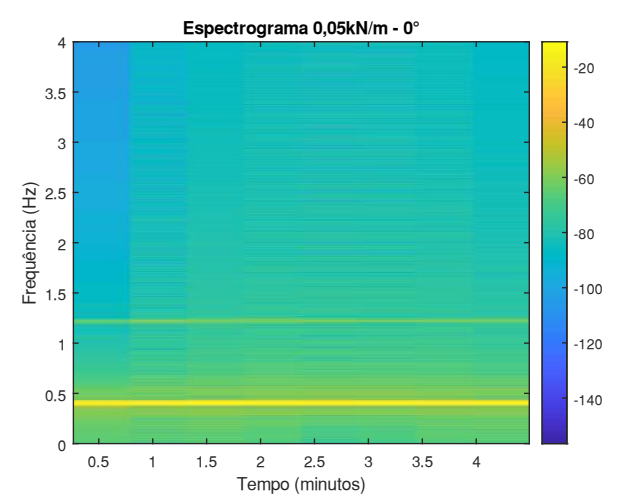

(a) $F=0,05 \mathrm{kN} / \mathrm{m} \operatorname{com} \beta=0^{\circ}$.

Espectrograma 0,25kN/m - $0^{\circ}$

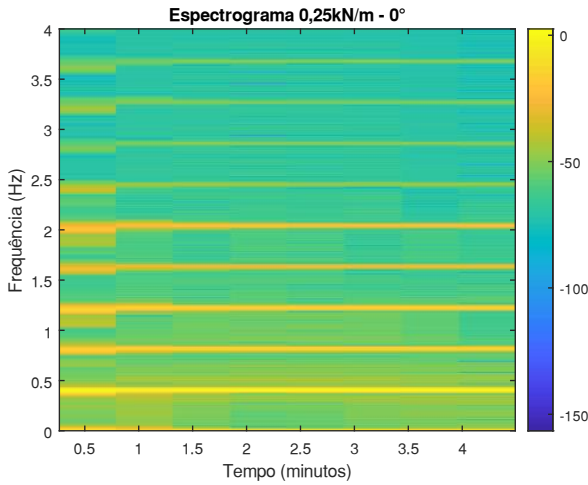

(c) $F=0,25 \mathrm{kN} / \mathrm{m} \operatorname{com} \beta=0^{\circ}$.

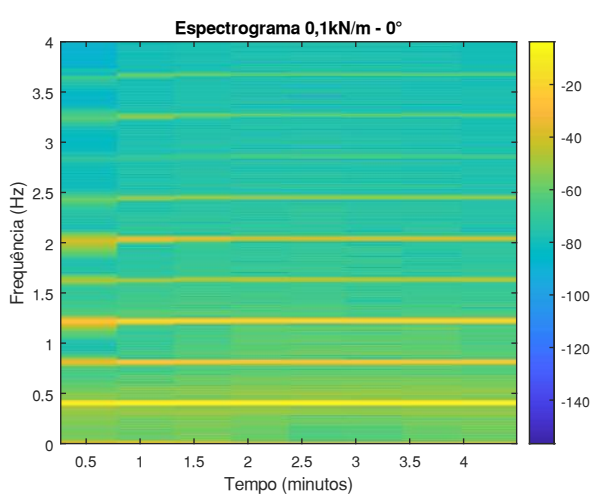

(b) $F=0,1 \mathrm{kN} / \mathrm{m} \operatorname{com} \beta=0^{\circ}$.

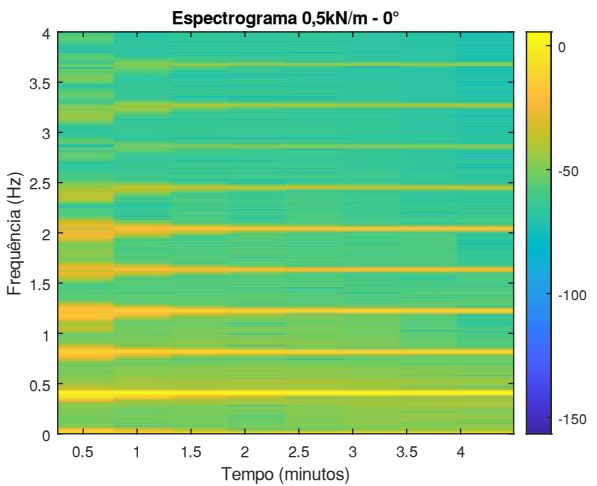

(d) $F=0,5 \mathrm{kN} / \mathrm{m} \operatorname{com} \beta=0^{\circ}$. 


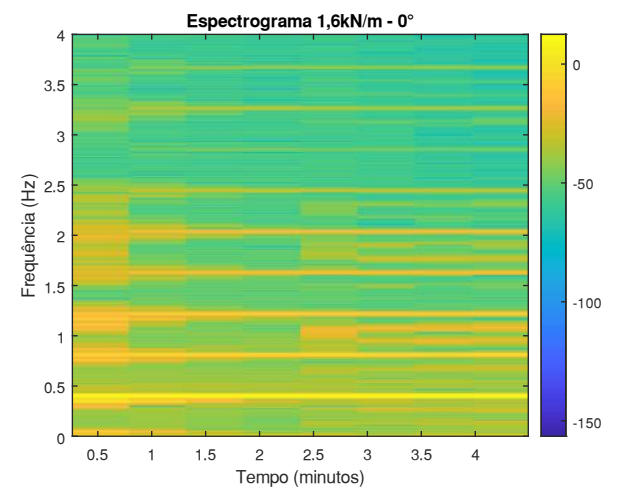

(e) $F=1,6 \mathrm{kN} / \mathrm{m} \operatorname{com} \beta=0^{\circ}$.

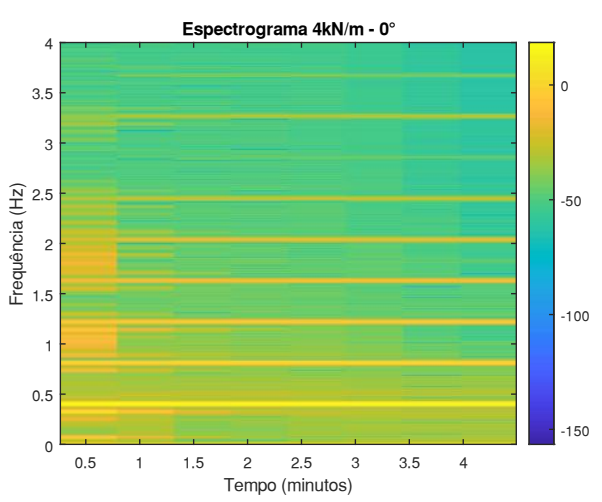

(g) $F=4 k N / m \operatorname{com} \beta=0^{\circ}$.

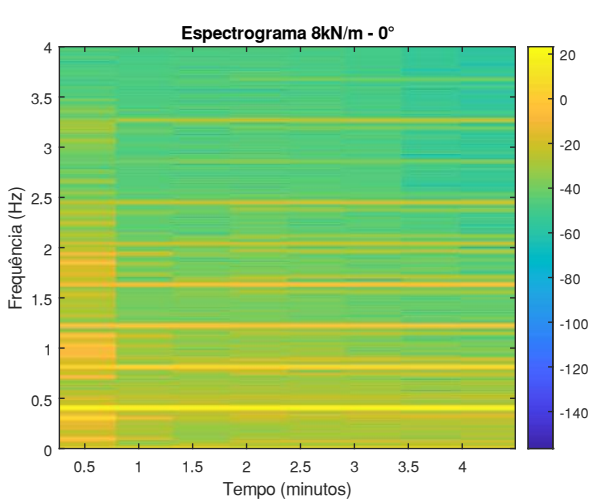

(i) $F=8 \mathrm{kN} / \mathrm{m} \operatorname{com} \beta=0^{\circ}$.

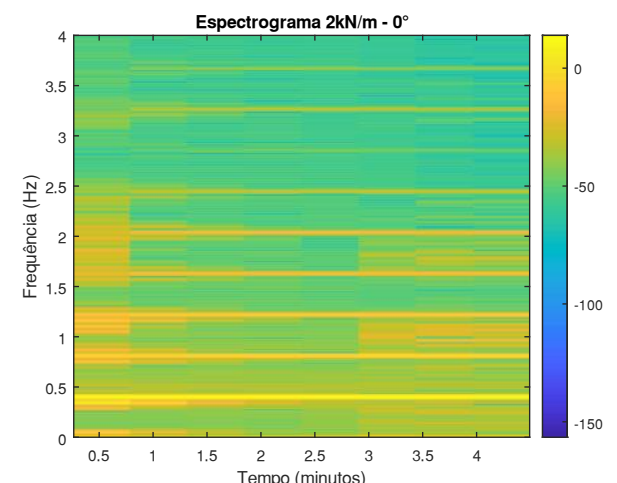

(f) $F=2 \mathrm{kN} / \mathrm{m} \operatorname{com} \beta=0^{\circ}$.

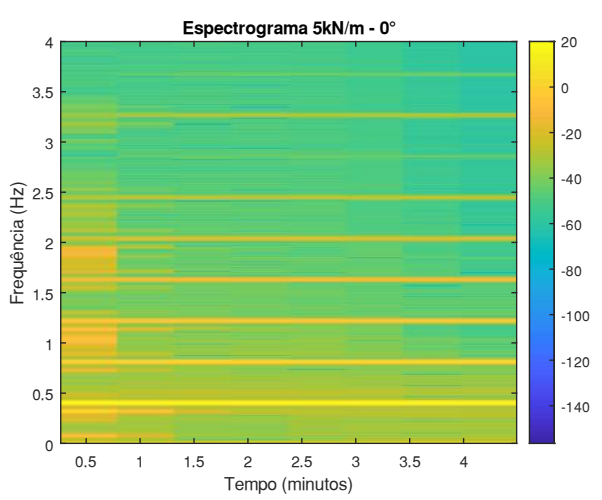

(h) $F=5 \mathrm{kN} / \mathrm{m} \operatorname{com} \beta=0^{\circ}$.

Figura B. 3 - Influência da magnitude da força na resposta em regime permanente $\operatorname{com} \beta=0^{\circ}$, análise de frequências espectrograma 2D. 


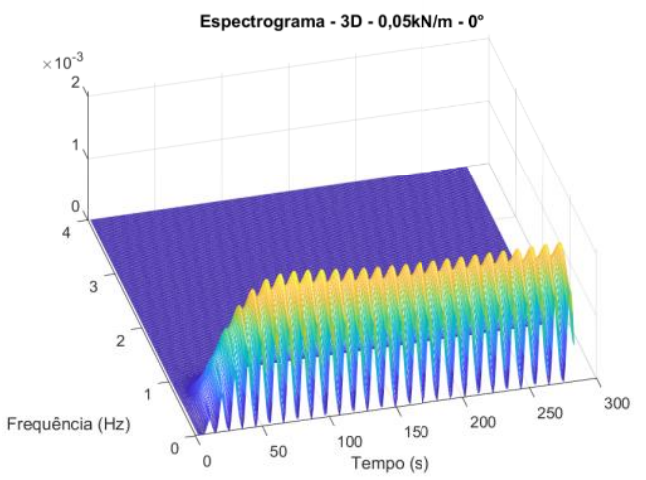

(a) $F=0,05 \mathrm{kN} / \mathrm{m} \operatorname{com} \beta=0^{\circ}$.

Espectrograma - 3D - 0,25kN/m - $0^{\circ}$

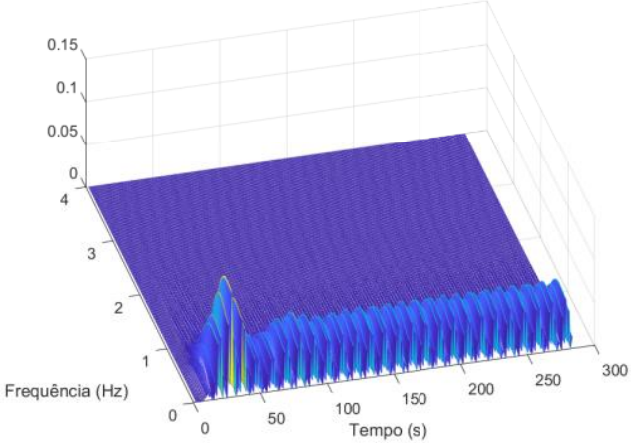

(c) $F=0,25 \mathrm{kN} / \mathrm{m} \operatorname{com} \beta=0^{\circ}$.

Espectrograma - 3D - 1,6kN/m - $0^{\circ}$

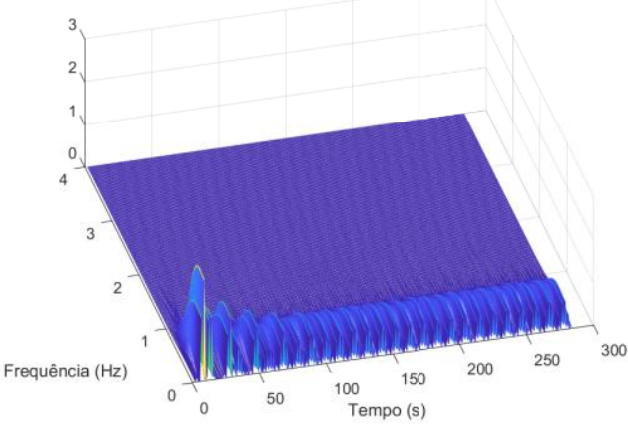

(e) $F=1,6 \mathrm{kN} / \mathrm{m} \operatorname{com} \beta=0^{\circ}$.

Espectrograma - 3D - 4kN/m - $0^{\circ}$

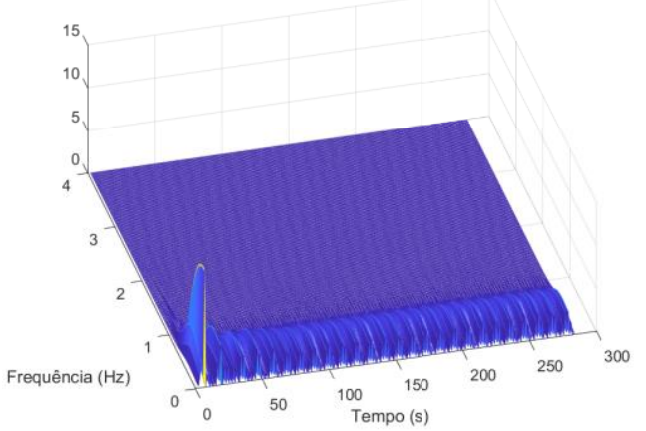

(g) $F=4 \mathrm{kN} / \mathrm{m} \operatorname{com} \beta=0^{\circ}$.

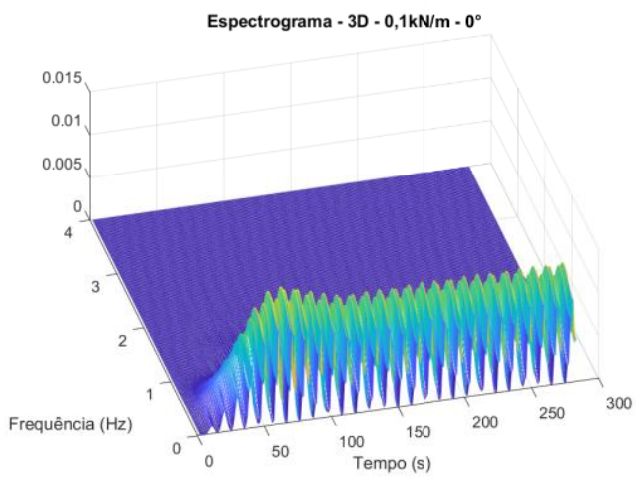

(b) $F=0,1 \mathrm{kN} / \mathrm{m} \operatorname{com} \beta=0^{\circ}$.

Espectrograma - 3D - $0,5 \mathrm{kN} / \mathrm{m} \cdot 0^{\circ}$

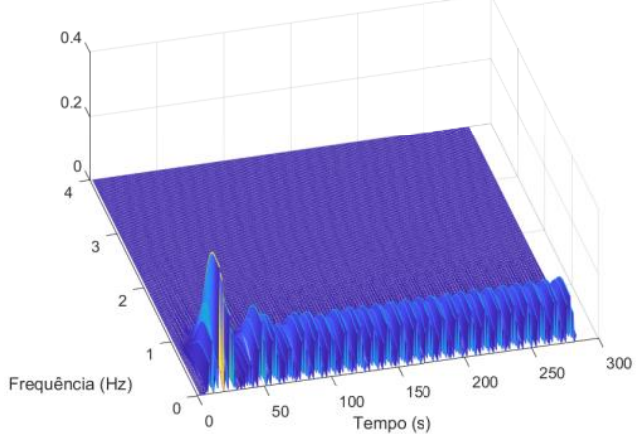

(d) $F=0,5 \mathrm{kN} / \mathrm{m} \operatorname{com} \beta=0^{\circ}$.

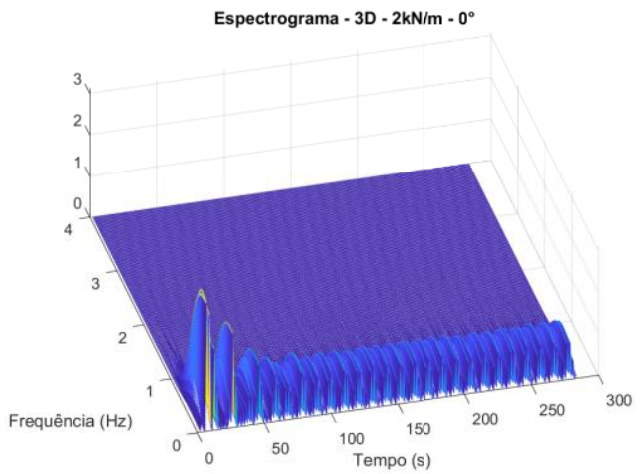

(f) $F=2 \mathrm{kN} / \mathrm{m} \operatorname{com} \beta=0^{\circ}$. Espectrograma - 3D - $5 \mathrm{kN} / \mathrm{m}=0^{\circ}$

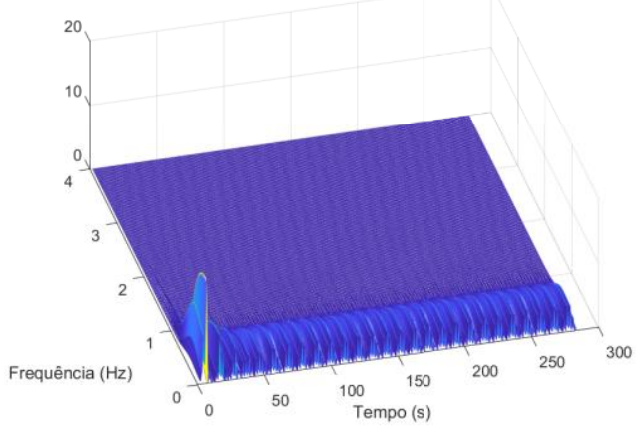

(h) $F=5 \mathrm{kN} / \mathrm{m} \operatorname{com} \beta=0^{\circ}$. 


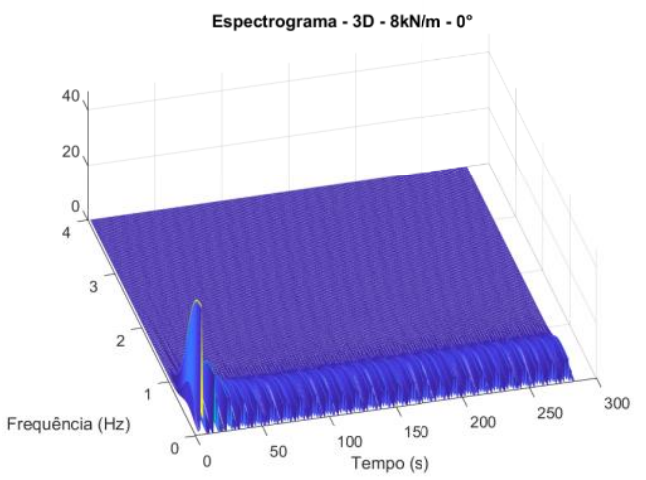

(i) $\quad F=8 \mathrm{kN} / \mathrm{m} \operatorname{com} \beta=0^{\circ}$.

Figura B. 4 - Influência da magnitude da força na resposta em regime permanente com $\beta=0^{\circ}$, análise de frequências espectrograma 3D

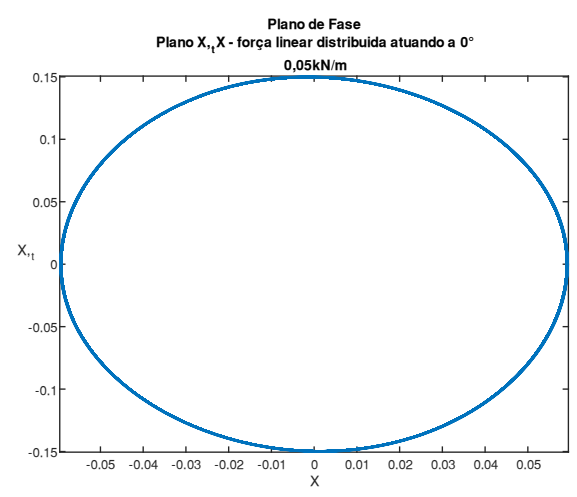

(a) $F=0,05 \mathrm{kN} / \mathrm{m} \operatorname{com} \beta=0^{\circ}$.

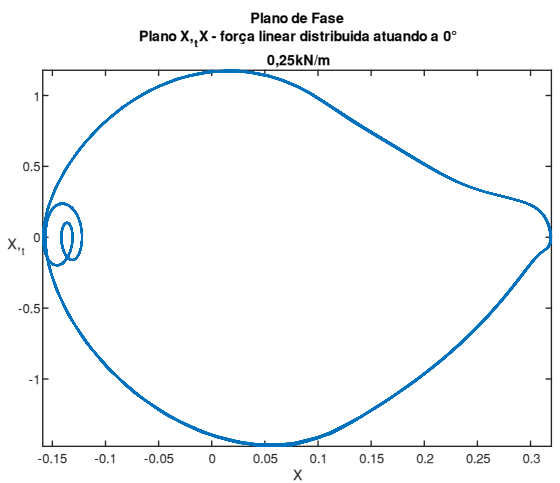

(c) $F=0,25 \mathrm{kN} / \mathrm{m} \operatorname{com} \beta=0^{\circ}$.

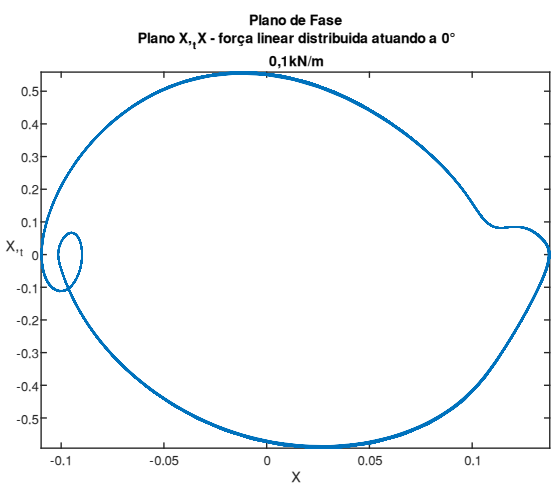

(b) $F=0,1 \mathrm{kN} / \mathrm{m} \operatorname{com} \beta=0^{\circ}$.

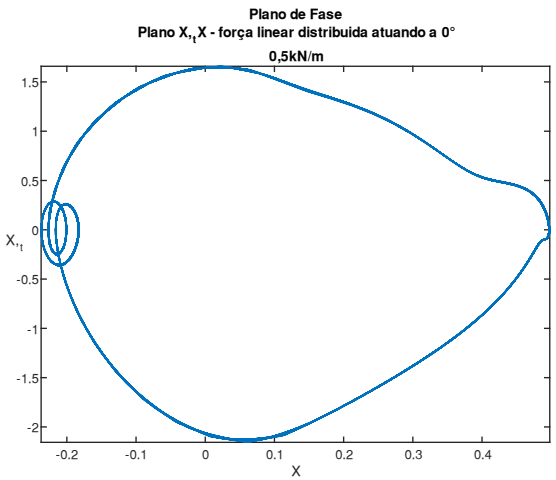

(d) $F=0,5 \mathrm{kN} / \mathrm{m} \operatorname{com} \beta=0^{\circ}$. 

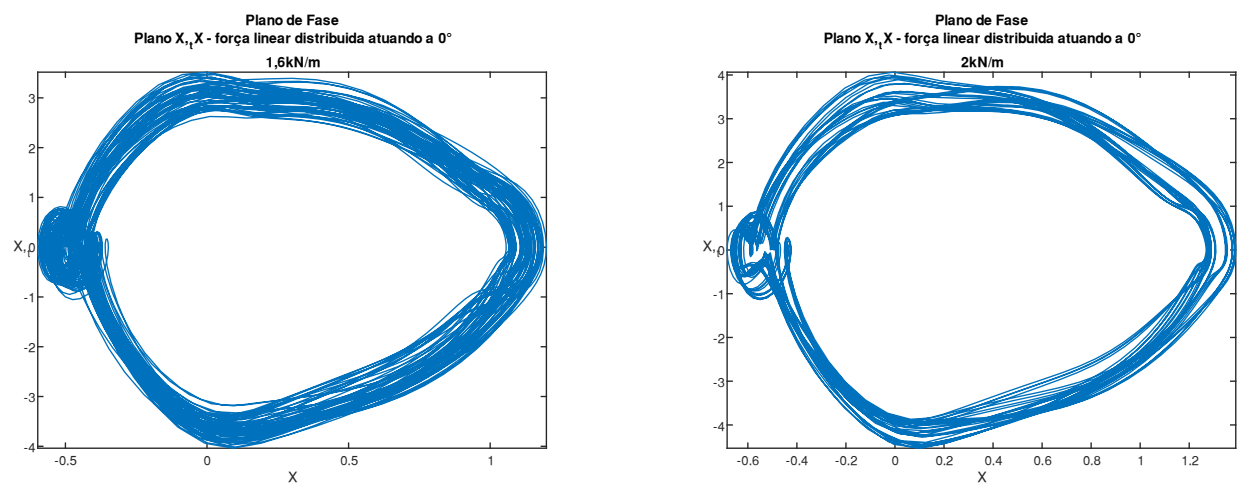

(e) $F=1,6 \mathrm{kN} / \mathrm{m} \operatorname{com} \beta=0^{\circ}$.

(f) $F=2 \mathrm{kN} / \mathrm{m} \operatorname{com} \beta=0^{\circ}$.
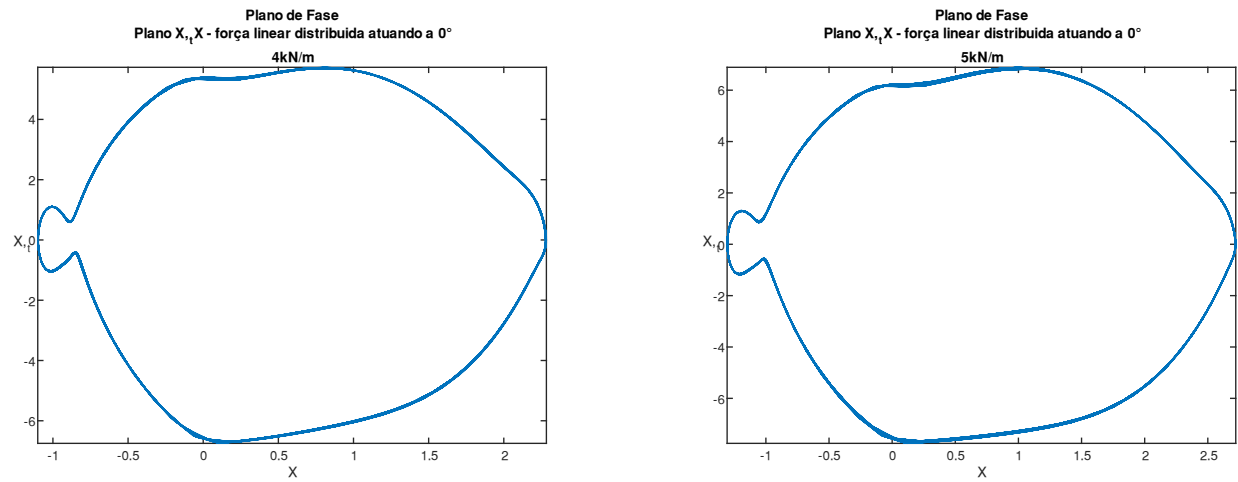

(g) $F=4 \mathrm{kN} / \mathrm{m} \operatorname{com} \beta=0^{\circ}$.

(h) $F=5 \mathrm{kN} / \mathrm{m} \operatorname{com} \beta=0^{\circ}$.

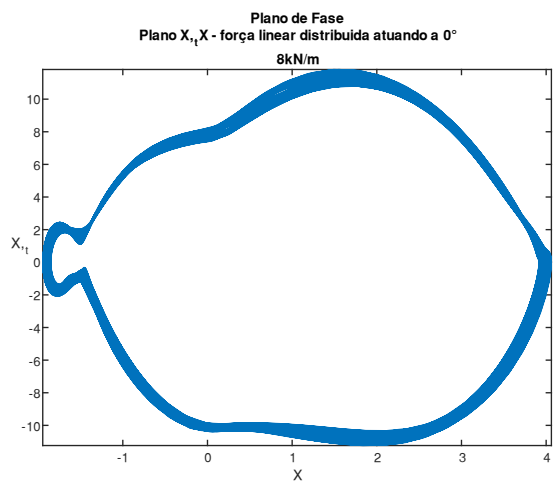

(i) $F=8 \mathrm{kN} / \mathrm{m} \operatorname{com} \beta=0^{\circ}$.

Figura B. 5 - Influência da magnitude da força na resposta em regime permanente $\operatorname{com} \beta=0^{\circ}$,

Planos de fase Velocidade x Deslocamento no eixo X. 


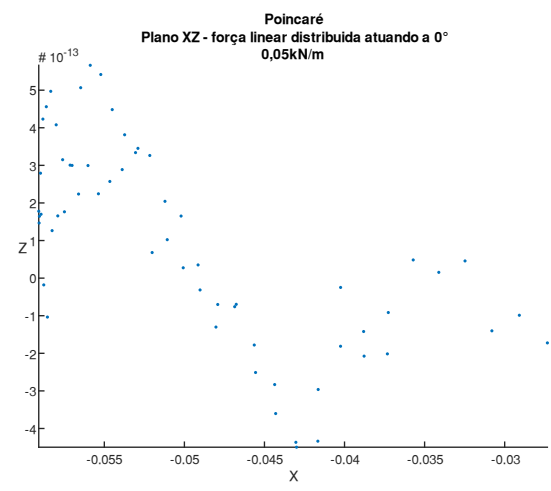

(a) $F=0,05 \mathrm{kN} / \mathrm{m} \operatorname{com} \beta=0^{\circ}$.

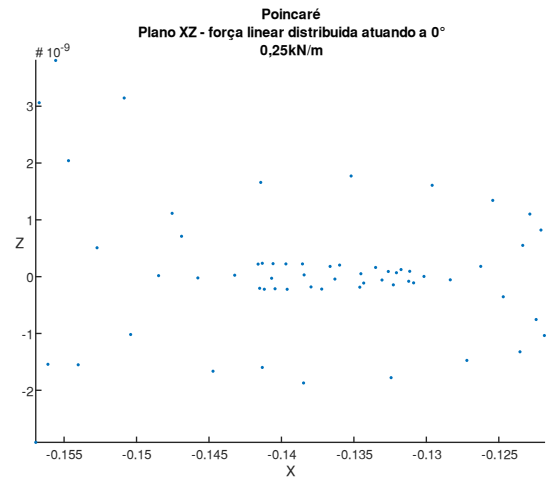

(c) $F=0,25 \mathrm{kN} / \mathrm{m} \operatorname{com} \beta=0^{\circ}$. Plano XZ - força linear distribuida atuando a $0^{\circ}$

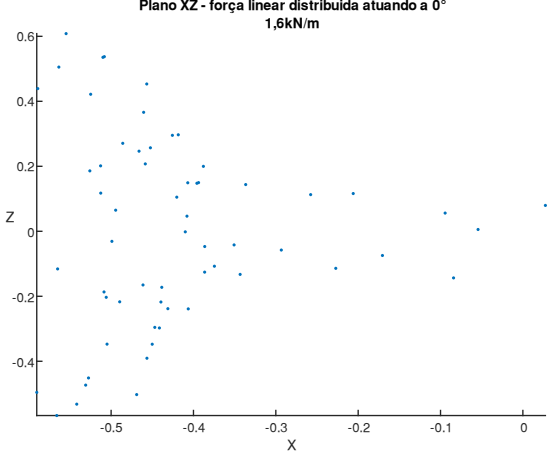

(e) $F=1,6 \mathrm{kN} / \mathrm{m} \operatorname{com} \beta=0^{\circ}$. Plano XZ - força linear distribuida atuando a $0^{\circ}$

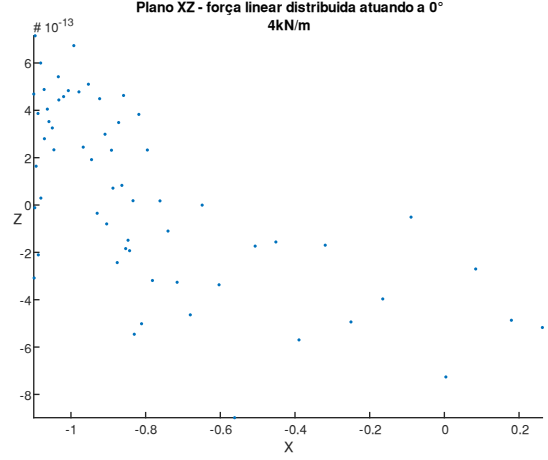

(g) $F=4 \mathrm{kN} / \mathrm{m} \operatorname{com} \beta=0^{\circ}$.

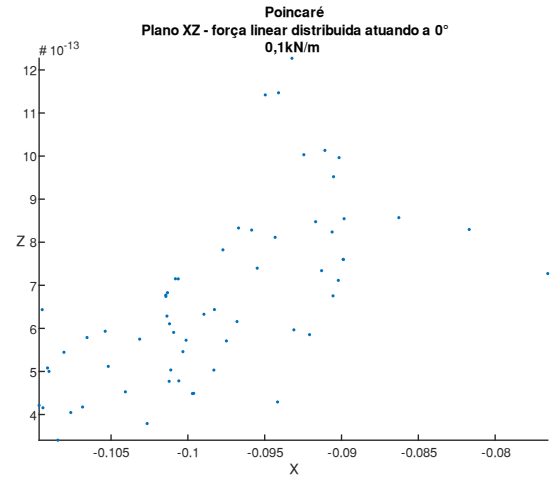

(b) $F=0,1 \mathrm{kN} / \mathrm{m} \operatorname{com} \beta=0^{\circ}$.

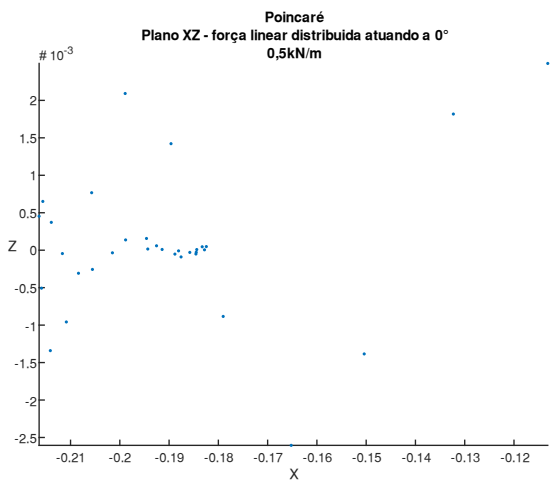

(d) $F=0,5 \mathrm{kN} / \mathrm{m} \operatorname{com} \beta=0^{\circ}$.

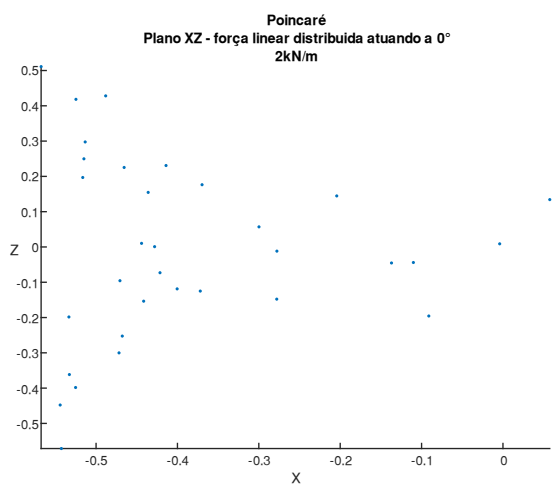

(f) $F=2 \mathrm{kN} / \mathrm{m} \operatorname{com} \beta=0^{\circ}$.

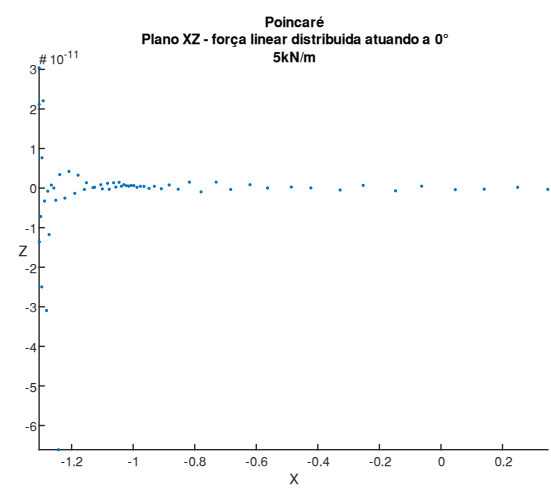

(h) $F=5 \mathrm{kN} / \mathrm{m} \operatorname{com} \beta=0^{\circ}$. 


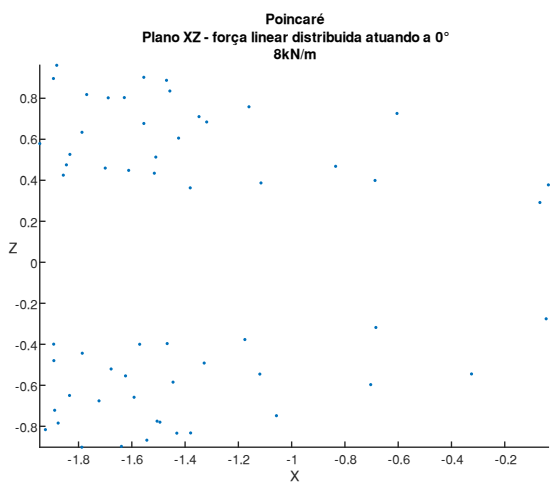

(i) $\quad F=8 \mathrm{kN} / \mathrm{m} \operatorname{com} \beta=0^{\circ}$.

Figura B. 6 - Influência da magnitude da força na resposta em regime permanente $\operatorname{com} \beta=0^{\circ}$,

Mapeamento de Poincaré no plano XZ.

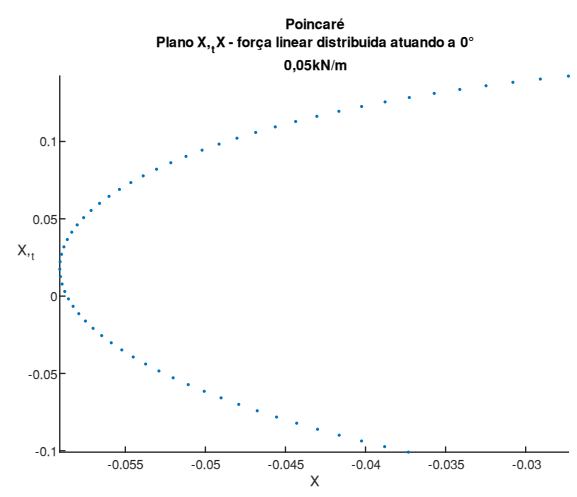

(a) $F=0,05 \mathrm{kN} / \mathrm{m} \operatorname{com} \beta=0^{\circ}$. Poincaré
Plano $\mathrm{X}, \mathrm{X}$ - torça linear distribuida atuando a $0^{\circ}$
$0.25 \mathrm{kN} / \mathrm{m}$

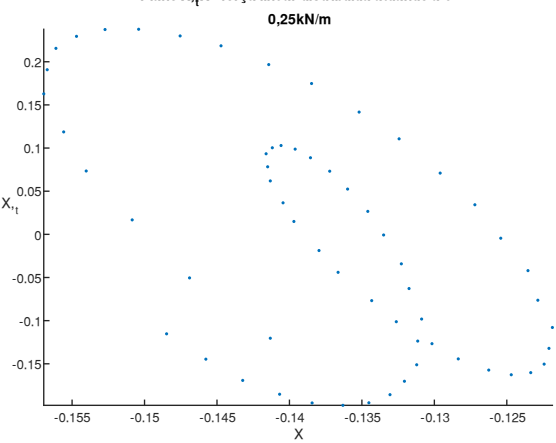

(c) $F=0,25 \mathrm{kN} / \mathrm{m} \operatorname{com} \beta=0^{\circ}$.

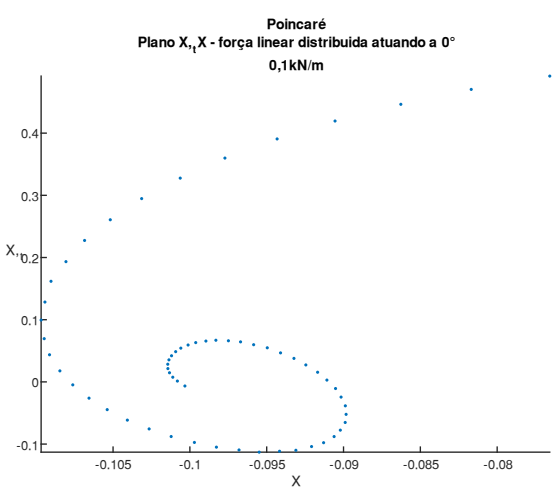

(b) $F=0,1 \mathrm{kN} / \mathrm{m} \operatorname{com} \beta=0^{\circ}$.

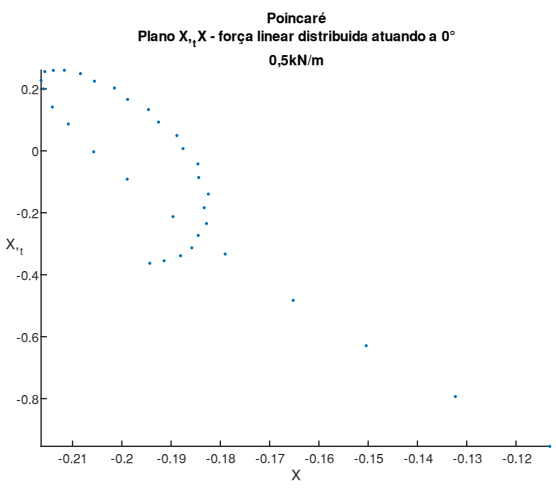

(d) $F=0,5 \mathrm{kN} / \mathrm{m} \operatorname{com} \beta=0^{\circ}$. 

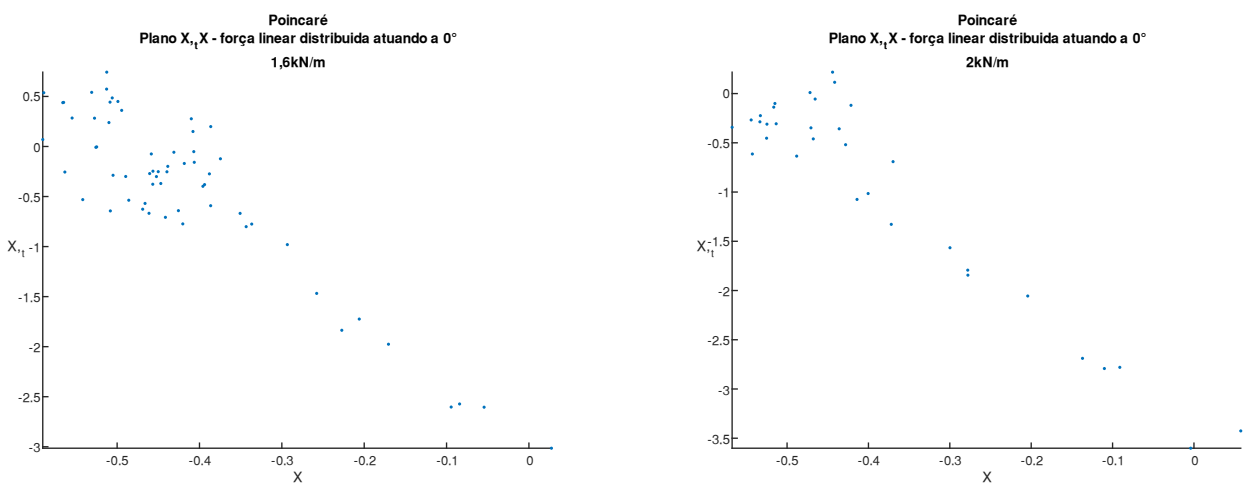

(e) $F=1,6 \mathrm{kN} / \mathrm{m} \operatorname{com} \beta=0^{\circ}$.

(f) $F=2 \mathrm{kN} / \mathrm{m} \operatorname{com} \beta=0^{\circ}$.
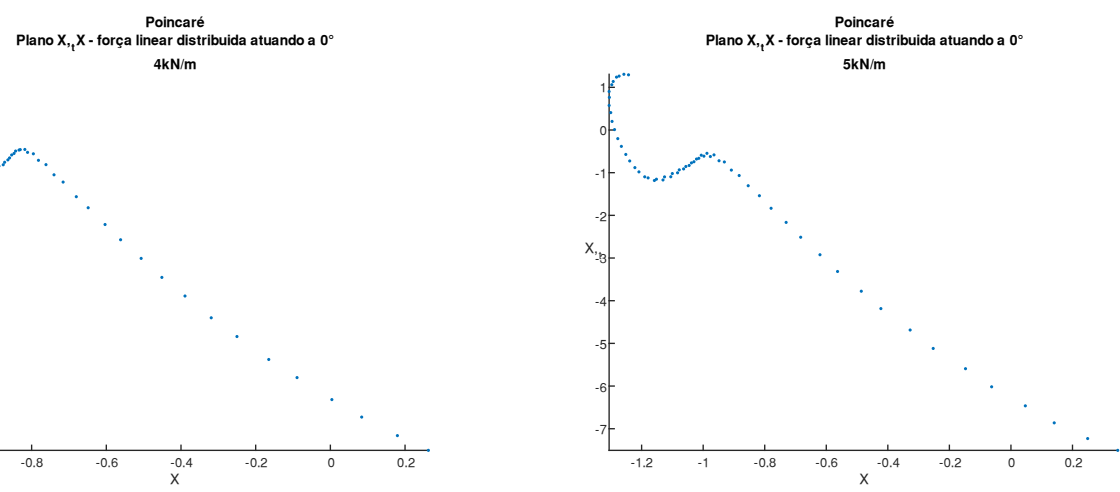

(g) $F=4 \mathrm{kN} / \mathrm{m} \operatorname{com} \beta=0^{\circ}$.

(h) $F=5 \mathrm{kN} / \mathrm{m} \operatorname{com} \beta=0^{\circ}$.

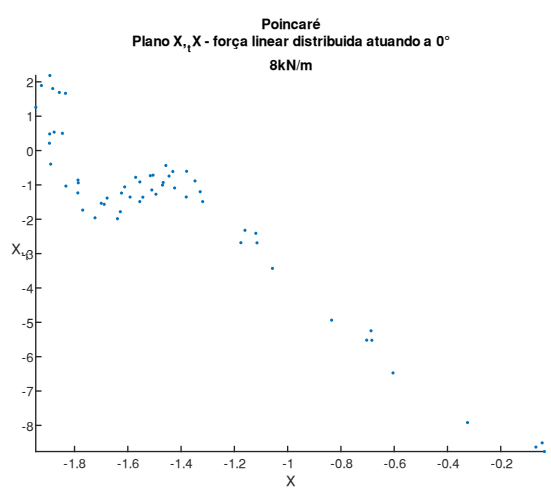

(i) $F=8 \mathrm{kN} / \mathrm{m} \operatorname{com} \beta=0^{\circ}$.

Figura B. 7 - Influência da magnitude da força na resposta em regime permanente com $\beta=0^{\circ}$, Mapeamento de Poincaré relacionando Velocidade x Deslocamento no eixo X. 


\section{Apêndice C}

Respostas dinâmicas para $\beta=6^{\circ}$

Neste apêndice são apresentadas todas as respostas dinâmicas para a estrutura quanto a variação da magnitude da força harmônica $\operatorname{com} \beta=60^{\circ}$. São expostas as respostas no tempo, análise FFT, análise no espectro de frequência por espectrograma no plano, análise no espectro de frequência por espectrograma no espaço, planos de fase relacionando Velocidade $x$ Deslocamento no eixo $\mathrm{X}$, Mapeamento de Poincaré no plano XZ, Mapeamento de Poincaré relacionando Velocidade $x$ Deslocamento no eixo X, respectivamente Figura C. 1, Figura C. 2, Figura C. 3, Figura C. 4, Figura C. 5, Figura C. 6 e Figura C. 7.

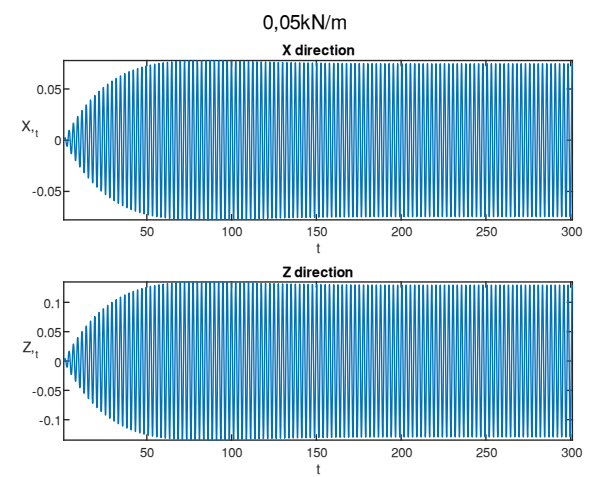

(a) $F=0,05 \mathrm{kN} / \mathrm{m} \operatorname{com} \beta=60^{\circ}$.
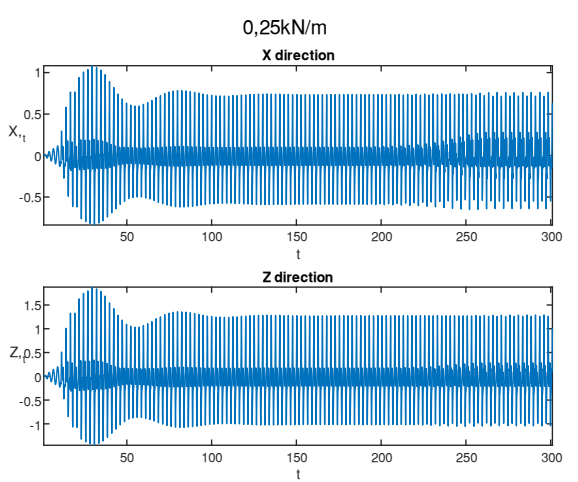

(c) $F=0,25 \mathrm{kN} / \mathrm{m} \operatorname{com} \beta=60^{\circ}$.

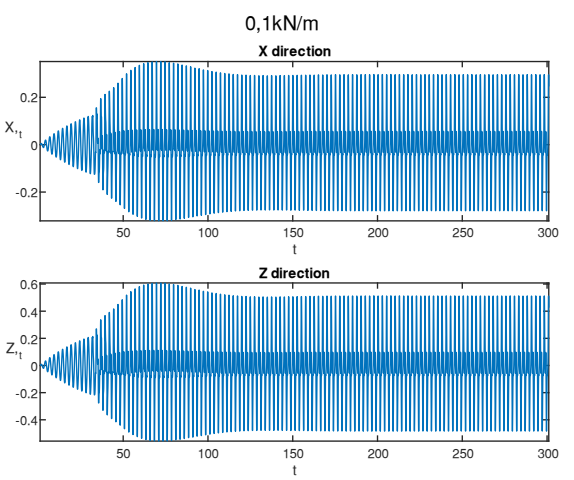

(b) $F=0,1 \mathrm{kN} / \mathrm{m} \operatorname{com} \beta=60^{\circ}$.

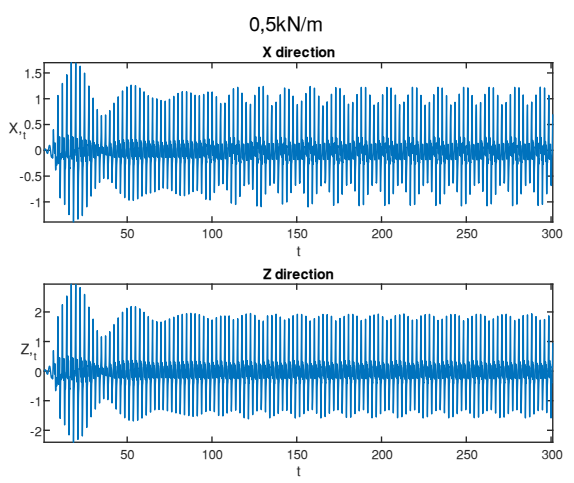

(d) $F=0,5 \mathrm{kN} / \mathrm{m} \operatorname{com} \beta=60^{\circ}$. 

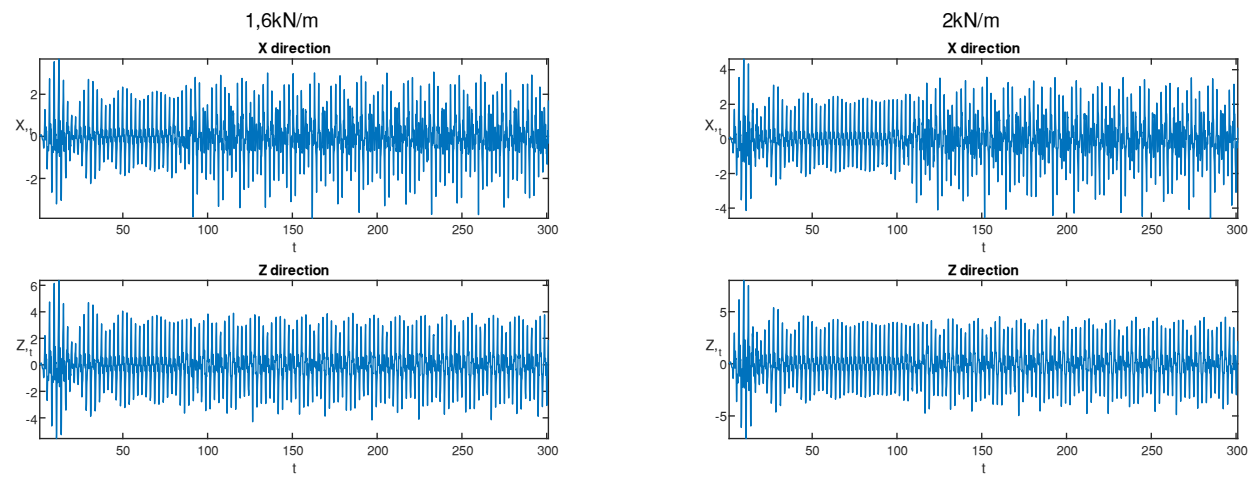

(e) $F=1,6 \mathrm{kN} / \mathrm{m} \operatorname{com} \beta=60^{\circ}$.

(f) $F=2 \mathrm{kN} / \mathrm{m} \operatorname{com} \beta=60^{\circ}$.
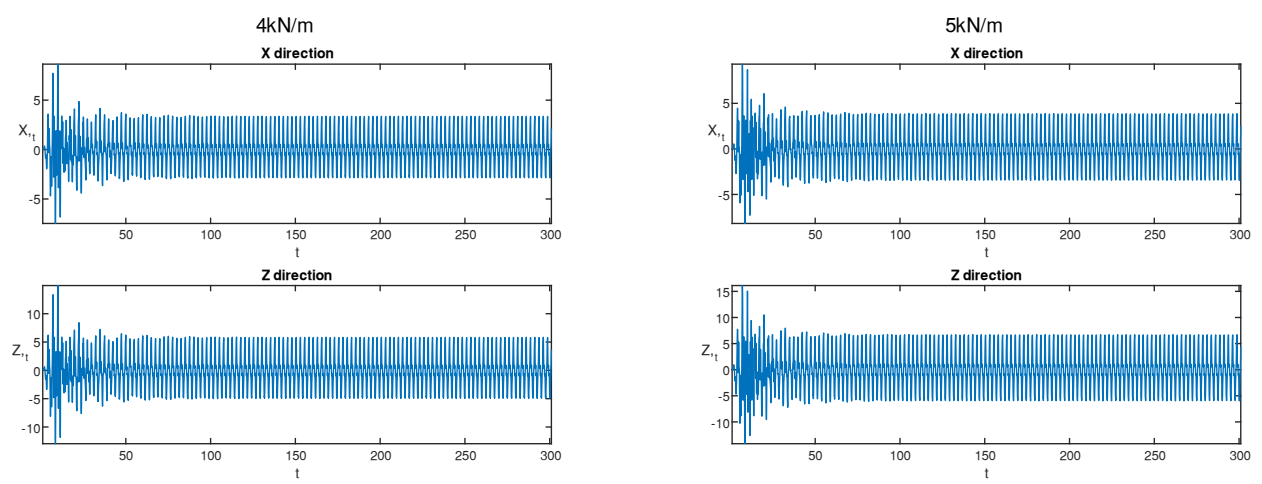

(g) $F=4 \mathrm{kN} / \mathrm{m} \operatorname{com} \beta=60^{\circ}$.

(h) $F=5 \mathrm{kN} / \mathrm{m} \operatorname{com} \beta=60^{\circ}$.

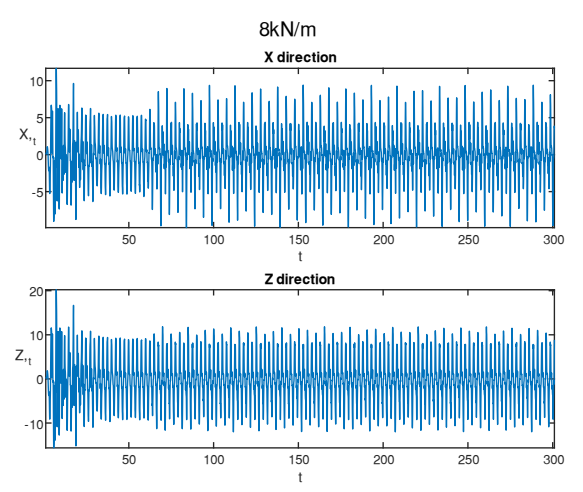

(i) $F=8 \mathrm{kN} / \mathrm{m} \operatorname{com} \beta=60^{\circ}$.

Figura C. 1 - Influência da magnitude da força na resposta em regime permanente com $\beta=60^{\circ}$, resposta no tempo. 


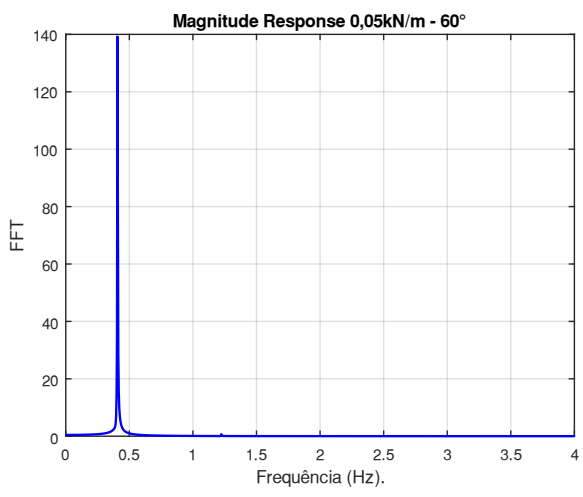

(a) $F=0,05 \mathrm{kN} / \mathrm{m} \operatorname{com} \beta=60^{\circ}$.

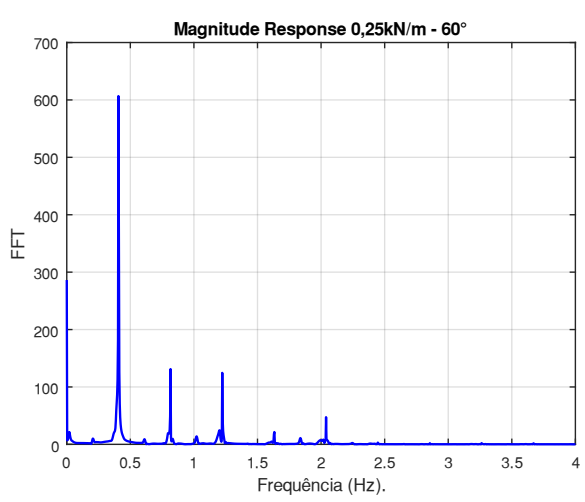

(c) $F=0,25 \mathrm{kN} / \mathrm{m} \operatorname{com} \beta=60^{\circ}$.

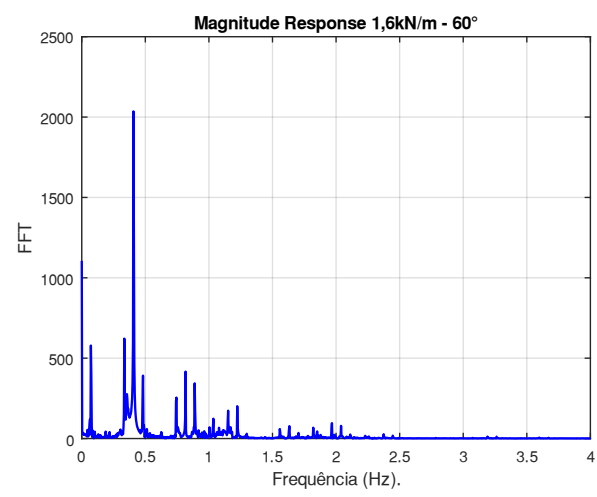

(e) $F=1,6 \mathrm{kN} / \mathrm{m} \operatorname{com} \beta=60^{\circ}$.

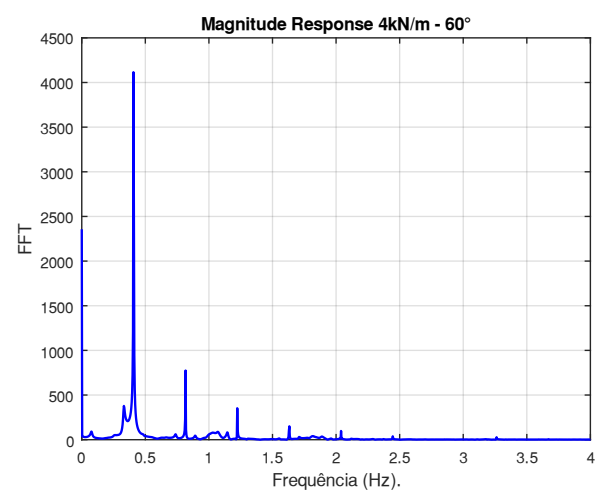

(g) $F=4 \mathrm{kN} / \mathrm{m} \operatorname{com} \beta=60^{\circ}$.

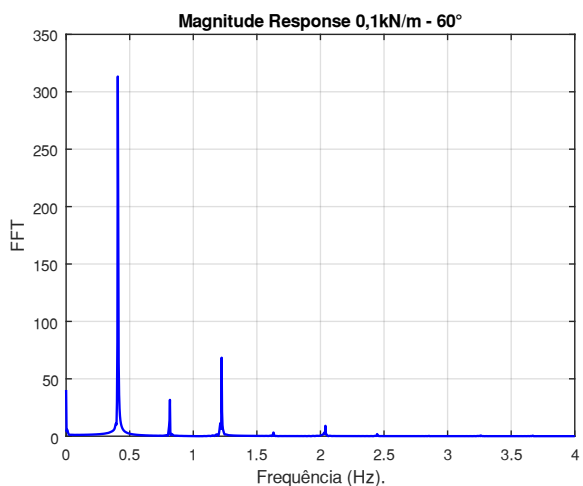

(b) $F=0,1 \mathrm{kN} / \mathrm{m} \operatorname{com} \beta=60^{\circ}$.

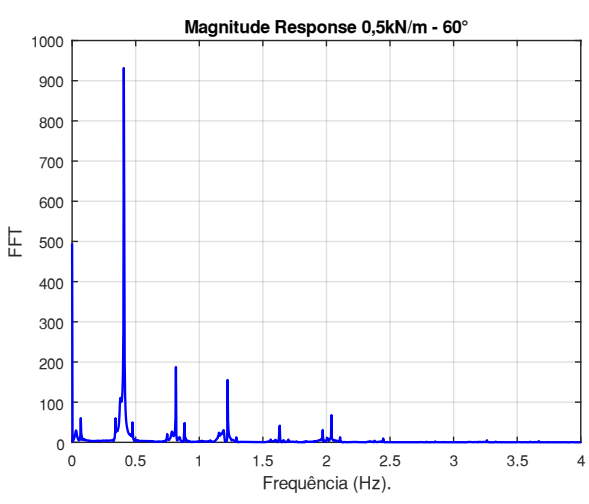

(d) $F=0,5 \mathrm{kN} / \mathrm{m} \operatorname{com} \beta=60^{\circ}$.

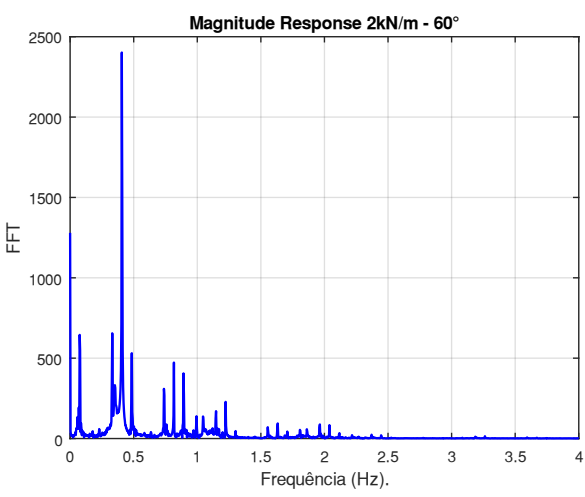

(f) $F=2 \mathrm{kN} / \mathrm{m} \operatorname{com} \beta=60^{\circ}$.

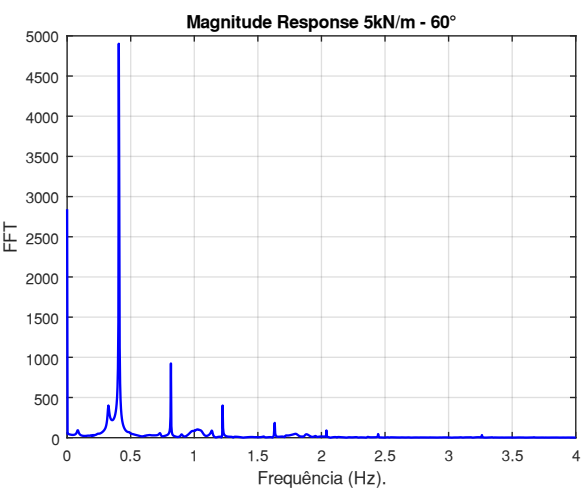

(h) $F=5 \mathrm{kN} / \mathrm{m} \operatorname{com} \beta=60^{\circ}$. 


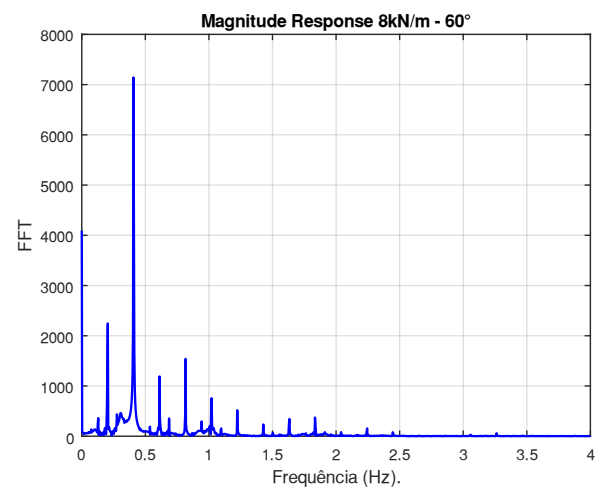

(i) $F=8 \mathrm{kN} / \mathrm{m} \operatorname{com} \beta=60^{\circ}$.

Figura C. 2 - Influência da magnitude da força na resposta em regime permanente com $\beta=60^{\circ}$, análise de frequências FFT.

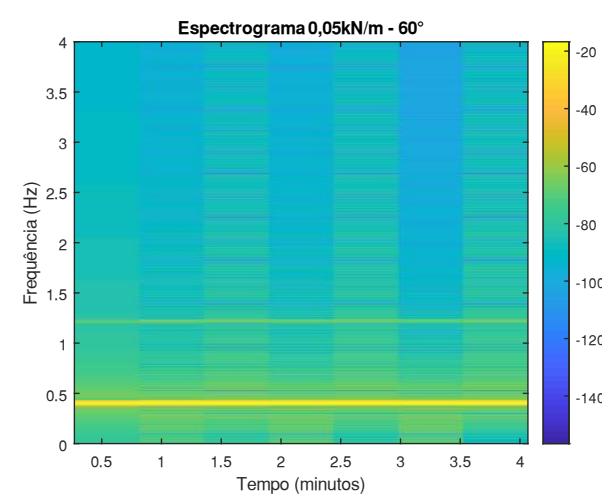

(a) $F=0,05 \mathrm{kN} / \mathrm{m} \operatorname{com} \beta=60^{\circ}$.

Espectrograma $0,25 \mathrm{kN} / \mathrm{m}-60^{\circ}$

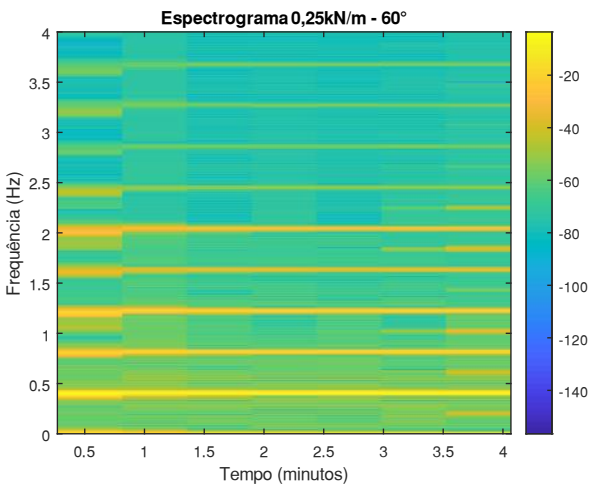

(c) $F=0,25 \mathrm{kN} / \mathrm{m} \operatorname{com} \beta=60^{\circ}$.

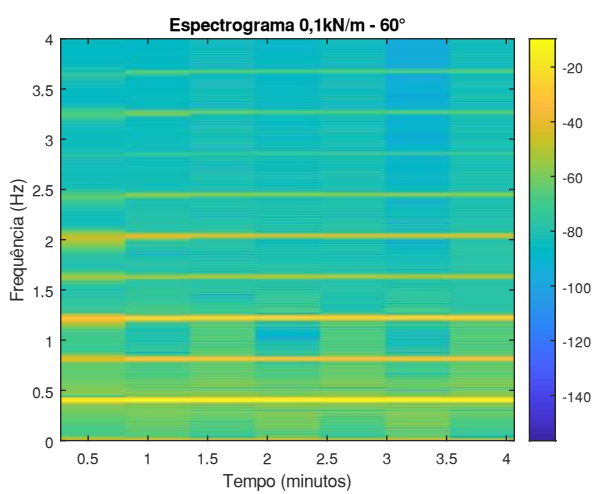

(b) $F=0,1 \mathrm{kN} / \mathrm{m} \operatorname{com} \beta=60^{\circ}$.

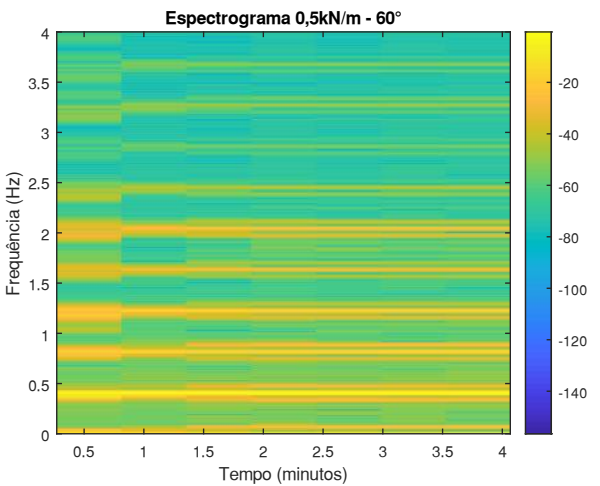

(d) $F=0,5 \mathrm{kN} / \mathrm{m} \operatorname{com} \beta=60^{\circ}$. 


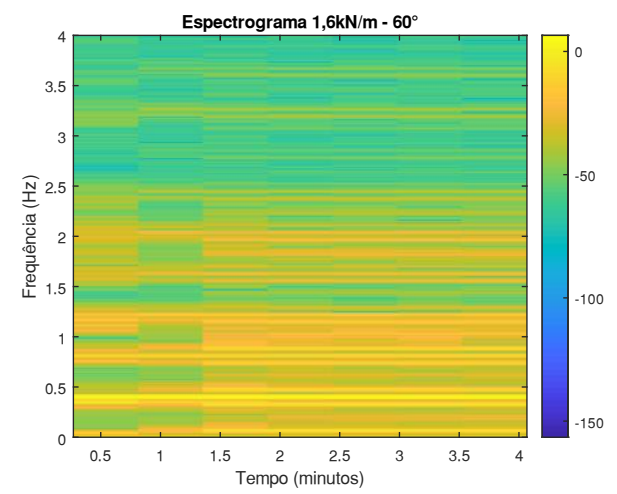

(e) $F=1,6 \mathrm{kN} / \mathrm{m} \operatorname{com} \beta=60^{\circ}$.

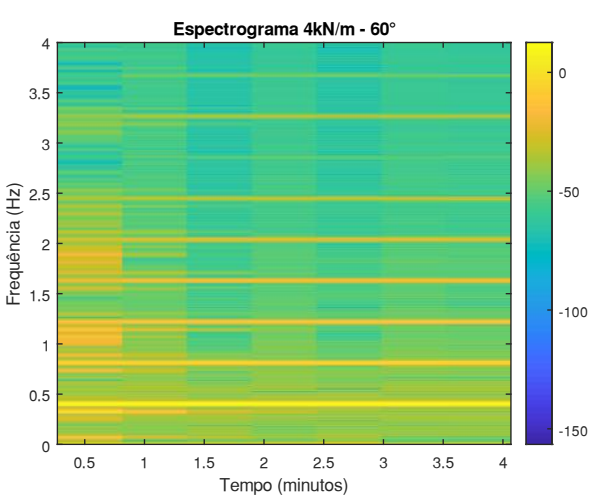

(g) $F=4 \mathrm{kN} / \mathrm{m} \operatorname{com} \beta=60^{\circ}$.

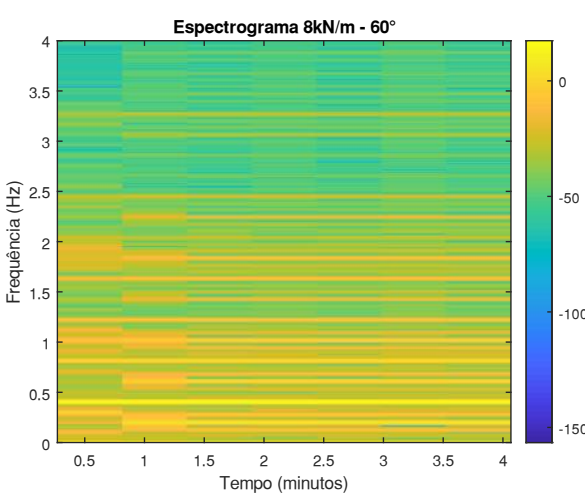

(i) $F=8 \mathrm{kN} / \mathrm{m} \operatorname{com} \beta=60^{\circ}$.

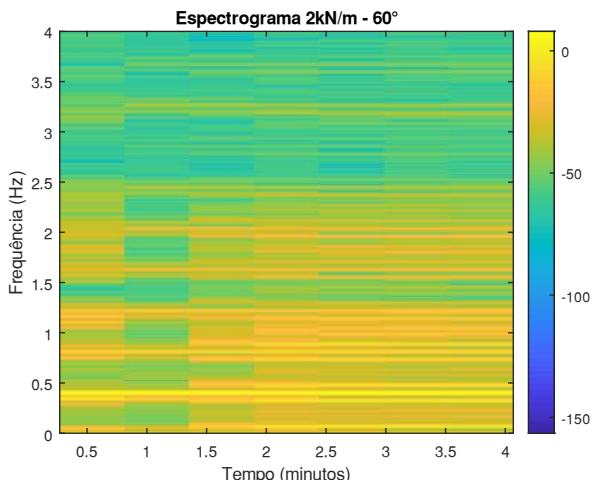

(f) $F=2 \mathrm{kN} / \mathrm{m} \operatorname{com} \beta=60^{\circ}$.

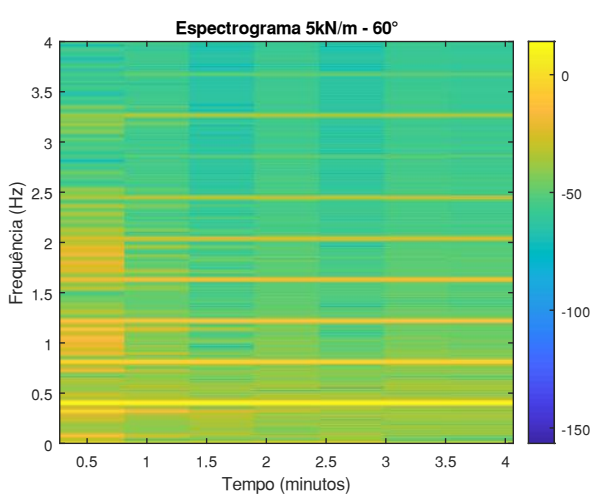

(h) $F=5 \mathrm{kN} / \mathrm{m} \operatorname{com} \beta=60^{\circ}$.

Figura C. 3 - Influência da magnitude da força na resposta em regime permanente com $\beta=60^{\circ}$, análise de frequências espectrograma 2D. 


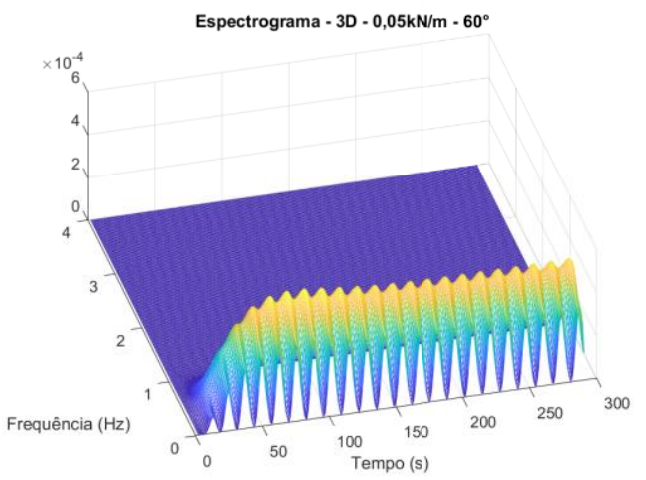

(a) $F=0,05 \mathrm{kN} / \mathrm{m} \operatorname{com} \beta=60^{\circ}$.

Espectrograma $-3 \mathrm{D}-0,25 \mathrm{kN} / \mathrm{m} \cdot 60^{\circ}$

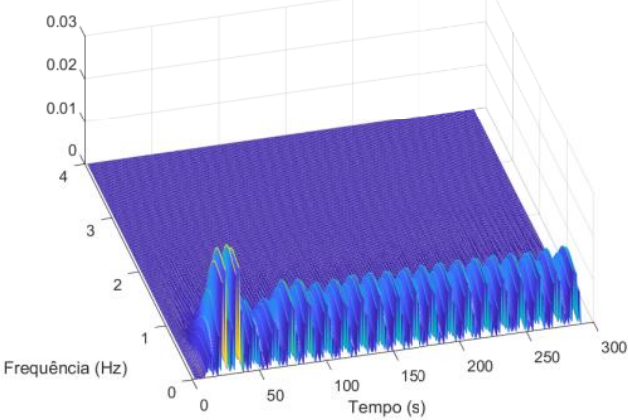

(c) $F=0,25 \mathrm{kN} / \mathrm{m} \operatorname{com} \beta=60^{\circ}$.

Espectrograma - 3D - 1,6kN/m - $60^{\circ}$

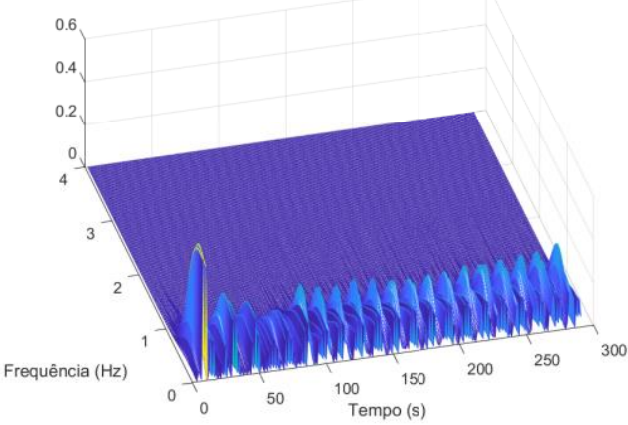

(e) $F=1,6 \mathrm{kN} / \mathrm{m} \operatorname{com} \beta=60^{\circ}$.

Espectrograma - 3D $-4 \mathrm{kN} / \mathrm{m}-60^{\circ}$

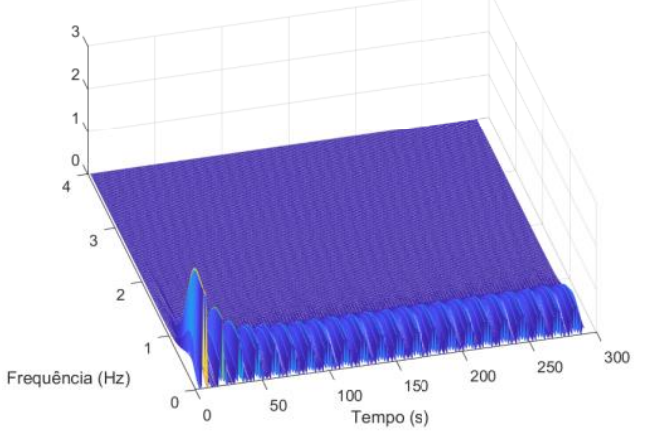

(g) $F=4 \mathrm{kN} / \mathrm{m} \operatorname{com} \beta=60^{\circ}$.

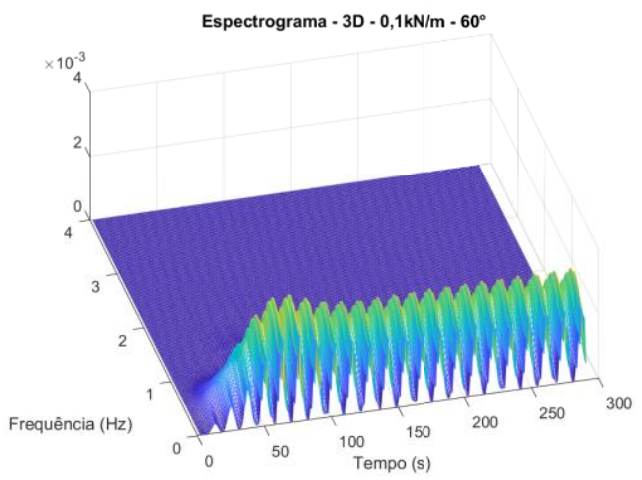

(b) $F=0,1 \mathrm{kN} / \mathrm{m} \operatorname{com} \beta=60^{\circ}$.

Espectrograma - 3D $-0,5 \mathrm{kN} / \mathrm{m}-60^{\circ}$

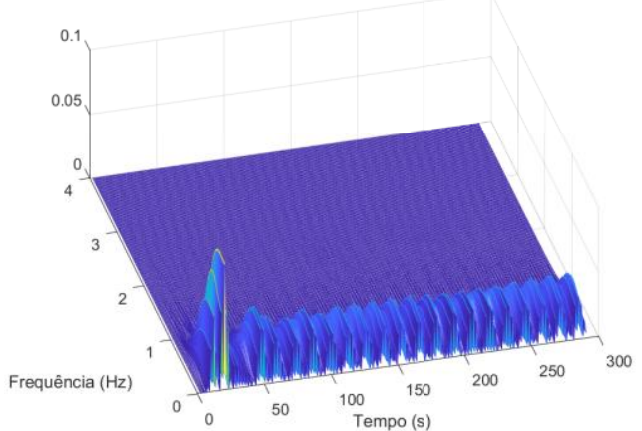

(d) $F=0,5 \mathrm{kN} / \mathrm{m} \operatorname{com} \beta=60^{\circ}$.

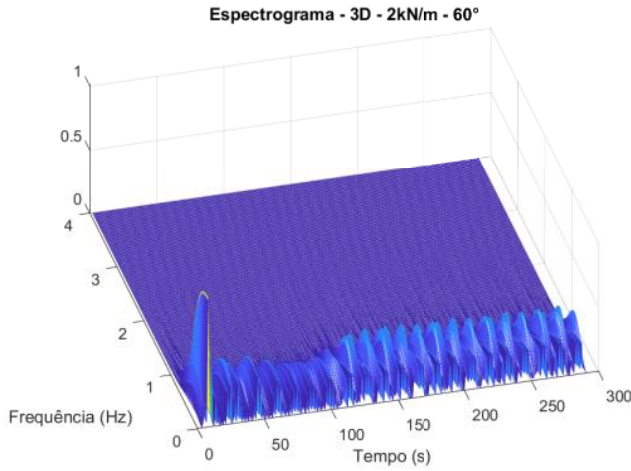

(f) $F=2 \mathrm{kN} / \mathrm{m} \operatorname{com} \beta=60^{\circ}$.

Espectrograma - $3 \mathrm{D}-5 \mathrm{kN} / \mathrm{m}-60^{\circ}$

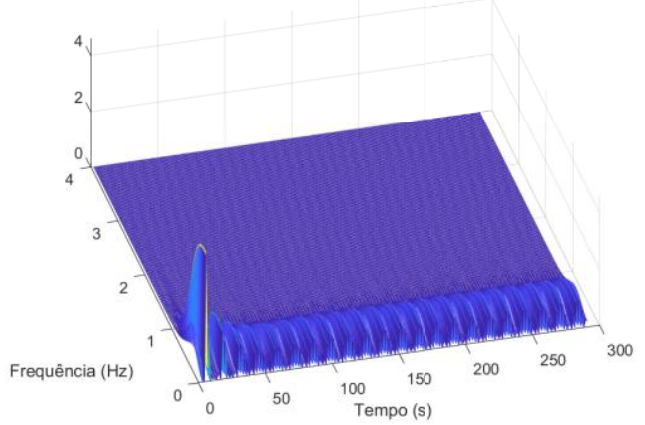

(h) $F=5 \mathrm{kN} / \mathrm{m} \operatorname{com} \beta=60^{\circ}$. 


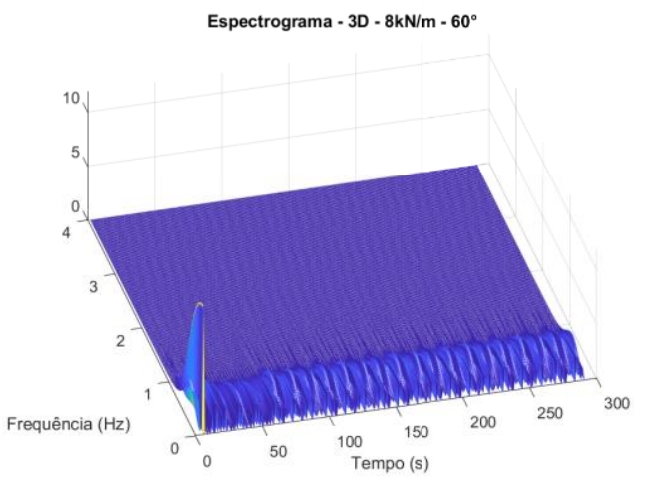

(i) $F=8 \mathrm{kN} / \mathrm{m} \operatorname{com} \beta=60^{\circ}$.

Figura C. 4 - Influência da magnitude da força na resposta em regime permanente $\operatorname{com} \beta=60^{\circ}$, análise de frequências espectrograma 3D.

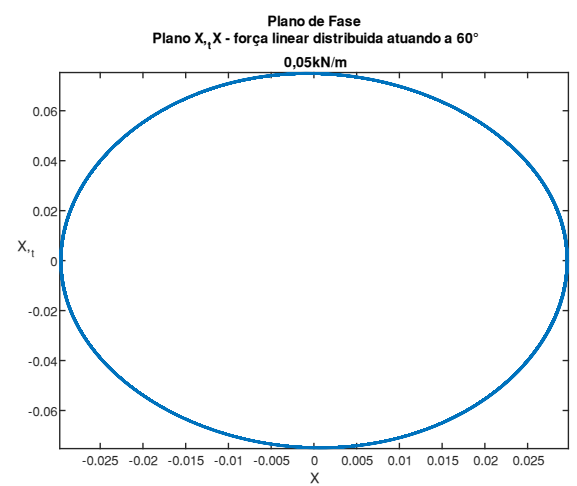

(a) $F=0,05 \mathrm{kN} / \mathrm{m} \operatorname{com} \beta=60^{\circ}$.

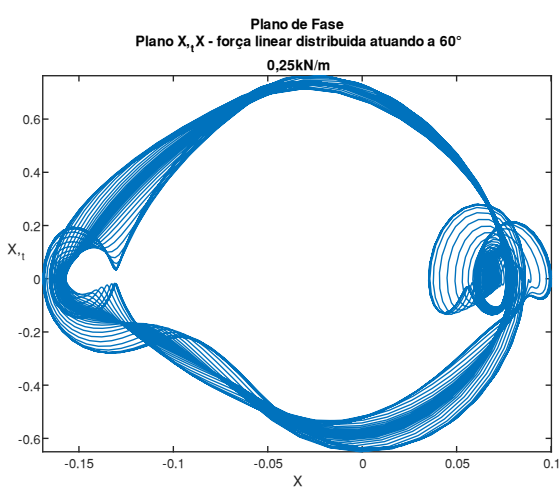

(c) $F=0,25 \mathrm{kN} / \mathrm{m} \operatorname{com} \beta=60^{\circ}$.

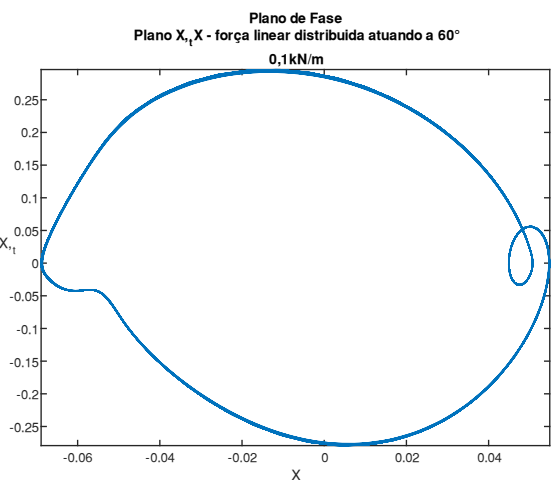

(b) $F=0,1 \mathrm{kN} / \mathrm{m} \operatorname{com} \beta=60^{\circ}$.

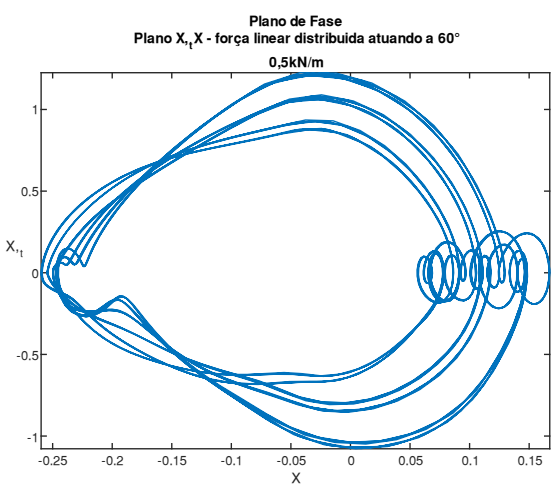

(d) $F=0,5 \mathrm{kN} / \mathrm{m} \operatorname{com} \beta=60^{\circ}$. 

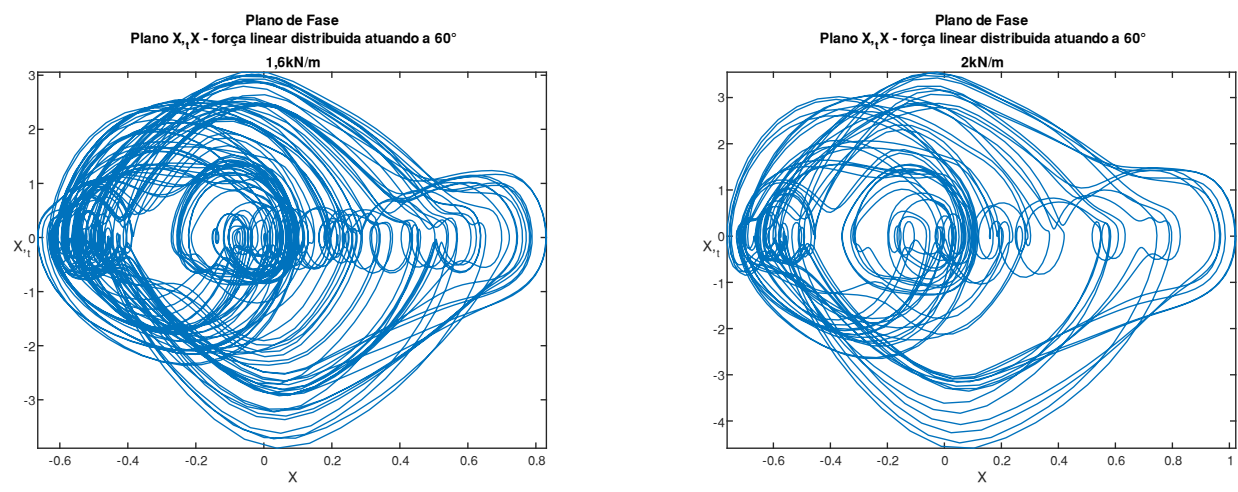

(e) $F=1,6 \mathrm{kN} / \mathrm{m} \operatorname{com} \beta=60^{\circ}$.

(f) $F=2 \mathrm{kN} / \mathrm{m} \operatorname{com} \beta=60^{\circ}$.
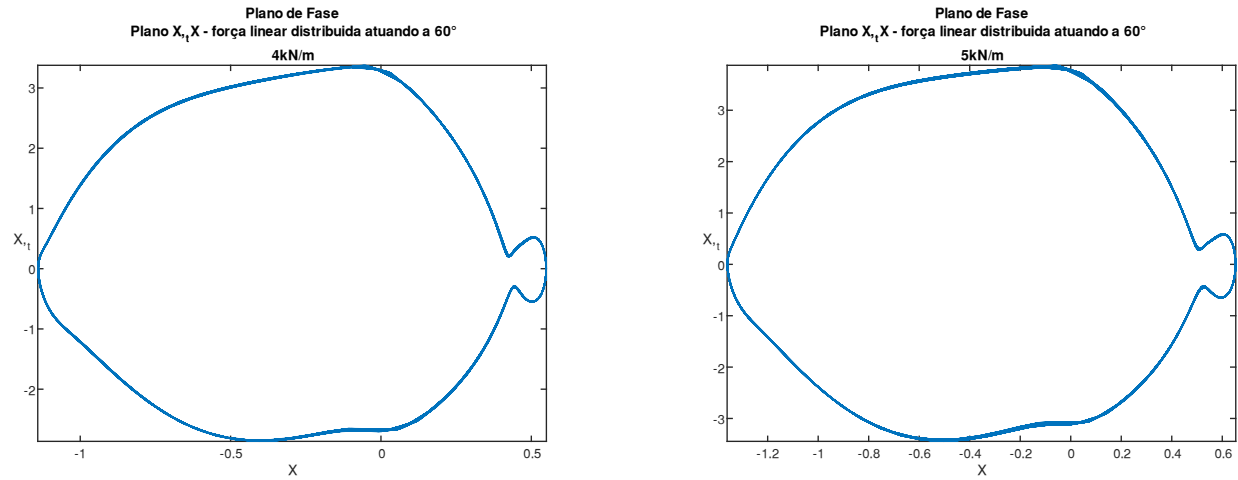

(g) $F=4 \mathrm{kN} / \mathrm{m} \operatorname{com} \beta=60^{\circ}$.

(h) $F=5 \mathrm{kN} / \mathrm{m} \operatorname{com} \beta=60^{\circ}$.

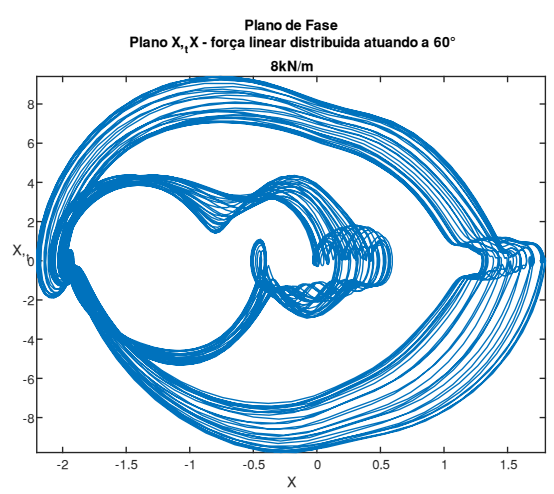

(i) $F=8 \mathrm{kN} / \mathrm{m} \operatorname{com} \beta=60^{\circ}$.

Figura C. 5 - Influência da magnitude da força na resposta em regime permanente com $\beta=60^{\circ}$,

Planos de fase Velocidade x Deslocamento no eixo X. 


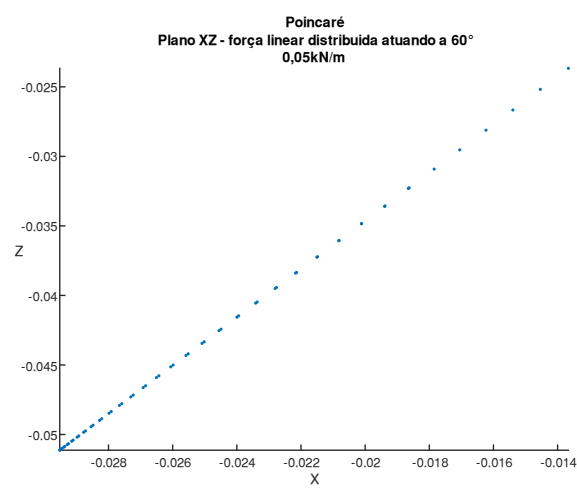

(a) $F=0,05 \mathrm{kN} / \mathrm{m} \operatorname{com} \beta=60^{\circ}$.

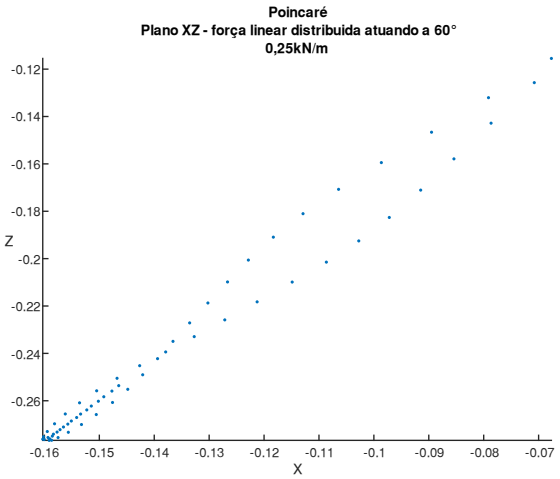

(c) $F=0,25 \mathrm{kN} / \mathrm{m} \operatorname{com} \beta=60^{\circ}$.

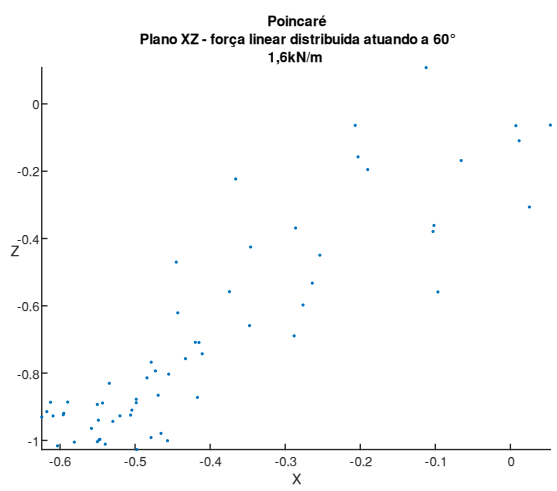

(e) $F=1,6 \mathrm{kN} / \mathrm{m} \operatorname{com} \beta=60^{\circ}$.

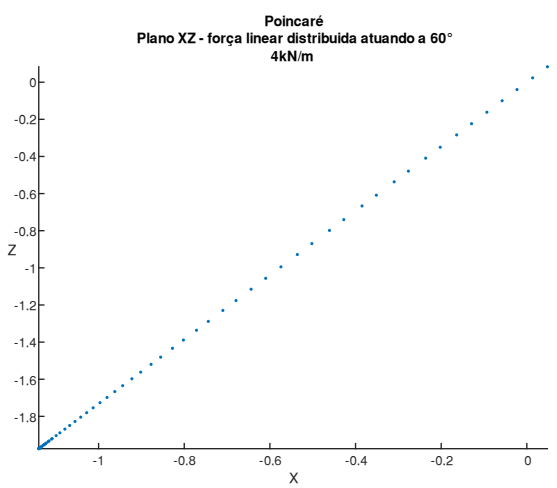

(g) $F=4 \mathrm{kN} / \mathrm{m} \operatorname{com} \beta=60^{\circ}$.

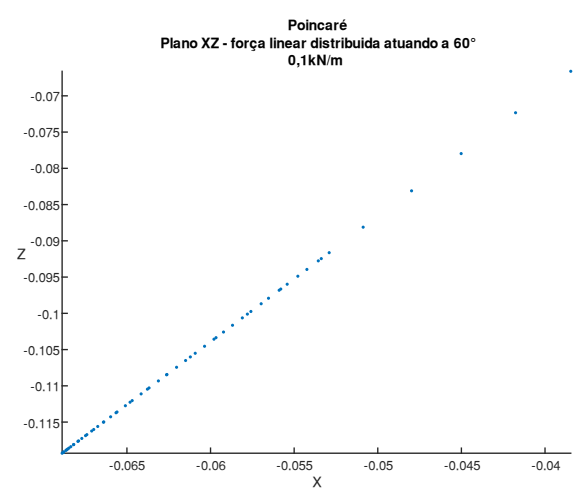

(b) $F=0,1 \mathrm{kN} / \mathrm{m} \operatorname{com} \beta=60^{\circ}$.

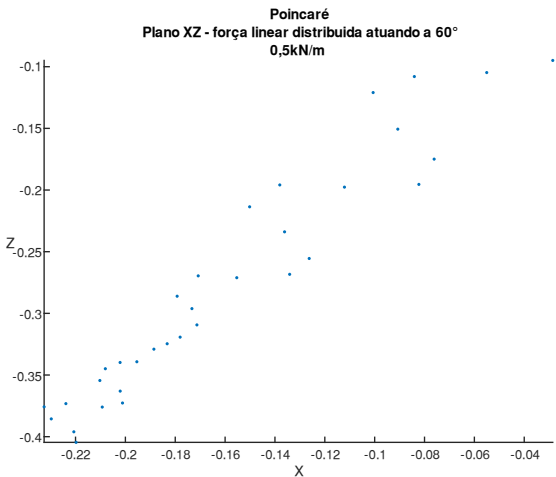

(d) $F=0,5 \mathrm{kN} / \mathrm{m} \operatorname{com} \beta=60^{\circ}$.

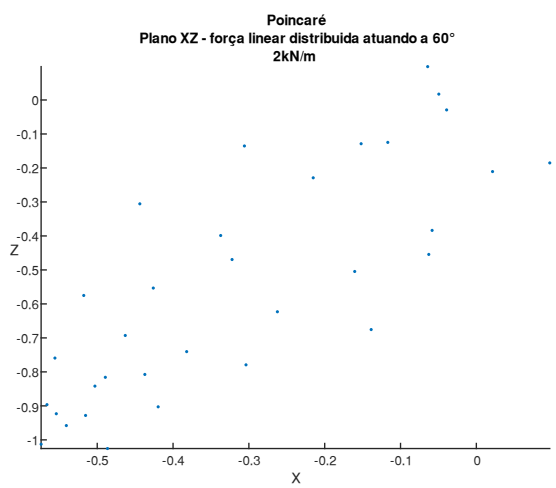

(f) $F=2 \mathrm{kN} / \mathrm{m} \operatorname{com} \beta=60^{\circ}$.

Plano $X Z$ - força linear distribuida atuando a $60^{\circ}$

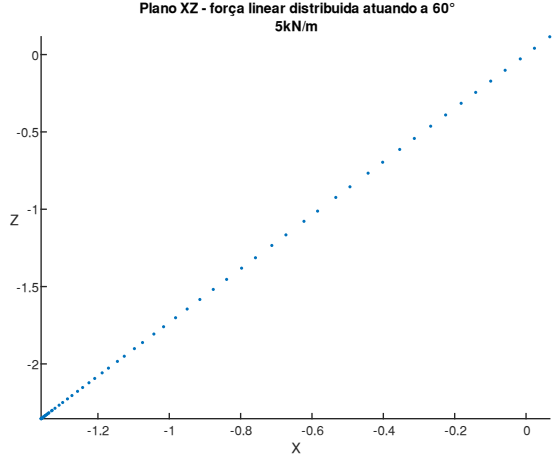

(h) $F=5 \mathrm{kN} / \mathrm{m} \operatorname{com} \beta=60^{\circ}$. 


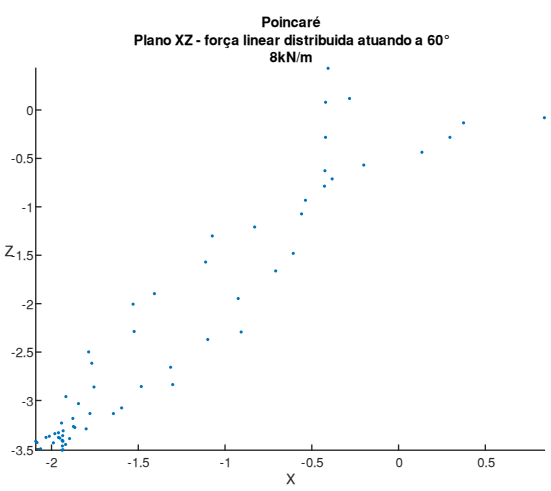

(i) $F=8 \mathrm{kN} / \mathrm{m} \operatorname{com} \beta=60^{\circ}$.

Figura C. 6 - Influência da magnitude da força na resposta em regime permanente $\operatorname{com} \beta=60^{\circ}$,

Mapeamento de Poincaré no plano XZ.

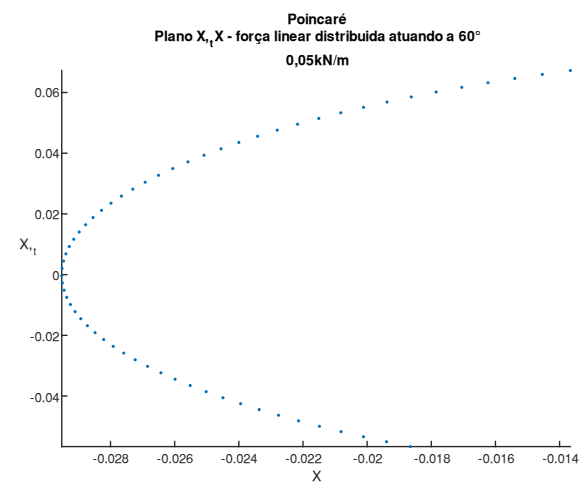

(a) $F=0,05 \mathrm{kN} / \mathrm{m} \operatorname{com} \beta=60^{\circ}$. Poincaré
Plano $\mathrm{X}, \mathrm{x}$ - força linear distribuida atuando a $60^{\circ}$

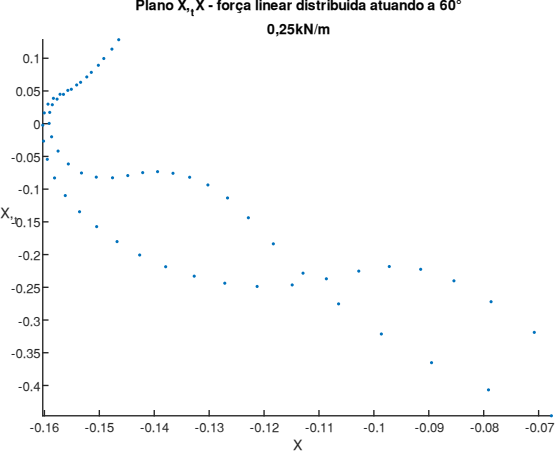

(c) $F=0,25 \mathrm{kN} / \mathrm{m} \operatorname{com} \beta=60^{\circ}$.

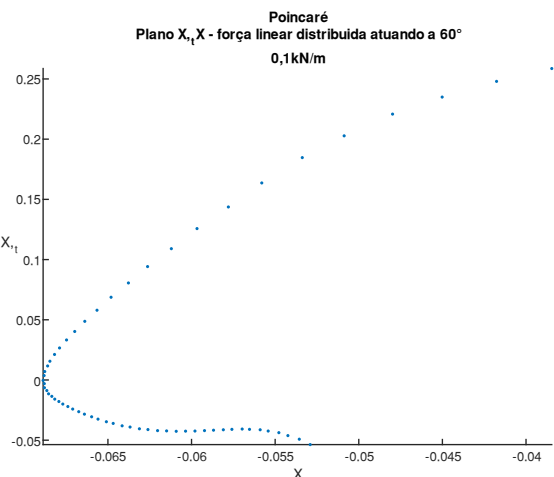

(b) $F=0,1 \mathrm{kN} / \mathrm{m} \operatorname{com} \beta=60^{\circ}$.

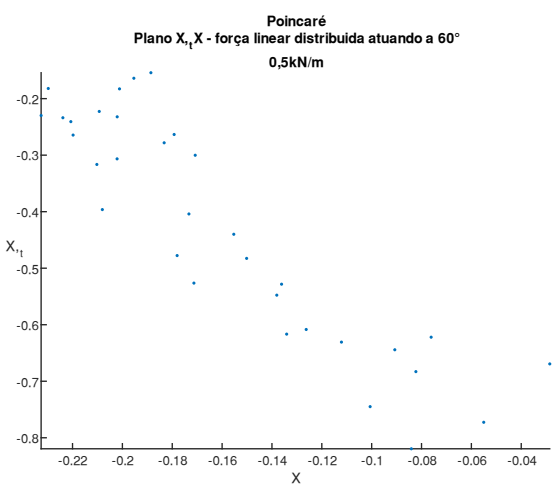

(d) $F=0,5 \mathrm{kN} / \mathrm{m} \operatorname{com} \beta=60^{\circ}$. 

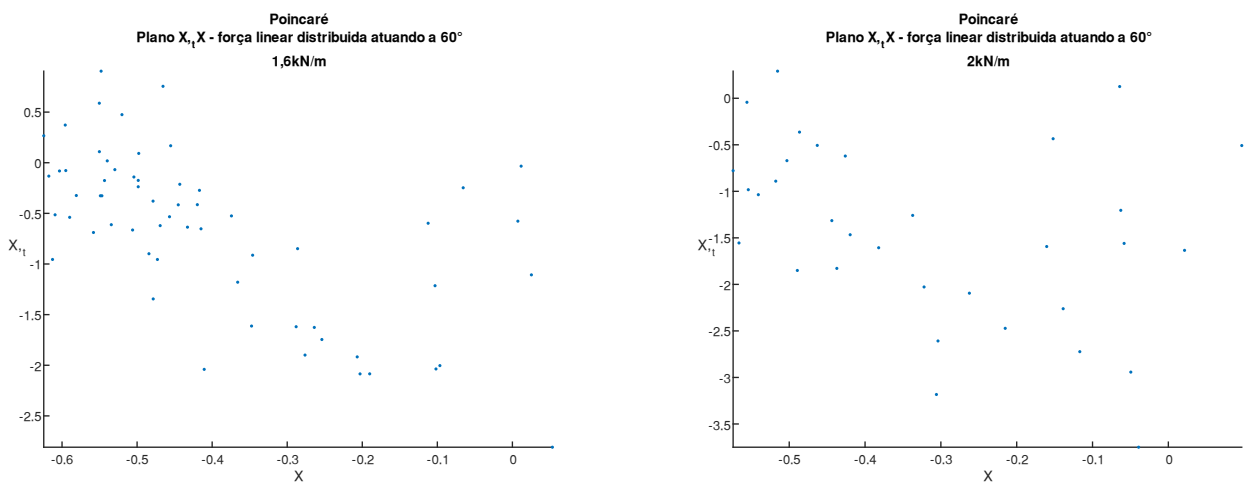

(e) $F=1,6 \mathrm{kN} / \mathrm{m} \operatorname{com} \beta=60^{\circ}$.

(f) $F=2 \mathrm{kN} / \mathrm{m} \operatorname{com} \beta=60^{\circ}$.
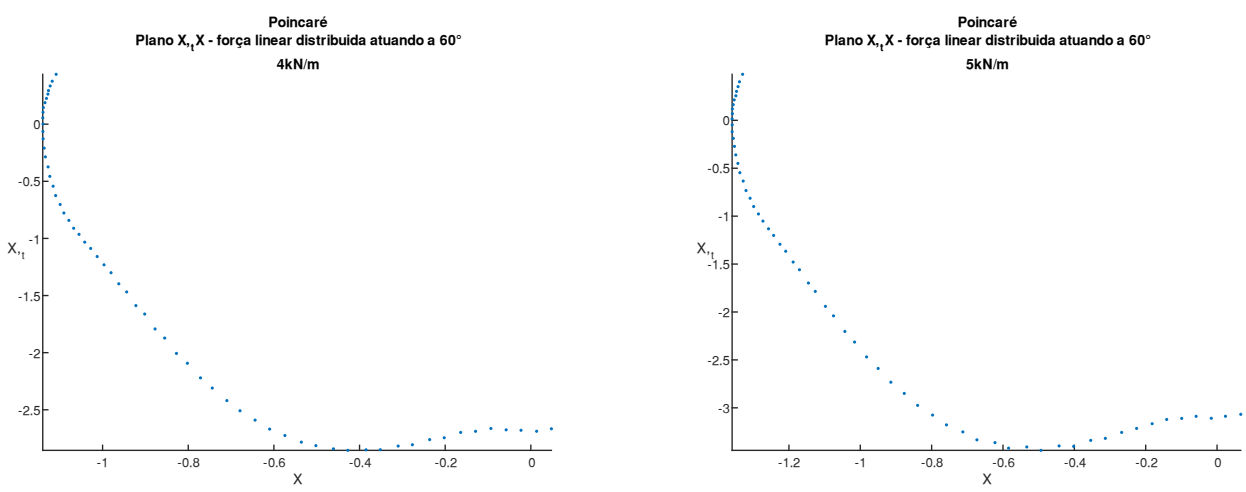

(g) $F=4 \mathrm{kN} / \mathrm{m} \operatorname{com} \beta=60^{\circ}$.

(h) $F=5 \mathrm{kN} / \mathrm{m} \operatorname{com} \beta=60^{\circ}$.

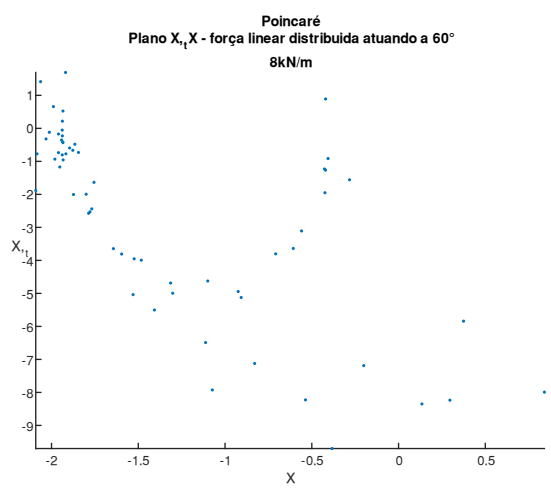

(i) $F=8 \mathrm{kN} / \mathrm{m} \operatorname{com} \beta=60^{\circ}$.

Figura C. 7 - Influência da magnitude da força na resposta em regime permanente com $\beta=60^{\circ}$, Mapeamento de Poincaré relacionando Velocidade x Deslocamento no eixo X. 